\title{
Heart failure: nurses care : effects of education and support by a nurse on self-care, resource utilization and quality of life of patients with heart failure
}

Citation for published version (APA):

Jaarsma, T. (1999). Heart failure: nurses care : effects of education and support by a nurse on self-care, resource utilization and quality of life of patients with heart failure. [Doctoral Thesis, Maastricht University]. Universiteit Maastricht. https://doi.org/10.26481/dis.19991028tj

Document status and date:

Published: 01/01/1999

DOI:

10.26481/dis.19991028tj

Document Version:

Publisher's PDF, also known as Version of record

Please check the document version of this publication:

- A submitted manuscript is the version of the article upon submission and before peer-review. There can be important differences between the submitted version and the official published version of record.

People interested in the research are advised to contact the author for the final version of the publication, or visit the DOI to the publisher's website.

- The final author version and the galley proof are versions of the publication after peer review.

- The final published version features the final layout of the paper including the volume, issue and page numbers.

Link to publication

\footnotetext{
General rights rights.

- You may freely distribute the URL identifying the publication in the public portal. please follow below link for the End User Agreement:

www.umlib.nl/taverne-license

Take down policy

If you believe that this document breaches copyright please contact us at:

repository@maastrichtuniversity.nl

providing details and we will investigate your claim.
}

Copyright and moral rights for the publications made accessible in the public portal are retained by the authors and/or other copyright owners and it is a condition of accessing publications that users recognise and abide by the legal requirements associated with these

- Users may download and print one copy of any publication from the public portal for the purpose of private study or research.

- You may not further distribute the material or use it for any profit-making activity or commercial gain

If the publication is distributed under the terms of Article 25fa of the Dutch Copyright Act, indicated by the "Taverne" license above, 


\section{Heart failure: Nurses care}

Effects of education and support by a nurse on self-care, resource utilization and quality of life of patients with heart failure 
Heart failure: Nurses care.

Effects of education and support by a nurse on self-care, resource utilization and quality of life of patients with heart failure

Tiny Jaarsma

ISBN $90-9013057-8$

Cover: Illustration: Silvia Steiger

tckening uit publicatic VAN HARTEN-I998

boekje met 50 tekeningen

$\mathrm{I}^{\mathrm{e}}$ exclusieve druk: oplage 50

HeartArt KUNST OP MAAT:

http://www. HeartArt.nl en info@HeartArt.nl

Design: Datawyse Matastricht

Lay out: $\quad$ Wybo Dekker, Servalys

www hobby.nl/ ${ }^{\sim}$ servalys

Printing: Datawyse Maastricht 
HEART FAILURE: NURSES CARE

Effects of education and support by a nurse on self-care, resource utilization and quality of life of patients with heart failure.

\section{PROEFSCHRIFT}

ter verkrijging van de graad van doctor aan

de Universiteit Maastricht,

op gezag van de Rector Magnificus,

Prof. Dr. A.C. Nieuwenhuijzen Kruseman

volgens het besluit van het College van Decanen, in het openbaar te verdedigen

op donderdag 28 oktober 1999 om I 4.00 uur

$$
\text { door }
$$

Tiny Jaarsma 


\section{Promotores:}

Prof. Dr. H. Huijer Abu-Saad

Prof. Dr. K. Dracup (University of California at Los Angeles, CA, USA)

\section{Co-promotor:}

Dr. R. Halfens

\section{Beoordelingscommissie:}

Prof. Dr. H. Philipsen (voorzitter)

Prof. Dr. G.C.M. Evers (Katholieke Universiteit Leuven, België)

Prof. Dr. D. K. Moser (The Ohio State University, Columbus OH, USA)

Prof. Dr. C. Spreeuwenberg

Prof. Dr. H.J.J. Wellens

The studies presented in this thesis were conducted at Maastricht Health Research Institute for prevention and Care (Health), which participates in the Netherlands School of Primary Care Research (CaRe), acknowledged in 1995 by the Royal Dutch Academy of Science (KNAW).

The reported studies were financially supported by the Netherlands Heart Foundation (42.015 and 43.033).

The publication of the thesis was supported by a main grant of Zilveren Kruis, member of Achmea.

Financial support by the Netherlands Heart Foundation for the publication of this thesis is gratefully acknowledged. 
Voor Pierre 
vi 


\section{Contents}

1 General Introduction 1

I.I Background of the study ................ I

I.2 Heart failure . . . . . . . . . . . . . . . . 2

I.3 Resource utilization . . . . . . . . . . . . . . . 3

I.4 Quality of life . . . . . . . . . . . . . . . . . 4

I.5 Self-care . . . . . . . . . . . . . . . . . . . 4

I.6 Nursing care . . . . . . . . . . . . . . . . . . . . . . . . 4

I.7 The study . . . . . . . . . . . . . . . . . . 5

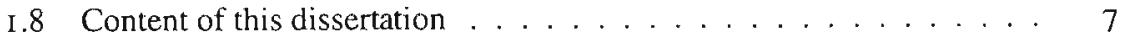

I.9 References......................... . . 8

I Background 13

2 Readmission of oider heart failure patients 15

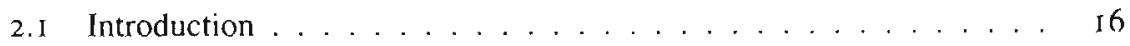

2.2 Method ............................ . . . . . . .

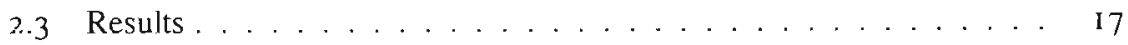

2.4 Conclusion . . . . . . . . . . . . . . . . . . . 22

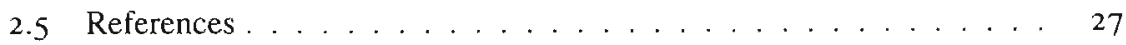

3 Maintaining the balance 31

3.1 Introduction . . . . . . . . . . . . . . 32

3.2 Method . . . . . . . . . . . . . . . . . 32

3.3 Results . . . . . . . . . . . . . . . . . . . . . 34

3.4 Discussion . . . . . . . . . . . . . . . . . . . . 42

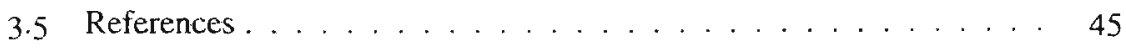

II Intervention 47

4 Developing a supportive-educative program 49

4.1 Introduction . . . . . . . . . . . . . . 50

4.2 Self-care Deficit Nursing Theory and Heart Failure . . . . . . 50

4.3 Method ........................ 52

4.4 Therapeutic Self-Care Demand . . . . . . . . . . . 52 
4.5 Self-Care Agency . . . . . . . . . . . . . . . . . . . . 54

4.6 Assessment tool for patients with heart failure . . . . . . . . . . . . 56

4.7 Education and support for heart failure patients . . . . . . . . . . 58

4.8 Testing the supportive-educative program . . . . . . . . . . . . 58

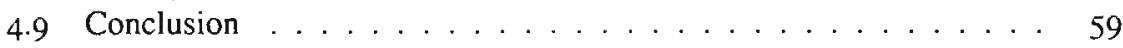

4. I0 References................... 6I

5 Education and support: a case study 63

5.1 Introduction . . . . . . . . . . . . . . . . 64

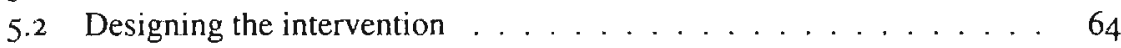

5.3 Using the intervention . . . . . . . . . . . . . . . . 66

5.4 Case history . . . . . . . . . . . . . . . . . . . 70

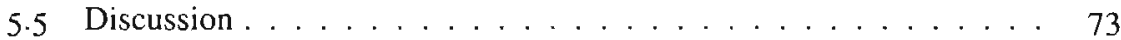

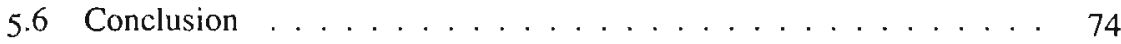

5.7 References...................... 75

III Method and Results 77

6 Method $\quad 79$

6.I Introduction ......................... 80

6.2 Research questions and design .............. . . 8I

6.3 Sampling and randomization ............... 82

6.4 Intervention and control group ................. 83

6.5 Outcome measures ...................... 83

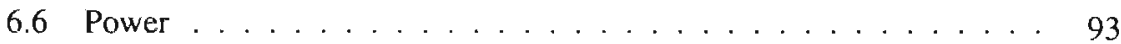

6.7 Population and attrition . . . . . . . . . . . . . . . . . . . . 93

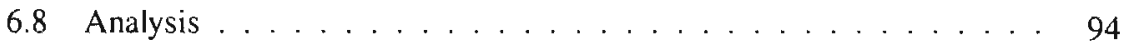

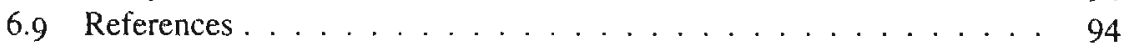

7 Self-care behavior and its limitations 99

7.1 Introduction . . . . . . . . . . . . . . . . . I00

7.2 Background and literature . . . . . . . . . . . . . . IOO

7.3 Theoretical framework .................... IOI

7.4 Method ........................ I02

7.5 Results ........................... 104

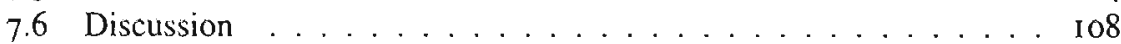

7.7 Conclusion . . . . . . . . . . . . . . . . . . I I I

7.8 References.......................... II I

8 Effects on resource utilization $\quad 115$

8. I Introduction . . . . . . . . . .......... I I6

8.2 Method .......................... I 6

8.3 Results .............................. II9

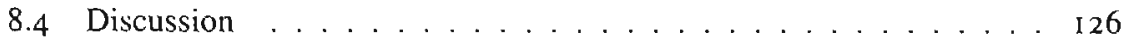

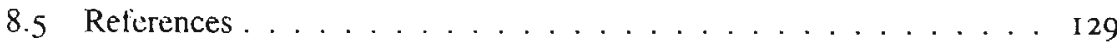


9 Effects on quality of life 133

9. I Introduction . . . . . . . . . . . . . . . . . . . . 1.34

9.2 Method . . . . . . . . . . . . . . . . . . . . . . . 13.34

9.3 Results . . . . . . . . . . . . . . . . . . . . . . . . . . . . . . . . 1.37

9.4 Discussion . . . . . . . . . . . . . . . . . . . . . . . 143

9.5 Conclusion and clinical implications ... . . . . . . . . 146

9.6 References. . . . . . . . . . . . . . . . 146

10 Effects on quality of life 149

IO.I Introduction . . . . . . . . . . . . . . . . I50

10.2 Method ....................... I5I

10.3 Results . . . . . . . . . . . . . . . . . . . . . . . . . 155

10.4 Discussion. . . . . . . . . . . . . . . . . . . . . . 162

I0.5 Recommendations . . . . . . . . . . . . . . I65

I0.6 References. . . . . . . . . . . . . . . . . . . . . . I66

11 Changes in quality of life $\quad 169$

II.I Introduction .................... I70

I 1.2 Method . . . . . . . . . . . . . . . . . . I70

11.3 Results . . . . . . . . . . . . . . . . . . . . . . . I74

11.4 Discussion. . . . . . . . . . . . . . . . . . . . . . . . . . . . 179

II.5 References. . . . . . . . . . . . . . . . . . . . . . I82

12 General discussion $\quad 185$

I 2.I Reflections on theory and methods . . . . . . . . . . . . . I86

12.2 Implications for practice and research . . . . . . . . . . . . 197

12.3 References. . . . . . . . . . . . . . . . . . 203

$\begin{array}{ll}\text { Summary } & 207\end{array}$

$\begin{array}{ll}\text { Samenvatting } & 215\end{array}$

$\begin{array}{ll}\text { Dankwoord / Acknowledgement } & 223\end{array}$

$\begin{array}{ll}\text { Curriculum Vitae } & 227\end{array}$

$\begin{array}{lr}\text { Curriculum Vitae } & 229\end{array}$ 
CONTENTS 


\section{List of Figures}

I.I Research model . . . . . . . . . . . . . . . . . . 6

4. $\mathrm{I}$ Development of a supportive-educative program . . . . . . 52

6.I The design of the study . . . . . . . . . . 80

8. I Self-care abilities (ASA) $n=I I I$, theoretical range $24-120 \ldots \ldots$ I 21

8.2 Heart failure related self-care behavior $n=128$, theoretical range $0-19$. I 21

I2. I Research model . . . . . . . . . . . . . . . . . . I 88

12.2 Final model . . . . . . . . . . . . . . . . . . . 195 
xii

LIST OF FIGURES 


\section{List of Tables}

2.x Research studies on nursing interventions .......... 23

3. I Categories used in the interviews with the nurses . . . . . . . . 33

3.2 Topics concerning observation and assessment . . . . . . . . 36

3.3 Symptom-relieving interventions .............. 37

3.4 Topics for education and counseling ............ 40

4. I Self-care requisites affected by heart failure . . . . . . . . . . . 53

4.2 Power components . . . . . . . . . . . . . . . 54

4.3 Example of elaboration of patient's required capabilities . . . . . . 55

4.4 Examples of assessment questions . . . . . . . . . . . . . 57

4.5 Nursing actions with regard to fluid intake and output . . . . . . . . 59

5.I The 9 categories in the SNCP . . . . . . . . . . . . . 66

5.2 Aspects of education and support from the SNCP (standard) . . . . . 67

5.3 Sample page from the SNCP for heart failure patients . . . . . . . . 69

6. I Criteria for congestive heart failure (Boston Score) . . . . . . . . . 8 I

6.2 Instruments used in the study . . . . . . . . . . . . . . . . . 84

6.3 The Heart Failure Self Care Behavior Scale . . . . . . . . . . . . . . 86

6.4 Factor loadings of Heart Failure Self-Care Behavior Scale . . . . . . . 87

6.5 Demographic and clinical variables collected in the study . . . . . . 91

6.6 Exclusion and attrition during the study period . . . . . . . . . . . . . 92

6.7 Attrition due to mortality and nonresponse . . . . . . . . . . . . . 94

7.I Aspects of the supportive-educative intervention . . . . . . . . . I03

7.2 Demographic and clinical characteristics of the sample $(n=128) \ldots$. I05

7.3 Self-care behaviour ........................ ro6

7.4 Heart failure related self-care behavior and its limitations . . . . . I07

8. I Demographic and clinical characteristics $(n=179) \ldots \ldots$ I20

8.2 Number of patients readmitted . . . . . . . . . . . . . . . I 22

8.3 Readmissions of patients who completed follow-up and who died . . . I 24

8.4 Use of health care resources ................. 125

9.I Instruments and their reliability's used in the study . . . . . . . . I35

9.2 Characteristics in relation to type of heart failure . . . . . . . . . 138

9.3 Medication on admission and discharge of the total group . . . . . . I 39 
9.4 Dimensions of quality of life in relation to type of heart failure . . . I 40

9.5 Correlations between quality of life dimensions . . . . . . . . I4 I

9.6 Results of backward multiple linear regression analyses . . . . . . . I 42

IO.I Exclusion and attrition during the study period . . . . . . . . I54

I0.2 Demographic and clinical characteristicsof the sample $(n=132) \ldots . \quad 156$

I0.3 Self-care abilities and behavior, per protocol and alternative analysis . 157

10.4 Interaction between self-care behavior at baseline and the effect of the intervention on self-care behavior . . . . . . . . . 158

I0.5 Quality of life scores at baseline and during follow-up $(n=132) \ldots$ I 59

I0.6 Change in symptom severity and symptom distress . . . . . . 160

10.7 Correlation coefficients between quality of life and self-care variables at baseline, 3 months and 9 months follow-up . . . . . . I6r

II. I Demographic and clinical characteristics $(n=74) \ldots \ldots \ldots \ldots \ldots$. . . 173

I I.2 Baseline score and change in self-care and quality of life at 3 and 9 months after discharge . . . . . . . . . . . . . I75

I 1.3 Individual change in self-care and quality of life at 3 and 9 months after

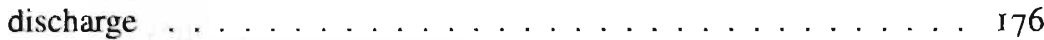

I 1.4 Results of regression analyses $(\beta)$ with the change in quality of life dimensions as the dependent variables . . . . . . . . . 178

II.5 Results of regression analyses $(\beta)$ with the change in overall well-being between 3 months and baseline and 9 months and baseline as dependent variables . . . . . . . . . . . . . . . . . . . 180 


\section{Chapter 1}

\section{General Introduction}

\subsection{Background of the study}

In contrast to favorable trends for most cardiovascular diseases, one of the growing chronic populations is the population of heart failure patients. Heart failure is a significant and growing public health problem in industrialized countries and sometimes referred to as an epidemic. ${ }^{\mathrm{I} 7}$

The prevalence estimates of heart failure range from 3 to 20 individuals per 1000 (crude prevalence $=$ unadjusted for age), with a prevalence of 30 to 130 individuals per 1000 for those aged over 65 years ${ }^{4}$ The crude incidence (unadjusted for age) in the general population ranges from $I$ to 5 cases per rooo population per year, with a steep increase with advancing age: with up to 40 cases per 1000 per year for those 75 of age. ${ }^{4}$ The number of patients with heart failure is expected to grow further as the proportion of elderly within the population increases, as the prognosis of patients with heart failure improves by surgical and medical interventions, and as survival from myocardial infarction improves ${ }^{6.8}$ The increasing number of older patients with chronic cardiac disease, denoting an increase in the use of health care resources (estimated at r\% of the health care budget in the Netherlands ${ }^{9}$ ) necessitates a shift in the emphusis of the health care system. In addition to the increased need for diagnosis and medical treatment, there is a growing emphasis on chronic care and adequate follow-up of the chronic patient population. ${ }^{10}$ Different strategies are used to improve quality of patient care, improve patient outcomes and decrease use of resources. Nurses are increasingly involved in these new care initiatives that often are aimed at improving continuity of care between hospital and home. In a multidisciplinary team nurses can play a key role in coordinating care of chronic patients. These changing aspects of care have consequences for the scope and organization of nursing care and have led to growing specialization and extension of roles of nurses in health care." In caring for chronic patient populations, nurses are increasingly involved in multidisciplinary home-care programs, ${ }^{12}$ nurse-run clinics or multidisciplinary clinics ${ }^{13-15}$ and followup programs. ${ }^{16}$ The effectiveness of these initiatives are increasingly tested. ${ }^{12.16}$

Optimizing care for heart failure patients by extending nurses' roles seems to have a relatively shorter history. With the exception of an innovative study of Rosenberg in $197 \mathrm{l}$, in which he showed that a multidisciplinary team, in which a nurse had 
a major role, could improve outcomes, ${ }^{17}$ studies on effects of the nonpharmacological interventions were rare until the $1990{ }^{18-29}$ Results of these "newer" studies report that multidisciplinary programs can be effective in improving quality of life and compliance and reducing readmission, but also may lead to increased use of resources. ${ }^{18-29}$ Heart failure programs or heart failure nurse specialists programs are scarce in the Netherlands. The need for nurses specialized in heart failure is being increasingly discussed. Arguments against such specialization include the fragmentation of care.$^{30}$ In particular, chronically ill patients with multiple problems would have to be subjected to a multitude of specialists resulting in fragmentation of care. Others argue that care provided by heart failure clinical nurse specialists with particular emphasis on patient education and follow-up will improve the quality of care provided. ${ }^{15,31,32}$ These developments necessitate research to test the effectiveness of nursing care provided to this patient population. They emphasize in addition, the delineation of the type of care provided by the nurse in the hospital and post discharge, which is vital to improving patient outcomes. No randomized Dutch studies have been reported that evaluate the effect of nursing care in a heart failure population. Results from the research project presented in this thesis will set the stage for discussing the role of the nurse in caring for patients with heart failure.

\subsection{Heart failure}

Many definitions of chronic heart failure exist, but in general none is considered entirely satisfactory. ${ }^{33}$ Heart failure is a complex clinical syndrome rather than an objective definable disease, and it is often characterized as the complex of symptoms that are related to the inadequate perfusion of tissue during exertion and often to retention of fluid. ${ }^{34.35}$ The diagnosis of heart failure relies on data from history, physical examinations and appropriate investigations. ${ }^{33 \cdot 36}$ Heart failure patients often suffer from symptoms like breathlessness or fatigue, either at rest or during exertion, or/and ankle swelling. These symptoms, however, may be difficult to interpret, particularly among elderly patients, the obese and in women. ${ }^{4.33 .37}$ Objective evidence of major cardiac dysfunction at rest should be present in addition to symptoms. ${ }^{33}$ Heart failure is a clinical diagnosis and there is no single clinical parameter that can be considered a "gold standard" to diagnose heart failure. ${ }^{+}$Scoring systems can be used to identify the patients with severe grades of heart failure. ${ }^{6}$ These scoring systems combine various signs and symptoms present in a patient with heart failure into a total score that is used to determine if a patient has heart failure.

Often a left ventricular ejection fraction $<40 \%$ is used to determine the presence of heart failure; however, abnormal function is not always associated with heart failure, and, on the other hand, symptoms of heart failure may arise in the absence of systolic abnormality ${ }^{38-40}$ Although heart failure patients with systolic dysfunction and those with primarily diastolic dysfunction may present with similar symptoms, the differentiation between the two syndromes can have important therapeutic and prognostic implications. Systolic dysfunction is characterized by reduced left ventricular contractility for the degree of preload and manifests in a reduced left ventricular ejection fraction. On the other hand, the fundamental problem in patients with diastolic 
dysfunction is impaired ventricular relaxation and decreased compliance in diastole. Patients with diastolic dysfunction usually have normal left ventricular ejection fractions but increased left atrial pressures and chamber pressures increase markedly in response to increases in left ventricular volume..$^{4-43}$ In general, ischemic heart disease is the most common reason for systolic dysfunction while left ventricular hypertrophy secondary to hypertension or valvular abnormalities accounts for the majority of diastolic dysfunction. Heart failure is a highly lethal syndrome with a mortality equal or greater than that of various malignancies. 44 The prognosis of patients with heart failure is poor, with a mortality one year following the onset of heart failure symptoms of around $30 \% .^{4}$ Data from hospital-based studies reflect even worse figures, since they include the more severe cases of heart failure. ${ }^{45}$

Both patients with systolic and/or diastolic dysfunction may suffer from symptoms affecting their daily functioning. In addition, treatment regimen can also have a major impact on their daily life. Progression of the disease, symptoms and treatment affect important outcomes like resource utilization and quality of life.

\subsection{Resource utilization}

The increase in the incidence of heart failure has led to an increase in hospital admissions..$^{3,4,6-48}$ A further increase in the number of hospital admissions for heart failure is likely since the number of persons above the age of 65 is expected to rise and medical care is still progressing. ${ }^{3}$ Correspondingly, in the Netherlands, the discharge rates for heart failure increased by $48 \%$ for men and by $40 \%$ for women in the period 1980 $1993 .^{3.4}$ The rise in the number of discharges was more pronounced in the older age groups. ${ }^{3}$ In the international literature heart failure is described as the most common cause of hospitalization for the older population. ${ }^{46.48}$ It is also reported that elderly patients who survive hospitalization for congestive heart failure are particularly vulnerable to readmission. ${ }^{49-52}$ Readmission rates of 14 to $50 \%$ within 6 months are reported among elderly heart failure patients. ${ }^{3.49 .53}$

In a Dutch survey of 7 hospitals in 1991 and 1992 , it was found that the proportion of the patients that returned to the hospital increased with every new admission. The percentage of patients that was readmitted for heart failure within six months after their first discharge within the research period was $14 \%$ (note that this was not always their first admission for heart failure). Of all patients discharged after their second admission $26 \%$ were readmitted within 6 months. For patients with a third admission the percentage increased to $34 \%,{ }^{3}$ Several authors have described that readmission could have been avoided in 40 to $59 \%$ of the patients if there had been better assessments, if rehabilitation had been more adequate, if discharge had been more carefully planned, if actual and potential non-compliance with medication had been identitied, if patients had been instructed to seek medical attention when symptoms occur, if patient followup had been more adequate, and if physicians had been better trained. .2-56 $^{2}$ 


\subsection{Quality of life}

It is generally recognized that one of the major goals in the treatment of patients with chronic heart failure is to improve quality of life $\mathrm{e}^{57-59}$ and this concept is therefore increasingly being incorporated in clinical trials as a complementary endpoint to the traditional outcomes of mortality and morbidity. Quality of life can be seen as reflecting the way patients perceive and react to their health status and to other aspects of their lives. ${ }^{60}$ Different approaches to define quality of life are used and discussed, and it is generally seen as multi-dimensional and subjective. ${ }^{60,61-64}$ Dimensions of quality of life that are considered to be important for patients with heart failure are functional capabilities, symptoms, and psychosocial perceptions. ${ }^{62}$ In addition, a global rating of well-being by a patient can provide new information, since this can reflect the disparate values and preferences of individual patients. ${ }^{60}$ Researchers have described a significantly compromised quality of life in patients with advanced heart failure ${ }^{65-67}$ and suggested that interventions to improve quality of life need to be targeted at reducing depression and hostility, increasing daily activity levels, and learning self-care. ${ }^{66,68}$

\subsection{Self-care}

Heart failure had a major impact on patients' lives, normal functioning and well-being. Severe symptoms, limited vital capacity, and treatment affect physical, personal and social aspects of the patient's life. As the disease progresses, patients have to make adjustments in their lives. Patients have to learn to live with the consequences of heart failure, which means: adhere to medication, diet and exercise, monitor symptoms, and seek assistance when symptoms occur. In Orem's general theory of nursing, these aspects are defined as self-care. ${ }^{69}$ Self-care is "the practice of activities that individuals initiate and perform on their own behalf in maintaining life, healthy functioning, personal development and well-being." ${ }^{69}$ In this dissertation this theory is used to structure and evaluate nursing care in a consistent and systematized way.

To adequately care for themselves in a changing health situation, patients need to take certain care measures and therefore they need particular knowledge and skills (self-care abilities). ${ }^{69}$ If the self-care abilities are not enough to meet their demand for self-care, a self-care deficit exists and a person may require nursing care. ${ }^{69}$ It can be hypothesized that increasing self-care ability and improving self-care (behavior) will have effects on readmission and quality of life. Since a lack of education of the patient and family and inadequate follow-up medical care is related to readmission rate, ${ }^{70}$ it can be expected that effective information and support will prevent self-care deficits and as a result decrease resource utilization and enhance quality of life.

\subsection{Nursing care}

Nurses are involved in the care of patients with heart failure across the disease trajectory: in the ICU during acute exacerbation of heart failure, on cardiology or general medicine wards during the recovery period, and during the post discharge period in the 
outpatient clinic. In addition, nurses provide follow-up care with emphasis on therapeutic and supportive care or palliative care in the terminal phase of the disease.

The scope of nursing care for cardiac patients encompasses those nursing activities which assist individuals to modify their lifestyle and environment so that they can attain optimum cardiac function and acceptable quality of life in congruence with life goals. ${ }^{71}$ In heart failure patients, nurses need to help patients adjust the physical, personal and social aspects of their lives to severe symptoms, limited vital capacity and effects of treatment. $^{72}$

Although several evidence-based guidelines on diagnoses and treatment of heart failure have appeared over the past few years, information on standards of nursing care are scarce. Some general guidelines on heart failure address topics of general counseling. ${ }^{36.73}$ These, expert-opinion-based suggestions, include general counseling on heart failure, prognosis, activity level, diet, medications and the importance of compliance with the treatment/care plan. Nurses can use these suggestions in structuring their patient education, but evidence-based guidelines on other aspects of care of heart failure patients are scarce.

Sometimes standard nursing care plans or protocols are used in the care for patients with heart failure. The protocols are mostly used in the acute care of patients admitted to an ICU/CCU, for example a protocol on intravenous medication. Nursing care plans for the chronic heart failure patients vary considerably and interventions are mostly not evidence-based. ${ }^{74}$ At the same time, it should be recognized that designing care for patients with heart failure is very complex, considering the high comorbidity of patients, the older age, and the chronic course of the disease. Therefore a patienttailored evidence-based intervention is needed to improve the quality of care and as a result improve patient outcomes. Research studies that assess the effectiveness of education and support in patients with heart failure are growing. In most of these studies education and support is combined with intensive follow-up and treatment and care by a specialized heart failure team. ${ }^{21.23 .24 .29}$ Despite benefits of these programs, no statements can be made in regard to the mechanisms of the beneficial effects and if of the contribution of nursing to these interventions. ${ }^{75}$

\subsection{The study}

\section{Intervention}

The supportive educative intervention designed for this study addresses aspects of discharge planning. noncompliance and symptom recognition. It consisted of intensive, systematized and planned education in hospital and at home, by a study nurse about the consequences of heart failure in daily life.

\section{The research study}

The aim of the study is to investigate whether education and support by a nurse in hospital and at home would enhance self-care abilities and self-care behavior of patients with heart failure. decrease resource utilization and improve quality of life. 


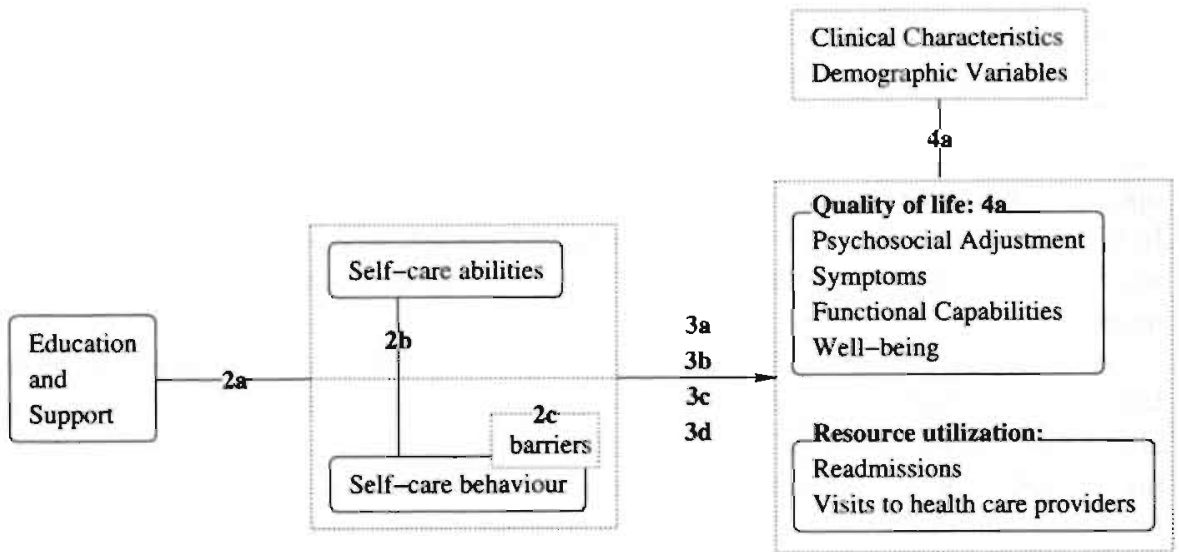

Figure I.I: Research model

In this thesis the following research questions are posed (figure I.I):

I. What constitutes the optimal education and support in patients with heart failure? Knowledge from literature, interviews with nurses and standard nursing care plans are used to develop an intervention for patients with heart failure, with Orem's General Theory of Nursing as a frame of reference.

2. To successfully care for themselves during the progress of heart failure, patients need certain knowledge and skills. The intervention was developed to increase self-care ability and to improve self-care behavior by education and support of patients. To test the effect of the intervention on self-care abilities and behavior and to gather additional information on the barriers of patients to perform selfcare behavior the following questions were formulated:

(a) What is the effect of education and support on self-care abilities and selfcare behavior of patients with heart failure?

(b) Do self-care abilities relate to self-care behavior?

(c) What are barriers for self-care behavior?

3. To test the effects of the intervention on resource utilization and quality of life, we hypothesized that the underlying mechanism for effects would be increase of self-care abilities and improve of self-care behavior. We therefore formulated the questions:

(a) Do self-care abilities and self-care behavior relate to resource utilization?

(b) What is the effect of education and support on resource utilization?

(c) Do self-care abilities and self-care behavior relate to quality of life?

(d) What is the effect of education and support on quality of life? 
4. To describe determinants of quality of life and to get insight into variables that are related to a change in quality of life we formulated:

(a) What are determinants of quality of life

(b) Does a change in quality of life relate to resource utilization, clinical characteristics and demographic variables?"

\section{Design}

A randomized controlled study was conducted to study the effects of a supportiveeducative nursing intervention on self-care (agency and behavior), resource utilization and quality of life. Patients were followed for 9 months with measurements during hospital admission (baseline), at I, 3 and 9 months.

\subsection{Content of this dissertation}

The dissertation consists of three parts. In the first part (chapters 2 \& 3) the background of the study is described. Chapter 2 presents a review of the literature on readmission of older heart failure patients. Chapter 3 describes the nursing care provided to heart failure patients based on a thorough review of the literature, interviews with nurses and standard nursing care plans currently in use in the Netherlands.

In part two the development of the supportive-educative intervention is described. Orem's General theory of Nursing ${ }^{73}$ was used to structure the design of the intervention (chapter 4). To illustrate and explain the interventions, a case-study is presented in chapter 5, describing care provided to a 71 -year-old patient admitted to the cardiology ward with symptoms of heart failure (chapter 5).

Part three of the dissertation starts with chapter 6 with a description of the method (design and variables) that is used to answer the research question. The effect of education and support on self-care agency and self-care behavior is first described in chapter 7. In this chapter the limitations for self-care behavior, described by the patient are discussed. Effects on resource utilization and quality of life are described in the chapters 8 and 10 . Relationships with quality of life and the change in quality of life are presented in chapters 9 and II. Finally, methodological reflections, general conclusions and implications for practice and research are presented.

It should be noted that in some chapters different terms are used for the same concept. This is a consequence of publication of chapters in or submission of chapters to different journals or type of journals (medicine or nursing). Readers outside the nursing profession do not always know terms like "self-care agency," "self-care" or "therapeutic self-care demand". Therefore other terms like self-care abilities (self-care agency) and self-care behavior(s) (self-care) are used interchangeably.

Publication and submission of chapters separately is also the reason for some overlap in description of methods and reporting of some results.

\footnotetext{
anue to the longitudinal approach of this question, this relationship is not depicted in the research model.
} 


\subsection{References}

r. Ho KK, Pinsky JL, Kannel WB, Levy D. The epidemiology of heart failure: The Framingham study. J Am Coll Cardiol 1993; 22: 6A-13A.

2. Bonneux L, Barendregt JJ, Meeter K, Bonsel GJ, van der Maas PJ. Estimating clinical morbidity due to ischemic heart disease and congestive heart failure: the future rise of heart failure. Am J Public Health 1994; 84: 20-28.

3. Reitsma JB, Mosterd A, de Craen AJM, Koster RW, van Capelle FJL, Grobbee DE, Thijssen JGP. Increase in hospital admission rates for heart failure in The Netherlands, 1980-1993. Heart 1996; 76: 388-392.

4. Mosterd A. Epidemiology of heart failure [Doctoral thesis]. Rotterdam: Erasmus University of Rotterdam, 1997.

5. Massie BM, Shah NB. Evolving trends in the epidemiological factors of heart failure: Rationale for preventive strategies and comprehensive disease management. Am Heart J 1997; 133: 703-7I 2.

6. Cowie MR, Mosterd A, Wood DA, Deckers JW, Poole-Wilson PA, Sutton GC, Grobbee DE. The epidemiology of heart failure. Eur Heart J 1997; 18: 209-225.

7. Hoes AW, Mosterd A, Grobbee DE. An epidemic of heart failure? Eur Heart J 1998; 19 (suppl. L): 2-ro.

8. McMurray JJV, Petrie MC, Murdoch DR, Davie AP. Clinical epidemiology of heart failure: public and private health burden. Eur Heart J 1998; 19(suppl. P): 9-16.

9. Koopmanschip MA, van Rooijen L, Bonneux L. Costs of diseases in the Netherlands. [Dutch] Report of the department of public hea]th and social medicine and the institute for medical technology assessment. Rotterdam: Erasmus University of Rotterdam, 1992.

10. Editorial. Disease Management in Europe BMJ 1998: 317: 426-427.

11. Hamric AB, Spross JA, Hanson CM. (eds.). Advanced nursing practice. An integrative approach. Philadelphia: WB Saunders Company, 1996.

12. Ketelaars C. Aftercare and specialized community nursing [Doctoral thesis]. Maastricht: University of Maastricht, 1996.

13. Strömberg A. Heart Failure clinics. Editorial. Heart 1998: 80: 426-427.

14. Temmink D, Franke AL, Kerkstra A. Talking about consulting hours [in Dutch]. Maarssen: Elsevier/de Tijdstroom, 1998.

15. Wal van der M. Consultation hour of a nurse on the cardiology outpatient department [in Dutch]. Cardiologie 1996; 3: 232-235.

16. Naylor MD, Brooten D, Campbell R, Jacobsen BS, Mezey MD, Pauly MV, Schwartz JS. Comprehensive discharge planning and home-follow-up of hospitalized elders. JAMA 1999: 281: 613-620.

17. Rosenberg SG. Patient education leads to better care for heart patients. HSMHA Health reports 1971 ; 86: 793-802.

18. Cintron G. Bigas C, Linares E, Aranda JM. Hernandez E. Nurse practitioner role in a chronic heart failure clinic: in hospital time, costs, and patient satisfaction. Heart Lung 1983: 12: 237-240. 
19. Kostis JB, Rosen RC, Cosgrove NM, Shindler DM, Wilson AC. Nonpharmacologic therapy improves functional and emotional status in congestive heart failure. Chest 1994; 106: 996-IOOI.

20. Kornowski R, Zeeli D, Averbuch M, Finkelstein A, Schwartz D, Moshkovitz M, Weinreb B, Hershkovitz R, Eyal D, Miller M, Levo Y, Pines A. Intensive homecare surveillance prevents hospitalization and improves morbidity rates among elderly patients with severe congestive heart failure. Am Heart J 1995; I29: $762-766$.

21. Rich MW, Beckham V, Wittenberg C, Leven CL, Freedland KE, Camey RM. A multidisciplinary intervention to prevent the readmission of elderly patients with congestive heart failure. N Engl J Med 1995; 333: I 190-1 195.

22. Weinberger $M$, Oddone EZ, Henderson WG. Does increased access to primary care reduce hospital readmissions? N Engl J Med I996; 334: I44 I-I I 47.

23. Hanumanthu S, Butler J, Chomsky D, Davis S, Wilson JR. Effect of a heart failure program on hospitalisation frequency and exercise tolerance. Circulation 1997; 96: $2842-2848$.

24. Funarov GC, Stevenson LW, Walden JA, Livingston NA, Steimle AE. Hamilton MA. Moriguchi J, Tillisch JH, Woo MA. Impact of a comprehensive heart lailure mandgement program on hospital readmission and functional status of patients with advanced heart failure. J Am Coll Cardiol I997; 30: 725-732.

25. Smith LE, Fabbri SA, Pai R, Ferry D, Heyman JT. Symptomatic improvement and reduced hospitalization for patients attending a cardiomyopathy clinic. Clin Cardiol 1997; 20: 949-954.

26. West JA, Miller NH, Parker KM, Senneca D, Ghandour G, Clark M, Greenwald G, Heller GS, Fowler MB, DeBusk RF. A comprehensive management system for heart failure improves clinical outcomes and reduces medical resource utilization. Am J Cardiol I 997; 79: 58-63.

27. Shah NB, Der E, Ruggerio C, Heidenreich PA, Massie BM. Prevention of hospitalization for heart failure with an interactive home monitoring program. Am Heart J 1998; 135: 373-378.

28. Stewart S, Pearson S, Horowitz JD. Effects of a home-based intervention among patients with congestive heart failure discharged from acute hospital care. Arch Intern Med I 998; 158: 1067-1073.

29. Cline CMJ, Israe]sson BYA. Willenheimer RB. Broms K, Erhardt LR. Cost effective management programme for heart failure reduces hospitalisation. Heart I 998: 80: 442-446.

30. Pasch T van de. Our Profession. Editorial [in Dutch]. TVZ 1993; 47: 695.

31. Balk AHMM. Heart failure: quality care with limited resources? A challenge to the Dutch cardiologist. Cardiologie I 995: 2: 279-280.

32. Results of the consensus meeting on heart failure [in Dutch]. Hartbulletin I994; 25: 256-262.

33. The Task Force on Heart Failure of the European Society of Cardiology. Guidelines for the diagnosis of heart failure. Eur Heart J I995; I 6: 741-75 I.

34. Meirs LJ, Arnold R. The cardiovascular response to exercise in the patient with congestive heart failure. J Cardiovasc Nurs I 990; 4: 347-358. 
35. Cohn JN. The management of chronic heart failure. New Engl J Med I $996 ; 335$ : 490-498.

36. Konstam M, Dracup K, Baker D et al. Heart failure: evaluation and care of patients with left ventricular systolic dysfunction. Clinical Practice Guideline No I I. AHCPR Publication No. 94-0612. Rockville, MD: Agency for Health care Policy and Research, Public Health Service, US Department of Health and Human Services, June I994.

37. Dargie HJ, McMurray JJV, Poole-Wilson PA. Managing Heart Failure in primary care. London: Blackwell Healthcare Communications, 1996.

38. McCall D. Recognition and management of asymptomatic patients with left ventricular dysfunction. Am J Cardiol I992; 69: I 306-1316.

39. Bonow RO, Udelson JE. Left Ventricular diastolic dysfunction as a cause of congestive heart failure. Ann Int Med 1992; I I7: 502-5 I0.

40. Goldsmith SR, Dick C. Differentiating systolic from diastolic heart failure: pathophysiology and therapeutic considerations. Am J Med I993; 95: 645-655.

41. Lehinan DJ, Gerson MC, Hoit BD, Walsh RA. Mechanisms, diagnosis, and treatment of diastolic heart failure. Am Heart J 1995; 130: 153-166.

42. McAlister FA, Teo KK. The management of congestive heart failure. Postgrad Med J. 1997; 73: 194-200.

43. Senni M, Redfield MM. Concise review for primary-care physicians. Congestive heart failure in elderly patients. Mayo Clin Proc 1997; 72: 453-460.

44. Eriksson H. Heart Failure: a growing public health problem. J Int Med 1995; 237: 135-I41.

45. Franciosa JA. Epidemiologic patterns, clinical evaluation and long-tenn prognosis in chronic congestive heart failure. Am J Med I986; 80: 14-2I.

46. Massie M, Shah NB. The heart failure epidemic: magnitude of the problem and potential mitigating approaches. Current opinion in Cardiology I996; I I: 22 I226.

47. McMurray J, McDonaugh T, Morrison CE, Dargie HJ. Trends in hospitalization for heart failure in Scotland I 980-1 990. Eur Heart J I 993; 4: I I 58-I I62.

48. Wolinski FD, Smith DM, Stump TE, Everhoge JM, Lubitz RM. The sequelae of hospitalization for congestive heart failure among older adults. J Am Geriatr Soc 1997: 45: 558-563.

49. Krumholz HM, Parent EM, Tu N, Vaccarino V, Wang Y, Radford MJ, Hennen J. Readmission after hospitalization for congestive heart failure among Medicare beneficiaries. Arch Int Med 1997; 157: 99-104.

50. Gooding J, Jette AM. Hospital readmissions among the elderly. J Am Geriatr Soc 1985; 33: 595-60I.

51. Reed RL, Pearlman RA, Buchner DM. Risk factors for early unplanned hospital readmission in the elderly. J Gen Intern Med 199 : 6: 223-228.

52. Vinson JM, Rich MW, Sperry JC. Early readmission of elderly patients with congestive heart failure. J Am Geriatr Soc I 990; 38: 1290-I 295.

53. Happ MB. Naylor MD. Roe-Prior P. Factors contributing to rehospitalization of elderly patients with heart failure. J Cardiovasc Nurs I997; I 1: 75-84. 
54. Nikolaus T, Specht-Leible N, Krusse W, Oster P, Schlierf G. The early rehospitalization of elderly patients; causes and prevention [in German]. Disch Med Wschr 1992: 403-407.

55. Graham H, Livesley B. Can readmissions to a geriatric medical unit be prevented? The Lancet $1983: 21: 404-406$.

56. Michalsen A, Konig G, Thimme W. Preventable causative factors leading to hospital admission with decompensated heart failure. Heart 1998; 80: 437-441.

57. Wiklund I. Swedberg K. Some methodological problems in analyzing quality of life data in severe congestive heart failure. J Clin Res Pharm 1991; 5: 265-273.

58. Taylor SH. Congestive heart failure: Towards a comprehensive treatment. Eur Heart J 1996; I7(suppl. B): 43-56.

59. Cohn JN. Current concepts in the treatment of congestive heart failure. Cardiology 1997: (suppl 2): 2-6.

60. Gill TM, Feinstein AR. A critical appraisal of the quality of life measurements. JAMA, 1994; 272: 619-626.

6I. McSweeny AJ, Creer TL. Health-related quality of life assisisment in medical care. Disease-a-Month, 1995; 1: I-72.

62. Wenger NK, Mattson ME, Furberg CD, Elinson J. (eds.) Assessment of quality of life in clinical trials of cardiovascular therapies. New York: Le Jacq Publishing, I 984 .

63. Bulpitt CJ, Fletcher AE. Measurement of the quality of life in congestive heart failure-influence of drug therapy. Cardiovasc Drugs Ther 1988; 2: 419-424.

64. Hays RD, Anderson R, Revicki D. Psychometric considerations in evaluating health-related quality of life measures. Qual Life Res I 993: 2: 44 I-449.

65. Eriksson H, Svardudd K, Larsson B, Welin L, Ohlson L, Tibblin G, Wilhelmsen L. Quality of life in early heart failure. Scan J Prim Health Care 1988; 6: I6I167.

66. Dracup K. Walden JA, Stevenson LW, Brecht ML. Quality of life in patients with advanced heart failure. J Heart Lung Transplant I 992; I I : 273-279.

67. Stewart AL, Greenfield S. Hays RD, Wells K, Roger WH, Berry SD, McGlynn EA, Ware JE. Functional status and well-being of patients with chronic conditions. JAMA 1989; 262: 907-9 2.

68. Hawthorne MH, Hixon ME. Functional status, mood disturbance and quality of life in patients with heart failure. Progress Cardiovasc Nurs 1994; 9: 2232.

69. Woods SL, Froelicher ESS, Halpenny CJ, Underhill SM (cds.) Cardiac Nursing. Philadelphia: JB Lippincott Company, I 995.

70. Dracup K, Baker DW, Dunbar SB, Dacey RA, Brooks NH, Johnson JC, Oken C. Massie BM. Management of Heart Failure, counseling, education, and lifestyle modifications. JAMA 1994: 272: 1442-1446.

7I. The Task Force of the Working Group on Heart Failure of the European Society of Cardiology. The treatment of heart failure. Eur Heart J I $997 ; 18$ : 736-753.

72. Jaarsma T, Huijer Abu-Saad. Nursing care and heart failure lin Dutch]. The Hague: Netherlands Heart Foundation, I995.

73. Orem DE Nursing: Concepts of practice ( $5^{\text {th }}$ ed.) S. Louis: Mosby 1995. 
74. Ashton CM, Kuykendall DH. Johnsin ML, Wray NP, Wu L. The association between the quality of inpatient care and early readmission. Ann Int Med 1995; I22: 4I5-42I.

75. McMurray JJV, Stewart S. Nurse led, multidisciplinary intervention in chronic heart failure. Editorial. Heart 1998; 80: 430-431. 
Part I

\section{Background}




\title{
Chapter 2
}

\section{Readmission of older heart failure patients}

\begin{abstract}
The purpose of this chapter is to provide an overview of the literature on factors associated with hospital readmission of older patients in general and more specific of older heart failure patients. Important factors reported to be related to rehospitalization are sociodemographic and medical factors, premature discharge, failing support system, medication related problems and noncompliance. To prevent readmission, interventions in the area of discharge planning, patient education and follow-up are recommended.
\end{abstract}

Adapted from:

- Jaarsma T, Halfens RJG, Huijer Abu-Saad H. Readmission of older heart failure patients. Prog Cardiovasc Nurs I 996; I I : I 5-20, 48.

- Letter to the editor. Heart 1999: 81: 676.

Translated to:

- Jaarsma T, Halfens RJG, Huijer Abu-Saad. H. Heropname van oudere patiënten met hartfalen. Cordiaal I 996; I7(5): I8-2 I. 


\subsection{Introduction}

Heart failure has become a significant health problim for cardiovascular caregivers as well as a large societal problem. Studies from different industrialized countries indicate that heart failure is an increasingly frequent reason for hospital admission. ${ }^{1.6}$ In the period 1973-1986 an increase of more than $50 \%$ of hospitalizations in the United States was described. ${ }^{7}$ Comparable trends have been described in European studies on heart failure. ${ }^{1-6} \mathrm{~A}$ rapidly rising prevalence of heart failure is expected to continue well into the $2 \mathrm{I}^{\mathrm{st}}$ century. ${ }^{7.8}$

Longer survival with heart failure, an increased incidence of heart failure or perhaps more complete reporting, have been cited as leading reasons for the rise in hospitalization rates for heart failure patients. ${ }^{3}$ Reported rates on hospitalization indicate that among newly diagnosed patients and readmitted patients, patients with heart failure have the highest readmission rates. ${ }^{9}$

Several studies have concluded however that readmissions could have been avoided in 40 to $59 \%$ of the patients if there had been better assessments, if rehabilitation had been more adequate, if discharge had been more carefully planned, if potential noncompliance problems with medications and diet had been identified, and if patients had been instructed to seek medical attention when symptoms occur. ${ }^{10-13}$ Yet, despite a well structured multidisciplinary approach and careful discharge planning, it is estimated that at least $8 \%$ of patients still will be readmitted within three months. ${ }^{1.4}$ An additional consideration in the heart failure population is that most heart failure patients are elderly and therefore more vulnerable to poorer outcomes and a decline in functional status during the first few weeks after hospital discharge. ${ }^{15}$ In the following, factors associated with the rehospitalization of older patients in general and elderly heart failure patients in particular are described. Additionally suggested (nursing) interventions to prevent readmission of the older heart failure patients are described.

\subsection{Method}

The objective for this literature review is to identify factors associated with hospital readmission of older patients in general and elderly heart failure patients in particular. In addition an overview of suggested (nursing) interventions to prevent readmission of the older heart failure patients are described. In a first stage a computer search of the MEDLINE database from 1966 to 1995 was performed. In a later phase an additional search from I $995^{-1998}$ was performed. The term heart failure was used combined with one or more of the following terms: disease management, home care services, patient care planning, patient education, readmission, nursing, rehabilitation. prevention and control. Observational and experimental studies were included. 


\subsection{Results}

\section{Factors influencing rehospitalization in elderly patients}

\section{Sociodemographic and medical factors}

Age and gender differences among the general older population are known factors related to hospital readmission. ${ }^{12,16}$ Factors such as widowhood and life satisfaction influence the probability of hospital readmission among elderly patients within 6 weeks of discharge. ${ }^{16}$ Over a longer period of time ( 1 year), a history of previous hospitalizations is an additional factor influencing readmission. These sociodemographic factors alone however are not predictive of recurrent hospitalizations. There is no single sociodemographic profile that predicts readmission ${ }^{10,12,16-18}$ Medical history and severity of illness also have been identified as factors contributing to hospital readmissions in the elderly. ${ }^{18.14}$ Other factors include the patient's medical history, number of additional chronic medical conditions, and the number of medications being taken at time of discharge. ${ }^{\text {th }}$ Others have found that readmitted patients have more severe illnesses compared to patients that are not readmitted. In older patients, the readmission diagnosis is often the same as the initial admitting diagnosis. ${ }^{19}$ This suggests that many readmissions are due to a relapse or breakdown of the original medical condition. ${ }^{14.18,19}$ While sociodemographic factors and factors associated with the medical history or severity of illness cannot be changed, they can be used to develop prediction models for hospital readmission among high-risk patients.

\section{Premature discharge}

A few studies have examined readiness of patients for discharge. ${ }^{14.19}$ A patient's own assessment seems to be predictive of the need for subsequent readmission. Patients who felt they were discharged too soon werc more likely to be readmitted than pitients who felt they were ready to be discharged. ${ }^{19}$ In one study, a researcher that questioned caregivers and patients retrospectively, found that both groups attributed premature discharge as being a common contributory factor $(58 \%)$ in unplanned readmission within 28 days of discharge. ${ }^{4}$ This was congruent with the patient's general practitioner who judged that in $3 \mathrm{I} \%$ of the cases the patient had been discharged too soon. ${ }^{14}$ However, no prospective studies are known that address the problem of premature discharge.

\section{Failing support system}

Most patients are discharged without adequate preparation for discharge, that includes arrangement for assistancic from community or home health services or adequate rehabilitation. ${ }^{11.12 .19 .20}$

Elderly patients, who often have an inadequate support system, generally require more assistance after discharge for a longer period of time than the general population. ${ }^{21}$ The elderly tend to live alone or with an elderly spouse, who often also has a health problem. While stronger mental, emotional and social environment have not been found to influence readmission. ${ }^{16}$ other investigators have demonstrated that a failing social support systems can be related to hospital readmission. ${ }^{19}$ Relatives sometimes are not able to cope with lili-style adjustments required by the medical condition 
of the patient. The illness may put family roles and material resources under stress and spouses may not be physically and emotionally capable of caring for the patient. ${ }^{19}$

Problems at home, which have been found to be related to the readmission of elderly with an inadequate support system include failure to involve home health care, prolonged time to next appointment with the physician, inadequate family involvement, failure of the patient to seek medical attention when symptoms occur. getting prescribed medications or buying diet restricted foods. These problems may occur if the patient is discharged home without support. ${ }^{1,12,19}$

\section{Medication-related problems}

Several studies have linked medication problems to the readmission of elderly patients. ${ }^{11,12,19.22}$ Medication-related problems reported include accidental or intentional poisoning, adverse drug effects and noncompliance. ${ }^{23.24}$ Because elderly patients have a decreased renal function they are unable to excrete drugs readily in the active form. If this is not considered and dosage is not appropriately adjusted, readmission due to an adverse drug reaction may occur. ${ }^{23-25}$ Use of multiple drugs, age and female sex have often been identified as risk factors for developing problems with medications. ${ }^{23}$

\section{Compliance}

Noncompliance with medications, with diet changes or other medical recommendations such as seeking medical attention when symptoms recur, is recognized as an important factor for early readmission in elderly patients. ${ }^{11,12,19.24}$ Factors that contribute to noncompliance include misunderstanding of instruction given by the general practitioner, senility. effects of adverse drug reactions, running out of medicine, as well as the patients' perceived lack of need for the medicinc. ${ }^{2+26}$

\section{Heart failure in the elderly}

The body of literature on readmission of patients with heart failure is growing. Literature is presented in this section which focuses solely on patients with heart failure. Additional studies that include a special cohort of patients with heart failure are also discussed. ${ }^{9,11.23}$

It is found that patients with a primary diagnosis of heart failure were at highest risk for hospital readmission. ${ }^{9}$ This is confirmed by others who found that the most frequent diagnosis in a readmitted elderly population is heart failure. " Recurrent heart failure is the most common cause for readmission and is often unavoidable. ${ }^{4.10}$

\section{Premature discharge}

Readmission rates were investigated in a cohort of 148 heart failure patients. ${ }^{9}$ Although no significant differences were described in rate of readmission by length of hospital stay, some interesting trends were noted. Of the I 48 patients with heart failure, 53 $(36 \%)$ were readmitted within 6 months after discharge. However. the overall rate of readmissions in this study was underestimated because information about patients who died within 6 months after discharge, or who were readmitted to another hospital was not available. Almost half $(45 \%)$ of the patients discharged within seven days returned 
to the hospital within six months; $34 \%$ of these with length of stays of 8 to 20 days and $22 \%$ of those staying 2 I or more days were readmitted within six months. ${ }^{9}$ Factors including poor quality care, being discharged too soon and discharged in an unstable condition have a negative impact on outcomes. ${ }^{27,28}$

\section{Failing social support system}

An early study found that almost $40 \%$ of heart failure patients discharged directly home were readmitted to hospital within six months compared to $20 \%$ of those discharged to a secondary facility (skilled nursing facility, rehabilitation center, chronic care hospital). ${ }^{9}$ The authors reported that the complex patient who is sent directly home appears to be at considerably greater risk of hospital readmission.

One study showed that caregiving for a heart failure is burdensome and stressful. Reportedly, one third of the caregivers, who were primarily female, had a cardiovascular illness themselves. The ability to provide care may be impaired if these caregivers have medical limitations or concerns to consider in addition to a spouse's daily needs. ${ }^{29.30}$

\section{Medication-related problems}

Adverse drug effects are a common problem in cardiac patients. ${ }^{10,24.31}$ For heart failure patients drug reactions from thiazide diuretics are often the cause of admissions. They can cause hypokalemia with symptoms such as nausea, vomiting, and fatigue. Another drug-related problem is failure on the part of the practitioner to prescribe the most effective dose of medications. ${ }^{32} 35$ In $17 \%$ of a group of 10 I heart failure patients, inadequately prescribed drug therapy was identified as a precipitating factor for readmission. ${ }^{36}$ Others identified iatrogenic factors responsible for relapse of heart failure in $10 \%$ of the patients. ${ }^{38}$ Michalson et al., described $12 \%$ of the readmissions were the result of inadequate medical treatment. ${ }^{13}$

\section{Compliance}

Similar to the general population noncompliance is a major cause of morbidity and unnecessary hospital admissions in the heart failure population. ${ }^{10,13 \cdot 32.36-40}$ In one study, lack of adherence to the prescribed medical regimen was the most common factor precipitating readmission. ${ }^{36}$ This included noncompliance with diet and/or medication. A large proportion of patients who began digoxin substituted this for other medications or consumed substantially less medication (e.g. Angiotensin converting enzyme inhibitors or diuretics) than expected in the first year of therapy. ${ }^{40}$ In that study only $10 \%$ of patients was identified taking the right heart failure medication. Other noncompliance issues regarding diet and fluid intake are also described. Descriptive rescarch found that less than half of the Heart Failure patients could correctly identify their medications, almost three-quarters of paticnts did not weigh themselves daily, and of patients who were instructed to weigh themselves every day and were given a chart to record their weights, only $40 \%$ actually did so. ${ }^{4 t}+3$ 


\section{Implications for nursing practice}

The review of the literature on readmission of patients with heart failure suggests that patients are often rehospitalized due to a wide range of factors. Several factors such as demographic and medical factors cannot be changed. Others however, if modified, such as premature discharge, a failing support system, medication-related problems and noncompliance can reduce hospital readmission. These factors can be influenced by (nursing) interventions that are summarized in table 2.I (see page 23.)

\section{Discharge planning}

To facilitale the transition from the hospital to the home environment proper discharge planning is esscntial. For the elderly it may be necessary to make specific arangements for additional assistance and support such as assistance in getting prescribed medication, or transportation to doctor ${ }^{\circ}$ appointments. In some cases, patients and families need emotional support to decreasi their anxiety. 29.30

The effects of comprehensive discharge planning were studied for the hospitalized elderly. ${ }^{15}$ A lower readmission rate and fewer total days of rehospitalization was found in a medical population which received comprehensive discharge planning and followup by clinical nurse specialists. Similarly, in a study that specifically targeted the heart failure population, comprehensive treatment strategy included early consultation with social services to facilitate discharge planning. ${ }^{30}$

Planning for social and environmental support has to be a part of hospital discharge planning. Some studies of elderly patients recommend that a qualified individual (e.g. Clinical Nurse Specialist (CNS) or Nurse Practitioner (NP)) designs and coordinates the discharge plan. ${ }^{15,44,46,47}$ To adequately plan the discharge of an older heart failure patient the CNS or NP must be knowledgeable about elderly nursing care as well as nursing care for elderly heart failure patients. An important function of this CNS or NP is providing education and anticipatory guidance for these patients. In addition the need for centers specialized in the management of patients with heart failure is stressed in the literature. ${ }^{48}$

\section{Education and counseling}

The vital importance of education and counseling of patients with heart failure and their families by nurses or other health care professionals has been well established. ${ }^{10.19 \cdot 32.45-60}$ Nurses in their day to day contact with patients and families have the best opportunity to assess potential problems, discuss the medical regimen, and teach the patients and family members warning signs and symptoms of recurrent heart failure and the appropriate actions to take to prevent readmission. In the assessment of the educational needs of heart failure patients, medication information was rated as the most important category of knowledge to have, followed by anatomy and physiology and risk factors. Information related to activities was rated as least important to learn ${ }^{58}$ Other literature, however, suggests that information related to activity is important for heart failure patients. ${ }^{32.60}$ Other specific topics for patient, family and caregiver counseling are suggested in the clinical practice guidelines for heart failure patients of the US Department of Health and Human Services..$^{32}$ Recommendations bases on expert opinion include 
general counseling on heart failure, prognosis, activity recommendations, dietary recommendations, medications and the importance of compliance with the treatment/care plan. Research studies that assess the effectiveness of education in patients with heart failure are growing. One study found a reduction in the number of readmissions and days of rehospitalization in heart failure patients as a result of a home teaching program. ${ }^{51.56}$ There was no effect on compliance. Several studies have been conducted that combined in-hospital individualized heart failure patient education with follow-up teaching when the patient was at home. ${ }^{39.51-55.58}$ These studies reported a reduction in the number and length of readmissions. ${ }^{39.51-55}$ It is noticeable that in one study, an increased rather than decreased rehospitalization rate was found after intensive education in the hospital and increased follow up. Patients in the intervention group were, nevertheless more satisfied with their care. ${ }^{6 r}$ In another recent study, education was only given at home by a nurse or a pharmacist and no "extra" inhospital teaching was included in the intervention. ${ }^{56}$ This intervention showed to be effective in reducing unplanned readmissions plus out-of-hospital deaths within 6 months of discharge from the hospital.

\section{Follow-up}

During a follow-up visit in the patient's home by a social worker, clinical nurse specialist, community nurse or physician, the home environment can be surveyed and additional problem areas identified. Education of the patient and family can be continued and reinforced. Once the patient is home, some activities, e.g. daily weighing or taking medication, may require more effort than in the hospital. A follow-up visit with additional support and counseling can help the patient and family cope with a new regimen. ${ }^{15.39}$ Different types of follow-up are described in the literature. ${ }^{15.39 .57-59}$ In some intervention studies, mailed reminders of appointments and signs and symptoms were used to inform the patient and encourage them to keep these appointments. ${ }^{53-55}$ Follow-up by telephone calls is also described as being helpful to monitor the patient's progress and answer questions. In a previous study, reported from Israel a weekly home-visit by a physician decreased days of rehospitalization. ${ }^{62}$ The role of the nurse in that program was limited to drawing blood, injecting drugs and providing other paramedical support.

An early study used group sessions for heart failure patients conducted by a health educator and a multidisciplinary team, resulting in higher levels op patients knowledge and decreased readmission rates. ${ }^{49}$ Another new development is home monitoring by a telemedical system in which daily weight and symptoms are assessed and interpreted by a nurse. ${ }^{63}$ First results of this intervention seem positive regarding readmission, however, no experimental studies are reported.

Data from most studies suggest that heart failure patients may benefit from followup care, but it has to be noted that only 4 published studies ${ }^{39.56-58}$ using follow-up or a home visit used a randomized design to evaluate effects. In addition, most studies use interventions that consist of more component than only follow-up. The exact mechanism of each intervention and which component of the intervention is successful remains unknown. ${ }^{6.4}$ 


\section{Limitations of studies}

Although we did not review every study on methodological criteria, some general remarks can be made regarding design, intervention, population and outcomes. As mentioned before, only a few studies testing a specialized and intensive follow-up of patients with heart failure used a randomized controlled trail. Other studies compared hospitalization rates and quality of life in the year before the intervention to the year after the intervention. These before-after designs have to be interpreted with caution since there can be considerable bias due to for example new treatment strategies (e.g. medication) education of health care providers or the introduction of clinical guidelines. It also had to be considered that the interventions that are described differ in content, length and intensity. It therefore is difficult to make a general statement on the effects of "specialized interventions". In addition t here is a huge difference in the populations studied in the different studies. Rich et al. (1995) ${ }^{39}$ and Steward et al.(1998) ${ }^{56}$ used a "high risk sample" for hospital readmission. This means that a specific subgroup of the very heterogeneous heart failure population can benefit from that specific intervention. Others use patients from a transplant clinic. ${ }^{53}$ Caution should be used when applying the results to practice. Not every intervention could be effective in every practice situation.

Endpoints in the effect studies often are not comparable. There is a lot of difference between studies reported in this chapter. Some authors use rehospitalization as a primary endpoint, others combine this with mortality. Accumulating endpoints to a "major event" variable (e.g. rehospitalization and mortality) may increase power of studies, but it sometimes makes comparison with other studies difficult.

In addition it should be noted that assessment of the effects on quality of life is often limited. In these elderly and often very vulnerable patients, one of the major goals in the treatment of patients with chronic heart failure is to improve quality of life. ${ }^{65,66}$ Testing results of new interventions should consider this important outcome in their evaluation.

\subsection{Conclusion}

Rehospitalization occurs frequently in the heart failure population. Many of these readmissions are related to premature discharge, failing support systems, medicationrelated problems, lack of knowledge regarding symptom management and noncompliance. Nurses can play a vital role in preventing rehospitalization of patients with heart failure. While there are a few studies showing that adequate discharge planning, education and counseling and follow-up can be effective in preventing readmissions, more studies are needed to establish the effect of various interventions on readmissions in an older heart failure population. Research about specific components of interventions is needed (e.g. education and support or follow-up), as well about the underlying mechanism (e.g. enhancing compliance, adequate monitoring). Although recently several studies have been reported describing the effects of various interventions on rehospitalization, limited randomized controlled studies are available and few results are reported on quality of life. 
Table 2.r: Research studies on nursing interventions in older patients and older patients with heart failure.

\begin{tabular}{lllll}
\hline author & design & $\mathrm{n}$ & intervention & effect \\
\hline
\end{tabular}

\section{Older patients (general)}

\begin{tabular}{|c|c|c|c|c|}
\hline $\begin{array}{l}\text { Hendriksen } \\
1984\end{array}$ & exp. & 572 & assessment and advice & $\begin{array}{l}\text { number of } \\
\text { admissions } \\
\downarrow \text { number of } \\
\text { emergency calls }\end{array}$ \\
\hline
\end{tabular}

\begin{tabular}{|c|c|c|c|c|}
\hline $\begin{array}{l}\text { Kennedy } \\
1987\end{array}$ & exp. & 80 & $\begin{array}{l}\text { comprehensive discharge } \\
\text { planning }\end{array}$ & $\begin{array}{l}\downarrow \text { hospital stay } \\
\uparrow \text { time between } \\
\text { discharge and } \\
\text { readmission }\end{array}$ \\
\hline $\begin{array}{l}\text { Townsend }{ }^{47} \\
1988\end{array}$ & exp. & 903 & $\begin{array}{l}\text { community based } \\
\text { discharge scheme: } \\
\text { - support from care } \\
\text { attendants }\end{array}$ & $\begin{array}{l}\downarrow \text { number of } \\
\text { readmissions } \\
\downarrow \text { days of } \\
\text { rehospitalization }\end{array}$ \\
\hline
\end{tabular}

Weinberger ${ }^{52}$ exp. $\quad 1001$ multitaceted intervention $\downarrow$ number of I 988

- teaching

- follow-up readmissions

$\downarrow$ costs

Naylor's

exp.

276 comprehensive discharge

$\downarrow$ number of planning:

- discharge plan

- telephone availability readmissions

$\downarrow$ days of

- follow-up rehospitalization

$\downarrow$ readmission charges

$\downarrow$ charges health care services

Heart Failure patients

\begin{tabular}{|c|c|c|c|c|}
\hline $\begin{array}{l}\text { Rosenberg } \\
1971\end{array}$ & exp. & 100 & $\begin{array}{l}\text { multidisciplinary team } \\
\text { approach } \\
\text { - planned and } \\
\text { coordinated education } \\
\text { - close follow-up nursing } \\
\text { care } \\
\text { - appropriate social } \\
\text { services } \\
\text { - instruction in diet }\end{array}$ & $\begin{aligned} \downarrow & \text { number of } \\
& \text { readmissions } \\
\downarrow & \text { days of } \\
& \text { rehospitalization } \\
\uparrow & \text { knowledge }\end{aligned}$ \\
\hline
\end{tabular}


Table 2.1: Research studies on nursing interventions (continued)

\begin{tabular}{|c|c|c|c|c|}
\hline author & design & $\mathbf{n}$ & intervention & effect \\
\hline $\begin{array}{l}\text { Cintron } 5^{\circ} \\
1983\end{array}$ & $\begin{array}{l}\text { one } \\
\text { group } \\
\text { protest- } \\
\text { posttest }\end{array}$ & 15 & $\begin{array}{l}\text { nurse practitioner in } \mathrm{HF} \\
\text { clinic: } \\
\text { - clinic visits } \\
\text { - patient education } \\
\text { - availability of nurse }\end{array}$ & $\begin{array}{l}\downarrow \text { number of } \\
\text { readmissions } \\
\downarrow \text { medical costs } \\
\uparrow \text { patient satisfaction }\end{array}$ \\
\hline $\begin{array}{l}\text { Ashby }{ }^{51} \\
1988\end{array}$ & exp. & 71 & home teaching & $\begin{array}{l}\downarrow \text { number of } \\
\text { readmissions } \\
\downarrow \text { days of } \\
\text { rehospitalization } \\
\circ \text { compliance }\end{array}$ \\
\hline $\begin{array}{l}\text { Rich }^{33.39} \\
\text { I } 993\end{array}$ & exp. & 98 & $\begin{array}{l}\text { multidisciplinary strategy: } \\
\text { - teaching } \\
\text { - medication review } \\
\text { - discharge planning } \\
\text { - follow-up }\end{array}$ & $\begin{array}{l}\downarrow \text { number of } \\
\text { readmissions } \\
\downarrow \text { days of } \\
\text { rehospitalization } \\
\uparrow \text { compliance } \\
\uparrow \text { quality of life }\end{array}$ \\
\hline $\begin{array}{l}\text { Kostis }^{67} \\
\text { I } 994\end{array}$ & exp. & 20 & $\begin{array}{l}\text { multimodal intervention: } \\
\text { - cxcise training } \\
\text { - cognitive therapy } \\
\text { - dietary instruction }\end{array}$ & $\begin{array}{l}\downarrow \text { body weight } \\
\uparrow \text { functional capacity } \\
\uparrow \text { mood status }\end{array}$ \\
\hline $\begin{array}{l}\text { Kornowski }^{62} \\
\text { I } 995\end{array}$ & $\begin{array}{l}\text { one } \\
\text { group } \\
\text { before- } \\
\text { after }\end{array}$ & 42 & $\begin{array}{l}\text { Intensive home care } \\
\text { surveillance } \\
\text { - weekly home visit by } \\
\text { physician } \\
\text { - availability of nurse for } \\
\text { paramedical support } \\
\text { - availability of } \\
\text { physiotherapy and } \\
\text { home oxygen }\end{array}$ & $\begin{array}{l}\downarrow \text { hospital readmission } \\
\uparrow \text { functional status }\end{array}$ \\
\hline $\begin{array}{l}\text { Fonarov } 53 \\
1997\end{array}$ & $\begin{array}{l}\text { one } \\
\text { group } \\
\text { before- } \\
\text { after }\end{array}$ & 214 & $\begin{array}{l}\text { Comprehensive HF } \\
\text { management program } \\
\text { - medication tailoring } \\
\text { - follow-up (telephone } \\
\text { and clinic) } \\
\text { - education }\end{array}$ & $\begin{array}{l}\downarrow \text { hospital readmission } \\
\downarrow \text { functional status } \\
\downarrow \text { costs }\end{array}$ \\
\hline
\end{tabular}


Table 2.I: Research studies on nursing interventions (continued)

\begin{tabular}{|c|c|c|c|c|}
\hline author & design & $\mathrm{n}$ & intervention & effect \\
\hline $\begin{array}{l}\text { Hanumanthu }{ }^{45} \\
\text { I997 }\end{array}$ & $\begin{array}{l}\text { one } \\
\text { group } \\
\text { before- } \\
\text { after }\end{array}$ & 187 & $\begin{array}{l}\text { Specialist cardiologist } \\
\text { and nurses at clinic visits } \\
\cdot\end{array}$ & $\begin{array}{l}\downarrow \text { hospital readmission } \\
\uparrow \text { exercise tolerance }\end{array}$ \\
\hline $\begin{array}{l}\text { Smith } \\
1997\end{array}$ & $\begin{array}{l}\text { one } \\
\text { group } \\
\text { before- } \\
\text { after }\end{array}$ & 21 & $\begin{array}{l}\text { Cardiomyopathy clinic } \\
\text { - optimizing medical } \\
\text { treatment } \\
\text { - education } \\
\text { - follow-up by nurse } \\
\text { practitioner }\end{array}$ & $\begin{array}{l}\uparrow \text { NYHA } \\
\uparrow \text { ejection fraction } \\
\uparrow \text { clinic visits } \\
\downarrow \text { rehospitalization } \\
\uparrow \text { quality of life }\end{array}$ \\
\hline $\begin{array}{l}\text { West }^{54} \\
1997\end{array}$ & $\begin{array}{l}\text { one } \\
\text { group } \\
\text { before- } \\
\text { after }\end{array}$ & 51 & $\begin{array}{l}\text { Multifit: Physician } \\
\text { supervised, nurse } \\
\text { mediated, home based } \\
\text { system implementing } \\
\text { pharmacological and } \\
\text { dietary therapy }\end{array}$ & $\begin{array}{l}\downarrow \text { hospital readmission } \\
\downarrow \text { ER visits } \\
\downarrow \text { medical and } \\
\text { cardiology visits } \\
\uparrow \text { medication dose } \\
\downarrow \text { dietary sodium } \\
\text { intake } \\
\uparrow \text { functional status }\end{array}$ \\
\hline $\begin{array}{l}\text { Shah } \\
1998\end{array}$ & $\begin{array}{l}\text { one } \\
\text { group } \\
\text { belore- } \\
\text { after }\end{array}$ & 27 & $\begin{array}{l}\text { Interactive home } \\
\text { monitoring program } \\
\text { - patient education } \\
\text { material } \\
\text { - reminders for } \\
\text { medication } \\
\text { - self-monitoring weight } \\
\text { and vital signs } \\
\text { - facilitated } \\
\text { communication with a } \\
\text { nurse monitor }\end{array}$ & $\begin{array}{l}\downarrow \text { hospital } \\
\text { readmissions }\end{array}$ \\
\hline $\begin{array}{l}\text { Weinberger }{ }^{6 !} \\
\text { I } 996\end{array}$ & exp. & 504 & $\begin{array}{l}\text { increased access to } \\
\text { primary care } \\
\text { - close follow-up by } \\
\text { nurse + physician } \\
\text { - education in hospital + } \\
\text { telephone and at clinic } \\
\text { - availability of primary } \\
\text { care }\end{array}$ & $\begin{array}{l}\uparrow \text { readmission rate } \\
\uparrow \text { readmission days } \\
\uparrow \text { satisfaction }\end{array}$ \\
\hline
\end{tabular}


Table 2.I: Research studies on nursing interventions (continued)

\begin{tabular}{|c|c|c|c|c|}
\hline author & design & $\mathrm{n}$ & intervention & effect \\
\hline $\begin{array}{l}\text { Stewart }{ }^{56} \\
1998\end{array}$ & exp. & 97 & $\begin{array}{l}\text { home visit by nurse or } \\
\text { pharmacist } \\
\text { - optimize medication } \\
\text { management } \\
\text { - identify deterioration } \\
\text { - intensify follow-up }\end{array}$ & $\begin{array}{l}\downarrow \text { unplanned } \\
\text { readmissions }+ \\
\text { out-of hospital } \\
\text { deaths } \\
\downarrow \text { days of readmissions }\end{array}$ \\
\hline $\begin{array}{l}\text { Cline }^{57} \\
1998\end{array}$ & exp. & 190 & $\begin{array}{l}\text { management program } \\
\text { - medication organizer } \\
\text { - education program } \\
\text { - telephone availability } \\
\text { HF clinic nurse } \\
\text { - prescheduled follow-up } \\
\text { after } 8 \text { months }\end{array}$ & $\begin{array}{l}\text { - quality of life } \\
\text { survival } \\
\downarrow \text { time to readmission } \\
\downarrow \text { cost }\end{array}$ \\
\hline $\begin{array}{l}\text { Ekman }^{58} \\
\text { I } 998\end{array}$ & exp. & 158 & $\begin{array}{l}\text { structured care program } \\
\text { - availability of HF nurse } \\
\text { - several clinic visits } \\
\text { - symptom monitoring } \\
\text { - nurse initiated contacts }\end{array}$ & $\begin{array}{l}\text { - readmission } \\
\text { o readmission days }\end{array}$ \\
\hline
\end{tabular}




\subsection{References}

I. Ho KK, Pinsky JL, Kannel WB, Levy D. The epidemiology of heart failure: The Framingham study. J Am Coll Cardiol 1993; 22: 6A-I3A.

2. Gillum RF. Epidemiology of heart failure in the United States (editorial). Am Heart Joumal I993; 126: I042-I047.

3. Cowie MR, Mosterd A, Wood DA, Deckers JW, Poole-Wilson PA, Sutton GC, Grobbee DE. The epidemiology of heart failure. Eur Heart J I 997; I8: 209-225.

4. Mosterd A. Epidemiology of Heart Failure [Doctoral thesis]. Rotterdam: Erasmus University of Rotterdam, I997.

5. Hoes AW, Mosterd A, Grobbee DE. An epidemic of heart failure? Eur Heart J I 998; I9(suppl. L): 2-ro.

6. McMurray JJV, Petrie MC, Murdoch DR, Davie AP. Clinical epidemiology of heart failure: public and private health burden. Eur Heart J I 998; I 9(suppl. P): 9-16.

7. Fleg JL. CHF: reflections on current management of the older patient. Geriatrics I 986; 4 I : $97 \mathrm{I}-98 \mathrm{x}$.

8. Bonneux L, Barendrecht JJ, Meeter K, Bonsel GJ, van der Maas PJ. Estimating clinical morbidity due to ischeamic heart disease and congestive heart failure: the future rise of heart failure. Am J Publ Health I994; 84: 20-28.

9. Gooding J, Jette AM. Hospital readmissions among the elderly. J Am Geriatr Soc $1985 ; 33: 595-60$ I.

Io. Vinson JM, Rich MW, Sperry JC. Early readmission of elderly patients with congestive heart failure. J Am Geriatr Soc 1990; 38: I 290-r 295.

I I. Nikolaus T, Specht-Leible N, Krusse W, Oster P, Schlierf G. The early rehospitalization of elderly patients; causes and prevention. Dtsch Med Wschr I992; I 17: 403-407.

I2. Graham H, Livesley B. Can readmissions to a geriatric medical unit be prevented? The Lancet $1983 ; 2 x$ : 404-406.

13. Michalsen A, Konig G, Thimme W. Preventable causative factors leading to hospital admission with decompensated heart failure. Heart 1998; 80: 437-44I.

14. Andrews $\mathrm{K}$. Relevance of readmission of elderly patients discharged from a geriatric unit. J Am Geriatr Soc 1986; 34: 15-2 I.

I5. Naylor M, Brooten D, Jones R, Lavizzo-Mourey R, Mezey M, Pauly M. Comprehensive discharge planning for the hospitalized elderly: A randomized clinical trial. Ann Intern Med I994; I 20: 999-1006.

I6. Fethke CL, Smith IM, Johnson N. Risk factors affecting readmission of the elderly into the health care system. Med Care 1986; 24: 429-437.

17. Anderson GF, Steinberg EP. Hospital readmissions in the Medicare population. N Engl J Med 1984; 31 I: 1349-I 353.

I8. Victor CR, Vetter NJ. The early readmission of the elderly to the hospital. Age Aging 1985; 14: 37-42.

I9. Williams EL, Fitton F. Factors affecting early unplanned readmission of elderly patients to hospital. BMJ I988; 297: 784-787.

20. Burns R, Nichols LO. Factors predicting readmission in older general medicine patients. J Gen Int Med I99 I ; 6: 389-393. 
21. Johnson $H$, Fethke $C$. Postdischarge outcomes and care planning for the hospitalized elderly. In McCleland E, Kelly K, Buckwater KC. (eds.) Continuity of Care: Advancing the concept of discharge planning. Orlando: Grune and Stratton, I985.

22. Kruse W. Early readmission of elderly patients with congestive heart failure. J Am Ger Soc I991; 39: 1045-1046.

23. Bergman U, Wiholm BE. Drug-related problems causing admission to a medical clinic. Eur J Clin Pharm I981; 20: 193-200.

24. Davidson F, Haghfelt T, Gram LF. Adverse drug reactions and drug noncompliance as primary causes of admission to a cardiology department. Eur J Clin Pharm 1988; 34: 83-66.

25. Dargie HJ, McMurray JJV, Poole-Wilson PA. Managing Heart Failure in primary care. London: Blackwell Healthcare Communications, 1996.

26. Berkman B, Dumas S, Gastfriend J, Poplawski J, Southworth M. Predicting hospital readmission of elderly cardiac patients. Health Social Work 1987: 22 I-228.

27. Kosecoff J, Kahn KL, Rogers WH et al. Prospective payment system and the impairment at discharge: 'the quicker and sicker' story revisited. JAMA I990: $1980-1983$.

28. Cleland JGF. Health economic consequences of the pharmacological treatment of heart failure. Eur Heart J 1998; I 9(suppl. P): 32-39.

29. Karmilovich SE. Burden and stress associated with spousal caregiving for individuals with heart failure. Prog Cardiovasc Nurs 1994: 9: 33-38.

30. Doering LV, Dracup K. Tullman D, Walden J, Westlake C, Livingston N, Hamilton MA. What predicts the emotional health of spouses of advanced heart failure patients? Circulation 1998 (suppl. I): 64 .

31. Feenstra J. Grootheest AC, Stricker BHCh. The farmaco-therapeutic treatment of heart failure [in Dutch].Hartbulletin 1998; 29: 199-203.

32. Konstam M, Dracup K, Baker D et al. Heart failure: evaluation and care of patients with left ventricular systolic dysfunction. Clinical Practice Guideline No I 1. AHCPR Publication No. 94-06r2. Rockville, MD: Agency for Health care policy and research, public health service, US Department of Health and Human Services, June 1994.

33. Hillis GS, Trent RJ, Winton $P$, et al. Angiotensin-converting enzyme inhibitors in the management of cardiac failure: are we ignoring the evidence? QJM 1996; 89: $145-50$.

34. McMurray JJV. Failure to practice evidence based medicine: why do physicians not treat patients with heart failure with Angiotensin-converting enzyme inhibitors? Eur Heart Journal I998; 19 (suppl L): I 5-22.

35. Forman DE, Chander RB, Lapane KL, Shah P. Stoukides J. Evaluating the use of Angiotensin-coverting enzyme inhibitors of older nursing home residents with chronic heart failure. JAGS 1998; 46: 1550-4.

36. Ghali JK. Kadakia S, Cooper R, Ferlinz J. Precipitating factors leading to decompensation of heart failure. Arch Intern Med 1988: 148: 2013-2017.

37. Rich MW, Vinson JM, Sperry JC. Shah AS. Spinner LR, Chung MK, DavilaRoman V. Prevention of readmission in elderly patients with congestive heart failure. J Gen Intern Med I993: 8: 585-590. 
38. Opasich C, Febo O, Riccardi PG et al. Concommitant factors of decompensation in chronic heart failure. Am J Cardiol 1996; 78: 354-357.

39. Rich MW. Beckham V. Wittenberg C, Leven CL, Freedland KE, Carney RM. A multidisciplinary intervention to prevent the readmission of elderly patients with congestive heart failure. N Engl J Med 1995; 333: I I90-I 195.

40. Struthers AD. Emerging issues on the role of Angiotensin-converting enzyme inhibition in the treatment of cardiac failure. Clin Card 1996; 19(Suppl. I): 2-4.

4I. Monane M, Bohn RL. Gurwitz JH, Glynn RJ, Avorn J. Noncompliance with congestive heart failure therapy in the elderly. Arch Int Med I994; I 54: 433437.

42. Bushnell FK. Self-care teaching for congestive heart failure patients. J Geront Nurs 1992; 18: 27-32.

43. Sulzbach-Hoke LM, Kagan SH, Craig K. Weighing behavior and symptom distress of clinic patients with CHF. Medsurg Nurs 1997; 6: 288-293.

44. Hendriksen C, Lund E. Stromgard E. Consequences of assessment and intervention among elderly people: a three-year randomized controlled trial. BMJ 1984 ; 289: I 522-I 424 .

45. Hanumanthu S, Butler J, Chomsky D, Davis S. Wilson JR. Effect of a heart failure program on hospitalization frequency and exercise tolerance. Circulation 1997; $96: 2842-2848$.

46. Kennedy L, Neidlinger S, Scroggins K. Effective comprehensive discharge planning in hospitalized elderly. The Gerontologist $1987 ; 27: 577-580$.

47. Townsend J, Piper M, Franck AO. Reduction in hospital readmission stay of elderly patients by a community based hospital discharge scheme: a randomized controlled trial. BMJ I 988; 297: 544-547.

48. Smith LE, Fabbri SA, Pai R, Ferry D, Heywood JT. Symptomatic improvement and reduced hospitalization for patients attending a cardiomyopathy clinic. Clin Cardiol 1997; 20: 949-954.

49. Rosenberg SG. Patient education leads to better care for heart patients. HSMHA Health reports $197 \mathrm{I} ; 86: 793-802$.

50. Cintron G, Bigas C. Linares E, Aranda JM, Herdandez E. Nurse practitioner role in a chronic heart failure clinic: in hospital time, costs, and patient satisfaction. Heart Lung 1 983; 1 2: 237-2 to.

5I. Ashby BSH. Home teaching: Effect on compliance, hospital readmissions and days of rehospitalization for patients with chronic congestive heart failure. Unpublished doctoral dissertation. Richmond: Virginia Commonwealth University, 1988.

52. Weinberger M. Smith DM, Katz. BP, Moore PS. The cost-effectiveness of intensive postdischarge care. Med Carc 1988; I I: 1092-I I OI.

53. Fonarov GC. Stevensun LW. Walden JA, Livingston NA, Steimle AE, Hamilton MA, Moriguchi J, Tillisch JH, Woo MA. Impact of a comprehensive heart failure management program on hospital readmission and functional status of patients with advanced heart failure. J Am Coll Cardiol 1997; 30: 725-732.

54. West JA, Miller NH, Parker KM. Senneca D, Ghandour G, Clark M, Greenwald G, Heller GS, Fowler MB, DeBusk RF. A comprehensive management system 
for heart failure improves clinical outcomes and reduces medical resource utilization. Am J Cardiol 1997; 79: 58-63.

55. Shah NB, Der E, Ruggerio C, Heidenreich PA, Massie BM. Prevention of hospitalization for heart failure with an interactive home monitoring program. Am Heart J 1998; 135: 373-378.

56. Stewart S, Pearson S, Horowitz JD. Effects of a home-based intervention among patients with congestive heart failure discharged from acute hospital care. Arch Intern Med 1998; 158: 1067-1072.

57. Cline CMJ, Israelsson BYA, Willenheimer RB, Broms K, Erhardt LR. Cost effective management programme for heart failure reduces hospitalization. Heart 1998; 80: $442-446$.

58. Ekman I, Andersson B, Ehnfors M, Matejka G, Persson B, Fagerberg B. Feasibility of a nurse-monitored, outpatient-care programme for elderly patients with moderate-to-severe, chronic heart failure. Eur HeartJ 1998; 19: 1254-1260.

59. Hagenhoff BD, Feutz C, Conn VS, Sagehorn KK, Moranville-Hunziker M. Patient education needs as reported by congestive heart failure patients and their nurses. J Adv Nurs 1994; 19: 685-69o

60. Task Force of the Working Group on Heart Failure of the European Society of Cardiology. The treatment of heart failure. Eur Heart J 1997; 1 8: 736-753.

6I. Weinberger M, Oddone EZ, Henderson WG. Does increased access to primary cüre reduce hospital readmissions:? N Engl J Med 1996; 334: 144I-1447.

62. Komowski R. Zeeli D, Averbuch M, Finkelstein A, Schwartz D, Moshkovitz M, Weinreb B, Hershkovitz R, Eyal D. Miller M, Levo Y, Pines A. Intensive homecare surveillance prevents hospitalization and improves morbidity rates among elderly patients with severe congestive heart failure. Am Heart J I995: I 29: $762-766$.

63. Mancini D, Cordisco MA, Beniaminovits A, Prince M. Use of telemedical monitoring to decrease rate of hospitalization in patients with severe heart failure. Circulation I 998 (suppl I): 483 .

64. McMurray JJV, Stewart S. Nurse led, multidisciplinary intervention in chronic heart failure. Editorial. Heart 1998; 80:430-43r.

65. Cohn JN. Current concepts in the treatment of congestive heart failure. Cardiology 1997; (suppl 2): 2-6.

66. Taylor SH. Congestive heart failure: towards a comprehensive treatment. Eur Heart J 1996; I 7(suppl B): 43-56.

67. Kostis JB, Rosen RC, Cosgrove NM, Shindler DM, Wilson AC. Nonpharmacologic therapy improves functional and emotional status in congestive heart failure. Chest 1994; r: 996-100r. 


\title{
Chapter 3
}

\section{"Maintaining the balance"-Nursing care of patients with chronic heart failure}

\begin{abstract}
Nurses in different settings are involved in caring for patients with heart failure. In the clinic, hospital, nursing home or patient's home, the nurse has a role in detecting, identifying and treating heart failure. In order to provide optimal care, literature on possible and effective interventions should be available to nurses.

This study gives an overview of nursing care for patients with heart failure as described in practice, literature and standard nursing care plans. Based on interviews of 45 nurses, a review of literature published between 1983-1993 and a review of standard nursing care plans used in the Netherlands to care for patients with heart failure, four composite themes emerged; namely basic nursing care, assessment and observation, symptom-relieving interventions and patient education. Caring for patients with heart failure is very complex and is often aimed at keeping a very delicate balance between e.g. rest and activity, fluid intake and elimination and therapeutic cost and benefit. Treatment strategies for optimizing care for these patients are described.
\end{abstract}

Adapted from:

- Jaarsma T, Huijer Abu-Saad H, Halfens R, Dracup K. "Maintaining the balance" Nursing care of patients with chronic heart failure. Int J Nurs Studies 1997; 34: 2 I $3-22$ I.

Translated and adapted from:

- Jaarsma T, Huijer Abu-Saad. Verpleegkundige zorg en hartfalen. Den Haag: Nederlandse Hartstichting. I995.

- Jaarsma T, Huijer Abu-Saad. Verpleegkundige zorg voor patiënten met hartfalen, verschil tussen literatuur en werkelijkheid. Cordiaal I995; I6: I $15-1$ I 8. 


\subsection{Introduction}

Heart tailure is a syndrome that is increasing in prevalence in industrialized countries. In the United Stales it is suggested that 2 to 4 million people, that is more than $2 \%$ of the adult population, have heart failure. ${ }^{1.2}$ As a result of increasing longevity the number of hospitalizations due to heart failure is increasing. In Europe similar trends have been described. ${ }^{3-7}$ Both prevalence and incidence rates of heart failure are increasing, a reality which points towards heart failure being a major community health problem. ${ }^{7.8}$

Heart failure is a complex clinical syndrome rather than an objective definable disease, and it is often characterized as the complex of symptoms that are related to the inadequate pertusion of tissue during exertion and often to retention of fluid. ${ }^{9}$ It is a chronic condition in which severe functional abilities and therapeutic options are limited. The impact of heart failure on a patient's life and family relationships often leads to serious problems.

In optimizing patients' functioning and quality of life, nurses can play an important role. $^{r .11}$ For this reason it is important that nursing care for these patients includes interventions to meet physiological and psychosocial needs. Patients with heart failure need high acuity care in the acute phase of pulmonary edema, and they also need educition and support concerning their drug regimen, dietary restrictions, prognosis, symptoms of worsening heart failure and what to do if symptoms reoccur. ${ }^{10.12 .13}$ Due to the chronicity of the discase and the major impact of the disease on daily functioning, scveral aspects of nursing care for these patients differ from care for patients with other cardiac problems. In order to provide optimal care, nurses should rely on the scientilic literature when choosing their interventions. Interventions that are on the bases of experience and routine should consequently be questioned and/or subjected to further testing before they are implemented in clinical practice. This situation does not, however, exist. Nursing care, in general, is not guided by the results of research and scientific knowledge. On the one hand, some nursing interventions are not described in the literature and on the other, some interventions described in literature are not used in practice. A comprehensive overview of nursing care for patients with heart failure as a result is not easily accessible. Therefore the purpose of this study was to examine and give an overview of nursing care for patients with heart failure as described in practice, literature and standard nursing care plans.

\subsection{Method}

\section{Data collection}

Data were collected using the following sources of information:

1. journal articles and textbooks.

2. standard nursing care plans on heart failure available in the Netherlands, and

3. semi-structured interviews with 4.5 nurses.

First, a search was made of the national and international literature (1983-1993) for nursing interventions in heart failure patients. Search methods included MEDLINEsearch and search in available textbooks and articles for references. In addition to both 
Table 3.I: Categories used in the interviews with the nurses

\begin{tabular}{l}
\hline respiration \\
fluid intake and fluid excretion \\
nutrition \\
bowel elimination \\
activity and exercise \\
sleep-rest \\
coping/learning to live with heart failure \\
social relationships \\
psychological function \\
prevention of complications \\
patient education
\end{tabular}

descriptive and experimental research, all articles describing the nursing care of heart failure patients were included. The scientific literature on nursing care of patients with heart failure is scarce. In addition to journal articles, textbooks were used to get as much information as possible on the nursing care provided to patients with heart failure. A computer search of the MEDLINE database from 1966 to 1993 was performed. The term heart failure was used combined with one or more of the following terms: nursing, rehabilitation, prevention and control. therapy and psychology.

Second, standard nursing care plans were collected from all the cardiac and coronary care units in the Netherlands. Of the $25 \mathrm{I}$ wards approached, 28 used standard nursing care plans for heart failure patients consisting of a description of patient problems and nursing interventions. Two wards used the same standard nursing care plan. so 27 standard nursing care plans were used in the analysis. The content of these 27 care plans was written into I I categories (table 3.1). Finally, interviews with 34 cardiac nurses and I I home health nurses were conducted in an attempt to describe actual nursing practice. Nurses were selected from a list of all the institutions that were approached in the collection of the standard nursing care plans. No special selection method was used. The researcher aimed at a variety of institutions, working with or without a standard nursing care plan, with or without a specialized cardiac nurses. During the interview nurses were asked to describe the nursing care they provide patients with heart failure. To complete the information on care provided, I I sensitizing concepts were used during the interviews (table 3.1). These I I concepts were derived from nursing literature and were used to help nurses describe care. ${ }^{14-16}$

\section{Reliability and validity}

To enhance reliability and validity of the data, data triangulation was used. ${ }^{17}$ Data based on standard nursing care plans and interviews were collected from different settings: university hospitals, general hospitals and home health care agencies from different parts of the country. Interviews were conducted with a variable number of nurses. Sixteen nurses were interviewed individually, nine interviews were held with two nurses at 
the same time, one interview took place with three nurses and two interviews with four nurses. The rationale for conducting different numbers was that in this way information could be gathered from individual nurses as well as from a group. Discussion amongst nurses in the group-interviews led to detailed information. In addition methodological triangulation was used by including several methods of data collection namely: interview, standard nursing care plans, journal articles and textbooks. ${ }^{17}$

Interventions that were collected from interviews were categorized by the researcher. To improve reliability of the data, interviews were tape recorded and transcribed. The transcribed data were given to five of the nurses that were interviewed for their comments on accuracy of transcribing. Three interviews were also categorized by an independent nurse to check if the information was transcribed and categorized correctly, and member checks were used.

\subsection{Results}

Based on data from the three sources (literature, standard nursing care plans and interviews) four composite themes emerged: basic nursing care, assessment and observation, symptom-relieving interventions and patient education. Information in these four themes was organized in three tables and will be further discussed here.

\section{Basic (cardiac) nursing care}

Nurses caring for patients with heart failure are primarily concerned with the assessment and management of cardiac problems, both physiological and psychosocial. From the three sources (literature, standard nursing care plans and interviews) it became clear that the care nurses give to patients with heart failure includes interventions that are not specifically relevant for patients with heart failure but are also relevant for other cardiac patients. In an interview a nurse stated:

You want me to describe specific care for a patient with heart failure? Well, that is very difficult because a lot of care that we give to these patients does not differ from care we give to a patient with, let's say, arrhythmia's. We make an ECG, connect them to a monitor, make an $X$-ray and give them medication.

Other interventions that are important for the cardiac population in general are: monitoring vital signs, cardiac assessment, administering and evaluating effects of prescribed medication, assessing the patient for symptoms of underlying heart disease (e.g. angina), providing emotional support to patient and family, listening attentively, aiding the patient in assessing risk factors and controlling them. All these interventions are relevant in the cardiac population, including heart failure patients.

In addition, care is given that is not even specific to cardiac patients but is provided for patients in hospital in general. Interventions that deal with problems related to hospital admission, anxiety or coping with the disease are relevant for most patients admitted to the hospital. An example from a nursing care plan is: 
provide information and support to the patient and family so they can copt with hospitalization

The importance of general nursing care next to specialized cardiac care is also emphasized by home health nurses. They often provide support in activities of daily living, schedule medications or counsel patients concerning anxiety or fear. The underlying disease does not always determine the care:

if you are talking about dependency, a patient with heart failure does not differ much from a patient with arthritis or COPD.

On the other hand, nurses described several problems of patients that actually are related to heart failure but were not recognized as such:

A lot of patients have constipation, but that is not related to heart failure, is it?

and

A loss of appetite is a symptom that is present in a lot of diseases. but I do not know if that is specific in patients with heart failure.

\section{Assessment and observation relating to heart failure}

During the interviews, nurses were asked to describe nursing interventions. Many nurses included topics for assessment and observation in their responses. Caring for patients with heart failure means paying close attention to these patients. Table $\mathbf{3 . 2}$ shows topics concerning observation and assessment that were collected from literature, standard nursing care plans and interviews.

Nursing observations and assessment are often aimed at "maintaining the balance". It is, for example, important to keep a balance between intake and output. On the one hand patients take diuretics to control excessive fluid retention, and on the other it is important that patients do not dehydrate or lose too many electrolytes. In this context nurses have to observe intake and output, serum electrolytes, skin turgor, mucous membranes, and feelings of thirst of the patient. ${ }^{18} \mathrm{~A}$ lot of both physical as well as psychosocial aspects have to be assessed and observed as part of caring for the patient and family. No structured assessment and observation lists or schemes were used in practice or described in standard nursing care plans or literature for patients with heart failure. But during interviews nurses gave detailed descriptions of what they observed and assessed in a patient with heart failure.

It's not enough to know only if a patient suffers from dyspnea, you want to know several things about dyspnea in the patient: when does it occur, can he still sleep without pillows, how long does it take before he gets better, etceteras. 
Table 3.2: Topics concerning observation and assessment, collected from literature, standard nursing care plans and interviews.

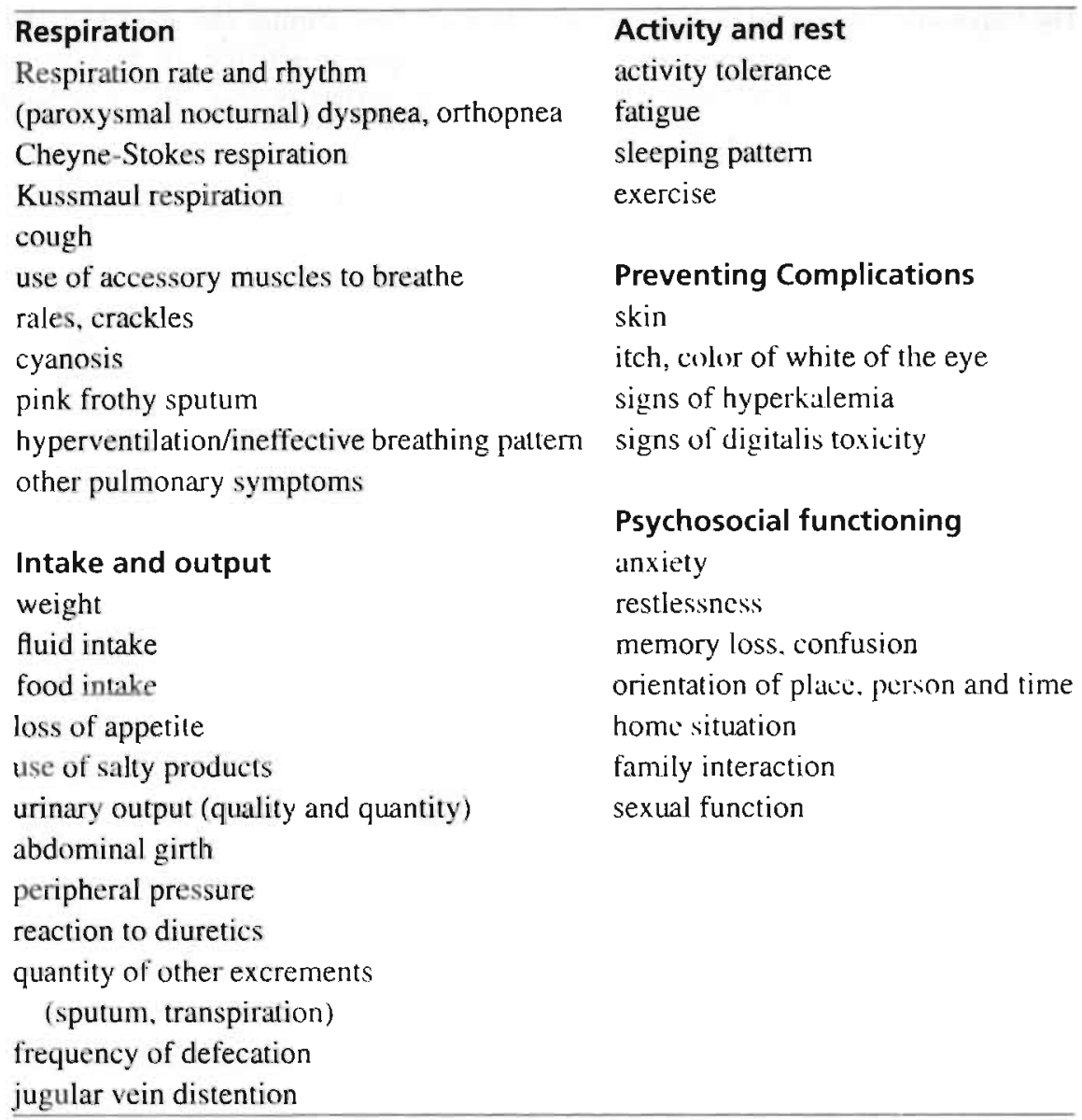

\section{Symptom-relieving interventions}

Most nursing interventions are directed toward relief of symptoms and improving the condition of the patient. Both independent nursing activities as well as collaborative activities were described during this study (table 3.3). Symptom-relieving interventions were described concerning problems that are a direct consequence of heart failure (e.g. fatigue, dyspnea, anorexia) but also concerning problems that result from treatment (e.g. diureses, cough) or psychosocial responses to heart failure (e.g. anxiety, powerlessness).

In all three sources (literature, standard nursing care plans, interviews) attention was given to fluid restriction including its emotional consequences. Especially during the interviews very practical information was gathered about making the fluid restric- 
Table 3.3: Symptom-relieving interventions for patients with heart failure, collected from literature, standard nursing care plans and interviews.

\begin{tabular}{|c|c|}
\hline $\begin{array}{l}\text { Respiration } \\
\text { promote normal respiration } \\
\text { position patient in (semi) Fowler } \\
\text { promote emotional and physical rest } \\
\text { provide cool environment } \\
\text { administer suppl. oxygen as prescribed } \\
\text { possibly assist with ventilation } \\
\text { comfort patient to reduce anxiety } \\
\text { involve therapist for breathing exercises } \\
\text { give thyme syrup in case of cough } \\
\text { Intake and output } \\
\text { restrict orally and iv fluids to <2 liters } \\
\text { provide for a low sodium diet } \\
\text { instruct about avoiding high sodium foods } \\
\text { restore appetite and food intake } \\
\text { apply elastic stockings } \\
\text { time diuretics } \\
\text { prevent constipation by diet or laxatives } \\
\text { prevent losing potassium (diarrhea) } \\
\text { weigh daily. adjust diuretics accordingly }\end{array}$ & $\begin{array}{l}\text { Activity and rest } \\
\text { dose nitrate before exercise if needed } \\
\text { conserve energy, pace activities } \\
\text { plan activities } \\
\text { help recognize activity limitations } \\
\text { teach active and passive exercises } \\
\text { promote rest: } \\
\text { advise daily resting times } \\
\text { help patient to get help at home } \\
\text { promote good night rest } \\
\text { comfort patient at night } \\
\text { time diuretics to promote slecp } \\
\text { Psychosocial functioning } \\
\text { discuss emotional feeling } \\
\text { organize hcip in the connunity } \\
\text { stimulate social contacts } \\
\text { help to make short-term plans } \\
\text { stimulate hobbies } \\
\text { discuss feelings of anxiety, loneliness } \\
\text { use imagery, relaxation techniques } \\
\text { prepare for home emergency } \\
\text { discuss prognosis } \\
\text { refer to support groups as needed }\end{array}$ \\
\hline
\end{tabular}

tion bearable for patients and their farnilies. For example: use espresso cups instead of coffee cups or mugs, advice to brush teeth several times a day to take the feeling of thirst away, and help patients plan their fluid intake during the day.

As was noted in the previous theme, nurses intervene to "keep the balance". Not only the balance between the actual intake and output. but also the balance between the therapeutic profit to the patient of fluid restriction and the burden entailed. In addition to practical advice concerning fluid restriction, the emotional consequences of fluid restriction were mentioned by a nurse who stated:

Sometimes people are obsessed with fluids and the fluid restriction prescribes their whole day. You can teach them how to make it easier by using small cups, suck on an icc-cube or chew on (sugar-free) gum. But it still remains terrible for them.

Nurses need to be aware of the burden of the fluid restriction for some patients as was stated by a home health nurse: 
I think it is not humane to restrict a patient's fluids if a patient is very ill and if you know that she will only live a few months or so.

Another example of "maintaining the balance" is timing of the diuretics. Most patients with heart failure need to take diuretics once or twice a day to prevent their heart failure worsening. It is essential to find a good time to administer these drugs to the patient in a way that the therapeutic effect is maximal and the disadvantages are minimal. As a nurse described:

It is hard to find out the best time to give diuretics. You cannot give them too late in the evening because they have to urinate all night. But if they only get lasix in the early moming, they often get dyspneic at night.

Another balance that is important for a patient with heart failure is the balance between rest and activity. On the one hand it is important to decrease the heart's workload and therefore limit physical activity. Interventions to promote rest are described in all three sources: for example, conserve energy by pacing oneself or have assistance with activities of daily living. ${ }^{19.20}$ On the other hand, patients need to keep their strength and stay active. They have to learn which activities put a lot of stress on the heart and which do not.

During exercise, two types of muscular activity are used. Dynamic exercise involves large changes in muscle length with small changes in muscle tension. Static exercise involves large changes in muscle tension with minimal changes in muscle length. Excrcise that includes both static and dynamic activity such a shoveling snow, digging dirt, or carrying a basket of laundry creates a much greater stress on the heart than pure forms of either exercise. So called static-dynamic exercise produces both greater afterload work and greater preload work.

Symptom-relieving interventions include those helping a patient cope with heart failure or the negative consequences of treatment. However, nurses do not always feel able to intervene effectively if patients and/or families have problems with anxiety, coping or helplessness. One of the ICU nurses stated:

Most patients are very anxious during episodes of dyspnea and they are atraid it will come back. The only thing you can do is talk with them, be there and comfort them.

Both in hospital and at home a lot of patients consider nighttime the worst part of the day. They often cannot sleep because they are anxious or short of breath. In the literature relaxation techniques like meditation, listening to soothing music, imagery or selfhypnosis are described to help the patient deal with sleeping problems or anxiety. ${ }^{18,21,22}$ In interviews very hasic interventions were sometimes mentioned, as exemplified by one CCU nurse:

My experience is that patients with dyspnea are very frightened at night. It often helps to stress that the nurses on the night shift are watching them and if they need them they just have to call. 


\section{Patient education}

Parients with heart failure need education, counseling and support to enable them to adjust to their chronic illness. ${ }^{12,13}$ Patients and family get information during treatment or in a discharge interview. In our study, nurses stressed the importance of timing of education.

In the $\mathrm{CCU}$ it is sometimes difficult to explain to people that they have a cardiac problem, they only feel in need of air and are not receptive to information about their heart disease. It's better to wait with education till patients are at a step-down unit.

Educating heart failure patients and families is a vital nursing activity. Patients and their families need a lot of new information, but nurses also described having an important role in tracing misunderstandings of patients and families and giving proper information to correct these misunderstandings:

A readmitted patient told me he could not understand why the nurses in the hospital were so strict in restricting fluids, while the family doctor gave him diuretics and therefore he had to drink a lot of water, otherwise the diuretics would not work

No structured education program was used in nursing practice or described in literature and standard nursing care plans. However, several topics for patient education were described in all three sources. Literature on heart failure often describes topics commonly used in patient education; for example, nature of heart failure, pathophysiology, prognosis, drug and diet regimen, monitoring symptoms of worsening heart failure, medications, follow-up and activity. ${ }^{12,13,23-27}$ All these topics were clustered in table 3.4 around 6 themes based on the clinical practice guidelines of the U.S. Department of Health and Human Services. ${ }^{10,12}$

\section{general counseling}

Patients and their families need information about the disease and the consequences for their daily life. Symptoms of heart failure have to be explained and patients should be told that as soon as symptoms of heart failure (e.g. shortness of breath or fatigue) worsen, they should warn their family physician (GP) or another health care provider. As one of the nurses stated:

I always tell them that they have to contact their family doctor in time when they do not feel well, and that they should not wait too long. Lots of patients wait too long and arrive in the hospital with their slippers because their shoes did not fit any more the last few weeks! This means they waited much too long

Patients and their families not only need information about the disease, but also on the treatment in the hospital, the long-term treatment plan and recommended life-style changes like keeping a diet and refraining from smoking. Some patients and families 
Table 3.4: Topics for education and counseling of heart failure patients and families collected from literature, standard nursing care plans and interviews.

\begin{tabular}{|c|c|}
\hline General counseling & Prognosis \\
\hline explanation of heart failure & life expectancy \\
\hline explanation of symptoms & expectations of the future \\
\hline monitor daily weight & advance directives \\
\hline \multicolumn{2}{|l|}{ symptoms of worsening heart failure } \\
\hline what to do if symptoms worsen & Diet \\
\hline expected symptoms & sodium restriction \\
\hline explanation of treatment/care plan & -identify high and low sodium food \\
\hline role of family members & - read labels of food and medication \\
\hline availability of support groups & - restaurants with low sodium dishes \\
\hline patients and family responsibilities & potassium enhanced diet (if required) \\
\hline importance of tobacco cessation & fiber rich diet (to prevent constipation) \\
\hline possibilities of community services & bealthry dict \\
\hline stress & maintain minimal required metabolic needs \\
\hline \multicolumn{2}{|l|}{ prevention of hazards } \\
\hline prevention of flu or cold & Fluids \\
\hline importance of obtaining vaccinations & $\begin{array}{l}\text { balance between fluid intake and output } \\
\text { minimal and maximum fluid intake }\end{array}$ \\
\hline & avoidance of excessive fluid intake \\
\hline recommend leisure and work activity & fluid restriction (if required) \\
\hline recognize activity limitations & alcohol restriction/abstinence \\
\hline \multicolumn{2}{|l|}{ maintain regular physical activity } \\
\hline prevent exhaustion & Medication \\
\hline rest after heavy meals & benefits of medication \\
\hline conserve energy & dosing \\
\hline avoid temperature extremes & adverse effects \\
\hline possibility of rehabilitation program & coping with complicated regimens \\
\hline sexual difficulties and coping strategies & availability of lower-cost medication \\
\hline positioning & signs of (digitalis) intoxication \\
\hline elastic stockings & sign of hyperkalemia \\
\hline \multicolumn{2}{|l|}{ plan rest during the day } \\
\hline \multirow[t]{3}{*}{ balance between activity and restr } & Compliance \\
\hline & expected side effects \\
\hline & benefits of medication \\
\hline
\end{tabular}


need support from health care professionals like community nurses or from support groups to learn to live with heart failure.

Another important topic is the prevention of hazards. Patients with edema can be susceptible to skin problems. They also need to optimize their resistance to infections, a danger to which they are particularly susceptible. Patients should avoid getting the flu or a cold by getting an anti flu-shot and keep their condition in a most optimal status.

\section{prognosis}

It is important that patients with heart failure understand what their prognosis is. They need information about estimated survival rates but also about factors influencing the quality of their lives. Some patients have to be supported in making decisions about how to change their life-style, and still enjoy their lives. Other patients need support in setting realistic goals for the future. A nurse stated:

I try to help patients make realistic plans for the future, for example I recently advised a patient and his wife to celebrate their $49^{\text {th }}$ wedding anniversary this year, instead of waiting till the $50^{\text {th }}$ anniversary next year. If he is still alive next year, well then he can celebrate it again.

\section{activity}

Although discussions about exercise and the benefit of rehabilitation programs for patients with heart failure are still ongoing, patients with heart failure and their families need to be informed about desired activity levels. Sometimes patients have difficulties in balancing what they want to do and what their heart allows them to do. Some patients are inclined to become unnecessarily inactive, while others are inclined to be carelessly overactive. Patients should stay active without exhausting themselves. They can maintain regular physical activities but need to recognize activity limitations.

Some patients need support in setting priorities concerning their activities. A home health nurse reported:

I teach them how to conserve their energy in activities of daily living. For example. I advise them to sit down if they are bathing themselves or if they are preparing their meals. The energy they conserve can be used in doing things they enjoy, for example visiting the neighbors or farmily.

In addition to information about work or leisure activities, health care providers should discuss sexual activities. It is important to clarify misconceptions and to provide the information required by both patient and spouse to adapt to the disease. Advanced heart failure does not necessarily mean the end of satisfying sexual relations, but it is important that physicians and nurses address the alterations that may occur related to the disease and provide appropriate counselling. ${ }^{28}$

\section{diet}

In most of the literature, interviews and standard nursing care plans it is reported that patients with heart failure should restrict their dietary sodium. It is often reported that 
a no-salt-added diet is enough, but patients also need information on hidden sources of sodium. Most processed foods and restaurant meals contain a lot of salt and patients do not always realize this.

Sure, almost every patient know's not to take salty peanuts, but there are more persons than you think who take soft ice-cream without knowing they'd better not take it.

It is not enough to tell patients they have to follow a sodium-restricted diet. The nurse should consider the life style of the patient and the consequences of the sodium restriction for the patient and family: for example, give advice on choosing restaurants that offer low-sodium dishes on their menus, teach the patient to check package labeling and to watch for hidden sources of sodium, such as softened water or some cough medicines. ${ }^{2 y}$ It is also vital that patients maintain adequate nutrition in the face of a frequently diminished appetite due to congestion of the gastrointestinal tract. Patients can be encouraged to eat frequently in small amounts. Sometimes patients suffer from a syndrome of chronic wasting, referred to as "cardiac cachexia". Patients can be advised to take vitamin supplements.

\section{medications}

Many patients with heart failure have complicated drag regrimens. Patients need to understand their medication schedule and also the benefits of these medications. They also need to know how to adjust their diuretics within certain limits, how to recognize symptoms of intoxication or adverse drug reactions and what to do if something goes wrong in taking medications. Very practical information and support is necessary in regard to systematic preparation of their medication or financial consequences.

\section{compliance}

Information from literature and from interviews suggested that noncompliance with diet and medication is an important problem in patients with heart failure. ${ }^{30}$ In addition to motivation for certain life-style changes and importance of medication, possible consequences of noncompliance need to be discussed. Possible side effects of medication need to be discussed in an open way and the possibility of alternative medication has to be considered in case of unbearable side effects.

\subsection{Discussion}

The purpose of this study was to examine and give an overview of nursing care for patients with heart failure. In addition to basic nursing care, patients with heart failure need to be observed and assessed carefully. Both in hospital and at home it is vital to "maintain the balance". Both nurses and patients need to observe signs and symptoms of heart failure adequately. Although no standard observation scales were reported in literature, standard nursing care plans or interviews, an extensive list with topics of observation was described. 
There is a considerable variety in type and intensity of (cardiac) assessment don in different settings (national and international). To assess and observe all the relevant criteria in patients with heart failure, an observation scale that contains standard topics would be necessary. An adapted version of such an observation scale could be used at home by a patient or a primary care provider. In this study the main focus was on describing nursing practice. In research settings additional data will be assessed, for example assessment of depression and overall quality of life.

In addition to observation and assessment, nursing interventions are often aimed at relieving symptoms of heart failure or helping the patient and family cope with the consequences of heart failure. Information from the different sources described how nurses intervene to maintain the balance between rest and activity, intake and output, therapeutic effects and disadvantages of treatment. However, to intervene adequately, nurses have to know which interventions are appropriate and which interventions have been tested for effectiveness. A limitation of this chapter concerns the summarizing of the information in the tables $3.2,3.3$, and 3.4 in which the source of the information (literature, interview, standard nursing care plan) is not provided.

In this study we found that regularly nurses do not know how to intervene regarding a problem that results from heart failure: for example, how to deal adequately with feelings of powerlessness, hopelessness or anxiety. Descriptive studies are needed to elaborate on problems of patients with heart failure and relevant interventions. Preliminary studies have shown that patients with heart failure often are depressed and have mood disturbances..$^{31.32}$ However, effective descriptions of nursing interventions for these mood disturbances are scarce. It might be appropriate to investigate nursing interventions that are used and are tested for effectiveness in other chronic populations that have severe functional disabilities. We also described the importance of prescribing exercise. In most situations infomation on how to prescribe exercise to these severely limited patients is not known to nurses.

Another issue to be considered is the fact that nurses sometimes use interventions in caring for patients with heart failure that are not described in literature, or not tested for effectiveness. Some of these interventions have to be questioned.

Other interventions described in literature but not implemented in practice, however, can be appropriate in patients with heart failure. For example, we found that relaxation techniques are suggested to help decrease anxiety levels. ${ }^{8.21,22}$ However, in nursing practice patients rarely are taught relaxation techniques.

In this study we also found that in addition to symptom-relieving interventions, patient education and counseling is an important issue in caring for patients with heart failure and their families by nurses or other health care professionals. However two comments have to be made. First it has to be noticed that there is little experimental data that supports the effect of education in this population, and second it is important to consider the multidisciplinary context of the education.

A few studies were found that addressed education in heart failure paticnts. A quasi-experimental study found that home teaching during a home visit was cflicetive in decreasing hospital readmission and decreasing days of rehospitalization for patients with chronic congestive heart failure. ${ }^{27}$ These home visits were guided by an individualized nursing care plan with various teaching objectives. Another, descriptive, study 
on the nurse practitioner role in a heart failure clinic showed that in-hospital time and yearly medical costs decreased markedly and patients' satisfaction increased. ${ }^{23}$ However, the results of these studies must be interpreted with some care because of their methodological limitations.

The multidisciplinary context of the education is also important, as described in a treatment strategy of Rich et al. ${ }^{33.34}$ In addition to patient education, the intervention consisted of intensive training of the patient by a geriatric cardiac nurse, a detailed review of medications by a geriatric cardiologist, early consultation with social services to facilitate discharge planning, and close follow-up after discharge by home care and the study team. Results showed that treatment by a multidisciplinary team was effective in reducing both number and length of rehospitalization and medical costs.

Another multimodal intervention was tested by Kostis et al. ${ }^{35}$ This nonpharmacologic approach consisted of an exercise program combined with structured cognitive therapy, stress management and dietary intervention. This intervention was compared to a digitalis group and a placebo group. The nonpharmacological intervention was found to improve functional capacity, body weight and mood status in patients with congestive heart failure. In contrast, digoxin improved ejection fraction without corresponding changes in exercise tolerance or mood status. The results of this study should also be interpreted with caution due to a small sample size.

In these studies follow-up or care in the outpatient department as part of the intervention seems effective in preventing readmissions and decreasing medical costs. Nurses in our study stress that some settings or time periods are more appropriate to educate patients than others. Health care providers should realize that patients cannot absorb all the information in one session. Patient teaching in the hospital should be continued in the home setting or in the outpatient setting. . $2,23,24^{2}$

Caring for patients with heart failure is very complex and is often aimed at keeping a very delicate balance. To optimize care for these patients, it is advisable to devilop a structured assessment scale to use in different care-settings. Data described in this study can be used to develop such an assessment scale.

To provide optimal care, it is essential that individual clinical expertise is integrated with results from research. Discussions on "evidence based medicine" can be extended to nursing care. Sackett et al. (1996) wrote "good doctors use both individual clinical expertise and the best available external evidence, and neither alone is enough." ${ }^{6}$ This also applies to nurses. In this study we described a lot of information that came from clinical experience and clinical practice. To provide high quality care, this information from clinical expertise has to be combined with research. Therefor descriptive and experimental studies are needed to elaborate on problems of patients with heart failure and relevant interventions. It is also vital that interventions for patients with heart failure are tested in experimental designs in which both cost-effectiveness and quality of life are measured. 


\subsection{References}

I. Franciosa JA. Epidemiologic patterns, clinical evaluation and long-term progno$s i s$ in chronic congestive heart failure. Am J Med 1986; 80: 14-21.

2. Ho KK, Pinsky JL, Kannel WB, Levy D. The epidemiology of heart failure: The Framingham study. J Am Coll Cardiol I993; 22: 6A-13A.

3. Bonneux L, Barendregt JJ, Meeter K, Bonsel GJ, van der Maas PJ. Estimating clinical morbidity due to ischeamic heart disease and congestive heart failure: the future rise of heart failure. Am J Public Health 1994; 84: 20-28.

4. Reitsma JB, Mosterd A, de Craen AJM, Koster RW, van Capelle FJL, Grobbee DE, Thijssen JGP. Increase in hospital admission rates for heart failure in The Netherlands, 1980-1993. Heart 1996; 76: 388-392.

5. Mosterd A. Epidemiology of heart failure [Doctoral thesis]. Rotterdam: Erasmus University of Rotterdam, 1997.

6. Cowie MR, Mosterd A, Wood DA, Deckers JW, Poole-Wilson PA, Sutton GC, Grobbee DE. The epidemiology of heart failure. Eur Heart J 1997; 18: 209-225.

7. McMurray JJV, Petrie MC, Murdoch DR, Davie AP. Clinical epidemiology of heart failure: public and private health burden. Eur Heart J I998; 19(suppl. P): $9-16$.

8. Eriksson H, Wilhelmsen L, Caidahl K, Svardsudd K. Epidemiology and prognosis of heart failure. Z. Kardiol I99I; 80(suppl. 8): I-6.

9. Cohn JN. The management of chronic heart failure. New Engl J Med I 996; 335: $490-498$.

10. Konstam M, Dracup K, Baker D et al. Heart failure: evaluation and care of patients with left ventricular systolic dysfunction. Clinical Practice Guideline No I I. AHCPR Publication No. 94-0612. Rockville, MD: Agency for Health care policy and research, public health service, US Department of Health and Human Services, June I 994.

I I. Jaarsma T, Halfens RJG, Huijer Abu-Saad H. Readmission of older heart failure patients. Prog Cardiovasc Nurs 1996; 1 I

I 2. Dracup K, Baker DW, Dunbar SB, Dacey RA, Brooks NH, Johnson JC, Oken C, Massie BM. Management of Heart Failure, counseling, education, and lifestyle modifications. JAMA 1994: 272: 1442-1 446.

13. Hagenhoff BD, Feutz C, Conn VS, Sagehom KK, Moranville-Hunziker M. Patient education needs as reported by congestive heart failure patients and their nurses. J Adv Nurs 1994; 19: 685-90.

14. Doenges ME, Jeffries HF, Moorhouse HF. Nursing care plans: nursing diagnoses in planning patient care. Philadelphia: FA Davies, 1984.

15. Orem DE Nursing: Concepts of practice ( $5^{\text {th }}$ ed.) St. Louis: Mosby, 1995.

16. Gordon M. Nursing diagnosis: process and application. New York: McGraw Hill, 1987.

17. Mitchell ES. Multiple triangulation: a methodology for nursing science. Adv Nurs Scienc I 986: 8: 18-26.

I 8. Ryan AM. Stopping CHF while there's still time. RN 1986: 28-36.

19. Duncklee J5: Protocol: Congestive Heart Failure. Nurs Pract 1984; sept: 15-24. 
20. Letterer RA, Carew B, Reid M, Woods P. Learning to life with Congestive Heart Failure. Nursing 1992; 34-37.

2I. Fuduka N. Outcome standards for the client with congestive heart failure. J Cardiovase Nurs 1990; 4, 59-70.

22. Wingate S. Cardiac Nursing. A clinical management and patient care resource. Maryland: Aspen Publisher, r99 I.

23. Cintron G, Bigas C, Linares E, Aranda JM, Hernandez E. Nurse practitioner role in a chronic heart failure clinic: in hospital time, costs, and patient satisfaction. Heart Lung 1983; 1 2: 237-240.

24. Ashby BSH. Home teaching: Effect on compliance, hospital readmissions and days of rehospitalization for patients with chronic congestive heart failure. Unpublished doctoral dissertation. Richmond: Virginia Commonwealth University, 1988.

25. Bushnell FK. Self-care teaching for Congestive Heart Failure patients. J Gerontol Nurs I992: 28-32.

26. Goodwin DR. Critical pathways on home health care. JONA 1992:22: 235-240.

27. Dungan J. You make the diagnosis. Nurs Diag I993; 4: 55, 77-78.

28. Jaarsma T, Dracup K, Walden J, Stevenson LW. Sexual function in patients with advanced heart failure. Heart Lung I 996; 4: 262-270.

29. Molleson AL, Gallagher-Allred CR. Patient education aids for this issue: dietary modifications for CHF. Patient Care 1987; 30: 82-84.

30. Monane M, Bohn RL, Gurwitz JH, Glynn RJ, Avorn J. Noncompliance with congestive heart fiilure therapy in the elderly. Arch Intern Med I994; I 54: 433437.

31. Walden JA, Dracup K, Hamilton MA, Chemlimsky-Fallick C, Moriguchi J. Quality of life in advanced heart failure. Circulation I990 (suppl III): 705.

32. Hawthorne MH, Hixon ME. Functional status, mood disturbance and quality of life in patients with heart failure. Prog Cardiovasc Nurs 1994; 9: 22-32.

33. Rich MW, Beckham V, Wittenberg C, Leven CL, Freedland KE, Carney RM. A multidisciplinary intervention to prevent the readmission of elderly patients with congestive heart failure. N Engl J Med 1995; 333: I I90-I I95.

34. Rich MW, Vinson JM, Sperry JC, Shah AS, Spinner LR, Chung MK, DavilaRoman V. Prevention of readmission in elderly patients with congestive heart failure. J Gen Intern Med 1993; 8: 585-90.

35. Kostis JB, Rosen RC, Cosgrove NM, Shindler DM, Wilson AC. Nonpharmacologic therapy improves functional and emotional status in congestive heart failure. Chest 1994; 106: 996-1001.

36. Sackett DL, Rosenberg WMC, Gray JAM, Haync's RB, Richardson WS. Evidence based medicine: what it is and what it isn 't. BMJ 1996: 31 2: 7I-72. 


\section{Part II}

\section{Intervention}





\title{
Chapter 4
}

\section{Developing a supportive-educative program for patients with advanced heart failure within Orem's General Theory of Nursing}

\begin{abstract}
Recovery from heart failure and coping with the effects of this serious condition has a major impact on the self-care demand of patients with heart failure. To prevent potential self-care deficits, education and support are important issues in nursing care. The focus of this paper is to describe the development of a supportive-educative program that is designed to develop self-care abilities of patients with heart failure. To structure nursing care for these patients and their families in a consistent systematized way, Orem`s General Theory of Nursing is used as a frame of reference.
\end{abstract}

Adapted from:

- Jaarsma T. Halfens R. Senten M. Huijer Abu-Saad H. Dracup K. Developing a supportive-educative program for patients with advanced heart failure within Orem's General Theory of Nursing. Nurs Scie Quart I998; I I: 79-85. 


\subsection{Introduction}

Using nursing theory to structure nursing care in a consistent and systematic way has considerable potential for improving the quality of care.' There seems to be a resurgence of interest in using nursing theory as the basis for nursing practice as well as for research. ${ }^{2-5}$ However, it is often difficult to match abstract nursing theories to practical bedside problems. The chief problem in theory application is no longer the issue whether theory should be applied to practice, but rather how to accomplish this goal.

In previous work, the Nursing Development Conference Group used Orem's theory to organize knowledge extracted from the literature around the nursing system. ${ }^{6}$ The purpose of this paper is to illustrate how Orem's General Theory of Nursing guided the development of a supportive-educative program for a specific patient population..$^{7.8}$ The program was used to structure nursing care for heart failure patients. In a later phase, the program will be evaluated in an experimental study.

Nurses in many settings are involved in the care of patients in different phases of heart failure. In the clinic, hospital, nursing home or patient's home, the nurse has a major role in detecting, identifying and treating heart failure. ${ }^{9-15}$ Heart failure has a major impact on patients" lives, normal functioning and well being. Severe symptoms, limited vital capacity, and treatment affect several dimensions of a person's life. e.g. physical, personal and social aspects. As the disease progresses, patients have to make adjustments in their lives. To successfully make these adjustments, patients need certain knowledge and skills. Nurses can help patients by support, guidance, provision of a developmental environment and teaching ("supportive-educative" system). ${ }^{8}$ To successfully use such a supportive-educative system. nurses need to focus on specific needs for patients with heart failure. There is no known well-defined or structured program available that can be used to enhance heart failure paticnts" abilities to engage in self-care. To develop such a supporive-educative program for patients with heart failure, Orem's General Theory of Nursing, specifically the Self-care Deficit Nursing Theory (S-CDNT) was used. ${ }^{7.8}$

\subsection{Self-care Deficit Nursing Theory and Heart Failure}

Orem's Selt-care Deficit Nursing Theory focuses on the action capabilities of individuals and their demands for self-care. Self-care is "the practice of activities that individuals initiate and perform on their own behalf in maintaining life, healthy functioning, personal development, and well-being". $8($ pio4)

The total of activities that should be performed is called the therapeutic self-care demand (TS-CD). It stands for a specification of the kinds and numbers of care measures that are known or presumed to be regulatory of an individual's human functioning and development within some time frame. ${ }^{8(\mathrm{p} 187)}$ Three types of self-care requisites can be identified: eight universal $S-C$ requisites, two developmental $S-C$ requisites and six health deviation S-C requisites. Whether self-care is performed or not depends on the individual's capability, to perform the necessary actions to meet the demands. To en- 
gage in effective self-care, persons need to have an adequate self-care agency (S-CA). Three types of capabilities are needed:

1. The ability to determine what needs to be done to regulate health and well being (estimative self-care operations);

2. The ability to judge and decide what to do from the information obtained (transitional self-care operations); and

3. The ability to actually perform the self-care actions once the knowledge is obtained and the decision to act has been made (productive self-care operations). ${ }^{8}$

If a person's capabilities are inadequate to meet the TS-CD, a self-care deficit exists. According to Orem's theory, persons whose S-CA is not adequate, because of their health status or health care requirements. or will become inadequate to meet their TS-CD, may require nursing care. ${ }^{8}$ Clearly, patients with heart failure and their families' face changing self-care demands associated with consequences of the disease and treatment. Often patients can manage their self-care for some time but new demands will emerge that require more complex actions. As the disease progresses, the capacity for work diminishes and the ability to perform and to direct their care may diminish. In this stage, patients and families may require nursing care to meet existent and emerging demands for continuing self-care. They often need special knowledge and skills to meet the TS-CD in order to promote their own development and functioning, their health and well being. Nurses can help patients to prepare themselves for the future increase in self-care requirement, predicted on the basis of consequences of heart failure in physical, personal and social dimensions.

To care effectively, nurses have to (a) review the therapeutic self-care demand, (b) estimate the self-care agency and (c) determine the existence or potential for self-care deficits of the heart failure patient.

Although an individual's exact self-car'e demand cannot be known until it is actually reviewed, ${ }^{8}$ one can reason that there are certain actions needed to meet self-care requisites that are globally the same in every patient with heart failure. Such a description of a "potential" TS-CD of a heart failure patient can be useful in designing and planning nursing care that focuses on extending patients' S-CA. Standardized areas of concern in which a patient with heart failure needs certain capabilities to engage in self-care can be indicated. This information can be used to design and plan nursing care for an individual heart failure patient.

It has to be noted that, in designing nursing care for a patient with heart failure. this theoretical description is not sufficient. It is not possible to design a blueprint for the TS-CD and S-CA of every heart failure patient. Each person has his or her unique features including specific properties affected by basic conditioning factors such as health status, age, gender, environmental factors, etc. ${ }^{8}$ This is why the nurse has to compare the actual TS-CD and S-CA with the theoretically possible self-care demand and abilities needed. For example, it could be stated that every heart failure patient needs information about fluid balance. If a heart failure patient has renal problems. the information on fluid balance needs to be adapted to his/her diet. Inn addition to standardized areas of concern, specific data need to be gathered to individualize nursing care. 


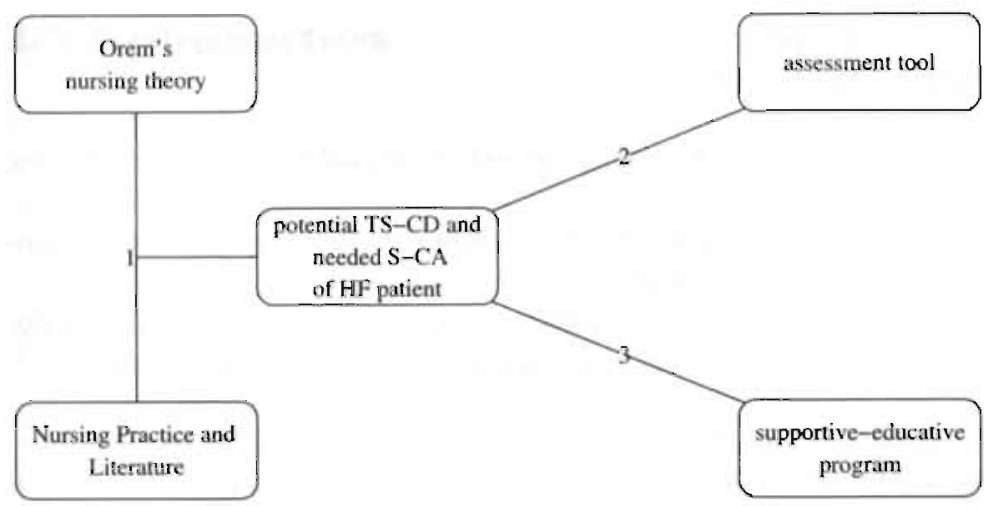

Figure 4.1: Development of a supportive-educative program

\subsection{Method}

Ti develop a supportive-educative program within Orem ss self-care deficit theory of nursing, 3 steps were taken (Figure 4.1 ). ${ }^{8}$

First the potential TS-CD and necessary S-CA of a "prototypical" heart failure paticnt were described. With this information an assessment tool was developed that can he used to describe the "actual" TS-CD and S-CA of a specific heart failure patient. Finally a supportive-educative nursing program was designed for patients with hoat failure. Ultimately, the supportive educative nursing program will be tested in an experimental study.

\subsection{Therapeutic Self-Care Demand}

To describe the potential TS-CD of a heart failure patient, the following sources of information were used:

1. journal articles and textbooks,

2. 24 standard nursing care plans on heart failure available in the Netherlands, and

3. semi-structured interviews with 45 nurses.

Two of the authors, who are nurse researchers in the field of cardiology (TJ, MS), then systematically discussed the possible self-care demand of a heart failure patient. By applying the information from literature, standard nursing care plans and interviews to the situation of a heart failure patient, it was concluded that changes in each of the eight universal self-care requisites could be expected. In addition, changes in healthdeviation self-care requisites exist as a result of heart failure and its treatment. The developmental self-care requisites can also change. In an older population, however, the effects of heart failure on meeting developmental self-care requisites can be expected to be minimal. We therefore chose to concentrate on universal and health-deviation self-care requisites. 
Table 4.r: Self-care requisites affected by heart failure

\section{Universal self-care requisites}

I Maintaining a sufficient intake of air

impact of heart failure

2 Maintaining a sufficient intake of water

dyspnea, cough

3 Maintaining a sufficient intake of food

edema

4 Providing care associated with elimination processes and excrements

loss of appetite

constipation as result of bedrest urine output as result of diuretics

5 Maintaining a balance between activity and rest

fatigue as result of low EF

bedrest

sleeping problems

6 Maintaining a balance between solitude and social interaction

social activity as result of fatigue and anxiety

7 Preventing hazards to human life, human functioning, and well-being

8 Promoting human functioning and development within social groups in accord with human potential, known human limitations and the human desire to be normal

\section{Health deviation self-care requisites}

I Seeking and securing appropriate medical assistance

2 Being aware of and attending to the effects and results of pathological conditions and states

3 Effectively carrying out medically prescribed measures

4 Being aware of and attending to or regulating the discomforting or deleterious effects of medical care measures

5 Modifying the self-concept in accepting oneself as being in a particular state of health and in need of specific forms of health care

6 Learning to live with the effects of health state and treatment in a lifestyle that promotes continued personal devel-

awareness of symptoms keep appointments

recognize symptoms

fatigue, dyspnea

take medication restrict fluids and sodium

side-effects

thirst

feeling disabled

consequences of treatment terminal phase in life opment 
Table 4.2: Power components

\begin{aligned} & \hline I vigilance \\ & 2 controlled use of physical energy \\ & 3 control body position \\ & 4 reason within frame of reference \\ & 5 motivation \\ & 6 make and operationalize decisions \\ & 7 acquire, retain, operationalize knowledge \\ & 8 skills to perform self-care operations \\ & 9 set priorities \\ & I0 integrate operations \\ & \hline\end{aligned}

Table 4. I describes the self-care requisites on which heart failure has a major impact. Examples are given of the aspects of heart failure that influence these requisites. For example, dyspnea as a consequence of pulmonary edema needs actions to be taken for the purpose of meeting the (universal) self-care requisite: "maintaining a sufficient intake of air". Also, decreased social interaction as a consequence of symptoms (dyspnea, fatiguc) and treitment (diuretics) needs actions to be taken for meeting the (universal) sclf-care requisite: "maintaining a balance between solitude and social interaction". In addition to universal self-care requisites, health-deviation self-care reçuisites exist as a result of the disease and of medical care measures prescribed by physicians. In patients with heart failure, the control of fluid and sodium intake is an example of such a medical care measure. Other examples of health-deviation self-care requisites in patients with heart failure are seeking appropriate medical assistance when symptoms of heart failure recur or worsen, etfectively taking prescribed medication or learning to live with the side-effects of certain medications (for example, cough as possible side-effect of Angiotensin Converting Enzyme-inhibitors).

\subsection{Self-Care Agency}

To perform self-carc, a person needs an adequate S-CA. This means that a patient's needs "empowering capabilities" for self-care that are developed and operational. Orem formulated to power components (table 4.2) necessary to have the capabilities to engage in self-care behavior. ${ }^{7}$ These can be summarized as knowledge, attitude and skills that cnable the individual to engage in self-care. ${ }^{16}$

To desuibe the self-care abilities needed by "a heart failure patient", we discussed, for "ach of the universal self-care requisites and health deviation requisites, the possible capabilitics needed (as described in the 10 power components). In other words, we discussed whether patients with heart failure without self-care deficits use this power component of S-CA. This was done requisite by requisite. In total 140 questions were discussed in this way ( $r$ power components $x$ I 4 self-care requisites). The information that was gathered during this discussion was summarized in the 3 kinds of operations 
described by Orem (I995): estimative, transitional and productive operations. ${ }^{8}$

In table 4.3 an example of the potential capabilities required by "a heart failure patient" is elaborated for two of the eight universal requisites and two of the six health deviation requisites. It was decided to summarize the estimative and transitional operations together because distinction is rarely useful. We found that in order to meet the (universal) self-care requisite "the maintenance of a sufficient intake of air", patients with heart failure need to have various capabilities to engage in several self-care operations. Patients need to know what causes their dyspnea, what they can do and why it is so important to take action (estimative self-care operation). They also need to decide what actions to take, e.g. extra diuretics, and/or rest, and/or a high Fowler position, etc. (transitional self-care operation). They also need to have abilities and skills to meet this self-care requisite, e.g. ability to change position (productive self-care operation) or buy and take the right medication. In regard to the (health deviation) self-care requisite "seeking and securing appropriate medical assistance", we found that patients need to know the signs and symptoms they should monitor to recognize worsening of their condition. They also have be aware of the fact that a quick reaction often is of vital importance and they should be motivated to take action, for example, ask for help (estimative and transitional self-care operations). They also need to be able to warn a health professional (to know telephone numbers, able to use the phone)(productive sell-care operations.)

Table 4.3: Example of elaboration of a heart failure patient's potential required capabilities

\section{Ūniversal self-care requisites:}

\section{1: the maintenance of sufficient intake of air}

estimative and transitional operations

- be aware of causes that can change respiratory condition

- be aware of decrease in cardiac output

- recognize importance of a good respiratory condition

- know causes of dyspnea

- be aware of consequences of dyspnea for other self-care activities

productive operations

- use techniques to increase pulmonary ventilation

- take a proper position

- adapt other self-care activities to regulate dyspnea

- take extra medication

- priorities in Activities of Daily Living 
Table 4.3: Example of elaboration of patient's required capabilities (continued)

\section{2: sufficient intake of water}

estimative and transitional operations

- know which fluid intake is appropriate (minimum and maximum)

- know relationship fluid intake, cardiac output and medication

- motivated to monitor fluid intake and excretion

- recognize signs and symptoms of fluid overload and dehydration

- know effects of diuretics

- be able to inform relatives/friends about fluid restriction

productive operations

- restrict fluid intake

- monitor fluid status by measuring fluid intake, output and daily weight

- take diuretics as prescribed

- assess presence of edema

- recognize signs and symptoms of dehydration

\section{Health deviation self-care requisites:}

\section{1: seeking and securing appropriate medical assistance}

estimative and transitional operations

- know sign and symptoms of worsening heart failure

- know what to do when symptoms occur

- know that quick reaction is important

- dare to request help

- be motivated to ask for help in time

productive operations

- react adequately on symptoms: medication, ask for help or adjustments

- have access to important telephone numbers

6: learning to live with the effects of health state and treatment in a lifestyle that promotes continued personal development

estimative and transitional operations

- know disease progression and treatment

- accept disease progression

productive operations

- set realistic life goals (with spouse)

- talk with spouse about "future"

\subsection{Assessment tool for patients with heart failure}

To design and plan nursing care for a heart failure patient. the nurse has to gather relevant information on the patient's demand for care measures that will meet his or her 
Table 4.4: Examples of assessment questions related to universal and health-deviation self-care requisites to assess limitations of knowing, limitations in judgement/decision making or limitations of production of action.

\section{Universal $\mathrm{S}-\mathrm{C}$ requisite 1:}

\section{the maintenance of sufficient intake of air}

knowledge

- What caused your dyspnea/shortness of breath?

- What is, according to you, the relationship between dyspnea and your heart condition?

- What are the consequences of being short of breath?

judgement and decision making

- What did you do when you became short of breath?

Why did you do this?

Did it help?

(check position, medication, resting)

production of action

- Do you have practical problems with getting or taking medication, changing position, getting rest, etc.?

- What are your priorities in activities of daily living?

Health Deviation S-C requisite 1:

seeking and securing appropriate medical assistance in the event of ...

knowledge

- What according to you are, signs and symptoms of deterioration of your health? (ask about edema, fatigue, weight gain, angina, etc.)

- Why is a quick reaction important?

judgement and decision making

- What did you do when something was wrong? (edema, angina, etc.)

- What are you planning to do in the future when symptoms occur? (ask: call someone, or go to emergency room immediately etc.)

- Whom can you contact in case of emergency?

production of action

- Can you reach the hospital in case of emergency?

- Do you have access to important telephone numbers?

- How are you going to seek medical assistance in case of worsening symptoms? (ask: did you program telephone numbers? can your wife drive a car? etc.)

SC-requisites. In addition, information on the patient's S-CA is necessary. Judgements about the adequacy of self-care agency, or capacity to act on one's own behalf, are based on the patient's usual self-care practices and the way the person is taking action to meet the current therapeutic self-care demand. 5 To assess possible limitations of knowing, limitations in judgement/ decision making or limitations of production of action, a checklist with questions was developed. This checklist was based on the theoretical TS-CD and required S-CA of a prototypical heart failure patient as described in stcp one. 
Table 4.4 presents a part of this checklist. For example, regarding "the maintenance of sufficient intake of air", questions are formulated on knowledge (causes of dyspnea, consequences of dyspnea), judgement/decision making (the actions the patient took during dyspnea the first time) and production of action (ability to get medication, proper position).

Information that is gathered by using this checklist will help the nurse express the relationship between the demand for self-care and the ability to meet that demand related to one self-care requisite. This will lead to a specific nursing diagnosis.

\subsection{Education and support for heart failure patients}

Together with the patient and family, the nurse can plan actions to develop the patient's self-care agency. Patients with heart failure and their families probably need teaching, support, guidance and a developmental environment regarding different aspects of their changed self-care requirements.

They need, for example, information on the relationship of heart failure with dyspnea or fatigue. But it is also very likely that a patient needs advice about how to maintain a balance between activity and rest, which activities to decrease, how to cope with chronic disease, how to prevent social isolation, etc.

This actual care giving and management of care is supported by possible nursing actions listed in our supportive-educative program. These actions are based on literature, standard nursing care plans and interviews with nurses. Table 4.5 illustrates part of the listed actions concerning the universal S-C requisites 2 and 4 (intake of water and elimination).

For example, in case of an actual or potential limitation in knowledge, reasons and consequences of fluid overload are discussed. Relationships with other self-care requisites (e.g. promoting normalcy) are established. In addition to verbal information, patients and families are provided with written information. They also can practice to recognize edema or keep their daily weight and anticipate in case of weight gain. This also will help the patient to discuss and to practice making the right decisions on actions to take in case of Huid overload or dehydration. Nurses can guide. direct and teach the patient and family, provide physical and psychological support, provide and maintain an environment that supports personal development.

\subsection{Testing the supportive-educative program}

It is expected that effective information and support for patients with heart failure and their families will prevent self-care deficits. Persons who effectively engage in selfcare are not in need of (nursing) care and will not need to be hospitalized. The effects of this program on self-care agency, prevention of readmission and quality of life of patients are currently being tested in an experimental study (RCT). In the control group, 60 patients receive care as usual and patients in the experimental group receive extra care according to the supportive-educative program. Data on self-care agency, selfcare, readmission and quality of life are collected before the intervention and 1. 3 and 
Table 4.5: Example of nursing actions from the supportive-educative program with regard to fluid intake and output

\section{guidance}

- discuss reasons for fluid restriction with patient and family

- help patient and spouse to plan fluid intake (set priorities, e.g. take medication together with food instead of glass of water)

- discuss the timing of diuretics with patient and spouse

support

- encourage the patient to evaluate fluid intake and output on a regular basis (e.g. once a week)

- provide forms to keep fluid balance

- help the patient to practicing keeping a fluid balance

- support patient in difficult times (e.g. extreme thirst)

provide a developmental environment

- encourage the patient and family to ask questions and discuss problems with fluid restriction, diuresis in daily life (for example how to act during holidays, social events, etc.)

teaching

- discuss reasons and consequences of fluid overload

- discuss relationship of fluids, diuretics, sodium, diuresis, thirst and heart failure

- show patient how to recognize edema

- discuss the importance of daily weighing

- discuss possibilities and abilities of patients to weigh daily

- discuss consequences of edema for daily living

- if necessary: tell the patient how much he/she is allowed to drink

- teach patient and family how much a cup, a glass, etc., contains (use hospital booklet: "fluid restriction")

9 months after the intervention. Results of the study should be forthcoming within the year.

\subsection{Conclusion}

The purpose of this paper was to describe the development of a supportive educative program within Orem's General Theory of Nursing for one type of patient population. Developing effective care for these patients is a very complex process because symptoms of heart failure and treatment affect a wide range of aspects of the lives of patients and families. All these aspects are often very closely related and they all need to be addressed. By using a theory as frame of reference, these aspects can be structured in a consistent systematized way.

The application of the concept "TS-CD" to the specific situation of heart failure patients and their families gave insight into the impact of heart failure on various aspects of life. Consequences of heart failure are often viewed from a biomedical perspective. 
Using the multi-dimensional approach of the self-care requisites prevented this. In addition to describing physical symptoms and consequences of heart failure, social and personal aspects were addressed.

Use of the power components within the concept "S-CA" provided an extensive framework to describe the capabilities required by heart failure patients. In this way the actual and potential needs of this population became concrete. However, by using each of the Io power components for the I 4 self-care requisites, an extensive list in potential capabilities with considerable overlap arose. The authors had to summarize all the capabilities into a workable list. It was also difficult to separate the estimative and transitional operations. By combining these operations, we still could describe potentially required capabilities in a way that is relevant and useful to clinical practice.

The distinction between limitations on knowing, judgement and production of action directed the questions for assessment related to universal and health deviation $\mathrm{S}-\mathrm{C}$ requisites. By considering all three types of limitations, the assessment will not be restricted to aspects in knowledge but also include information on other aspects. A complete assessment will provide a basis for designing and planning of effective care. In this program we focused on diagnosing very specific self-care deficits. This leads to particularistic diagnoses instead of more general diagnoses. We realize that there are more levels of diagnosis appropriate within the S-CDNT. ${ }^{17}$ Future work in the area of developing nursing diagnoses for this specific patient population is recommended.

By reviewing the nursing roles that are appropriate in a supportive-educative system (support, guidance, and provision of a developmental environment and teaching), nursing actions could be listed completely in a systemized way.

The supportive-educative program that has been developed contains elements from both theory and practice. Topics for helping as described in the theory are combined with information from literature and practice. It is not a standard program for educition; individual patient goals can be developed and implemented. For example, if a heart failure patient is a diabetic too, the nurse can adapt the education and support by adding actions regarding coping. diet, medication, etc. Other factors that affect S-CA and TS-CD (Basic Conditioning Factors) should also be considered.

This program is developed to educate and support the paticnt with heart failure and their families. A lot of the nursing actions are formulated towards the patient. However, when appropriate, nurses should also involve family members. To make this supportive-educative program more family focussed additional study is recommended. By testing this program designed by using a nursing theory in a practice situation, we stress the importance of the relationships among theory, practice and research. 


\subsection{References}

I. Huch MH. Theory-based practice: Structuring nursing care. Nurs Scie Quart I995; 8: 6-7.

2. Brown JS, Tanner CA, Padrick KP. Nursing's search for scientific knowledge. Nurs Res 1984; 33: 26-32.

3. Jaarsma T, Dassen $T$. The relationship of nursing theory and research: the state of the art. J Adv Nurs 1993; I 8: 783-787.

4. Moody LE, Wilson ME, Smith K, Schwartz R, Tittle M, VanCott ML. Analysis of a decade of nursing practice research: 1977-I986. Nurs Res 1988; 37:374379 .

5. Taylor SG. Nursing theory and Nursing process: Orem's theory in practice. Nurs Scie Quart I988; I: I I I-I I 9.

6. Nursing Development Conference Group (NDGC). Concept formulation in nursing: Process and product. Boston: Little, Brown, 1973.

7. Orem DE. Nursing: Concepts of practice ( ${ }^{\text {th }}$ ed.). St. Louis: Mosby, 199 I.

8. Orem DE. Nursing: Concepts of practice $\left(5^{\text {th }}\right.$ ed.). St. Louis: Mosby, 1995.

9. Bushnell FK. Self-care teaching for congestive heart Failure patients. J Gerontol Nurs 1992; I 8: 27-32.

Io. Dracup K. Baker DW, Dunbar SB, Dacey RA, Brooks NH, Johnson JC, Oken $\mathrm{C}$, Massie BM. Management of heart failure: counseling, education and lifestyle modifications. JAMA 1994; 272: 1442-I446.

II. Hagenhoff BD, Feutz C, Conn VS, Sagehorn KK, Moranville-Hunziker M. Patient education needs as reported by congestive heart failure patients and their nurses. J Adv Nurs 1994; 19: 685-690.

I2. Kostam M, Dracup K, Baker D, et al. Heart failure: Evaluation and care of patients with left ventricular systolic dystunction. Clinical Practice Guideline No I1. AHCPR Publication No. 94-06r2. Rockville, MD: Agency for Health Care Policy and Research, Public Health Service, US Department of Health and Human Services, 1994 .

13. Rich MW, Berkham V, Wittenberg C, Leven CL, Freedland KE, Carney RM. A multidisciplinary intervention to prevent the readmission of elderly patients with congestive heart failure. New Engl J Med 1995; 333: I 190-I I 95.

14. Vinson JM, Rich MW, Sperry JC, Shah AS, McNamara T. Early readmission of elderly patients with congestive heart failure. J Am Geriatr Soc 1990; 38 : I $290-$ I 295 .

I 5. Williams EL, Fitton F. Factors affecting early unplanned readmission of elderly patients to hospital. BMJ I 988; 297: 784-787.

16. Hartweg DL. Orem's: Self-care deficit theory. Newbury Park: Sage Publications Inc., r99I.

I7. Taylor SG. The structure of Nursing Diagnosis from Orem's Theory. Nurs Scie Quart 1991; 4: 24-32. 


\title{
Chapter 5
}

\section{Education and support for chronic heart failure patients: a case study}

\begin{abstract}
Care of patients with heart failure could possibly be improved by structured education and support in hospital and at home.

In this article the development of a supportive-educative nursing intervention is shortly discussed. A case study is used explain and illustrate the intervention and to review the importance of the standard nursing care plan.
\end{abstract}

Translated and adapted from:

- Jaarsina T, Halfens RJG, Cleuren G. Voorlichting en begeleiding van een patiënt met chronisch hartfalen: een case study. Verpleegkunde I997; I 2: 205-217. 


\subsection{Introduction}

It is generally recognized that more attention ought to be paid to improving the care of chronic patients in hospitals and at home. ${ }^{1.2}$ Gooding \& Jette (I985) found that elderly patients were readmitted to hospital sooner if they were discharged home than if they were discharged to an institution. These authors also emphasized the importance of improving medication and diet compliance, and they advocated improved home care and better coordination between the hospital and the home situation. A study of various forms of transmural nursing care in the Netherlands found that "nurses still focus too much on institutional care and lack sufficient understanding of the patients needs at home and at the hospital", and that "nursing care plans generally lack a broad vision covering more than the care offered by just one organisation". ${ }^{2}$ It is claimed that chronic patients in particular could benefit from more adequately coordinated care plans.

A growing group of chronic patients is that of heart failure patients. The aging of the population and the increasing chances of surviving acute cardiac problems is resulting in increased numbers of chronic heart failure patients. ${ }^{3-5}$ Although treatment of these patients has made great progress in recent years, patients are often readmitted with new symptoms or worsening of existing symptoms. Some researchers have described factors contributing to "avoidable" readmission. including incorrect use of prescribed medication, non-compliance with dietary instructions, inadequate discharge planning or follow-up, failing social support systems and failure to seek professional help as symptoms occur. ${ }^{6-8}$ These authors claim that 40 to $59 \%$ of readmissions could have been avoided if more individual attention had been paid to patients' problems and to discharge planning. Various authors have recommended that more attention should be paid, to discharge planning, follow-up and instructing patients about the consequences of heart failure for daily life, e.g., medication, dict and physical disabilities. ${ }^{7.9-11}$ The effects new interventions including such education and support efforts are increasingly evaluated. ${ }^{1-17}$

In an attempt to optimize the care of chronic heart failure patients at the Maastricht University Hospital, an intervention was designed, based on education and support both during the hospital stay and at home. The effect of this intervention will be evaluated in an experimental study.

The present paper describes the intervention that is bascd on information from the literature and from practice. After this description it discusses a case in which the intervention is applied, with the aim of illustrating the nature of the intervention as clearly as possible. The case presented combines aspects of two real patients.

\subsection{Designing the intervention}

The intervention discussed here, consisting of patient education and support by a nurse, is guided by a standard nursing care plan (SNCP). This was designed on the basis of information obtained from the relevant literature, from existing SNCPs and from interviews with Dutch nurses. ${ }^{18}$ 


\section{Collecting relevant information}

Information on nursing care interventions for heart failure patients was collected from international scientific and descriptive literature (1983-1993). In addition, all 251 cardiology departments of Dutch hospitals, as well as 53 home care organizations were asked whether they had any standard nursing care plans or protocols for the care of heart failure patients. A total of 27 SNCPs were thus collected. Finally, 34 cardiology nurses and I $\mathrm{I}$ home care nurses were asked to describe the current and ideal care of heart failure patients.

On the basis of the information obtained from these sources, an SNCP was designed emphasizing education and support for chronic heart failure patients.

\section{Design of the SNCP}

The information from the above three sources was structured on the basis of theoretical constructs from the Self-Care Deficit Nursing Theory developed by Orem. ${ }^{19}$ The first step was to indicate the influence of the health status of heart failure patients on their self-care demand. For instance, dyspnea as a result of pulmonary edema needs actions to be taken for the purpose of maintaining a sufficient intake of air. It may be assumed that each heart failure patient will face an altered self-care demand. Some needed actions are highly individual, but there will also be a number of needed actions that are globally the same in every patient with heart failure. To care for himself stfectively the heart failure patient needs certain knowledge, as well as the ability to take decisions and perform certain activitics.

In order to describe the self-care behavior expected of a particular patient and the abilities he or she will need. a description was drawn up of a hypothetical heart failure patient who experiences altered self-care demand but no self-care deficits. In other words. we analyzed everything a patient should know, decide and do in order to survive and to improve his or her health and well-being. As soon as this desired behavior profile has been established for this hypothetical heart failure patient, it can be used to assess whether actual patients at a clinic fit this profile, in other words whether they will be able to cope with the altered self-care demand. Should their ability prove inadequate. for instance because patients fail to recognize the symptoms of worsening heart failure or are unable to operate the oxygen equipment, they can be said to have an actual or potential self-care deficit. The nursing staff can then take action by improving the patients abilities, e.g. by means of education and support.

The description covered 9 aspects (table 5.I) of the life of a heart failure patient and was used to develop a form that can be used to assess the self-care abilities of a patient at the clinic and an SNCP. During assessment the nurse asks the patient questions to determine whether that patient is able to meet the altered self-care demand resulting from heart failure. For instance, the following questions on respiration are asked.

1. How has your respiration/dyspnea been lately? Has it become better or worse?

2. When, in what situations is your dyspnea better or worse?

3. Which factors influence the severity of your dyspnea?

4. What do you do when you are short of breath? 
Table 5.I: The 9 categories in the SNCP

Respiration
Fluid intake and fluid excretion
Nutrition
Bowel elimination
Activity and rest
Social relationships
Learning to live with heart failure
Psychological function
Prevention of complications/seeking help

Nursing activities are then planned on the basis of the answers to these questions. As regards respiration, for instance:

I. if it is found that a patient's knowledge is insufficient, the relation between heart failure and dyspnea is discussed;

2. if it is found that a patient is unable to decide what actions to take, the nurse discusses with him or her how to deal with dyspnea and the options which may be useful to them in paricular situations;

3. if it is found that a patient lacks a particular skill, the corresponding action is undertaken, e.g. by teaching him or her breathing exercises, to take extra medication or if needed by ordering oxygen to be delivered to the patient's home.

\subsection{Using the intervention}

\section{Content of the SNCP}

The SNCP consists of 9 categories (see table 5.1), each including (potential) problems, objectives, interventions and aspects relevant to evaluation. The interventions mainly take the form of nursing education and support. A number of items are always included the education and support (table 5.2), while additional potential problems have been formulated and corresponding interventions described. Table 5.3 shows one page of the SNCP for the "respiration" category.

The SNCP describes a number of interventions for each problem, with an indication of the concrete implementation of this intervention. If, for instance, the intervention consists of "discussing what to do if symptoms get worse", there will also be an indication of the type of information to be given. the source where this information can be obtained (e.g. a nursing manual) or what educational materials could be used. 
Table 5.2: Aspects of education and support from the SNCP (standard)

\section{Respiration}

a Discussing relation between heart failure and dyspnea

b Discussing with patient and partner any obvious causes (diet, too much activity, too much fluid intake, medication)

c Teaching signs of deterioration (see instruction card)

d Discussing what to do if condition worsens

e Discussing with patient what is and is not allowed as regards exertion, diet, etc. (advice by physician) and set priorities

\section{Fluid intake and fluid excretion}

a Discussing relations between fluid, diuretics, sodium, diuresis, thirst and heart failure

b Teaching patient how to recognize edema

c Importance of regular (daily) weight checks

d Teaching patient to cope with consequences of edema (swollen legs, feeling "full")

e Teaching patient to take diuretics at the right time

f Indicating how much patient can drink in one day

\section{Nutrition}

a Discussing sodium, fluids, heart failure and symptoms

b Discussing diet

c Discussing high-salt products

d Discussing hidden sources of sodium

e Pointing out to patient that reduced appetite, nausea and feeling "full" are signs of deterioration, requiring the GP/cardiologist to be consulted

\section{Bowel elimination}

a Discussing consequences of diarrhea

\section{Activity and rest}

a Discussing the relation between fatigue and heart failure

b Discussing what is and is not allowed, and when help is to be sought

c Discussing and supporting reasonable activity levels

d Motivating patient not to overexert nor underexert

e Teaching patient to be aware of increasing fatigue or exhaustion

\section{Social relationships}

a Discussing consequences of heart failure with patient's relatives/friends

b Discussing roles of partner/relatives/friends in patient care

c Discussing options for care and social contacts 
Table 5.2: Aspects of education and support from the SNCP (standard) (continued)

\section{Learning to live with heart failure}

a Discussing cause and prognosis of the condition

b Discussing future perspectives

c Discussing medication

- name, dosage, effects and side-effects of medication (physician)

- timing of medication

- effects of non-compliance

- preparing medication (for one day/one week/by someone else/in a medicine box)

- what to do after non-compliance

d Providing medication schedule

e Discussing lifestyle/dietary regimen

f Discussing purpose and nature of appointments with GP/cardiologist and motivating patient to keep them up

\section{Psychological function}

a Discussing how to avoid deterioration

\section{Preventing complications/seeking help}

a Explaining the importance of a safe environment

b Discussing symptoms of deterioration

c Discussing ability to get help

d Discussing the importance of flu prevention

e Discussing the importance of early recognition of signs and rapid response

f Discussing patient's ability to seek help

\section{Procedure}

As soon as patients are in a stable condition, the assessment takes place and interventions are planned on the basis of the SNCP. These are then implemented during the patients' hospital stay. Should patients be discharged before the planned care program has been completed, this will be continued at their home. by means of a home visit, follow-up by phone or coordination with available home help. After patients have been discharged. the nurse will visit them at home at least once in order to optimice education and support. In the current health care situation, heart failure patients will not automatically come into contact with a district nurse or other home care organizations. If patients are already receiving home care, the project nurse will (if needed) contact the regular home care organizations. Another option is that the project nurse visits patients at home for a while and then transfers them to a regular home care organization. As far as the project is concerned. the intervention is completed within 7-Io days after hospital discharge.

In the following section the SNCP is illustrated by a case history. 
Table 5.3: Sample page from the SNCP for heart failure patients ${ }^{a}$

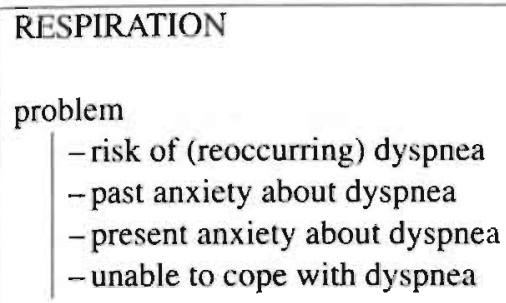

education/instruction

$X$ - Discussing the relation between heart failure and dyspnea

$X$ - Discussing with patient and partner any obvious causes (diet, too much activity, too much fluid intake, medication)

$x$ - Teaching signs of deterioration ${ }^{b}$ (use instruction card)

$X$-Discussing what is to be done if condition worsens'

- Providing tips on correct body position ${ }^{\mathrm{d}}$

-Teaching patient how to handle oxygen equipment ${ }^{e}$

support

- Discussing with patient and partner the experience of dyspnea and the associated feelings of anxiety ${ }^{\prime}$

$X$ - Discussing with patient and partner what is and is not allowed as regards exertion, diet, etc. (advice physician) and set priorities ${ }^{9}$

evaluation

- patient can cope with dyspnea (knows correct posture, can adapt his tempo, can handle oxygen equipment if required)

- patient and partner are aware of symptoms of worsening

- patient and partner know what to do if condition worsens

- patient and partner have discussed their feelings (anxiety, insecurity) about dyspnea

"superscripts indicate the source of information, e.g. textbook or manual, the nurse can use. 


\subsection{Case history}

A 71 -year-old man has been admitted to the cardiology ward with symptoms of heart failure.

\section{Background information}

The patient has a history of heart failure based on arrhythmias and ischaemia since I 988 . He has been readmitted to the cardiology wards with similar symptoms six times before. His Left Ventricular Ejection Fraction is low. At admission, he was using a number of drugs, including three types of diuretics. The patient retired $\mathbf{2} 2$ years ago and is living with his wife in a single-family house in a small village. They used to get home help, but that has been discontinued.

\section{Assessment}

The patient is assessed at the cardiology ward and it is found that he is no longer as short of breath as he was at the time of admission. The symptoms had started at home and had gradually deteriorated. The severity of the symptoms is related to his activities, and in his own views also to the weather conditions. If he is short of breath. he sits up and ases oxygen if necessary. He teels he has been retaining a lot of fluid lately, since his legs and abdomen have been swollen. In his view, this is due to his heart condition and to the fact that he has been drinking a lot of fluids. He had to get up three times a night to urinate. The patient had felt very tired lately, which greatly affected his lifestyle. "I used to be very active before, and had lots of contacts. Now there's hardly anybody. People don't see anything wrong with me and think I'm simulating." He prefers not to depend on other people. He also tells that he has no fluid restriction at home, but is on a sodium-restricted diet.

At home, the patient knew what medication he was using, but he has lost track of this at the hospital. His wife used to make sure he took the right medication, and had drawn up a useful schedule for this purpose. As regards his expectations for the future, he hopes to recover to a certain extent and to be able to take up various activities again.

\section{Entries in the SNCP}

In addition to the routine support and education items (table 5.2), the following SNCP interventions are ticked off:

- teach patient how to handle oxygen equipment;

- fluid restriction: hand out and discuss the hospital brochure;

- discuss problems of fluid restriction and diuresis and their consequences for daily life:

- discuss how his social network can be made to understand the fluid restriction;

- hand out the guidelines for sodium intake;

- tell patient to elevate his legs while resting;

- discuss the importance of relaxation; 
- discuss the patient's sense of increasing dependence and of not being able to do things he used to do: try to make patient and partner accept this (and take advantage of "good diys");

- provide support and advice about finding help, calling on others;

- discuss responses from people around the patient and his feelings about them;

- discuss the integration of diet and medication into the patient's daily routine and special problems on holidays, etc.;

- discuss options for the near future, i.e., short-term planning.

\section{Nurse's report}

\section{Intervention during first visit (during admission)}

As I visit the patient for the first time and fill in the assessment form, the patient asks many questions about treatment details. He wonders about the fluid restriction imposed on him at the hospital ("why is that necessary; does the water in fruit count as well; how much water is there in grapes", etc.) He also worries about why the doctor often checks his neck. I explain this to him, but I also stimulate him to ask the doctor himself at his next visit. He also asks a lot of questions on practical matters: the hospiral routine, the cardiologists, the cause of his admittance, etc. As a result, the assessment takes too much time and will have to be completed tomorrow.

\section{Second visit (during admission)}

We finish the assessment and I start some education items. I hand the patient a brochure on fluid restriction and talk him through it. New questions on various matters keep cropping up. He says he has lost track of his medication, while at home he always knew exactly what he was tuking. This makes him fee] insecure. I provide him with information about the new medication he is receiving and its timing. My impression is that he does understand what I tell him but is still uncertain about various aspects. As we discuss signs of deterioration, it turns out that he is aware of some of these (swollen legs and increasing dyspnea) but that he fails to see the importance of checking his weight regularly. He rarely checks his weight: "I'm not a woman; why should I watch my weight?" I explain to him the importance of checking his weight. He agrees that it would be a good idea to do this from now on and to contact his family doctor if it increases by more than $2 \mathrm{~kg}$. He also says he does not sleep well here in the hospital, but is afraid to talk about it to the doctor. We agree that he will bring up the subject at the doctor's next round, or if that does not succeed, I will bring it up tomorrow.

\section{Third visit (during admission)}

I ask the patient about his sleeping problems; he has requested and received sleeping tablets. In response to his complaint that he is losing track of his medication, I hand him a medication schedule with a full description of his current medication, showing names and times but also some indication of each medicine's purpose and side-effects. He will show this to his wife when she comes to visit him. 


\section{Fourth visit (during admission)}

Patient is to be discharged today. His medication has been slightly changed the last days and he would like to have a new schedule to take home. I briefly discuss his medication with his wife. The doctor tells him that he can gradually reduce his lasix dosage at home (from $40 \mathrm{mg}$ twice daily to $40 \mathrm{mg}$ once a day). This prospect makes him slightly nervous. We agree that I will phone him about this on Monday (i.e., in four days). I also write on the card his weight at discharge as well as the maximum safe weight. He is to contact his cardiologist or his GP if he exceeds this maximum. Finally, I check whether he fully understands the guidelines he has been given for fluid restriction.

\section{Telephone conversation (four days after discharge)}

I phone the patient to make an appointment and to check the effects of reducing the medication. He says he is not doing well. He is not short of breath, but does feel dizzy and suffers from headache and low blood pressure. He blames this on drugs which he was given on his discharge but which he was not taking during his hospital stay. We agree that I will visit him in two days and at the mean time will discuss his problems with his cardiologist.

After the conversation, I go to the cardiology department and check the patient"s file and discharge form. I discuss the patient with a cardiologist, who feels that the decision should be taken another cardiologist. I contact him and he proposes a change in the medication regime. He asks me to pass this on to the patient tomorrow, but I point out to him that I am not authorized to change medication. The cardiologist will call the patient himself.

\section{Visit to patient's home (two days after phone conversation)}

Patient has followed the doctor's advice and is feeling somewhat better, but definitely not as well as he used to do. He has gained I kilo, and I advise him to check his weight closely and to contact his GP or the hospital (whose phone numbers he has) if his weight should rise to over $7 \mathrm{I} \mathrm{kg}$ this week. We also talk about his accepting his illness. about gradually expanding his acrivities and about some dietary guidelines, such as fluid restriction. Patient has some questions about the use of alcohol and diuretics.

He also reports that he has not been sleeping well. The hospital has not prescribed hin any sleeping medication and the GP is unwilling to prescribe them. I advise him to bring up the subject at his first check-up visit to the cardiologist, which is in two wecks. The patient and his wife ask questions about reimbursements for the use of taxis. I promise to look it up for them and to let them know.

$\mathrm{He}$ also indicates that he still feels "socially isolated". He had already said so at the hospital and it is hitting him harder again now that he is back home. He would like 10 go out more and do something useful. There is little I can do for him at this point. except letting him talk about the problem.

\section{Letter}

I send the patient a brief letter explaining the options for using taxis, referring him to the outpatient clinic for further details. 


\section{Phone call from patient's partner, two months after discharge}

The patient's wife calls me. Her husband is very short of breath and has gained several kilo's in a short period of time. She does not know what to do. I refer them to the cardiologist. the outpatient clinic or the hospital ward, since the intervention (as a part of the project framework) now officially ended. I check later and find the patient has consulted the cardiologist over the phone.

\subsection{Discussion}

This case history illustrates that the use of this SNCP structures the education and support for heart failure patients.

Since the patient asked many questions during the first visit, the nurse at first tended to restrict her counseling to answering these questions. This creates the risk that certain important items are overlooked. Using an assessment form adapted to the SNCP ensured that a number of essential aspects were discussed. The nurse found out that the putient was unaware of the importance of regular weight checks. By providing him with clear information about the importance of such checks, but also by telling him what to do if he should gain weight, she was able to motivate him to check his weight regularly.

Another advantage was that various forms of intervention could be used. It was not enough to tell this patient about the medication he was reciving at the hospital. He was therefore given a medication schedule, allowing him to check the nature and purpose of each drug he was given.

Another observation was that just mentioning each type of intervention in the SNCP is not enough: the interventions must also be described in detail. In this way the nurse could use a suggested nursing manual to look up the information.

An additional aspect of this SNCP is its "transmural" nature, meaning that is used in both the hospital and at home. Some of the problems that the patient mentioned at the hospital could not be fully "solved" there or came up again after his return home. This particular patient said at the hospital that he was uncertain about fluid restriction. This aspect of his diet was therefore discussed during his hospital stay, but it was also checked again later, after his discharge, to see whether he understood everything. Sinc: the same SNCP was used both at the hospital and during the aftercare at home, "old" problems could be checked again. This revealed for instance that his sleeping problems had returned and had to be dealt with in the home situation.

The case history also illustrates the importance of follow-up options and the availability of an easily accessible contact person for these patients. After the patient's discharge, both he and his partner were faced with certain problems, which had not emerged at the hospital. Home visits and phone calls from the nurse allowed these problems and questions to be dealt with.

The case history also shows that it is very useful for the nurse to have easy access to the patient's medical file and to the doctors at the cardiology department. This meant that rapid steps could be taken to adapt the patient's medication without him having to return to the outpatient clinic or to the emergency heart center. 
At the same time, it turned out that certain of the patient's problems were beyond the nurse's expertise, for instance his sense of isolation. The SNCP failed to provide detailed interventions for this, since merely discussing the problem is not always enough. A possible intervention in this case could have been referring the patient to a contact in the village or trying to find some useful activity for him in the village without overstraining his physical abilities.

A SNCP needs not be as standardized as its name would seem to imply. In addition to at number of routine items of education and support, various "potential" problems and interventions can be included, which allow the SNCP to be expanded to deal with the individual problems of a patient and his/her partner. The implementation of each intervention requires a tailored approach for each individual patient. In the present case, the patient needed a list of the medication he was given at the hospital, which he could discuss with his wife at an early stage. Other patients may require completely different interventions to ensure they receive their medication correctly. These may involve the involvement of home help organizations to fill a medicine box or instructing a relative to prepare the patient's medication for him once a day.

The case study shows the usefulness of an SNCP that is systematically implemented by one and the same nurse both during the hospital stay and after discharge. In addition to routine education items, however, the plan must also make allowance for a patient's individual problems. The continuity of care provided by one and the same nurse both at the hospital and at the patient's home ensures that these problems are dealt with at the right time and place and give the patient easy access to someone who can answer his or her questions. The disadvantage of the present intervention project was that interventions ended within 7-10 days after discharge from the hospital. It was needed to show patients the way to existing services or to hand over the patient's care to the doctor responsible for his treatment, to the GP or to the district nurse. It could be desirable to extend the follow-up period and expand the specific interventions to include a number of psychosocial problems.

\subsection{Conclusion}

In this project, an SNCP was developed on the basis of literature data, existing SNCPs and interviews with nursing staff. A case history was used to illustrate the use of the SNCP. Although the authors are convinced of the importance of using such an SNCP, this is not enough to decide whether such a plan is actually effective. That is why an experimental study (RCT) was initiated to assess the effects of this intervention using a number of effect measures, such as quality of life and the number of readmissions. 


\subsection{References}

I. Gooding J, Jette AM. Hospital readmissions among the elderly. J Am Geriatr Soc 1985; 33: 595-60I.

2. Brasker J. Transmural nursing: from wish to reality [in Dutch]. Amsterdam: Academisch Ziekenhuis Vrije Universiteit, onderzoekscentrum $1^{\mathrm{e}}-2^{\mathrm{e}}$ lijn, 1992.

3. Eriksson $\mathrm{H}$. Heart failure: a growing public health problem. J Intern Med I995; 237: 135-141.

4. McMurray J, McDonagh T. Morrison CE, Dargie HJ. Trends in hospitalization for heart failure in Scotland 1980-I990. Eur Heart J I 993: I 4: I I 58 - I 62.

5. Reitsma JB, Mosterd A, de Craen AJM. Koster RW, van Capelle FJL. Grobbee DE, Thijssen JGP. Increase in hospital admission rates for heart failure in The Netherlands, I 980-1993. Heart 1996; 76: 388-392.

6. Graham H, Livesley B. Can readmissions to a geriatric medical unit be prevented? The Lancet 1983:2 I: 404-406.

7. Vinson JM, Rich MW, Sperry JC, Shah AS, McNamara T. Early readmission of elderly patients with congestive heart failure. J Am Geriatr Soc 1990; 38: I 290-1295.

8. Nikolaus T, Specht-Leible N, Kruse W, Oster P, Schlierf G. The early rehospitalization of elderly patients. Causes and prevention [in German]. Dtsch Med Wschr 1992; 1 I 7 : 403-407.

9. Konstam M, Dracup K, Baker D, al. e. Heart Failure: Evaluation and care of patients with left-ventricular systolic dystunction. Clinical practice guideline no I I. Rockville. MD: Agency for health care policy and research, public health service, U.S. Department of Health and human services, 1994. vol AHCPR Publication No. 94-06122.

Io. Dracup K, Baker DW, Dunbar SB, Dacey RA, Brooks NH, Johnson JC, Oken C. Massie BM. Management of heart failure. II. Counseling, education, and lifestyle modifications. JAMA 1994; 272: 1442-1446.

I I. Rich MW. Beckham V, Wittenberg C. Leven CL, Freedland KE, Carney RM. A multidisciplinary intervention to prevent the readmission of elderly patients with congestive heart failure. N Engl J Med I 995: 333: I I90-1 195.

12. Ashby BSH. Home teaching: Effect on compliance, hospital readmissions and days of rehospitalization for patients with chronic congestive heart failure [Doctoral thesis|. Richmond: Virginia Commonwealth University, 1988.

13. Weinberger M, Oddone EZ, Henderson WG. Does increased access to primary care reduce hospital readmissions? Veterans Affairs Cooperative Study Group on Primary Care and Hospital Readmission. N Engl J Med 1996; 334: 144 I1447.

14. Fonarow GC. Stevenson LW, Walden JA. Livingston NA, Steimle AE, Hamilton MA. Moriguchi J, Tillisch JH, Woo MA. Impact of a comprehensive heart failure management program on hospital readmission and functional status of patients with advanced heart failure. J Am Coll Cardiol 1997: 30: 725-7321.

I5. Hanumanthu S. Butler J. Chomsky D. Davis S. Wilson JR. Effect of a heart failure program on hospitalization frequency and exercise tolerance. Circulation 1997: 96: 2842-2848. 
16. West JA, Miller NH, Parker KM, Senneca D, Ghandour G, Clark M, Greenwald G, Heller GS. Fowler MB, DeBusk RF. A comprehensive management system for heart failure improves clinical outcomes and reduces medical resource utilizition. Am J ( ardiol r 997: 79: 58-63.

17. Stewart S, Pearson S. Horowitz JD. Effects of a home-based intervention among patients with congestive heart failure discharged from acute hospital care. Arch Intern Med I998; 158: 1067-1072.

18. Jaarsma T, Huijer Abu-Saad H, Halfens R, Dracup K. "Maintaining the balance"nursing carc of patients with chronic heart failure. Int J Nurs Stud 1997; 34: 213-22I.

19. Orem D. Nursing: Concepts of practice. (5 $5^{\text {th }}$ ed.) St. Louis: Mosby Year Book, 1995. 
Part III

Method and Results 


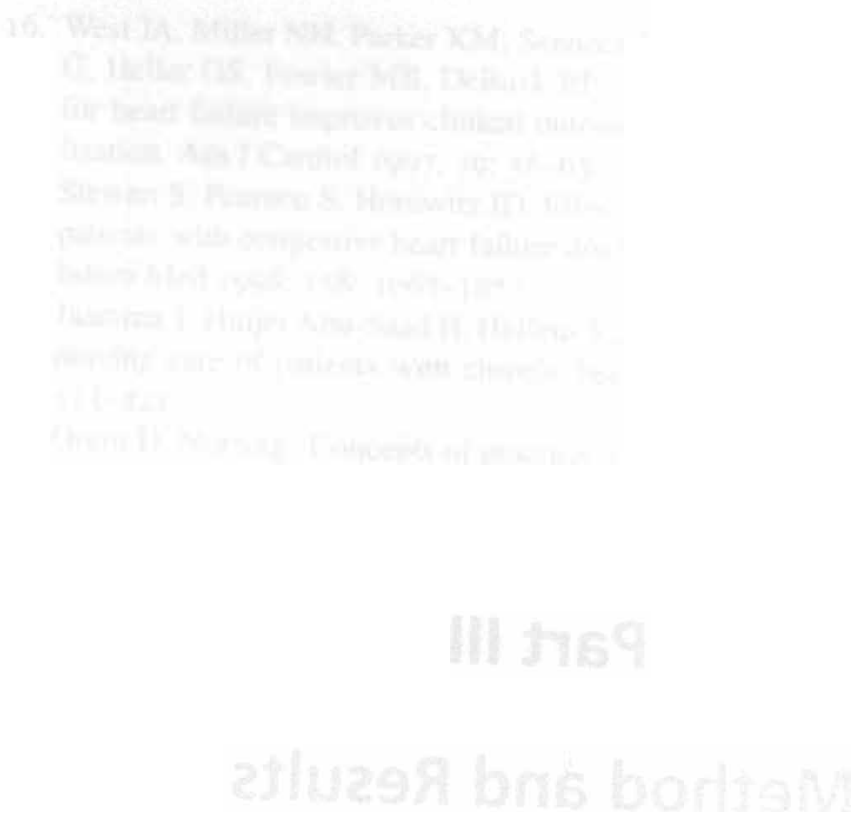




\title{
Chapter 6
}

\section{Method}

\begin{abstract}
A randomized controlled study was conducted to study the effects of a supportiveeducative nursing intervention on self-care (agency and behavior), resource utilization and quality of life.

Heart failure patients admitted to the cardiology ward (May 1994-March 1997) of the University Hospital in Maastricht (the Netherlands) were screened for potential eligibility to the study. Patients were randomly assigned to a control or intervention group. Patients in the intervention group $(n=84)$ received extra education and support from a nurse guided by a standard nursing care plan. The control group ( $n=95$ ) received care as usual. To evaluate the effect of the supportive-educative nursing intervention, data were collected at baseline (hospital admission), and I, 3 and 9 months after discharge. Data were collected on self-care agency, self-care behavior and use of resources (readmissions, contacts with health care providers). Three dimensions of quality of life were evaluated: functional capacity, symptoms and psychosocial adjustment to illness; and a global score of overall well-being was given by the patient. Atrrition due to mortality was $21 \%$ and due to other reasons $5 \%$.
\end{abstract}




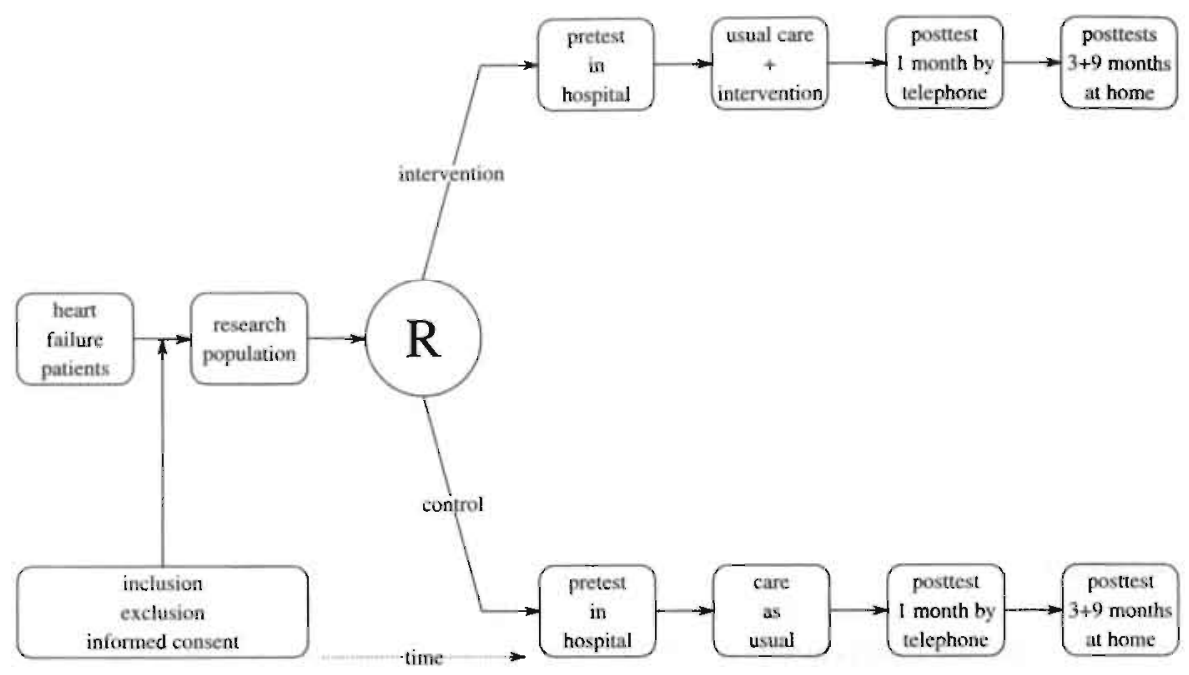

Figure 6.I: The design of the study

\subsection{Introduction}

Heart failure is described as a growing public health problem. ${ }^{1-4}$ Symptoms of heart failure and its treatment can have a considerable impact on the lives of patients and families $^{5-7}$ Consequently, it is important that patients with heart failure receive optimal care. Optimizing care for heart failure patients is increasingly the subject of discussions, where it is contented that interventions to improve outcomes should be targeted at improving self-care, reducing psychosocial problems and increasing daily activity levels ${ }^{5.8}$ In addition, attention should be paid to better assessments, adequate rehabilitation, discharge planning, and adequate follow-up. ${ }^{9-13}$ It is recognized that nurses can play an important role in improvement of care in heart failure patients. ${ }^{14-16}$ Positive effects are found in regard to compliance, readmission and quality of life. However, it is difficult to compare the different interventions and make a general statement on the effectiveness and general applicability. Interventions often consist of several components, for example education, intensive follow-up. or medication review. In addition. interventions differ in length and intensity, for example. only I home visit or 24 weeks follow-up. The role of the nurse also differs in each program. In some programs the role of the nurse is limited to drawing blood and injecting drugs while in other programs nurses have key roles in education and follow-up. It is often difficult to separate the contribution of nursing to most interventions. In addition, limited information is reported on the impact of these interventions on the quality of life of patients with heart failure. The aim of this study is to evaluate the effect of a supportive-educative intervention on self-care, resource utilization and quality of life. This chapter presents the research method of the study, describing the design and sampling method and the variables and instruments for data collection. This chapter ends with the description of the attrition that occurred in the study and statistical analysis performed. 
Table 6. I: Criteria for congestive heart failure (Boston score) $)^{17}$

\begin{tabular}{lc}
\hline Category & point value $^{a}$ \\
\hline I: history & \\
Rest dyspnea & 4 \\
Orthopnea & 4 \\
Paroxysmal nocturnal dyspnea & 3 \\
Dyspnea on walking on level & 2 \\
Dyspnea on climbing & I \\
II: physical examination & \\
Heart-rate abnormality & \\
$\quad$ if 9I-I Io beats/min & I \\
$\quad$ if $>$ I Io beats/min & 2 \\
Jugular venous pressure elevation & \\
$\quad$ plus hepatomegaly or edema & 3 \\
$\quad$ otherwise & 2 \\
Lung crackles & \\
$\quad$ if basilar & I \\
$\quad$ if more than basilar & 2 \\
Wheezing & 3 \\
Third heart sound & 3 \\
chest radiography & 3 \\
Alveolar pulmonary edema & 3 \\
Interstitial pulmonary edema & \\
Bilateral pleural effusions & \\
Cardiothoracic ratio >0.50 & \\
Upper-zone flow redistribution & 3 \\
\hline
\end{tabular}

"No more than 4 points are allowed in each of three categories; the composite score (the sum of the subtotal from each category) has a possible maximum of 12 points. The diagnosis of heart failure is classified as definite for a score of 8 to 12 points, possible for 5 to 7 points, and unlikely for 4 points or less.

\subsection{Research questions and design}

After developing a supportive-educative intervention for patients with heart failure (research question $\mathrm{I}$, see page 6 ). The following research questions need to be answered:

2. (a) What is the effect of education and support on self-care abilities and selfcare behavior of patients with heart failure?

(b) Do self-care abilities relate to self-care behavior?

(c) What are barriers for self-care behavior?

3. (a) Do self-care abilities and self-care behavior relate to resource utilization?

(b) What is the effect of education and support on resource utilization?

(c) Do self-care abilities and self-care behavior relate to quality of life? 
(d) What is the effect of education and support on quality of life?

4. (a) What are determinants of quality of life

(b) Does a change in quality of life relate to resource utilization, clinical characteristics and demographic variables?

Figure 6. I presents the study design. The design includes four moments of measurement: one at baseline during hospitalization, and three measurements after discharge. Data were collected by interview, chart review and use of the hospital computer database. The institutional review boards approved the study.

\subsection{Sampling and randomization}

Patients admitted with heart failure to the cardiology ward $\left(\mathrm{B}_{3}\right)$ of the University Hospital Malastricht were potentially eligible. To confirm a diagnosis of heart failure, the Boston scoring system was used (table 6.1). ${ }^{17}$ In this scoring system the various signs and symptoms documented in the history. physical examination and chest radiography are given a score. The score ranges from o to $\mathrm{I} 2$; a score of 8 and higher is designated as heart failure. Inclusion and exclusion criteria were:

\section{Inclusion criteria}

I. New York Heart Association (NYHA) functional class III and IV

2. diagnosed with heart failure longer than 3 months

3. older than 50 years of age

4. literate in Dutch

\section{Exclusion criteria}

1. suffering from a co-existing severe chronic debilitating disease (e.g. cancer) ${ }^{\mathrm{a}}$

2. discharged to a nursing home

3. psychiatric diagnosis or dementia

4. had a previous CABG, PTCA or valve replacement in the last 6 months

5. expected to have CABG, PTCA or valve replacement within 3 months

6. dopamine/lasix treatment in day care

\section{Procedure}

From May 1994 to March 1997 a researcher and a research assistant screened patients admitted to the cardiology unit for their potential eligibility to the study. The attending physician determined the Boston score and whether the patient met the selection criteria. The researcher/research assistant obtained informed consent and collected

\footnotetext{
an regard to co-morbidities is should be noted that only patients with severe, short-term life threatening co-morbidities were excluded. Other co-morbidities like diabetes or arthritis were not used as exclusion criterion.
} 
base-line data from the medical char and by interview. By drawing from an envelope, patients were randomly assigned to receive either care-as-usual or the supportiveeducative intervention. Patients from the control group and intervention group were never assigned to the same room on the nursing unit. All patients were followed for nine months. The researcher/research assistant telephoncd the patient I month after discharge, and visited the patient 3 months and 9 months after discharge for data collection.

\subsection{Intervention and control group}

The supportive educative intervention consisted of intensive. systematized and planned education by a study nurse about the consequences of heart lailure on daily life, using a standard nursing care plan developed by the researchers for older patients with heart failure (chapters 4 and 5). Important topics were discussed with every patient, for example, recognition of warning symptoms of worsening heart failure. sodium restriction, fluid balance, and compliance. In addition, individual problems of patients were discussed, for example problems in social interaction, sexual function or limited access to the general practitioner.

During hospital stay, the study nurse assessed the patient's needs, provided education and support to the patient (and family), gave the patient a card with warning symptoms, and discussed discharge. Within one week after discharge the study nurse telephoned the patient to assess potential problems and to make an appointment for a home visit. During the home visit the study nurse reinforced and continued education as warranted by the patient situation. Most patients received, on average, 4 visits in the hospital, I telephone call and I home visit. If needed, the honne care service was informed in writing about specific patient needs. Between discharge and home visit, patients could call the study nurse in case of problems. After the home visit, the patient was advised to call their cardiologist, general practitioner or emergency heart center in case of problems. The intervention lasted from hospital admission to io days after discharge from the hospital.

Patients assigned to the "care as usual" (control group) received all standard care. This meant that a nurse or physician, depending on their individual insight or the patient's questions, provided these patients with education about medication and lifestyle. Patients from the control group did not receive structured education, information about warning symptoms, a follow-up telephone call or home visits by a nurse. The two study nurses were involved in data collection as researcher and research assistant. However, the person who collected the data was never the same nurse who visited the patient for the intervention and vice versa.

\subsection{Outcome measures}

Major endpoints of the study were self-care (agency and behavior). resource utilization and quality of life. Table 6.2 presents the instruments used in the study. 
Table 6.2: Instruments used in the study ${ }^{a}$

\begin{tabular}{|c|c|c|}
\hline Instrument & & $\begin{array}{l}\text { Measured } \\
\text { at (months) }\end{array}$ \\
\hline \multicolumn{3}{|l|}{ Self-care } \\
\hline General self-care agency (ASA) & 24 items & 0.3 .9 \\
\hline HF self-care behavior scale (HFSCB) & I 9 items & $0,1,3,9$ \\
\hline Limitations of self-care behavior & verbatim & $0,3,9$ \\
\hline \multicolumn{3}{|l|}{ Resource Utilization } \\
\hline Readmission (number, days) & AZM & 1.3 .9 \\
\hline Visits EHC (number, frequency) & $A Z M$ & $1,3,9$ \\
\hline Visits medical specialists & $\mathrm{AZM}$ & 1.3 .9 \\
\hline Contacts with & Self-report & $1,3,9$ \\
\hline \multicolumn{3}{|l|}{ - general practitioner } \\
\hline \multicolumn{3}{|l|}{ - home nursing care } \\
\hline \multicolumn{3}{|l|}{ - home help } \\
\hline \multicolumn{3}{|l|}{ - physiotherapist } \\
\hline \multicolumn{3}{|l|}{-social work } \\
\hline - arrangements for meals & & \\
\hline - alternative healer & & \\
\hline
\end{tabular}

\section{Quality of life}

Functional capabilities:

$-\mathrm{HF}$ functional status inventory (MET)

-6-minute walk

Symptoms

- number of symptoms

- symptom distress

-symptom severity

Psychosocial adjustment to illness (PAIS)

- total

- health care orientation

- vocational environment

- domestic environment

- sexual relationships

- extended family relationships

13 items

0.3 .9

meters

0

$0 \ldots 7.83$

mers

6 items

$0, \mathrm{I}, 3,9$

$0 \ldots$

VAS

0.3 .9

o...6

VAS

$0,3,9$

0... IO

46 items

0.3 .9

$0 . . .10$

- social environment

8 items

o...1 38

6 items

$0 \ldots 24$

8 items

0.... 8

6 items

0...24

5 items

O... 18

6 items

o... 15

- psychological distress

7 items

o...I 8

o...2 I

Overall well-being

- Cantril's ladder of life

Ladder

$0,1,3.9$

$0 \ldots 10$

"AZM: registration University Hospital, EHC: emergency heart center, VAS: Visual Analogue Scale 


\section{Self-care variables}

\section{Self-care agency}

Concept: In Orem's general theory of nursing, self-care is described as "the practice of activities that individuals initiate and perform on their own behalf in maintaining life, healthy functioning, personal development and well-being." 8 To perform self-care, a person needs an adequate self-care agency (also referred to as self-care abilities). Selfcare agency is the power of an individual to engage in the operations essential for selfcare. $^{18}$ Based on Orem's work, the Appraisal of Self-care Agency (ASA) Scale was developed. revised, and tested by Brouns, et al. ${ }^{19.20}$ This scale assesses the patient's ability to care for him/herself.

Format: The ASA scale is a 24 -item self-appraisal instrument. Scores range from 24 to 124 , in which 24 represents minimal and 120 maximal abilities for self-care. An example of an item included in the scale is: "I often lack the energy to care for myself in the way that I know I should".

Reliability and validity: The ASA scale has been used in Dutch cardiac populations and is considered a reliable, internally consistent and valid instrument. ${ }^{19,20}$ In this study Cronbach's alpha's of the ASA scale was computed for 3 measurement moment:

Time of enrollment:

$\alpha=0.80(n=169)$

3 months after discharge $\alpha=0.85(n=137)$

9 months after discharge $\alpha=0.87(n=121)$

\section{Self-care behavior}

Concept: The term self-care behavior in this study refers to Orem's concept of selfcare. ${ }^{18}$ Self-care is defined as "the practice of activities that individuals initiate and perform on their own behalf in maintaining life, healthy functioning, personal development and well being". The purposes for self-care are universal (needed by every person), health-deviated (arise from health problems) and developmental (arise from a specific stage of life). ${ }^{8}$ This study focused on self-care behavior related to heart failure, operationalized as the number of healthy behaviors, that patients need to perform in daily life. To measure the behavior related to heart failure, the Heart Failure Self-care Behavior Scale was developed (table 6.3).

Format: The Heart Failure Self-care Behavior Scale is a I9-item questionnaire, with each item listing a specific activity related to heart failure. For example "I weigh myself twice a week" or "I restrict my sodium intake". For each item the patient is asked to respond by yes or no. A total score is calculated by adding all positive answers.

Reliability and validity: Items of the scale were derived from literature describing behav ior of heart failure patients required for optimal functioning and treatment compliance. A panel of experts established content validity. At first an additional item on visits to the outpatient department was included in the scale: however, this item did not 
Table 6.3: The Heart Failure Self Care Behavior Scale (Jaarsma, 1994)

I I weigh myself every day/once a week

2 In case of dyspnea/shortness of breath I take rest

3 When I am unable to do something because of dyspnea or fatigue, I ask for help

4 In case of increasing dyspnea/shortness of breath. I alert my doctor or somebody else

5 When my feet/legs swell. I alert my doctor

6 I call a doctor in case of 2 kilos weight gain in a week

7 I restrict my fluid intake

8 I take notice how much I urinate per day

9 When I feel anxious or insecure, I try to share this with someone else

Io When I experience increasing nausea, I alert my doctor

1. I restrict my activities

12 I plan my activities throughout the day

13 I rest during the day

I4 When I experience increasing fatigue, I alert my doctor

I 5 I comply with a low salt (low sodium) diet

I6 I take my medication as prescribed

17 I avoid people that have a cold/the flu

I8 I try to get some exercise on a regular basis

I9 I elevate my legs (e.g. on a chair) when I sit down

discriminate (all patients always visited the outpatients clinic) and was deleted from the sciale.

Conceptually, three dimensions can be distinguished in the Heart Failure Self-care Behavior Scale. The first dimension ("complying with regimen") covers 8 items related to daily weighing. fluid and sodium restriction, medication, elevating legs, measuring diuresis, preventing the flu and exercising. The second dimension ("asking for help") covers 7 items related to seeking help in case of weight gain, dyspnea, nausea, edema. fatigue and anxiety. The third dimension ("adapting activities") contains 4 items related to adapting one's activities to the condition, for example, taking enough rest or spreading activities throughout the day.

Factor analysis was conducted using a principal components extraction with varimax rotation to confirm the dimensions. The theoretically assumed dimensions were only partially confirmed. Several items loaded on more than one factor and the reliability of the subscales is low $(0.67,0.57,0.46)$ (table 6.4$)$. Therefore the subscales were not used for analysis, but the entire questionnaire was used. The Cronbach's alphas of the total heart failure self-care behavior scale have been computed for every measurement moment: 
Table 6.4: Factor loadings of Heart Failure Self-Care Behavior Scale ${ }^{a}$

\begin{tabular}{|c|c|c|c|c|}
\hline Theoretical Concepts with items & Factor $\mathrm{I}$ & Factor 2 & Factor 3 & $\bar{\alpha}$ \\
\hline \multicolumn{5}{|l|}{ Adapt activities } \\
\hline Divide activities & 0.76 & -0.16 & 0.19 & \\
\hline Restrict activities & 0.80 & -0.02 & 0.08 & \\
\hline Rest in case of dyspnea & 0.41 & -0.15 & 0.18 & \\
\hline Rest during the day & 0.66 & -0.15 & 0.18 & 0.67 \\
\hline \multicolumn{5}{|l|}{ Ask assistance } \\
\hline Warn doctor in case of nausea & 0.07 & 0.31 & 0.21 & \\
\hline Wam doctor in case of fatigue & 0.16 & 0.47 & 0.26 & \\
\hline Warn doctor in case of weight gain & 0.09 & 0.24 & 0.63 & \\
\hline Ask assistance in case of dyspnea & 0.22 & 0.65 & $-0.2 \mathrm{I}$ & \\
\hline Warn doctor in case of leg edema & 0.05 & $0.4 \mathrm{I}$ & 0.34 & \\
\hline Warn doctor in case of dyspnea & 0.03 & 0.79 & 0.00 & \\
\hline Share emotional distress & -0.10 & 0.48 & -0.01 & 0.57 \\
\hline \multicolumn{5}{|l|}{ Comply with regimen } \\
\hline Elevate legs & 0.37 & 0.23 & 0.13 & \\
\hline Sodium restriction & $-0.0 \mathrm{I}$ & -0.10 & 0.55 & \\
\hline Restrict fluids & 0.02 & 0.08 & 0.57 & \\
\hline Weighing & 0.08 & $0.1 \mathrm{I}$ & 0.60 & \\
\hline Medication & 0.18 & 0.04 & 0.29 & \\
\hline Notice diuresis & $-0.2 \mathrm{I}$ & $0.3 \mathrm{I}$ & $0.2 \mathrm{I}$ & \\
\hline Preventing the flu & 0.48 & 0.13 & 0.13 & \\
\hline Taking exercise & -0.49 & -0.10 & 0.15 & 0.46 \\
\hline Eigenvalue & 3.0 & 2.1 & 1.7 & \\
\hline Variance explained & 15.9 & II.O & 8.8 & \\
\hline
\end{tabular}

"Bold indicates item that fits conceptually and statistically. Cronbach's alpha is calculated for these items.

Time of enrollment: $\quad n=0.63(n=179)$

I month after discharge $\quad(x=0.68(n=167)$

3 months after discharge $\quad \alpha=0.68(n=147)$

9 months after discharge $\alpha=0.62(n=132)$

Because of the importance of the content of the items for heart failure patients, and in spite of a relatively low alpha, it was decided to use the 19 -item scale as an unidimensional scale in the further analysis. 


\section{Limitations for self-care}

Concept: To assess limitations to behavior, patients were asked about barriers for their behavior. Barriers were identified and categorized. In Orem's self-care deficit theory of nursing three sets of limitations for self-care are described: limitation of knowing, limitation of judgment and decision-making, and limitation of restriction on result-achieving courses of action. ${ }^{18}$ These three sets of limitations can be used to categorize the barriers patients experience in heart failure self-care behavior. Since these sets are described very broadly, they were reformulated and defined for use in the current study into knowledge, decision and skills.

Format: If a patient answered "no" on an item of the Heart failure self-care behavior scale, he/she was asked: why not: Answers were written down and categorized by two research nurses into the categories: knowledge, decision and skills.

Reliability and validity: Answers from the first 40 patients were independently rated by two research nurses and a Cohen's kappa to establish interrater agreement was calculated (between 0.56 and 1 ) . ${ }^{21}$ Differences were discussed until mutual agreement existed. Answers of these first 40 patients were used to categorize the answers of the following patients. The two nurse researchers independently categorized the answers and differences were discussed until agreement existed.

\section{Resource Utilization}

Concept: Resource utilization was operationalized as the number of contacts with various health care providers of a patient after discharge within a certain time period.

Format: A report form was developed to register the number of contacts with the general practitioner, home nursing care, home help, physiotherapist, social work, arrangement for meals, and alternative healers. During the follow-up interviews $(\mathrm{I}, 3$, and 9 months after discharge) patients reported on the contacts with these health care providers.

Additional information on readmission. visits to the emergency heart center and visits to the outpatient clinic (cardiologist or other medical specialists) were obtained from the hospital computer database. Reasons for readmission were collected from the medical chart of the patient.

Reliability and validity: To check the completeness of the report form. comparisons were made with resource utilization reported in a study in a general older population and no relevant differences existed. ${ }^{22}$

\section{Quality of life}

To evaluate quality of life a multi-dimensional approach was used. It is generally accepted that both objective and subjective dimensions must be included to adequately assess the impact of heart failure on the quality of life. ${ }^{23-26}$ Previous investigators have 
recommended using the three dimensions of functional capabilities, symptoms, and piychosocial perceptions. ${ }^{5.27}$ In this study a mix of subjective and objective instruments measured these three dimensions.

\section{Functional capabilities}

Concept: Functional capabilities (functional capacity) refers to the ability of patients to perform tasks in daily life. In this study functional capabilities were operationalized as the number of metabolic (MET) equivalents they could perform and the number of meters they could walk in 6 minutes.

Format: To measure functional capabilities two instruments were used: The Heart Failure Functional Status Inventory and the 6 -minute walking test. ${ }^{5.28}$ Since the posttest took place at the patient's home, the 6-minute walk could not be used as outcome measure.

The Heart Failure Functional Status Inventory is a self-report questionnaire in which 13 physical activities are listed and patients are asked if they can perform that activity. If patients cannot perform the activity, they are instructed to indicate by which symptom the physical activity is limited. Each activity was assigned a metabolic equivalent (MET) based on previous research. ${ }^{5.29}$ For example, if patients can bathe themselves. that activity is assigned 2 METs. A mean score of the three highest scored items is calculated. Functional capabilities were assessed at the time of enrollment, and at 3 and 9 months after discharge.

For the 6-minute walk patients were asked to walk as far as possible in 6 minutes in a hospital corridor. The distance covered was measured, as described by previous investigators..$^{50-33}$ The 6-minute walk was also used to give an indication of the functional capacity of the patients. Symptoms experienced by patients during the walk (e.g. angina. dyspnea) were recorded.

Reliability and validity: In a previous study content validity and interrater reliability of the Heart Failure Functional Status Inventory was considered as adequate. ${ }^{5}$ In this study no additional analyses on this scale were performed.

The 6-ninute walk is considered as a valid assessment and a useful alternative to treidmill exercise testing. ${ }^{31.32}$ Reliability of the 6-minute walk is discussed in literature. ${ }^{30}$ In this study standardized directions were given to the patient and the same hospital corridor was used each time to increase reliability of the test. No encouragement was given during the test. ${ }^{30}$

\section{Symptoms}

Concept: The severity of heart failure is often graded according to patient's reported symptoms. ${ }^{28}$ In this study symptoms were operationalized by the number of symptoms, symptom severity and symptom distress. Based on symptoms described in literature the following symptoms were assessed: ankle edema, sleep disturbance, loss of appetite, fatigue, dyspnea and cough. 
Format: A questionnaire on symptom occurrence, symptom severity and symptom distress was developed for this study. A total score of symptoms was calculated by summing the number of symptoms (min. (). max. 6). For each symptom experienced, patients were asked to rate symptom severity and distress on a ro-point scale. A mean severity and distress score was calculated as the average score on all symptoms experienced.

Reliability and validity: Symptoms were derived from literature and experts in the field of cardiology assessed content validity. Data were based on self-report and the self-determined score of patients was considered as valid. No predetermined endpoints were available, so reliability is difficult to established.

\section{Psychosocial Adjustment to Illness}

Concept: Psychosocial adjustment to illness is the quality of a patient's psychosocial adaptation to a current medical illness or its residual effects. ${ }^{34}$ Heart failure patients need to adapt different aspects of daily life as a consequence of symptoms or treatment, for example related to household activities, social functioning or family relationships. To measure this concept the Psychosocial Adjustment to Illness Scale (PAIS) was used. This scale measures the changes a person has experienced on seven psychological and social dimensions as a result of physical illness (health care orientation, vocational environment, domestic relationships, sexual relations, extended family relations, social and leisure activities and psychological distress). ${ }^{34}$

Format: The PAIS is a 46-item self-report questionnaire with questions on health care orientation, vocational environment, domestic relationships. sexual relations, extended family relations, social and leisure activities and psychological distress. All questions have 4 response statements scored from (no disturbance) to 3 (marked disturbance). The total score can range from $0-138$, with higher scores reflecting greater impairment.

To compare populations, some researchers use a standardized score. In this standardized score raw scores are converted to standardized area t scores; a score of 50 is the referenced norm, using a reference group of patients with ischemic heart disease. ${ }^{34}$. In our study we primarily report on the raw scores of the PAIS, since using a reference group of patients with ischemic heart disease does not seem appropriate when considering the different impact of heart failure on the psychological and social aspects of patients' lives. Using raw scores instead of the standardized scores enhances comparison with other researchers reporting on PAIS scores in heart failure patients that used the raw scores. However, when relevant for comparison, standardized scores were calculated.

Reliability and validity: The Fnglish version of PAIS has been tested on internal consistency, convergent, discriminative and predictive validity in various patient populations. ${ }^{34}$ The PAIS is used in cardiac populations and other chronic populations by various researchers. ${ }^{5 \cdot 34-40}$ 
Table 6.5: Demographic and clinical variables collected in the study

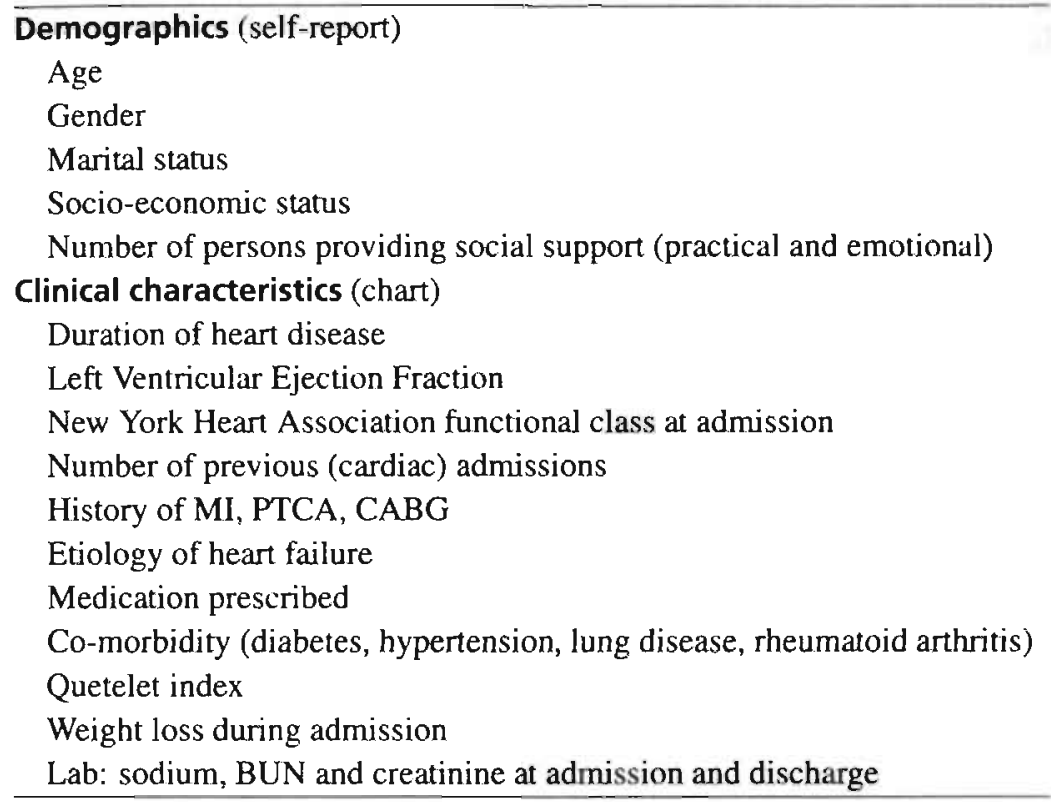

The PAIS was translated for this study to Dutch by a native speaker. After back translation into English the content of the scale was checked with a researcher that used the scale. A later published Dutch version of the PAIS did not differ noticeably from this translation. ${ }^{40}$ Validity and reliability of the Dutch version of the PAIS was tested by test-retest procedure, internal consistency and known-groups technique in a cardiac (bypass and heart failure) sample and was considered adequate. ${ }^{41}$ In this study reliability coefficients of the PAIS (total score) are:

Time of enrollment: $\quad \alpha=0.74(n=179)$

3 months after discharge $\alpha=0.78(n=141)$

9 months after discharge $\alpha=0.8$ I $(n=125)$

\section{Overall well-being}

Concept: Overall well-being is the patient's subjective and individual feeling of happiness or the overall quality of his/her life. To get a measure of overall well-being, Cantril's Ladder ("ladder of life") was used. ${ }^{42}$

Format: Patients were asked to rate their sense of well-being with 10 reflecting best possible life imaginable and o reflecting worst possible life imaginable (Fig 2).

Reliability and validity: The instrument had been used in previous studies in a cardiac population and is considered a valid measurement of "global well-being". 20.43 .44 


\section{Demographic and clinical variables}

Demographic and clinical data were collected to describe the sample and to determine predictors of quality of life (table 6.5).

Table 6.6: Exclusion and attrition during the study period

\begin{tabular}{lrr}
\hline Admitted to cardiology ward with $\overline{\mathrm{HF}}$ & 828 \\
readmissions & $-\mathrm{I} 84$ & \\
non-screened & -66 & \\
died during screening & -14 & \\
\cline { 2 - 2 } & -264 & \\
number of patients eligible & & 564
\end{tabular}

excluded according criteria:

history $<3$ months $\quad-$ I 7 I

Psychiatric diagnosis, dementia, cancer -3 I

NYHA <III. or cardiac intervention $\quad-22$

Boston score $<6 \quad-12$

Age $<50 \quad-12$

Discharged to nursing home $\quad-9$

Language $\quad-5$

More than one exclusion criterion $\quad-76$

Target population

226

No informed consent

$-40$

Baseline sample (randomized)

died before discharge

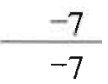

Discharged alive

died within I month

- I I

nonresponse within I month

$\frac{0}{-I I}$

I month

died between $1-3$ months

$-\mathrm{I} 4$

nonresponse between $\mathbf{I}-3$ months

$\frac{-4}{-18}$

3 month

died between 3-9 months

$-13$

nonresponse between 3-9 months

$\frac{-5}{-18}$

9 months 


\subsection{Power}

Major endpoints in the study were set at self-care, resource utilization and quality of life.

Since little information on possible effect size in self-care and resource utilization was known at the start of the study in a heart failure population, power was calculated for psychosocial adjustment to illness as measured by the PAIS. With data from a heart failure sample from the USA it was calculated that with a $f^{\prime}$ of 0.90 and an $\alpha$ of 0.005 a group of $2 \times 58$ patients would be sufficient to detect a change of 8 points on the PAIS.

\subsection{Population and attrition}

In table 6.6 an overview is provided of the basic population of heart failure patients. the target population and the number of patients that completed all three follow-up measurements.

As could be expected in patients with advanced heart failure, attrition during followup due to mortality was high $(n=38,21 \%)$. Table 6.7 shows the attrition from mortality and non-response in the two groups during follow-up.

Comparing the baseline characteristics of the patients that died after discharge or did not respond $(\mathrm{n}=47)$ to the patients that completed all three follow-up measurements $(n=132)$, it was found that patients that dropped out were significantly older, living more often in a home for the elderly, diagnosed with hypertension and had cardiomyopathy more often as the underlying reason for heart failure. Lab results showed higher levels of serum sodium, BUN and creatinine at baseline.

Since outcomes can be effected by selective attrition, it is important to study the attrition for both the control and the intervention group. Baseline demographics and clinical characteristics of the patients that did not complete all follow-up measurement did not differ between the control and intervention groups ( $n=21, n=26$ respectively).

Attrition and non-response is the reason for the different sample sizes in the following chapters:

- In chapter 7 , data on self-care behavior of the patients that completed all 4 measurements are reported. Since 4 patients did not complete all questionnaires, data of 128 patients are described.

- In chapter 8. data on resource utilization of all the patients that were discharged alive were reported $(n=179)$. However, since data on resource utilization were only available for those who were alive 9 months after follow-up, these data were reported for $n=132$.

- In chapter 9, baseline characteristics of the patients included in the study were analyzed $(n=186)$

- In chapter 10 , quality of life data of patients alive 9 months after follow-up $(n=132)$ were reported.

- In chapter I I, data of patients with complete data-sets $(n=74)$ were reported.

Demographic and clinical characteristics for these different cohorts are reported in the relevant chapters. 
Table 6.7: Attrition due to mortality and nonresponse in the intervention and control group

\begin{tabular}{|c|c|c|c|c|c|c|}
\hline \multirow[b]{3}{*}{$\begin{array}{c}\text { Months after } \\
\text { discharge }\end{array}$} & \multicolumn{6}{|c|}{ percent attrition } \\
\hline & \multicolumn{3}{|c|}{ Control $(n=95)$} & \multicolumn{3}{|c|}{ Intervention $(n=84)$} \\
\hline & death & $\begin{array}{l}\text { onres- } \\
\text { ponse }\end{array}$ & total & death & $\begin{array}{l}\text { onres- } \\
\text { ponse }\end{array}$ & total \\
\hline I & 4.2 & 0.0 & 4.2 & 8.3 & 0.0 & 8.3 \\
\hline $1-3$ & 9.5 & 2.I & I 1.6 & 6.0 & 2.4 & 8.3 \\
\hline $3-9$ & 3.2 & 3.2 & 6.3 & 11.9 & 2.4 & I 4.3 \\
\hline Total & I 6.8 & $5 \cdot 3$ & 22.I & 26.2 & 4.8 & 31.0 \\
\hline
\end{tabular}

\section{Compliance with group assignment}

No patients changed from the assigned group. However, two patients did not wish to receive a home visit from the intervention nurse. These patients remained in the intervention group (intention-to-treat). After completion of data collection (9 months after discharge) some patjents from the control group received additional patient education (if requested).

\subsection{Analysis}

Mean scores on outcome variables of patients from the intervention and control group (per protocol) were compared by using Student $t$-tests and Chi-square analysis, with correction for multiple testing. ${ }^{45}$ Since attrition was rather high and attrition seemed to be different in the control and intervention group, we also present an altemative analysis (chapter 10 ) in which we assumed that patients who dropped out did not improve their self-care agency. self-care behavior or quality of life since baseline (the null hypothesis).

To describe relationships Pearson's correlation coeflicients are reported, with correction for attenuation. In addition, regression analyses were performed to gain insight in relationships and predictors of quality of life. Significance level was set at $5 \%$.

In the following chapters the results of the study are presented.

\subsection{References}

I. Bonneux L, Barendregt JJ, Meeter K, Bonsel GJ, van der Maas PJ. Estimating clinical morbidity due to ischemic heart disease and congestive heart failure: the future rise of heart failure. Am J Public Health 1994; 84: 20-28.

2. Mosterd A. Epidemiology of heart failure [Doctoral thesis]. Rotterdam: Erasmus University of Rotterdam, 1997.

3. Hoes AW, Mosterd A, Grobbee DE. An epidemic of heart failure? Eur Heart J 1998; 19(suppl. L): 2-10. 
4. McMurray JJV. Petrie MC. Murdoch DR, Davie AP. Clinical epidemiology of heart failure: public and private health burden. Eur Heart J 1998; Ig(suppl. P): 9-16.

5. Dracup K. Walden JA, Stevenson LW, Brecht ML. Quality of life in patients with advanced heart failure. J Heart Lung Transplant I992; I I: 273-279.

6. Martinsson J, Karlsson JE, Fridlund B. Male patients with congestive heart failure and their conception of the life situation. J Adv Nurs 1997; 27: 579-586.

7. Martinsson J, Karlsson JE, Fridlund B. Female patients with congestive heart failure and how they conceive their life situation. J Adv Nurs 1998; 28: 1216I 224.

8. Hawthome MH, Hixon ME. Functional status, mood disturbance and quality of life in patients with heart failure. Progress Cardiovasc Nurs 1994; 9: 22-32.

9. Vinson JM, Rich MW, Sperry JC. Early readmission of elderly patients with congestive heart failure. J Am Geriatr Soc 1990; 38: I 290-I 295.

I0. Happ MB, Naylor MD, Roe-Prior P. Factors contributing to rehospitalization of elderly patients with heart failure. J Cardiovasc Nurs I 997; I I : 75-84.

I 1. Nikolaus T, Specht-Leible N, Krusse W, Oster P, Schlierf G. The early rehospitalization of elderly patients; causes and prevention [in German]. Disch Med Wschr 1992; Ir7: 403-407.

12. Graham H, Livesley B. Can readmissions to a geriatric medical unit be prevented? The Lancet 1983; 1 : 404-406.

13. Michalsen A, Konig G. Thimme W. Preventable causative factors leading to hospital admission with decompensated heart failure. Heart r 998; 80: 437-44I.

I4. Rich MW, Beckham V, Wittenberg C, Leven CL, Freedland KE, Carney RM. A multidisciplinary intervention to prevent the readmission of elderly patients with congestive heart failure. N Engl J Med I995; 333: I I90-I I95.

15. Stewart S, Pearson S, Horowitz JD. Effects of a home-based intervention among patients with congestive heart failure discharged from acute hospital care. Arch Intern Med I 998; I 58: I067-I 073.

I6. Cline CMJ, Israelsson BYA, Willenheimer RB, Broms K, Erhardt L.R. Cost effective management programme for heart failure reduces hospitalisation. Heart I 998; 80: 442-446.

17. Carkson KJ, Lee DC, Goroll AH, Leahy M. Johnson RA. An analysis of physicians' reasons for prescribing long term digitalis therapy in outpatients. J Chron Dis I $985 ; 38: 733-739$.

I8. Orem DE Nursing: Concepts of practice $\left(5^{\text {th }}\right.$ ed.) St. Louis: Mosby, 1995.

19. Evers GCM. Appraisal of self-care Agency: the ASA-scale [Doctoral thesis]. Maastricht: University of Maastricht, 1989.

20. Senten CMS. The well-being of patients having CAB surgery: a test of Orem's self-care nursing theory [Doctoral thesis]. Maastricht: University of Maastricht, I99I.

2I. Polit DF, Hungler BP. Nursing Research; principles and methods. Philadelphia: JB Lippincott Company, I 987.

22. Rossum van E. Effects of preventive home visits to the elderly [Doctoral thesis]. Maastricht: University of Maastricht, 1993. 
23. Levine S, Croog SH. What constitutes quality of life? In: Wenger NK, Mattson ME, Furberg CD, Elinson J. (eds.) Assessment of quality of life in clinical trials of cardiovascular therapies. New York: Le Jacq Publishing, I984: 46-56.

24. Aaronson NK. Quantitative issues in health related quality of life assessment. Health Policy 1988; 10: 21 7-230.

25. Hadorn D, Baker D, Dracup K, Pitt, B. Making judgments about treatment effectiveness based on health outcomes: theoretical and practical issues. J Qual Impr I 994: 20: 547-554.

26. McSweeny AJ, Creer TL. Health-related quality of life assessment in medical care. Disease-a-Month 1995 ; I: I-72.

27. Wenger NK. Mattson ME, Furberg CD, Elinson J. (eds.) Assessment of quality of life in clinical trials of cardiovascular therapies. New York: Le Jacq Publishing. 1984 .

28. Lipkin DP, Scriven AJ, Crake T, Poole-Wilson PA. Six minute walking test for assessing exercise capacity in chronic heart failure. BMJ I 986: 292: 053-655.

29. Fardy P, Yanowitz F, Wilson P. Cardiac rehabilitation of the coronary patient. Philadelphia: Lea \& Febiger, 1988.

30. Guyatt GH, Pugsley SO, Sullivan MJ, Thompson PJ, Berman LB, Jones NL, Fallens EL, Taylor DW. Effect of encouragement on walking test performance. Thorax 1984; 39: 818-822.

31. Guyatt GH, Thompson PJ, Berman LB, Sullivan MJ, Townsend M, Jones NL, Pugsley SO. How should we measure function in patients with chronic heart and lung disease. J Chron Dis 1985; 38: 5I7-524.

32. Bittner V, Weiner DH, Yusuf S, Rogers WJ, McIntyre KM, Bangdiwala S, Kronernberg MW, Kostis JB, Kohn RM, Guilotte M, Greenberg B, Woods PA, Bourassa MG. Prediction of mortality and morbidity with a 6-minute walk test in patients with left ventricular dysfunction. JAMA 1993: 270: 1702-1707.

33. Woo MA, Moser DK, Stevenson LW, Stevenson WG. Six-minute walking test and heart rate variability: lack of association in advanced stages of heart failure. Am J Crit Care 1997; 6: 348-354.

34. Derogatis L. Scoring and procedures manual for PAIS. Baltimore: Clinical Psychometric Research, 1976.

35. Raft D, McKee DC, Popio KA, Haggerty JJ. Life adaptation after PTCA and CABG. Am J Cardiol I985: 56: 395-398.

36. Kular JA. Dracup K. Psychosocial adjustment of patients with ventricular dysrythmias. J Cardiovasc Nurs 1990; 4: 44-55.

37. Muscr DK, Dracup K. Psychosocial recovery from a cardiac event: the influence of perceived control. Heart Lung I 995; 24: 273-280.

38. Dracup K. Moser, DK, Taylor SE. Guzy PM. The psychosocial consequences of cardiopulmonary resuscitation training for family members of patients at risk of sudden death. Am J Publ Health I 997; 87: 1434-1439.

39. Frost MH, Kelly AW. Mangan DB. Zarling KK. An analysis of factors influencing prychosocial adjustment to cardiomyopathy. J Cardiovase Nurs 1994; 30: I. 7 .

40. Beckers MJTM. Psychosocial adaptation after colonstoma: a controlled study [in Dutch][Doctoral thesis].Utrecht: University of Utrecht, I993. 
4I. Krook J. Reliability and validity of the Dutch version of the PAIS [in Dutch] [Masters thesis]. Maastricht: University of Maastricht, Health Sciences, 1996.

42. Cantril $H$. The pattern of human concerns. New Brunswick: Rutgers University Press, 1965.

43. Packa DR, Branyon ME, Kinney MR, Khan SH, Kelley R, Miers LJ. Quility of lifé of elderly patients enrolled in cardiac rehabilitation. J Cardiovasc Nurs 1989: 3: 33-42.

44. Jaarsma T, Kastermans MC. Recovery and quality of life one year after CABG. Scand J Caring Sci 1997; I1: 67-72.

45. Holm S. A simple sequentially rejective multiple test procedure. Scand J Stat I979; 6: 65-70. 
CHAPTER 6. METHOD 


\title{
Chapter 7
}

\section{Self-care behavior of patients with heart failure and its limitations}

\begin{abstract}
Heart failure related self-care behavior is important to optimize outcomes for patients with heart failure. This includes behaviors like adherence to medication, diet and exercise but it also refers to seeing assistance when symptoms occur or weighing daily. The study aim was to describe heart failure related self-care behavior, related limitations and the effect of education and support on this self-care behavior. Data were collected from 128 heart failure patients during hospital stay and I,3, and 9 months follow-up. Concepts from Orem's general theory of Nursing were used to describe the heart failure related self-care behavior, and its limitations. In addition, the effects of intensive systematized and planned education by a nurse in hospital and at home were evaluated. Results showed that the education and enhanced self-care behavior significantly at $\mathrm{I}$ and 3 months after discharge. Despite intensive education and support, several patients reported limited self-care behavior. Limitation in knowledge, judgment/decision-making skills were described by patients in both the intervention as in the control group. It can be concluded that a supportive-educative intervention is effective in enhancing heart failure related self-care behavior early after discharge. To optimize such an intervention more attention is needed for behavioral strategies (e.g. self-medication, self-efficacy), social support (e.g. from family members and from a heart failure team) and reinforcement (e.g. in a home visit).
\end{abstract}

Adapted from:

- Jaarsma T, Huijer Abu-Saad H, Dracup K, Halfens R. Self-care behavior of patients with heart failure and its limitations. Scand J Caring Sciences (accepted for publication) 


\subsection{Introduction}

Adherence to treatment is vital to the welfare of heart failure patients. ${ }^{1-3}$ Lack of adherence to medication and dietary sodium restriction are frequently documented as contributing factors to hospital admission in this patient population. ${ }^{4-6}$ In addition, identifying heart failure symptoms and reporting them promptly, fluid status and maintaining an exercise program are important aspects of a patient self-management program. ${ }^{7-9}$

Research on the specific behavior of patients with heart failure is scarce and insight into the underlying reasons limiting self-care behavior is needed. Although much can be learned from research on behavior in other chronic populations, specific information on heart failure patients and their self-care behavior is vital to tailor interventions to this population. The purpose of this study was twofold: 1) to describe self-care behavior and related limitations of patients with heart failure and 2) to describe the effect of education and support on patients' self-care behavior.

\subsection{Background and literature}

Several behaviors can positively contribute to the health and well being of patients with heart failure. ${ }^{8}$ These behaviors can be referred to collectively as "heart failure related self-care behavior" (HF-SC behavior). HF-SC behavior reflects the behavior that a patient undertakes to care for himself to promote health and well being. This definition includes behaviors like adherence to medication, diet and exercise, but it also refers to behaviors such as seeking assistance when symptoms occur or weighing daily. HF-SC behavior was described in the guidelines of the Agency for Health Care Policy and Research which include recommendarions for patients with heart failure on diet (including fluid, sodium and alcohol restriction). medications, and activity. ${ }^{8}$ Additional publications appeared on the behavior of these patients for whom the importance of recognition of symptoms and seeking assistance was supported. ${ }^{10.11}$ Limited information is available, however, on how patients with heart failure really conduct self-care behavior. Most authors have reported patients' compliance with prescribed drugs or dietary instruction as poor. ${ }^{2.4 .7}$ For example, a large proportion of patients who began digoxin substituted this for other medications or consumed substantially less medication than expected in the first year of therapy. ${ }^{2}$ Descriptive research of 41 patients with heart failure fiund that less than half of the patients could correctly identify their medications and almost three-quarters of patients did not weigh themselves daily. ${ }^{2}$ Another descriptive study on the weighing behavior of heart failure patients showed that of patients $(n=30)$ who were instructed to weigh themselves every day and were given a chart to record their weights, only $40 \%$ actually did so. Reasons why patients did not weigh themselves included not having a scale, forgetfulness, and not remembering being told. ${ }^{13}$ 


\subsection{Theoretical framework}

In Orem's self-care deficit theory of nursing three sets of limitations for self-care are described: limitation of knowing, limitation of judgment and decision-making, and limitation of restriction on result-achieving courses of action. ${ }^{14}$ These three sets of limitations can be used to categorize the barriers patients experience in heart failure-related self-care behavior. Since these sets are described very broadly they were reformulated and defined for use in the current study.

Knowledge: a limitation of knowing about one's own functioning, about needed selfcare and about activities. In this study we categorized answers, cited by the patient, that were related to limitation of knowledge cited by the patient (e.g. nobody ever told me that I should weigh myseli) or misunderstanding (e.g. I am supposed to drink a lot of water because I take diuretics).

Decision: a limitation in making judgments and decisions about what one should do to take care of oneself, including the inability to imagine alternative action, avoiding decision-making or having overriding interests or concerns. In this study, answers related to the decision of patients to perform inappropriate selfcare behavior (the patient knows what to do but decides to act differently) were categorized as decision.

Skill or opportunity: a limitation in engaging in result-achieving courses of action, derived from a lack of support, resources or energy. In this study we used this category to describe patients' answers reflecting a lack of resources (e.g. cannot use a normal scale because of blindness), skills (e.g. cannot take a pulse rate), opportunities (e.g. had no rehabilitation program), or support (nobody to help them with activities).

These limitations can restrict self-care behavior. Improving patients $\mathrm{HF}-\mathrm{SC}$ behavior can lead to improved outcomes. In previous research an intervention consisting of comprehensive patient education, medication review and intensive post-discharge follow-up improved medication compliance during the first 30 days following hospital discharge in elderly patients with heart failure. ${ }^{5}$ In our study a supportive-educative program was developed to enhance the abilities for self-care behavior of heart failure patients. ${ }^{16}$ In this program patients with heart failure and their families were provided with teaching, support, and guidance regarding different aspects of heart failure and treatment. An assessment about limitations of knowledge, judgment and decisionmaking and resources was made and interventions were planned accordingly. It was hypothesized that this nursing intervention would enhance heart failure related selfcare behavior and reduce the limitations.

The following rescarch questions were formulated:

I. Which types of heart failure related self-care behavior do patients with heart failure have?

2. Which limitations in for self-care behavior do heart failure patients cite?

3. What is the effect of education and support on self-care behavior and limitations of self-care? 


\subsection{Method}

\section{Subjects}

Two hundred and twenty-six patients who were admitted to the University Hospital of Maastricht for heart failure were asked to participate in the study. The patients had had symptoms of chronic heart failure for 3 months or longer, had been classified by the attending physician as New York Heart Association Class III or IV, were over 50 years of age and were literate in Dutch. Patients were excluded from the study if they suffered from a co-existing severe chronic debilitating disease; if they were discharged to a nursing home, if they had a psychiatric diagnosis, if they had had a previous bypass, angioplasty, or valve replacement in the last 6 months or were expected to have such a treatment within 3 months, or if they refused to give informed consent. The institutional review boards approved the study. Of the 226 patients. 40 ( $18 \%$ ) patients did not want to participate in the study, claiming fatigue or not feeling well enough. Age and gender of these 40 patients did not differ from the patients that participated in the study. Of the remaining I 86 patients, $45(24 \%)$ patients died during follow-up and 13 paticnts $(7, i)$ did not complete all follow-up questionnaires, with no significant differences between the two groups. In total 128 patients completed the Heart Failure Self-care Behavior Scale at baseline, I, 3 and 9 months after discharge.

\section{Procedure}

From May 1994 to March 1997 a researcher and a research assistant screened patients admitted to the cardiology unit for their potential eligibility for the study. The attending physician determined whether the patient met the inclusion criteria. The researcher/research assistant obtained informed consent and collected base-line data from the medical chart and by interview. Patients were randomly assigned, by drawing lots from an envelope, to receive either care-as-usual or a supportive-educative intervention.

All patients were followed for nine months. The researcher/research assistant telephoned the patient I month after discharge. and visited the patient 3 months and 9 months after discharge for data collection on heart failure self-care behavior. Data on motives and limitations were not collected during the telephone interview, but only at baseline, 3 and 9 months after discharge.

\section{Intervention and control group}

The supportive-educative intervention consisted of intensive, systematized and planned education by a study nurse about the consequences of heart failure in daily life, using a standard nursing care plan developed by the researchers for older patients with heart failure. ${ }^{16}$ Table 7.1 lists the major characteristics of the intervention. Patients assigned to the "care-as usual" (control group) received all standard care. This meant that this group was not provided with structured patient education, a follow-up telephone call or a home visit by a nurse. Patients from the control and intervention group were never assigned to the same room on the nursing unit. The two study nurses involved 
Table 7.I: Aspects of the supportive-educative intervention

\begin{tabular}{|c|c|}
\hline Where & in hospital and at home \\
\hline \multirow[t]{3}{*}{ How } & visits during admission $( \pm 4 x)$ \\
\hline & telephone call within 3 days of discharge (Ix) \\
\hline & home visit within Io days of discharge (IX) \\
\hline \multirow[t]{10}{*}{ Topics } & warning symptoms of worsening heart failure \\
\hline & sodium restriction \\
\hline & fluid balance \\
\hline & daily weights \\
\hline & medication compliance \\
\hline & rest and activity \\
\hline & accessing health care providers \\
\hline & support for psychosocial problems \\
\hline & setting priorities in regard to regimen \\
\hline & help in practical problems (e.g. how to arrange transportation) \\
\hline \multirow[t]{5}{*}{ Materials } & standard nursing care plan \\
\hline & list of "signs and symptoms of worsening heart failure" \\
\hline & medication schedule \\
\hline & pamphlet on diet (Netherlands Heart Foundation) \\
\hline & booklet on fluid restriction (University Hospital Maastricht) \\
\hline
\end{tabular}

in data collection were the researcher and research assistant. However, the person who collected the data was never the same nurse who visited the patient for the intervention.

\section{Instrument}

Data were collected using the Heart Failure Self-care Behavior Scale, which was developed for this study. This is a 19 -item questionnaire, with each iterm listing a specific activity related to heart failure. For example, "In case of dyspnea, I call a doctor" or "I restrict my sodium intake". For each item the patients is asked to respond by yes or no. A total self-care behavior score is calculated by summing all positive answers (range 0-19).

Conceptually, three dimensions can be distinguished. The first dimension ("complying with regimen") covers 8 items related to daily weighing, fluid and sodium restriction, medication, elevating legs, measuring diuresis, preventing the flu and exercising. The second dimension ("asking for help") covers 7 items related to seeking help in case of weight gain, dyspnea, nausea, edema, fatigue and anxiety. The third dimension ("adapting activities") contains 4 items related to adapting one's activities to the condition, for example, taking enough rest or spreading activities throughout the day.

Factor analysis was conducted using a principal components extraction with varimax rotation to confirm the dimensions. The theoretically assumed dimensions were 
only partially confirmed. Several items load on more than one factor and reliability of the subscales is low $(0.67,0.57,0.46)$. Therefor the subscales were not used for analysis, but the entire questionnaire was used (alpha 0.68). Based on the importance of the content of the items for heart failure patients and in spite of a relatively low alpha, it was decided to use the 19 -item scale as an uni-dimensional scale in the further analysis.

To assess limitations of patients' behavior, patients were asked about barriers. So if a patient answered "no" on an item of the HF-SC behavior scale, he was asked: why not? Answers were written down and categorized by two research nurses. Interrater agreement between 0.56 and $I$ was found. Differences were discussed until mutual agreement existed.

\section{Data Analysis}

Descriptive statistics were used to describe limitations. Differences between the intervention and control group were evaluated with Student t-tests. Correction for multiple testing was made. ${ }^{17}$

\subsection{Results}

\section{Study patients}

The mean age of the 128 patients was $72( \pm 9)$ years (table 7.2$)$. Sixty percent of the patients were male and most of them lived independently. Slightly more than half of the patients lived with a spouse and they received practical support from on average 3.4 persons. Most patients were NYHA class IV, with an average length of heart disease of 9 years $( \pm 7)$ and a left ventricular ejection fraction of $35 \%( \pm 14)$. Most patients suffered from one or more co-morbidities, with diabetes occurring in $3 \mathrm{I} \%$ of the patients. No differences between the patients in the control and intervention group were found regarding baseline demographic and clinical characteristics.

\section{Missing values}

During the study several patients cited that they found the interview intensive and tiring for them. Some became irritated when they had to cite what the reason for their behavior was. Priority was given to the collection of data on self-care behavior and then to limitations of patients' behavior. Therefore missing values exist in limitations for behavior. Limitations were only assessed if patients answered negatively on an item (= not performing that behavior). At baseline, 1264 limitations related to 19 behaviors were identified for the 128 patients. Of the 1264.421 limitations $(=33 \%)$ were not described. The limitations in regard to reporting nausea was most often not reported, since patients often replied they had never been nauseous. At three months the percentage of missing limitations was $49 \%$ and $4 \mathrm{I} \%$ for the control and experimental groups respectively. At 9 months this was $46 \%$ for both groups. 
Table 7.2: Demographic and clinical characteristics of the sample ( $n=128$ )

\begin{tabular}{lcc}
\hline & $\mathrm{n}(\%)$ & mean $\pm \mathrm{sd}$ \\
\hline Demographics & & \\
Age & & $72 \pm 9$ \\
Persons providing: & & $1.2 \pm 2$ \\
$\quad$ Emotional support & & $3.4 \pm 2.6$ \\
$\quad$ Practical support & $77(60 \%)$ & \\
Male gender & $71(56 \%)$ & \\
Married & $9(7 \%)$ & \\
Dependent living & & \\
Clinical characteristics & & $9 \pm 7$ \\
Length of heart disease (years) & $35 \pm 14$ \\
Left Ventricular Ejection Fraction $(\%)$ & & $3.2 \pm 2.6$ \\
Number of previous adnissions & & \\
Co-morbidities & & \\
$\quad$ Diabetes mellitus & $40(31 \%)$ & \\
$\quad$ Lung disease & $32(25 \%)$ & \\
$\quad$ Cerebral disease & $22(17 \%)$ & \\
$\quad$ Rheumatoid arthritis & $7(6 \%)$ & \\
Sodium (meq/l) & & $139 \pm 3.2$ \\
BUN (mg/dl) & & $12 \pm 6$ \\
Creatinine ( $\iota$ mol/ $/$ ) & & $132 \pm 53$ \\
NYHA III & & \\
NYHA III-IV & $22(17 \%)$ & \\
NYHA IV & $28(22 \%)$ & \\
\hline
\end{tabular}

\section{Heart failure related self-care behavior and its limitations at base- line}

At baseline, patients in both groups complied on average with 9 of the 19 items of selfcare behavior (table 7.3). The number of patients that answered negatively on each item and the limitations are summarized in table 7.4. As restriction for their behavior patients mentioned all three kinds of limitations, however, in different proportions per item. As table 7.4 shows, warning a doctor in case of nausea $(87 \%)$, fatigue $(82 \%)$ or weight gain $(77 \%)$ were often answered negatively. A limitation in decision-making or knowledge was cited most frequently. Several paticnts reported they did not recognize nausea $(n=19)$ or fatigue $(n=20)$ as symptoms that could be important to tell a doctor. Patients mentioned that they thought it had nothing to do with their heart disease or that it was something everybody probably had once in a while and would go away in due time. Not wanting to bother the doctor was given as major reason. Several patients mentioned that they did not believe their doctor would take them seriously with complaints like nausea or fatigue. Leg edema and dyspnea were more often reasons to 
Table 7.3: Self-care behaviour as measured by the Heart Failure Self-care Behavior Scale (range o-19)

\begin{tabular}{|c|c|c|c|c|}
\hline & $\begin{array}{r}\text { Control } \\
n=73 \\
\text { mean } \pm \text { sad }\end{array}$ & $\begin{array}{r}\text { Intervention } \\
\mathrm{n}=55 \\
\text { mean } \pm \mathrm{sd}\end{array}$ & $t$ & $\mathrm{p}$ \\
\hline Baseline & $9.4 \pm 3.1$ & $8.7 \pm 3.1$ & 1.2 & $0.2 \mathrm{I}$ \\
\hline I month & $12.2 \pm 2.9$ & $14.2 \pm 2.9$ & 3.8 & $<0.001$ \\
\hline 3 months & $10.6 \pm 3.2$ & $12.2 \pm 3.1$ & 2.9 & 0.005 \\
\hline 9 months & $10.3 \pm 2.8$ & II. $2 \pm 3.1$ & I.6 & $0.1 \mathrm{I}$ \\
\hline
\end{tabular}

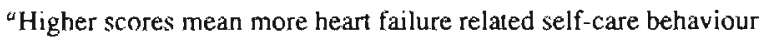

call a doctor, but in those cases where patients did not call, they also most often cited a limitation in decision as the reason. Some reported that they did not want to upset others or they believed nobody could help them in case of edema or dyspnea.

Items regarding fluid balance (i.e. diuresis and fluid restriction) and diet were often answered negatively for reasons of a limitation in knowledge. Several patients mentioned that they thought they needed a lot of fluids because they used diuretics or because they read in a magazine that the elderly need 2-3 liters of fluids a day. A significant minority of 39 reported that they never were told they were on a special diet or to note daily diuresis $(n=45)$. Less than $25 \%$ of patients did not adapt their activities (restrict and divide) or rest in time.

Reasons for not resting and not adapting the activities were related to the decision of patients. Some patients reported not wanting to depend on others or being too busy to restrict their ativities. Some patients said they preferred doing all the work in the morning so they could sit down the rest of the day. They did not want to divide it throughout the day. Only a few patients mentioned reasons for not adapting activities that could be classified as limitations in knowledge. Some patients did not know rest or adapting activities could benefit their condition. Some patients also mentioned they were not free to adapt their activities or to rest, for example, they had a job or were not put to bed by their caregivers.

Reasons for not weighing on a regular basis were most often related to patients' decision-making. Patients did not find it useful, did not know what to do with the information or considered it a vanity to weigh them daily. Eleven reported not being able to weigh themselves as a result of restricted eyesight, not having a scale or not being able to stand on the scale independently.

Most patients did not exercise on a regular basis because they did not have the possibility or skills. They reported not being able to do anything, not having enough energy or having problems due to edema or handicaps.

The item most patients answered positively was taking medication. Only eight patients decided not to take the medication as prescribed and 2 patients cited not knowing that they had to take the medication as prescribed. Self-care behavior and related limitations did not differ significantly at baseline between the two groups. 
Table 7.4: Number of patients (\%) not performing heart failure related self-care behavior patients at baseline, reported per item and their reason (limitation) why they did not perform this behaviour $(n=128)^{a}$

\begin{tabular}{|c|c|c|c|c|c|c|}
\hline & \multicolumn{4}{|c|}{ knowl- } & \multicolumn{2}{|r|}{ not } \\
\hline & $\mathbf{n}$ & $\%$ & edge & decision & skill & known \\
\hline Warn GP in case of nausea & I I I & 87 & 19 & 32 & - & 60 \\
\hline Warn GP in case of fatigue & 105 & 82 & 20 & 32 & 9 & 44 \\
\hline Notice diuresis & 100 & 78 & 45 & 3 & 6 & 46 \\
\hline Warn doctor about weight gain & 99 & 77 & $2 \mathrm{I}$ & 29 & 3 & 46 \\
\hline Restrict fluids & 99 & 77 & 60 & 19 & 4 & 16 \\
\hline Share emotional distress & $9 \mathrm{I}$ & 71 & I 2 & 42 & 13 & 24 \\
\hline Preventing the flu & 76 & 59 & 15 & 33 & 3 & 25 \\
\hline Ask assistance in case of dyspnea & 76 & 59 & 4 & 36 & I5 & 21 \\
\hline Warn doctor in case of leg edema & 75 & 58 & 8 & 31 & ro & 26 \\
\hline Warn doctor in case of dyspnea & 70 & 55 & 5 & 33 & 5 & 27 \\
\hline Elevate legs & 66 & 52 & I I & 31 & 6 & I 8 \\
\hline Sodium restriction & 64 & 50 & 39 & 13 & - & 12 \\
\hline Exercise & 59 & 46 & I & 6 & 37 & 15 \\
\hline Weigh daily & 55 & 43 & 18 & 25 & I I & 1 \\
\hline Divide activities & 30 & 23 & - & 13 & 4 & 13 \\
\hline Restrict activities & 27 & $2 \mathrm{I}$ & I & 14 & 3 & 9 \\
\hline Rest in case of dyspnea & 27 & $2 \mathrm{I}$ & 8 & 3 & 2 & 10 \\
\hline Rest during the day & 23 & I 8 & I & 16 & 3 & 3 \\
\hline Medication & $\mathrm{I} 5$ & 12 & 2 & 8 & - & 5 \\
\hline
\end{tabular}

"Higher response among limitation sets are noted in bold

\section{Effect of education and support on heart failure related self-care behavior and limitations}

The effect of the intervention was most clear short term, I month after discharge (table 7.4). One month after discharge, patients from both groups reported significantly higher self-care behavior compared with their baseline score $(t=6.1, p<0.00 \mathrm{I}$, $\mathrm{t}=\mathrm{I} \mathrm{I} .4, \mathrm{p} \cdot 0.001)$. Patients from the intervention group, however, reported complying with $\mathrm{I} 4$ of the 19 self-cure behaviors compared to 12 in the control group $(t=3.8$, $p=0.001$ ). Both control and intervention patients decreased their self-care behavior over time. However, patients from the intervention group still reported complying with more behaviors than control patients at 3 months ( $12.2 \mathrm{vs}$. 10.6, $t=2.9, p=0.005$ ) and at 9 months ( 11.2 vs. $10.3, t=1.6, n s$ ). The differences remain statistically significant after correction for multiple testing.

To compare the types of limitations experienced by patients in the intervention and control group, a mean score of the number of times a patient mentioned a limitation was calculated per patient. Mean scores on three limitations at 3 and 9 months were 
not significantly different. Only a trend was found three months after discharge, where the intervention group reported a limitation in knowledge less often than patients in the control group (mean $0.9 \pm \mathrm{I}$ vs. I. $4 \pm \mathrm{I} .5, \mathrm{t}=\mathrm{I} .7, \mathrm{p}=0.076$ ).

\subsection{Discussion}

\section{Methodological issues}

The study limitations related to the method of data collection. From research on medication compliance it is known that self-report is not always a reliable method to gather data on self-care behaviour. ${ }^{18.19}$ However, in our study a researcher not related to the therapeutic team approached the patients in a non-threatening, open-ended manner. In this way self-report might be reliable. ${ }^{18-20}$

Several patients did not mention a limitation, mainly for reasons of fatigue. Some patients became irritated that they had to mention the reason for their behavior. Sometimes this was related to the question (e.g. "Can't you see that I am exhausted, why do you ask about exercise?") or sometimes patients were too tired to report any limitation. This did not affect the self-care behavior scores but only the results regarding the limitations. One can imagine that patients who were not able to report their limitations experienced different limitations than patients who did report limitations.

The 19-item questionnaire was developed from the literature. The authors recognized that it was important to define an objective outcome measure for which the intervention was accountable and which at the same time gave additional clues for improvement of care. Therefore a practical and concrete instrument was developed. Factor analysis did not confirm the three dimensions of self-care behavior. For further research, additional work on the scale is needed. Items need to be reformulated more precisely (e.g. restriction of fluids) and the content of several items should be reconsidered, for example preventing the flu could be reformulated as "getting a flu shot". Currently, additional work is being done in co-operation with international colleagues to shorten and further improve the scale. It also should be considered to ascribe weights to the separate items. In addition, more objective criteria like weight or number of medications taken could give more insight in actual behaviour. Another option would be to analyse the separate items of he scale. Additional analyses between groups per item of the scale, however, revealed no significant differences per item.

\section{Heart Failure related Self-care Behavior}

In this study it was found that a supportive-educative nursing intervention enhanced self-care behavior in patients with heart failure. Patients from both the intervention and the control group increased their self-care behavior within I month of discharge. probably as a result of hospitalization. The increase in the intervention group, however, was significantly greater after I month. Although both groups decreased self-care behavior during the following 8 months, the increase from baseline remained statistically significant in the intervention group. while this was not the case in the control group. As can be expected, the intervention had its most powerful effects on short-term behavior, 
reflected in significant differences in self-care behavior between the two groups both $I$ and 3 months after discharge. Although the magnitude of the difference between the two groups can be questioned, the extra gain of the intervention lies in items that seem rather futile, but they can be of major importance to a patient with heart failure, for whom a weight gain or consumption of a high salt product can make a vital difference. After 9 months the effect of the intervention decreased. The supportive-educative intervention in this study focused on various aspects of self-care, for example, adherence to medication and diet, adapting activities to their condition and knowledge of symptoms of worsening heart failure and adequate reaction to these symptoms. Regarding separate items, the difference in self-care behavior caused by the intervention was related to warning a doctor if symptoms worsen (weight gain and leg edema), preventing the flu and elevating legs.

Despite intensive education and support, several patients in the intervention group reported limited self-care behavior. In this study three sets of limitations as described in Orem's self-care deficit theory of nursing were used to gain insight into limitations for self-care behavior. Patients mentioned all three sets of limitations, but only a few patients reported a limitation in skills or opportunities. Although a difference existed in self-care behavior of patients in the control and intervention group, the main reason for limited self-care behavior was not considerably different between the two groups. A trend towards fewer limitations in knowledge in the intervention group was described. These results can be used to improve the content of the intervention. Although Orem stated that the limitations provide a basis for nurses" judgment about valid methods of helping, she did not suggest concrete actions for each limitation, rather she described general methods that persons can use to assist or help others in the supportive-educative system. These are support, guidance, provision of a developmental environment and teaching. ${ }^{4}$ Information from our study can give some directions to specify the helping methods regarding limitations in this specific patient population.

\section{Limitation of knowledge}

At baseline, but also after edwcation and support, patients cited a limitation in knowleqdge on different items. Several patients in the intervention group in this study reported that they did not know they had to comply with a diet or fluid restriction or that it would be necessary to wam a doctor in case of leg edema. All patients received a card with waming symptoms of heatt failure and this card was discussed in detail. Sodium and fluid restrictions were: afso items that were discussed sith all patients. These findings support the idea that providing patients with information does not guarantee their knowledge. ${ }^{20.24}$ Learning may not take place if the person is not ready to learn, is unaware that he does not know, or is not interested in learning. ${ }^{14}$ Considerable information is lost during visits to a heatth care provider. According to Clepper, approximately $50 \%$ of patients forget what the physician said during the consultation immediately leaving the office. ${ }^{22}$ In a cardiac surgery population $71 \%$ had forgotten what their physician said during the visit. ${ }^{23}$ In addition, increasing knowledge may not automatically lead to increased self-care behaviour. ${ }^{24}$ These findings suggest that changing self-care behavior in regard to diet, fluid restriction, warning a doctor in case of leg ederna and behavior related to activity and rest needs additional approaches. In 
addition to reinforcement of education, patients probably would benefit from social support of family or a health care provider. Another potential strategy is to link the information to experiences in the hospital, for example, daily weight in the hospital can be used as an opportunity to explain the connection between fluid status and weight, the need to continue this behavior at home and the steps to take if weight increases.

It is also important that the content of education material is tailored more precisely to the specific needs of the patient. In health education, tailored education has proven to be effective in changing patients' diet or smoking habits. ${ }^{25.26}$ Education material in these programs was tailored to personal behavior, attitudes, perceived social influences, self-efficacy and awareness level. In applying this method to the education of patients with heart failure, information on their personal limitations should be used and tailored patient education materials developed.

\section{Limitation in judgment and decision making}

The majority of patients reported limitations in judgment and decision-making for HF$S C$ behavior. The answers that patients reported in this category were diverse and can be explained by various points of view.

First it is noticed that patients with chronic disease sometimes suffer from so called "treatment fatigue" and some patients in our study cited "quality of life" as the reason for not engaging in self-care behaviour." In this study some patients reported that they decided not to go to a doctor because they did not want to bother their doctor or because their doctor could not help them anymore. Some patients made a risk-benefit decision based on criteria important to them and intentionally did not comply with the regimen. One can argue that a health care provider should respect the autonomy of the patient and respect this decision. At the same time the health care provider has to assure himself the patient makes the decision based on all available information. ${ }^{8.10}$

A second explanation for a decision not to engage in self-care behavior can be found in the motivation of the paticnt. In a study of patients with renal disease, it was found that treatment of non-compliance with fluid restriction should focus on increasing motivation and attributions of success and personal effort of past performance. ${ }^{28}$ Providing opportunities for successful performance and tailoring the regimen to fit the patient's lifestyle are behavioral strategies designed to enhance adherence. ${ }^{19-21} \mathrm{~A}$ health care provider can plan to provide the patient with positive experiences of selfcare behavior. For example, to motivate patients weighing behavior, patients can be asked to bring a list with daily weight to the clinic visit. The patient can experience that his weight is used to guide treatment, which can motivate continuation of self-care behavior. Another example of stimulating a positive experience can be self-medication by patients in the hospital. ${ }^{29.30}$ During hospitalization patients become familiar with their complex medication schedule and develop abilities to prepare the medication at home.

Getting support from others can also be important in motivating the patient. This involves support received from partners, family and friends as well as support from health care providers. ${ }^{21,31.32}$ Rich et al., found in a heart failure population that persons not living alone tended to be more compliant with medication. ${ }^{15}$ The importance of health care provider characteristics on patients ${ }^{\circ}$ adherence had been described in previ- 
ous research. ${ }^{21,27,33}$ For example, the self-reported willingness to answer questions has a positive effect on adherence of patients. ${ }^{33.34} \mathrm{~A}$ good relationship with a health care provider can enhance self-care behavior. Patients' contacts with heart failure specialists working in a dedicated heart failure program can facilitate this. ${ }^{35}$

A third explanation for a limitation in decision making is a low belief in selfefficacy. Self-efficacy beliefs are defined as the perception that one can master a certain task or perform adequately in a given situation..$^{36}$ People thoughts about the capability to perform certain behavior can influence their activities. Previous experiences, observations from others, social influence and the physiological state of a person affects self-efficacy beliefs.

Helping a patient to get a positive experience with certain behavior, role modeling and social support can be important interventions to enhance patients belief that he can perform this behavior and that he will benefit from it.

\section{Limitation in skills}

Although few patients reported not having enough skills or resources as a barrier for self-care behavior. it is an important topic to consider in education and support. Reducing the complexity of a medication regimen can enhance the self-care behaviour. ${ }^{21}$ Simple interventions by a health care provider such as introducing a pill-box to enhance compliance with medication or referring to a rehabilitation program to enhance patients' activities can make an important difference for a patient's self-care behavior.

\subsection{Conclusion}

Supportive-educative intervention is effective in enhancing heart failure related selfcare behaviour. However, even after intensive education and support, several patients in the intervention group reported limitations in self-care behaviour. Limitations were sometimes related to knowledge, implicating that additional interventions to inform patients are needed.

The majority of the patients reported limitations in judgement and decision-making. implying that patients know how to behave. but choose to do different. To optimise an intervention for patients with advanced heart failure more attention is needed for behavioural strategies (e.g. self-medication, self-efficacy), social support (e.g. from family members and from a heart failure team) and reinforcement (e.g. in a home visit). Research is needed to evaluate both direct and objective effects (e.g. self-care, daily weight) of these interventions as well as long term effects (e.g. readmission and quality of life).

\subsection{References}

I. Kruse W. Early readmission of elderly patients with congestive heart failure. J Am Geriatr Soc 199 I: 39: 1045-1046. 
2. Monane M, Bohn RL, Gurwitz JH, Glynn RJ, Avorn J. Noncompliance with congestive heart failure therapy in the elderly. Arch Int Med 1994; 154: 433437.

3. Struthers AD. Emerging issues on the role of angiotensin-converting enzyme inhibition in the treatment of cardiac failure. Clin Card 1996; 19(Suppl 1): 2-4.

4. Ghali JK, Kadakia S, Cooper R, Ferlinz J. Precipitating factors leading to decompensation of heart failure. Arch Int Med 1988; 148: 2013-2017.

5. Wagdi P, Vuilliomenet A, Kaufmann U, Richter M, Bertel O. Inadequate treatment compliance, patient information and drug prescription as causes for emergency hospitalisation of patients with chronic heart failure. Schweiz Med Wochenschr 1993: 123: 108 - I 2 .

6. Michalsen A, Konig G, Thimme W. Preventable causative factors leading to hospital admission with decompensated heart failure. Heart 1998; 80: 437-44 I.

7. Bertel $O$. The influence of patientinformation, compliance and medical regimen on the prognosis of patients with chronic heart failure [in German]. Herz. 1991: I6(sonderheft I): 294-297.

8. Kostam M, Dracup K, Baker D et al. Heart failure: evaluation and care of patients with left ventricular systolic dysfunction. Clinical Practice Guideline No II. AHCPR Publication No 94-0612. Rockville, MD: Agency for Health care policy and research, public health service, US Department of Health and Human Services, June 1994.

9. Soler Soler J. Permanyer Miralda G. How do changes in lifcstyle complement medical treatment in heart failure? Br Heart J I 994; 72 (suppl): 87-9I.

10. Dracup K, Baker DW, Dunbar SB, Dacey RA, Brooks NH, Johnson JC. Oken C, Massie BM. Management of heart failure: counselling. education and lifestyle modifications. JAMA 1994; 272: 1442-1446.

1 I. Jaarsma T, Huijer Abu-Saad H, Halfens R, Dracup K. 'Maintaining the balance"nursing care of patients with chronic heart failure. Int J Nurs Stud 1997; 34: 213-22I.

I 2. Bushnell FK. Self-care teaching for congestive heart failure patients. J Geront Nurs 1992; 18(10): 27-32.

13. Sulzbach-Hoke LM, Kagan SH. Craig K. Weighing behaviour and symptom distress of clinic patients with CHF. Medsurg Nurs 1997; 6: 288-293.

14. Orem DE. Nursing: Concepts of Practice (5 $5^{\text {th }}$ ed.). St Louis: Mosby. 1995.

15. Rich MW, Gray DB, Beckham V, Wittenberg C. Luther P. Effect of a multidisciplinary intervention on medication compliance in elderly patients with congestive heart failure. Am Med J 1996; 10 I : 270-276.

16. Jaarsma T, Halfens R, Cleuren G. Education and guidance of a patient with chronic heart failure. A case study [In Dutch]. Verpleegkunde I 997; I 2: 205216.

17. Holm S. A simple sequentialy rejective multiple test procedure. Scand J Statist 1979; 6: 65-70.

18. Hilbert GA. Accuracy of self-reported measures of compliance. Nurs Res 1985 : 34: 319-320. 
19. De Geest S, Borgermans L, Gemoets H, Abraham I, Vlaminck H, Evers G, Vanrenterghem Y. Incidence. determinants, and consequences of subclincial noncompliance with immunosuppressive therapy in renal transplant recipients. Transplantation 1995: 59: 340-347.

20. De Geest $S$. Subclinical noncompliance with immunosuppressive therapy in heart transplant recipients [Doctoral thesis]. Leuven: Katholieke Univeristeit Leuven, 1996.

2I. Burke LE, Dunbar-Jacob J. Adherence to medication, diet, and activity recommendations: from assessment to maintenance. J Cardiovasc Nurs 1995; 9: 6279.

22. Clepper [. Noncompliance: the invisible epidemic. Drug Topics 1992; August I 7, 44-46. 49,50. 56,59,6062,65.

23. Robinson G, Merav A. Informed consent: recall by patients tested postoperatively. Ann Thor Surg 1976; 22: 209-212.

24. Miller NH. Compliance with treatment regimens in chronic asymptomatic diseases. Am Med J 1997; 102(2a), 43-49.

25. Brug J. Steenhuis I, van Assema P, de Vries $H$. The impact of a computer-tailored nutrition intervention. Prev Med r996: 25. 236-242.

26. Dijkstra A. Computer-tailored interventions for smoking cessation: lirgeting smokers with low readiness to quit [Doctoral thesis]. Malastricht: University of Maastricht. I 998.

27. Coambs RB, Jensen P. Her MH, Ferguson BS, Jarry JL, Wong JSW, Abrahamsohn RV. Health promotion Research: prescription noncompliance. Ontario: Health Promotion research, 1995.

28. Schneider MS, Fried R, Whitaker P, Wadhwa NK. Fluid noncompliance and symptomatology in end stuge renal discase: cognitive and emotional variables. Health Psych I991; I0: 209-2 I5.

29. Lowe CJ, Raynor DK, Courtncy EA, Purvis J, Teale C. Fiffects of silf-medication programme on knowledge of drugs and compliance with treatment in elderly patients. Br Med J 1995; 3 I0: 1229-123I.

30. Furlong $S$. Do programmes of medicine self-administration enhance patient knowledge, compliance and satisfaction? J Adv Nurs 1996: 23: 1254-1 262.

31. Doherty WJ, Schrott HG, Metcalf L, Iasiello-Vailas L. Effect of spouse support and health beliefs on medication adherence. J Fam Pract 1983; 17: 834-84I.

32. Hubbard P, Muhlenkamp AF, Brown N. The relationship between social support and self-care practices. Nurs Res 1984:33: 266-270.

33. DiMatteo MR, Sherbourne CD, Hays RD. Ordway L, Kravitz RL, McGlynn EA, Kaplan S, Roger WH. Physicians' characteristics influence patients' adherence to medical treatment: outcomes from The medical Outcomes study. Health Psych r993; 12: 93-102.

34. Smith P. Andrews J. Drug compliance not so bad, knowledge not so good- the elderly after hospital discharge. Age Ageing 1983; 12: 336-342.

35. Advisory Board Company. Beyond four walls: cost effective management of chronic congestive heart failure. Washington DC, 1994.

36. Bandura A. Self-efficacy mechanism in human agency. Am Psych 1982; 37 : I22-I 47. Table I: Aspects of the supportive-educative intervention. 


\title{
Chapter 8
}

\section{The effects of education and support on resource utilization}

\begin{abstract}
A total of 179 patients (mean age $73,58 \%$ male, NYHA III-IV) hospitalized with heart failure were evaluated prospectively. Patients were randomized to the study interventian or to care-as-usual. The supportive educative intervention consisted of intensive, systematized and planned education by a study nurse about the conseg̨uences of heart faibure in dally life, using ì standard nursing care plan developed by the researchers for older poticats with heart failure.

Edacation and sappont by a nurse in a bospital setting and at hone significantly increases self-cane hehavice jal potieats with heart failure. Patients from both the intervertion and the control increased their self-care behavio within s month of discharge, bet the increase in the intervention group was significantly more after 1 month. Aldhugh hoth groups decreased self-care hehaviou during the following 8 months, the increase frem basefine remsincd statistically significant in the intervention group but Dot in the control grwap. Na significant effects on rescurce utilization were found.

Intensive, systemanized, cailoned and planned education and support by a nurse resats in an iacrease ia pocients" self-care behavior. No significant effects were found on using heaklk care neseurces. Additional organizational changes such as. longer followw and the ansiliability of a heart failure specialict woold probably enhance the effects of edlacativa and sapport.
\end{abstract}

\section{Adapted truenc}

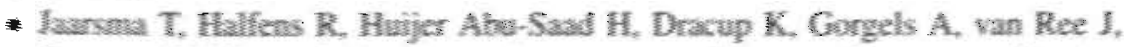
Stappers 1 . Effects of education and support on self-care and resource utilization in patieats wilh beart fallure. Ear Heart $1999 ; 20 x 673-682$. 


\subsection{Introduction}

Heart failure is increasingly recognized as a major public health problem in industrialized countries. ${ }^{1-4}$ With the aging of the population, more patients are expected to present with heart failure. ${ }^{5.6}$ heart failure has a major impact on the lives of patients and their families. Severe symptoms such as dyspnea or edema and increased exercisc intolerance affect important aspects of a person's life. In addition, patients often have to adjust their lifestyle by adhering to a complex medication regimen. changing their diet and fluid intake, adapting their activities, and monitoring symptoms of worsening heart failure. ${ }^{7}$ To make these adjustments and to care for themselves effectively. patients need particular knowledge and skills. Patient education and support are essential for enhancing self-care abilities, improving outcomes and decreasing unnecessary hospitalizations. ${ }^{7.8}$ Teaching patients to enhance their self-care behavior by education and support can have a positive effect on lifestyle modification (for example diet, exercise), on response to worsening symptoms, and on coping with chronic illness. To enhance the effectiveness, education should be tailored for each patient and their family. ${ }^{9,10}$ Support and education must me maintained for as long as necessary in the home setting to cover the transition from hospital to home. ${ }^{11.12}$ Potential non-compliance with advice and failure to seek medical attention when symptoms occur are related to rehospitalization. Thus it can be expected that patients who are able to care for themselves effectively will encounter fewer problems that can lead to rehospitalization or unnecessary visits to the emergency department. ${ }^{10.13-18}$ However, because of increased knowledge about the disease, it is also possible that education and support leads to an increase in health care resource use. Teaching patients to be more alert in identifying symptoms could result in an increased number of contacts with a general practitioner or cardiologist. ${ }^{19}$ For the education of heart failure patients several main points have been suggested, ${ }^{20}$ but research on the effects of education and support is scarce. In different multi-modal interventions, education is an important aspect of other interventions, such as a heart failure clinic or a heart failure team. ${ }^{15.21}$ The specific contribution of education and support alone to such programs is seldom isolated. The purpose of this study was to describe the effect of education and support by a nurse on self-care and resource utilization.

\subsection{Method}

\section{Patients}

Patients who were admitted to the cardiology ward of the University Hospital in Maastricht, the Netherlands, with symptoms of heart failure were potentially eligible. To confirm a diagnosis of heart failure the Boston scoring system was used. ${ }^{22}$ In this scoring system the various signs and symptoms documented in the history, physical examination and chest $\mathrm{X}$-ray are given a score. The score ranges from o to 12 , with a score of 8 and higher being designated as heart failure. After verifying the diagnosis with the Boston scoring system, patients were included in the study if they met the following criteria: New York Heart Association (NYHA) functional class III and IV, a 
diagnoses of heart failure at least 3 months before, aged at least 50 years and literate in Dutch. Patients were excluded from the study if they suffered from a co-existing severe chronic debilitating disease; if they resided in, or planned to be discharged to a nursing home, if they had a psychiatric diagnosis, if they had had a previous CABG, PTCA or valve replacement in the last 6 months or were expected to have such a treatment within 3 months, or if they refused to give informed consent. The institutional review boards approved the study.

\section{Study design}

From May 1994 to March 1997 a researcher and a research assistant screened patients admitted to the cardiology unit for their potential eligibility to the study. The artending physician determined the Boston score and whether the patient met the inclusion criteria. The researcher/research assistant obtained informed consent and collected baseline data from the medical chart and by interview. By drawing from an envelope, patients were randomly assigned to receive either care-as-usual or the supportive-educative intervention.

All patients were followed for 9 months. The researcher/research assistant telephoned the patient I month after discharge, and visited the patient 3 months and 9 months after discharge for data collection.

\section{Intervention and control group}

The supportive educative intervention consisted of intensive, systematic and planned education by a study nurse about the consequences of heart failure in daily life, using a standard nursing care plan developed by the researchers for heart failure patients in older age. ${ }^{23}$ Important topics were discussed with every patient, for example, recognition of warning symptoms of worsening heart failure, sodium restriction, fluid balance, and compliance. In addition, individual problems were discussed, for example problems in social interaction, sexual function or limited access to the general practitioner.

During hospital stay, the study nurse assessed the patient's needs, provided education and support to the patient (and family), gave the patient a card with warning symptoms and discussed discharge. Within I week after discharge the study nurse telephoned the patient to assess potential problems and to make an appointment for a home visit. During the home visit the study nurse reinforced and continued education as warranted by the patient situation. If needed, home care was informed in writing about specific patient needs. Between discharge and the home visit, patients could call the study nurse in case of problems. After the home visit, the patient was advised to call their cardiologist, general practitioner or emergency heart center in case of problems. The intervention lasted from hospital admission to so days after discharge from the hospital.

Patients assigned to the "care-as usual" (control group) received all standard care. This meant that they were not provided with structured patient education, a follow-up telephone call or a home visit by a nurse. Dependent on the insight of an individual nurse or physician the patient received information (in writing or oral) about med- 
ication and lifestyle. Patients from the control and intervention groups were never assigned to the same room on the nursing unit. The two study nurses were involved in data collection as researcher and research assistant. However, the person who collected the data and the nurse who visited the patient for the intervention were never the same.

\section{Data collection}

End points of the study are self-care ability, self-care behavior and resource utilization. To describe the population and correct for possible differences, additional clinical and demographic data were collected.

\section{Clinical and demographic data.}

At the time of enrollment. clinical data were collected from the patient's medical chart. Thesc included: patient's medical history, co-morbidities, laboratory data, Left Ventricular Ejection Fraction, NYHA class. weight and height. and medication prescribed. At the same time the patient was interviewed to collect demographic data including age, gender, marital status, socio-economic status, social support and living situation.

\section{Self-care}

The Appraisal of Self-care Agency (ASA) Scale was used to assess the patients' ability to care for him/herself. ${ }^{24}$ On this 24 -item self-appraisal instrument, scores range from 24-120. Cronbach's alpha in this study ranged from 0.80 to 0.87 . The scale was administered at the time of enrollment, 3 and 9 months after discharge.

Specific heart failure-related behavior was assessed using the Heart Failure Selfcare Behavior Scale. This is a 19-item questionnaire, with each item listing a specific activity related to heart failure. For example, "In case of dyspnea, I call a doctor" or "I restrict my sodium intake". For each item the patient is asked to respond with yes or no. A total score is calculated by all positive answers. Content validity of this scale was established by a panel of experts in the field of caring for heart failure patients. Data on self-care behavior were collected at the time of enrollment. and at 1,3 and 9 months after discharge. Cronbach's alpha for this scale ranged from 0.62 to 0.68 . Based on the importance of the content of the items for heart failure patients, it was decided to use this scale.

\section{Using health care resources}

During the follow-up interviews ( 1,3 , and 9 months after discharge) patients reported on the number, and reason for contacts with the general practitioner, cardiologist, medical specialists, physical therapist, social services or alternative health care providers. They also reported on using home care and meals on wheels. Additional inturination on readmission and visits to the outpatient clinic were obtained from the hospital computer database. Reasons for readmission were collected from the patient's medical chart. 


\section{Statistical analysis}

Descriptive statistics are expressed as means $\pm \mathrm{sd}$. The control and study groups were compared by Chi-square test for discrete variables and by Student 's t-test tor continuous variables. Correction for multiple testing was performed using a modification of Holm. ${ }^{25}$ Relationships were examined using Pearson product-moment corrclation coefficients.

\subsection{Results}

\section{Study patients}

During the period May 1994 to March 1997, 828 admissions for heart failure were registered in the cardiology ward of the University Hospital in Maastricht. Of these 828 admissions, $184(22 \%)$ were readmissions. Since patients could only enter the study once, 644 patients were screened. Among the remaining 644 patients, $458(71 \%)$ were excluded. Among them, 17I $(37 \%)$ were excluded because they were diagnosed with heart failure of less than 3 months, because heart failure was not confirmed by the Boston score $(n=12,3 \%)$ or because they died before the interview took place $(n=14$, $3 \%$ ). Other reasons for exclusion were dementia, a psychiatric or terminal illness $(\mathrm{n}=31,7 \%)$, a cardiac intervention was planned or had taken place recently or NYHA was $<$ III $(n=22,5 \%)$ or for demographic reasons (nursing home, age, language $(n=26$, $6 \%$ ). In addition, 76 patients $(17 \%)$ were excluded for more than one reason (mostly a combination of inadequate length of heart failure plus another reason), 66 (14\%) for logistic reasons (most commonly the inability to screen before discharge) and $40(9 \%)$ because the patient did not want to participate as they felt too ill to do so. The age and gender of these $4^{\circ}$ patients did not differ from the patients who participated in the study. In total, i 86 patients were enrolled in the study; however, before discharge seven (five in the intervention group, two in the control group) patients died. Analyses were performed on data of the remaining 179 patients. The study population consists of a general heart failure population since the University Hospital in Maastricht is the only hospital in the town of Maastricht.

The baseline demographic and clinical characteristics of the patients are shown in table 8. I. The mean age of the patients was 73 years: $58 \%$ were male and most lived independently at time of enrollment. Most of the participating patients were NYHA class IV during admission and the mean ejection fraction was $34 \%$. At the time of discharge most of the patients were using diuretics $(91 \%)$, nitrates $(84 \%)$, and vasodilators $(78 \%)(70 \%$ on ACE inhibitors). Digoxin was prescribed to $47 \%$ of the patients. Two patients had a Boston score $(6$ and 7$)$ indicating possible heart failure and the other patients had a score higher than 8 , indicating definite heart failure. The underlying reasons for heart failure, as mentioned in the medical chart were ischaemic heart disease $(52 \%)$, valvular disease $(46 \%)$, cardiomyopathy $(23 \%)$ and hypertension $(23 \%)$. Patients could be classified with more than one underlying reason for heart failure. Of the total sample, 35 patients were considered as having predominantly diastolic left ventricular dysfunction. There were no statistically significant differences in 
Table 8.x: Demographic and clinical characteristics at baseline of the patients in the study $(\mathrm{n}=179)^{\mathrm{a}}$

\begin{tabular}{|c|c|c|c|c|}
\hline & $\begin{array}{c}\text { Total } \\
n=179\end{array}$ & $\begin{array}{c}\text { Control } \\
\mathrm{n}=95\end{array}$ & $\begin{array}{l}\text { Intervention } \\
\qquad \mathrm{n}=84\end{array}$ & $\mathrm{p}$ value \\
\hline \multicolumn{5}{|l|}{ Demographics } \\
\hline Age in years & $73 \pm 9$ & $73 \pm 9$ & $73 \pm 9$ & ns \\
\hline \multicolumn{5}{|l|}{ Persons providing: } \\
\hline Emotional support & $I . I \pm 2 . I$ & $\mathrm{I} .2 \pm 2.5$ & $0.9 \pm 1.5$ & ns \\
\hline Practical support & $3.5 \pm 2.6$ & $3.6 \pm 2.7$ & $3.4^{ \pm 2.5}$ & ns \\
\hline Male gender & $103(58 \%)$ & $56(59 \%)$ & $47(56 \%)$ & ns \\
\hline Married & $96(54 \%)$ & $5 \mathrm{I}(54 \%)$ & $45(54 \%)$ & ns \\
\hline Dependent living & $19(11 \%)$ & $12(12 \%)$ & $7(8 \%)$ & ns \\
\hline \multicolumn{5}{|l|}{ Clinical characteristics } \\
\hline Length of heart disease in years & $9 \pm 8$ & $9 \pm 8$ & $9 \pm 8$ & ns \\
\hline Length of stay (days) & $13.6 \pm 8.4$ & $12.9 \pm 8.3$ & $14.5 \pm 8.5$ & ns \\
\hline Quetelet index $\left(\mathrm{kg} / \mathrm{m}^{2}\right)$ & $24.7 \pm 4.8$ & $24.5 \pm 4.2$ & $24.9 \pm 5.4$ & ns \\
\hline $\begin{array}{l}\text { Weight loss during admission } \\
\text { (kg) }\end{array}$ & $3.7 \pm 4.7$ & $3.3 \pm 4.2$ & $4.2 \pm 5.1$ & ns \\
\hline LVEF (\%) & $34.4 \pm I 4$ & $34 \cdot 5 \pm 14$ & $34 \cdot 3 \pm \mathrm{I} 2$ & ns \\
\hline No previous admissions & $3.3 \pm 2.5$ & $3.4 \pm 2.6$ & $3.3 \pm 2.4$ & ns \\
\hline Prior Ml & $105(59 \%)$ & $56(60 \%)$ & $49(58 \%)$ & ns \\
\hline Prior CABG & $46(26 \%)$ & $23(25 \%)$ & $23(27 \%)$ & ns \\
\hline Co-morbidity no. & $1.2 \pm 1.0$ & $1.2 \pm 0.9$ & $1.2 \pm 1.0$ & \\
\hline Diabetes mellitus & $54(30 \%)$ & $27(28 \%)$ & $27(32 \%)$ & ns \\
\hline Hypertension & $51(29 \%)$ & $29(31 \%)$ & $22(26 \%)$ & ns \\
\hline Lung disease & $42(24 \%)$ & $24(25 \%)$ & $18(2 \mathrm{I} \%)$ & ns \\
\hline Rheumatoid arthritis & I I $(6 \%)$ & $5(5 \%)$ & $6(7 \%)$ & ns \\
\hline Sodium $(\mathrm{meq} / \mathrm{l})$ & $138.7 \pm 3.5$ & $138.7 \pm 3.5$ & $138.7 \pm 3.6$ & ns \\
\hline BUN (mg/dl) & $13.0 \pm 7.8$ & $12.6 \pm 7.5$ & I3.5 \pm 8.1 & ns \\
\hline Creatinine $(\mu \mathrm{mol} / \mathrm{l})$ & $141.4 \pm 68.6$ & $139.0 \pm 70.4$ & $144.2 \pm 66.9$ & ns \\
\hline NYHA III & $31(17 \%)$ & $19(20 \%)$ & $12(14 \%)$ & \\
\hline NYHA III-IV & $37(21 \%)$ & $24(26 \%)$ & $13(16 \%)$ & \\
\hline NYHA IV & $110(61 \%)$ & $51(54 \%)$ & $59(70 \%)$ & $\mathrm{ns}$ \\
\hline
\end{tabular}

"LVEF: left ventricular ejection fraction, MI: Myocardial infarction, CABG: coronary artery bypass grafting, BUN: blood urea nitrogen 


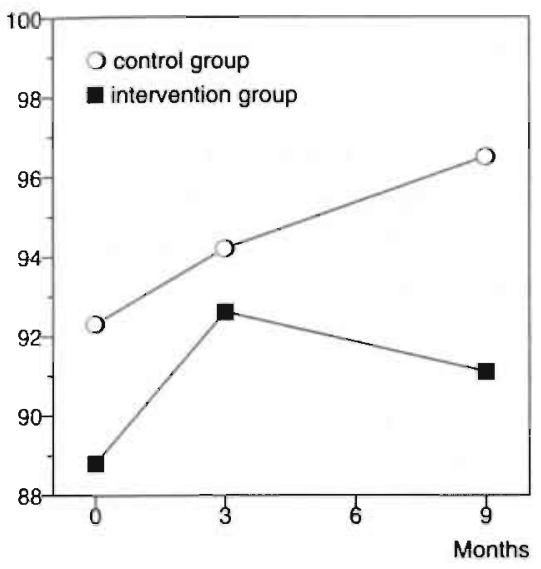

Figure 8.1: Self-care abilities (ASA) $\mathrm{n}=\mathrm{I}$ I I , theoretical range $24-120$

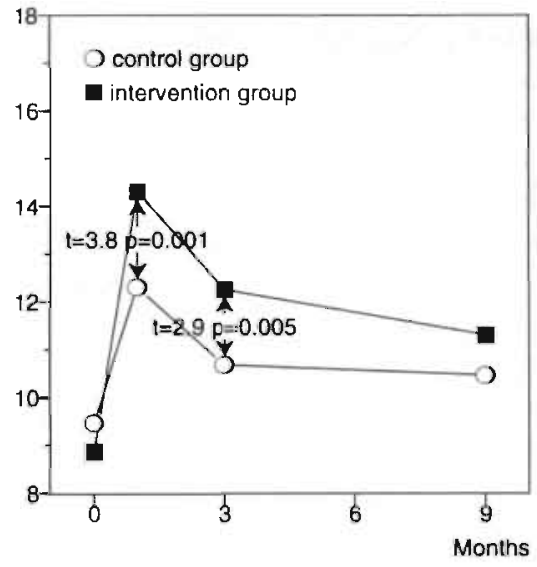

Figure 8.2: Heart failure related self-care behavior $n=I 28$, theoretical range o- 19

demographic and clinical variables between the control group (CG) and study group. although there was a trend towards increased severity of symptoms (NYHA IV) in the intervention group (IG) $(70 \%$ vs. $54 \%$, chi-square $=4.9, p=0.087)$. During the study period, 20 patients changed their home situation from independent living to an assisted living environment. six patients from the CG and 14 patients from the IG.

\section{Attrition}

During the 9-month period of follow-up, 16 patients ( $17 \%$ ) in the CG died compared to $22(26 \%)$ in the IG. Attrition due to non-response was the same $(5 \%)$ in both groups. Comparing the baseline characteristics of the patients who died or did not respond $(n=47)$ with the patients who completed all three follow-up measurements $(n=132)$, it was found that patients who dropped out were significantly older. lived more often in a home for the elderly, had been diagnosed with hypertension and had cardiomyopathy more often as the underlying reason for heart failure. Laboratory results showed higher levels of scrum sodium, BUN and creatinine at bascline. When the baseline characteristics of the control and intervention patients who dropped out of the study were compared, we found that no selective attrition had occurred. The baseline characteristics of the 74 control and 58 intervention patients remained comparable.

\section{Self-care abilities}

Analyses were restricted to subjects with valid scores at all three measurements (baseline, 3 and 9 months). Figure 8. r shows baseline and follow-up scores on the general self-care abilities of I I I of the 132 patients responding after 9 months. The ability of patients to care for themselves in general (ASA) was not significantly different between the two groups at any time. Patients in the CG increased their self-care abilities be- 
Table 8.2: Number of patients readmitted and readmission days of all included patients $(n=179)$

\begin{tabular}{|c|c|c|c|c|}
\hline \multirow[b]{2}{*}{ Period } & \multicolumn{2}{|c|}{ All causes } & \multicolumn{2}{|c|}{ Cardiac causes } \\
\hline & $\begin{array}{c}\text { Control } \\
n=95\end{array}$ & $\begin{array}{c}\text { Intervention } \\
\mathrm{n}=84\end{array}$ & $\begin{array}{c}\text { Control } \\
n=95\end{array}$ & $\begin{array}{c}\text { Intervention } \\
n=84\end{array}$ \\
\hline & \multicolumn{4}{|c|}{ Number of patients readmitted (\%) } \\
\hline a-I month & $14(15 \%)$ & II $(13 \%)$ & II $(12 \%)$ & $8(10 \%)$ \\
\hline o-3 months & $29(31 \%)$ & $22(26 \%)$ & $23(24 \%)$ & $18(2 \mathrm{I} \%)$ \\
\hline \multirow[t]{2}{*}{$0-9$ months } & $47(50 \%)$ & $3 \mathrm{I}(37 \%)^{a}$ & $37(39 \%)^{b}$ & $24(29 \%)$ \\
\hline & \multicolumn{4}{|c|}{ Number of Readmission days (mean $\pm s d$ ) } \\
\hline o-I month & $207(2.3 \pm 7)$ & $170(2.2 \pm 7)$ & $183(1.9 \pm 7)$ & $102(1.2 \pm 4)$ \\
\hline $0-3$ months & $485(5 . I \pm I I)$ & $430(5 \cdot I \pm I I)$ & $393(4 . I \pm 10)$ & $252(3 \pm 7)$ \\
\hline $0-9$ months & $86 \mathrm{I}(9 \pm \mathrm{I} 8)$ & $768(9 \pm 18)$ & $68 \mathrm{I}(7 . \mathrm{I} \pm 15)$ & $427(5 . I \pm I I)$ \\
\hline
\end{tabular}

${ }^{a} \mathrm{x}^{2}=2.8, \mathrm{p}=0.061$

${ }^{b} \lambda^{2}=2.1, p=0.096$

tween baseline and 9 months follow-up $(t=2.5, p=0.013)$. Patients in the IG increased their self-care agency between baseline and 3 months follow up $(t=2.4, p=0.020)$. After correction for multiple testing, these increases were not statistically significant.

\section{Heart failure related self-care behavior}

Analyses were restricted to 128 of the 132 patients responding after 9 months with valid scores on all four measurements on the Heart Failure Self-care Behavior Scale (baseline, 1,3, and 9 months). Patients in the IG had slightly lower self-care behavior scores than patients in the CG, but this difference at baseline was not statistically significant ( $t=1.3, p=0.208$ ) (figure 8.2). On average, patients complied with nine of the 19 items of self-care behavior. One month after discharge, patients from both the CG and the IG reported significantly higher self-care behavior compared with their baseline score $(t=6.1, p<0.00 I, t=I I .4, p<0.00 I)$. Patients from the IG, however, reported complying with $I_{4}$ of the 19 self-care behaviors compared to 12 in the CG $(t=3.8$, $\mathrm{p}=0.00 \mathrm{I})$. Both control and intervention patients decreased their self-care behavior over time. However, patients from the IG still reported complying with more behaviors than control patients at 3 months ( 2.2 vs. I0.6, $t=2.9, p=0.005$ ) and at 9 months ( 11.2 vs, $10.3, t=1.6, p=0,106$ ). The increase in self-care behavior between baseline and 9 months was statistically significant in the IG $(t=4.9, p<0.001)$, but not in the $\mathrm{CG}(\mathrm{t}=\mathrm{1.9}, \mathrm{p}=0.058)$. These significant differences remain statistically significant after correction for multiple testing. 


\section{Readmission}

\section{All patients in total study period}

During the 9 months follow-up, patients from this study had had i 629 days of readmission (table 8.2). The patients in the $\mathrm{CG}(\mathrm{n}=95)$ accounted for $86 \mathrm{I}$ readmission days, compared to 768 days in the IG $(n=84)$. This means an average of 9 readmission days in both groups. Of the 95 patients in the CG. $47(50 \%)$ were readmitted at least once during the study period, compared to $3 \mathrm{I}(37 \%)$ in the IG (chi-square=2.9. $\mathrm{p}=0.06$ ).

Cardiac reasons accounted for $68 \mathrm{I}$ readmission days (mean $7.1 \pm 15$ ) in the $\mathrm{CG}$ and 427 (mean 5.I $\pm \mathrm{II}$ ) in the IG, involving 37 patients $(39 \%)$ in the CG and 24 patients $(29 \%)$ in the IG (chi-square $=2.1, p=0.096$ ). No statistically significant differences were found in mean readmission days or number of readmissions between the two groups at the end of the 9-month study period.

\section{Short term: 1 month, 3 months}

To determine the short-term effects of the intervention, data from the $\mathrm{I}$ and 3 month follow-up were considered. Within I month of discharge, 25 patients $(14 \%)$ were readmitted to the hospital, leading to 377 days of hospitalization. Cardiac causes were the underlying reason for readmission in 19 patients, leading to 285 days of hospitalization (I83 CG, IO2 IG).

The number of patients readmitted within 3 months of discharge accumulated to 29 $(3 \mathrm{I} \%)$ in the $\mathrm{CG}$ and $22(26 \%)$ in the IG. The mean number of readmission days after 3 months was 5.1 in both groups. The number of patients readmitted for cardiac causes was $23(24 \%)$ in the CG and $18(21 \%)$ in the IG. Readmission for cardiac causes at three months accounted for 393 days (mean 4.I) in the CG compared with 252 (mean 3.0 ) in the IG. No differences between the two groups as regards readmission rate or readmission days were found at $\mathrm{I}$ and 3 months after discharge.

\section{Survivors}

To gain more insight into readmission of patients still alive after 9 months compared with patients who died during the study period, separate analyses were performed for these groups. As table 8.3 shows, patients who died during the study period were more often readmitted for all causes and specifically for cardiac causes within I month of discharge than surviving patients. In the CG $32 \%$ of the patients who died during the study period were readmitted within I month of discharge (all for cardiac causes), compared with $11 \%$ ( $7 \%$ for cardiac causes) readmission of the surviving patients. In the IG this was $23 \%$ vs. I I \% for all causes and I 4 vs. $9 \%$ for cardiac causes.

\section{Health care resources}

Over the 9 month study period, more patients in the CG $(38 \%)$ than in the IG $(24 \%)$ made a visit to the Emergency Heart Center (table 8.4). This difference did not reach statistical significance (chi-square $=2.7, p=0.074$ ). Of the patients who visited the Emergency Heart Center, patients from the IG made more visits (2.6 vs. I.4) than did the control patients $(t=0.2 .2, p=0.05 \mathrm{I})$. 
Table 8.3: Readmissions of patients who completed follow-up and patients who died within 9 months

\begin{tabular}{|c|c|c|c|c|}
\hline \multirow[b]{2}{*}{ period } & \multicolumn{2}{|c|}{$\begin{array}{l}\text { Surviving patients } \\
(\mathrm{n}=132)\end{array}$} & \multicolumn{2}{|c|}{$\begin{array}{l}\text { Patients who died within } \\
99 \text { months }(n=38)\end{array}$} \\
\hline & $\begin{array}{c}\text { Control } \\
n=74\end{array}$ & $\begin{array}{c}\text { Intervention } \\
\mathrm{n}=58\end{array}$ & $\begin{array}{c}\text { Control } \\
n=16\end{array}$ & $\begin{array}{l}\text { Intervention } \\
\qquad n=22\end{array}$ \\
\hline & \multicolumn{4}{|c|}{ All causes: } \\
\hline O-I month & $8(1 \mathrm{I} \%)$ & $6(10 \%)$ & $5(31 \%)$ & $5(23 \%)$ \\
\hline $0-3$ months & $2 \mathrm{I}(28 \%)$ & I $4(24 \%)$ & $6(38 \%)$ & $7(32 \%)$ \\
\hline \multirow[t]{2}{*}{ o-9 months } & $39(53 \%)$ & $23(40 \%)^{a}$ & $\mathrm{na}^{b}$ & na \\
\hline & \multicolumn{4}{|c|}{ Cardiac causes: } \\
\hline O-I month & $5(7 \%)$ & $5(9 \%)$ & $5(31 \%)$ & $3(14 \%)$ \\
\hline $0-3$ months & I5 $(20 \%)$ & I $2(2 \mathrm{I} \%)$ & $6(38 \%)$ & $5(23 \%)$ \\
\hline o- 9 months & $29(39 \%)$ & $18(31 \%)$ & na & na \\
\hline
\end{tabular}

" $\chi^{2}=2.2, p=0.094$

bdata are not available because patients were not alive at 9 months

Slightly more than half of the patients $(57 \%)$ visited their outpatient cardiologist for a scheduled check-up within a month of discharge. Most of the patients $(92 \%)$ had a scheduled appointment with their cardiologist within 3 months after discharge. Five percent of the patients had to wait more than 3 months to obtain such an appointment. A considerable number of patients also visited an internist or another medical specialist. Within the follow-up period of 9 months, $47 \%$ visited an internist and $72 \%$ another medical specialist at the outpatient department. Of the 57 patients $(43 \%)$ who did not visit the cardiologist within a month, Io $(8 \%)$ had contact with their internist within a month and an additional 34 (26\%) had contact with their general practitioner (GP) within a month. Only 10 patients did not have a scheduled contact with their cardiologist, their internist, or the GP within a month. During the y-month follow-up period. almost all patients contacted their GP at least once.

In total, $8 \mathrm{I}$ of the 132 patients $(62 \%)$ did not use home nursing care or home help. Further analysis revealed that only $16 \%$ of the patients used home nursing care (CG:13\%, IG: $22 \%$ ). About one third of the patients (38\%) had made arrangements for meals (e.g. meals on wheels, home help prepared meals). Patients were restrictive in their use of services from other health care providers (table 8.4). No significant differences were found in resource utilization between the control and intervention patients.

\section{Relationships between self-care and readmission, using Emer- gency Heart Center, and contacts with GP's}

It can be expected that a relationship exists between self-care and resource utilization. Since patients in the IG leamed how to react to worsening symptoms and comply with the medical regimen. this relationship was part of the intervention. Therefore separate correlation coefficients were calculated for the IG and CG. 
Table 8.4: Use of health care resources

\begin{tabular}{|c|c|c|c|c|}
\hline \multirow[b]{2}{*}{ Period } & \multicolumn{2}{|c|}{$\begin{array}{c}\text { Control } \\
n=74\end{array}$} & \multicolumn{2}{|c|}{$\begin{array}{c}\text { Intervention } \\
n=58\end{array}$} \\
\hline & $\mathrm{n}(\%)^{a}$ & visits ${ }^{b}$ & $\mathrm{n}(\%)$ & visits \\
\hline & \multicolumn{4}{|c|}{ Visiting emergency heart centre } \\
\hline o-I month & $3(4 \%)$ & I.O & $3(5 \%)$ & $1.3 \pm 0.6$ \\
\hline $0-3$ months & $15(22 \%)$ & 1.0 & $10(17 \%)$ & $1.8 \pm 1.0^{6}$ \\
\hline \multirow[t]{2}{*}{$0-9$ months } & $26(38 \%)$ & $1.4 \pm 0.86$ & $14(24 \%)^{d}$ & $2.6 \pm 2.1^{e}$ \\
\hline & \multicolumn{4}{|c|}{ Visiting outpatient cardiologist } \\
\hline o-r month & $42(57 \%)$ & & $33(57 \%)$ & \\
\hline $0-3$ months & $68(92 \%)$ & & $54(93 \%)$ & \\
\hline \multirow[t]{2}{*}{$0-9$ months } & $72(97 \%)$ & & $57(98 \%)$ & \\
\hline & \multicolumn{4}{|c|}{ Visiting outpatient "intemist" } \\
\hline O-I month & $10(15 \%)$ & & $14(24 \%)$ & \\
\hline $0-3$ months & $20(29 \%)$ & & $22(38 \%)$ & \\
\hline \multirow[t]{2}{*}{$0-9$ months } & $32(47 \%)$ & & $27(47 \%)$ & \\
\hline & \multicolumn{4}{|c|}{ Visiting other specialist $f$} \\
\hline o-1 month & $23(33 \%)$ & & $20(35 \%)$ & \\
\hline o-3 months & $35(51 \%)$ & & $37(64 \%)$ & \\
\hline \multirow[t]{2}{*}{$0-9$ months } & $51(74 \%)$ & & $45(78 \%)$ & \\
\hline & \multicolumn{4}{|c|}{ Contacting GP } \\
\hline o-r month & $48(67 \%)$ & & $34(62 \%)$ & \\
\hline $0-3$ months & $62(87 \%)$ & & $45(83 \%)$ & \\
\hline \multirow[t]{2}{*}{$0-9$ months } & $69(96 \%)$ & & $5 I(94 \%)$ & \\
\hline & \multicolumn{4}{|c|}{ Using home nursing care or home help ( $0-9$ months) } \\
\hline Total & $25(34 \%)$ & & $26(45 \%)$ & \\
\hline Home nursing care & $9(12 \%)$ & & $13(22 \%)$ & \\
\hline \multirow[t]{2}{*}{ Home help } & $22(30 \%)$ & & $22(38 \%)$ & \\
\hline & \multicolumn{4}{|c|}{ Using other facilities (o-9 months) } \\
\hline Arrangements for meals & $27(37 \%)$ & & $23(40 \%)$ & \\
\hline Physical therapist & $22(30 \%)$ & & $13(22 \%)$ & \\
\hline Pastor & I5 $(20 \%)$ & & II $(19 \%)$ & \\
\hline Social service & $2(3 \%)$ & & $2(3 \%)$ & \\
\hline Dietician & $4(5 \%)$ & & I $(2 \%)$ & \\
\hline Alternative healer & $1(1 \%)$ & & I $(2 \%)$ & \\
\hline
\end{tabular}

"valid percentages

${ }^{b}$ if visited, mean number of visits \pm sd

$c_{i=2.5, p=0.037}$

${ }^{t} \mathrm{I}^{2}=2.7, \mathrm{p}=0.074$

${ }^{c} \mathrm{t}=2.2, \mathrm{p}=0.051$

fother specialists as registered at the outpatient department of the hospitai

${ }^{g}$ contacts with general practitioner, either by phone, home visit or appointment 


\section{General self-care abilities}

Three months after discharge, the self-care abilities of the intervention patients were related to the number of contacts with their GP and number of readmission days in the following 6 months. Higher scores on self-care abilities meant less contact with their GP ( $\mathrm{r}=-0.33, \mathrm{p}=0.0 \mathrm{I} 8)$ and fewer readmission days in the following 6 months for cardiac causes. These relationships are not found in the $\mathrm{CG}$.

\section{Heart failure related self-care behavior}

Self-care behavior showed little or no relationship with number of readmissions for cardiac causes. In the CG a significant correlation existed between self-care behavior at I month after discharge and number of readmission days for cardiac reasons at 3 months after discharge $(r=-0.30, p<0.0 I)$. Patients with higher scores on self-care behavior had fewer readmission days for cardiac causes.

\subsection{Discussion}

This study demonstrates that education and support by a nurse in a hospital setting and at home significantly increases self-care behavior in patients with heart failure. The 19 -item questionnaire was developed from literature. The authors recognized that it was important to define an objective outcome measure for which the intervention was accountable and which at the same time gave additional clues for improvement of care. Therefore a practical and concrete instrument was developed. Despite the low internal consistency of the scale the authors decided to report the results, since they contained valuable information for health care providers. Patients from both the intervention and the control group increased their self-care behavior within I month of discharge. probably as a result of hospitalization. The increase in the IG, however, was significantly more after I month. Although both groups decreased self-care behavior during the following 8 months, the increase from baseline remained statistically significant in the IG while this was not the case in the CG. As can be expected, the the effect of the intervention was most powerful on short-term behavior, which is reflected in significant differences in self-carc behavior between the two groups both I month and 3 months after discharge. After 9 months, the effect of the intervention decreased. The supportive-educative intervention in this study focused on various aspects of self-care. For example, adherence to medication and diet, adapting activities to their condition and knowledge on symptoms of worsening heart failure and adequate reaction to these symptoms. The extra dimesion of the intervention lies in items, while appeitring rather futile, can be of major importance to a patient with heart failure. for whom weight gain or consumption of a high salt product can make a vital difference. It can be expected that certain aspects, for example aspects related to adapting activities, are not effected by education and support. In general, most patients already rested during the day. spread activities throughout the day and decreased activiries when needed. This was often due to their poor physical condition. The intervention probably did not change this behavior. Interventions that encourage regular exercise at their own pace may be needed, because it has been shown that exercise can improve functional capacity and improve one's attitude. ${ }^{26}$ 
With the questionnaire we assessed patients behaviors as reported by them. This can raise the question if they really performed that behavior or if they only knew to perform the behavior. As described by other researchers, providing patients with information does not guarantee their knowledge and in addition, increasing knowledge may not automatically lead to increased self-care behavior. ${ }^{27.28}$ It is therefore important to use interventions that include behavioral strategies.

Even though patients from the IG were sensitized to symptoms and encouraged to call their GP or come to the Emergency Heart Center in case of worsening heart failure, resource utilization did not increase. In fact, the trend was that intervention patients had fewer visits to the Emergency Heart Center. Perhaps this was because they identified symptoms earlier and were more compliant regarding self-care. It has to be noted however, that telephone calls to the Emergency Heart Center were not registered in this study.

It was also found that patients in the IG used the Emergency Heart Center more frequently than patients in the $\mathrm{CG}$ in the subgroup of patients who visited the Emergency Heart Center. Probably more unstable patients from the IG visited the Emergency Heart Center resulting in more visits from a smaller group, while in the CG more patients went to the Emergency Heart Center, but did not need to return.

The intervention did not have a significant effect on readmission rates in this study. In other studies, large reductions in readmission rates were found as a result of various intensive interventions. ${ }^{10,15,21.29}$ The absence of effects on readmission in our study may be due to several reasons. First, comparing our overall 3-month readmission rate $(26$ and $31 \%$ ) to other studies, we notice that readmission rates in our study were lower than those reported by other groups that found 90 -day $/ 3$ month readmission rates for all causes of 29 and $42 \% .^{15.30}$ Specifying this for readmissions for cardiac reasons, we notice that readmission after 90 days $(23 \%)$ was close to the $17 \%$ readmission rate of the IG in the study of Rich et al., who evaluated a multidisciplinary comprehensive discharge program. ${ }^{15}$ Control patients in that study had a readmission rate for heart failure of $39 \%$. Other studies reported that $50 \%$ of the heart failure patients were readmitted within 6 months. ${ }^{10.31}$ This is comparable to our 9-month findings ( $37 \%$ and $50 \%$ ). Our $23 \%$ readmission rate for cardiac reasons in surviving patients after 9 months can also be compared to the $19 \%$ readmission rate reported in non-transplanted patients after an intensive comprehensive heart failure management program. ${ }^{21}$ This strongly suggests that readmission rates in the United States are not comparable to European readmission rates, probably as a result of a different health care system. Our 90-day readmission rate is comparable to a Dutch epidemiological study of heart failure patients, in which it was reported that the percentage of patients readmitted for heart failure within 6 months after their first discharge was $14 \%$. 2

A second explanation for not finding a significant difference in readmission rates ciln be found in the length and intensity of the intervention (the "dose" of the intervention). ${ }^{33}$ During hospital admission patients were visited several times by the study nurse and after discharge patients were called and visited once. Considering the close need for follow-up the intervention period seems well chosen ${ }^{34}$ However, it could be more effective if the intervention had been applied partially in the home situation, and more tailored to the needs of the patient. A recent study reported that a home based 
intervention did not have statistically significant effects on the number of patients experiencing an unplanned readmission or death, but it was effective in preventing individual patients from requiring large numbers of readmissions with acute heart failure..$^{35}$ Continued home visits tailored to the patient needs would be more appropriate. On the other hand one could ask where the optimal point is between time spend with patients and the effectiveness of that time in modifying patients' behavior.

The fact that patients' self-care behavior decreased after I month may point to the need for a longer term intervention or reinforcement contacts. Various components of optimal care are described including a heart failure clinic, home health care cardiac specialists, community-based case managers, patient tele-management and hospitalsponsored cardiac rehabilitation. ${ }^{34}$ In several studies a combination of these resources was used, for example a special heart failure center with optimal dosing of drugs, follow-up contact and access to rehabilitation programs, ${ }^{21}$ a multidisciplinary comprehensive program including intense follow-up, ${ }^{15}$ intensive home-care surveillance ${ }^{36}$ and managing by patients' physicians with special expertise in heart failure. ${ }^{29}$

In the current study, we found that education and support are effective in improving patients self-care behavior; however, it is not enough to decrease readmission. Experiences during the study revealed that although patients knew what to do when symptoms occurred, they sometimes could not get the attention of a health care provider in time or the health care provider decided to wait for another week to take action because of busy schedules. Changes in the organization of patient care and the intensity of follow-up are probably indispensable to prevent unnecessary readmission. This could easily be accomplished by a close and longer follow-up by a health care professional (e.g. nurse or GP) and increased accessibility of such a person. Such an increased follow up and increased accessibility might work as a "safety net" for patients in case of deterioration.

An important aspect of disease management programs is the creation of a multidisciplinary culture so that treatment strategies can be undertiken in the patient's home rather than during hospitalization after the fact. ${ }^{11}$ Finally, patients in this study were somewhat older than patients in the studies reporting a decrease in readmission rates. ${ }^{15.21 .29}$ It is known that readmission rates in the elderly are high. Despite a wellstructured multidisciplinary approach and careful discharge planning it is estimated that at least $8 \%$ of patients will still be readmitted within 3 months. ${ }^{37}$ However, in addition to the importance of developing strategies, treatment and prevention of heart failure in older individuals. it is also important to improve the care of older heart failure patients. ${ }^{38}$ Different aspects of non-pharmacological interventions need to be studied, including content and organizational aspects (e.g. group intervention)

The high numbers of readmissions for diagnoses other than heart failure also have to be considered. Together with other authors, we noticed that co-morbid illness is an important cause of adverse outcomes among all hospitalized heart failure patients and that interventions should also focus on other causes of readmissions. ${ }^{39}$

Reviewing the resource utilization in this study, we found that within I month of hospital discharge, 75 of the patients $(57 \%)$ had a follow-up appointment with their cardiologist. Only to patients did not have any scheduled appointment with a cardiologist, internist or general practitioner within a month of discharge. Given that the 
first 30 days after hospital discharge are most important in preventing readmission, ${ }^{34}$ our findings of no difference in readmission rates may be related to the close medical follow-up patients received.

We also found that patients with heart failure use a considerable amount of health care resources within 9 months of discharge. This is reflected by the fact that in addition to scheduled appointments with an internist or cardiologist, $73 \%$ visited another specialist. On the other hand, patients showed limited use of home nursing care, home health and other health care services. Comparing our results to a general older population in the Netherlands, patients in this study used slightly more physiotherapy (27 vs. $14 \%$ ), but the use of home nursing care and home help was comparable. ${ }^{40}$ This is surprising considering the compromised physical capacity of patients in this study.

In conclusion, the current study suggests that intensive, systematic, tailored and planned education and support by a nurse results in an increase in patients self-care behavior, especially concerning complying with the heart failure regimen and asking for help if symptoms worsen. No significant effects were found on use of health care resources. Additional organizational changes such as longer follow-up and the availability of a heart failure specialist, will probably enhance the effects of education and support.

\subsection{References}

I. Ho KK, Pinsky JL, Kannel WB, Levy D. The epidemiology of heart failure: the Framingham Study. J Am Coll Cardiol I 993; 22(Suppl A): 6-I 3.

2. Bonneux L, Barendregt JJ, Meeter K, Bonse] GJ, van der Maas PJ. Estimating clinical morbidity due to ischemic heart disease and congestive heart failure: the future rise of heart failure. Am J Public Health 1994; 84: 20-28.

3. Eriksson H. Heart failure; a growing public health problem. J Intern Med I995; 237: 135-141.

4. Croft JB, Giles WH, Pollard RA, Casper ML, Anda RF, Livengood JR. National trends in the initial hospitalization for heart failure. J Am Geriatr Soc 1997:45: $270-275$.

5. Reitsma JB, Mosterd A, de Craen AJ, Koster RW, van Capelle FJL, Grobbee DE. Thijssen JGP. Increase in hospital admission rates for heart failure in The Netherlands, 1980-1993. Heart 1996; 76: 388-392.

6. McMurray J, McDonagh T, Morrison CE, Dargie HJ. Trends in hospitalization for heart failure in Scotland 1980-1990. Eur Heart J I 993; 14: I I58 1 I62.

7. Dracup K, Baker DW, Dunbar SB, Dacey RA, Brooks NH, Johnson JC, Okin C, Massie BM. Management of heart failure. II. Counseling, education, and lifestyle modifications. JAMA 1994; 272: 1442-1446.

8. Stockdale Woolley R. The effects of education on self-care agency. Public Health Nurs I 984; I: 97-106.

9. Hagenhoff BD, Feutz C. Conn VS, Sagehorn KK. Moranville-Hunziker M. Patient education needs as reported by congestive heart failure patients and their nurses. J Adv Nurs 1994; I 9: 685-690. 
Io. Happ MB. Naylor MD. Roe Prior P. Factors contributing to rehospitalization of elderly palients with heart failure. J Cardiovase Nurs I 997; I I: 75-84.

II. Mark DB. Eionomics of treating heart failure. Am J Cardiol 1997; 80 (suppl.): $33-38$.

I 2. Martens KH, Mellor SD. A study of the relationship between home care services and hospital readmission of patients with congestive heart failure. HomeHealthc-Nurse 1997; 15: 123-129.

13. Nikolaus T, Specht-Leible N, Kruse W, Oster P, Schlierf G. The early rehospitalization of elderly patients; causes and prevention [in German]. Dtsch Med Wschr 1992; I 17 : 403-407.

14. Rich MW, Gray DB, Beckham V, Wittenberg C, Luther P. Effect of a multidisciplinary intervention on medication compliance in elderly patients with congestive heart failure. Am J Med I996; Ior: 270-276.

I 5. Rich MW, Beckham V, Wittenberg C, Leven CL, Freedland KE, Carney RM. A multidisciplinary intervention to prevent the readmission of elderly patients with congestive heart failure. N Engl J Med I995; 333: I 190-I 195.

I6. Vinson JM, Rich MW, Sperry JC, Shah AS, McNamara T. Early readmission of elderly patients with congestive heart failure. J Am Geriatr Soc I990; 38: $1290-1295$.

17. Gooding J, Jette AM. Hospital readmissions among the elderly. J Am Geriatr Soc I 985; 33: 595-601.

18. Graham H, Livesley B. Can readmissions to a geriatric medical unit be prevented? The Lancet 1983; 2 I: 404-406.

19. Weinberger M, Oddone EZ, Henderson WG. Does increased access to primary care reduce hospital readmissions? Veterans Aftairs Cooperative Study Group on Primary Care and Hospital Readmission. N Engl J Med I 996; 334: I 44I1447.

20. Heart failure: management of patients with left ventricular systolic dysfunction. Agency for Health Care Policy and Research. Am Fam Physician I 994; 50: $603-616$.

21. Fonarow GC, Stevenson LW, Walden JA, Livingston NA, Steimle AE, Hamilton MA, Moriguchi J, Tillisch JH, Woo MA. Impact of a comprehensive heart failure management program on hospital readmission and functional status of patients with advanced heart failure. J Am Coll Cardiol 1997; 30: 725-732.

22. Carlson KJ, Lee DC, Goroll AH, Leahy M. Johnson RA. An analysis of physicians" reasons for prescribing long-term digitalis therapy in outpatients. J Chronic Dis 1985; $38: 733-739$.

23. Jaarsma $T$, Halfens R, Cleuren $G$. Education and guidance of a patient with chronic heart failure. A case study [in Dutch]. Verpleegkunde I997; I 2: 205216.

24. Brouns G, Evers, G., Isenberg, M., Philipsen, H., Senten, M. Beoordeling zelfzorg-vermogen ASA schaal [Appraisal of self-care-agency ASA scale]. Maastricht: University of Maastricht, I 988.

25. Holm S. A simple sequentialy rejective multiple test procedure. Scand J Statist 1979: 6: 65-70. 
26. McKelvie RS, Teo KK, McCartney N, Humen D, Montague T, Yusuf S. Effects of exercise training in patients with congestive heart failure: a critical review. $J$ Am Coll Cardiol r 995; 25: 789-796.

27. Burke LE, Dunbar Jacob J. Adherence to medication, diet, and activity recommendations: from assessment to maintenance. J Cardiovasc Nurs 1995; 9: 6279.

28. Miller NH. Compliance with treatment regimens in chronic asymptomatic diseases. Am J Med I 997; I02: 43-9.

29. Hanumanthu S, Butler J, Chomsky D, Davis S, Wilson JR. Effect of a heart failure program on hospitalization frequency and exercise tolerance. Circulation I997; 96: 2842-2848.

30. Pernenkil R, Vinson JM, Shah AS, Beckham V, Wittenberg C, Rich MW. Course and prognosis in patients. Am J Cardiol 1997; 79: 2 I6-2 I9.

31. Krumholz HM, Parent EM, Tu N, Vaccarino V, Wang Y, Radford MJ, Hennen J. Readmission after hospitalization for congestive heart failure among Medicare beneficiaries. Arch Intern Med 1997; I 57: 99-104.

32. Mosterd A. Epidemiology of heart failure [Doctoral thesis]. Rotterdam: Erasmus University of Rotterdam, 1997.

33. Brooten $D$, Naylor MD. Nurses' effect on changing patient outcomes. Image J Nurs Sch 1995; 27: 95-99.

34. Beyond four walls: cost-effective management of chronic congestive heart failure. Washington DC: Advisory Board Company, 1994.

35. Stewart S, Pearson S, Horowitz JD. Effects of a home-based intervention among patients with congestive heart failure discharged from acute hospital care. Arch Intern Med 1998; I 58: 1067-1072.

36. Kornowski R, Zeeli D, Averbuch M, Finkelstein A, Schwartz D, Moshkovitz M, Weinreb B, Hershkovitz R, Eyal D, Miller M. Levo Y, Pines A. Intensive homecare surveillance prevents hospitalization and improves morbidity rates among elderly patients with severe congestive heart failure. Am Heart J 1995: 129: $762-766$.

37. Andrews K. Relevance of readmission of elderly patients discharged from a geriatric unit. J Am Geriatr Soc 1986; 34: 5-I I.

38. Rich MW. Epidemiology, pathophysiology, and etiology of congestive heart failure in older adults. J Am Geriatr Soc $1997 ; 45: 968-974$.

39. McDermott MM, Feinglass J, Lee PI, et al. Systolic function, readmission rates, and survival among consecutively hospitalized patients with congestive heart failure. Am Heart J 1997; I 34: 728-736.

40. Rossum $\vee$ E. Effects of preventive home visits to the elderly [Doctoral thesis]. Maastricht: University of Maastricht, I993. 
132

CHAPTER 8. EFFECTS ON RESOURCE UTLIZATION 


\title{
Chapter 9
}

\section{Quality of life in patients with heart failure; differences between patients with systolic and diastolic dysfunction}

\begin{abstract}
In today's clinical practice health care providers are increasingly confronted with patients with symptoms of heart failure. either with decreased or normal systolic function. The aims of this study were: to get insight into the quality of life of a clinical practice sample of patients with heart failure that are admitted the hospital, to determine differences between patients with systolic and diastolic dysfunction and to describe factors relating to quality of life.

Three dimensions of quality of life (functional capabilities, symptoms and psychosocial adjustment to illness) were assessed during interviews of 186 patients with chronic heart failure.

On average patients walked 172 meters in 6 minutes and reported functioning in daily life at a mean level of 4.5 MET. Patients experienced four different symptoms of heart failure.
\end{abstract}

Adapted from:

- Jaarsma T Halfens R. Huijer Abu-Saad H, Dracup K, Stappers J, van Ree J. Quality of life in older patients with systolic and diastolic heart failure. Eur J Heart Failure 1999; I: I 5 I- I60. 


\subsection{Introduction}

Heart failure is rapidly becoming one of the most prevalent cardiovascular disorders and the incidence of heart failure is expected to continue to increase in the near future. $^{1,2}$ The incidence and prevalence of heart failure rise strongly with age; the prevalence increases from approximately $\mathrm{I} \%$ in persons in their fifties to over $10 \%$ in persons older than 80 years. $^{2}$ It is generally recognized that treatment of patients with chronic heart failure has only two goals: to improve quality of life and to prolong life. ${ }^{3.4}$ It is therefore important to have insight into aspects of quality of life and related factors. Quality of life is increasingly being incorporated in large clinical trials as a complementary endpoint to the traditional outcomes of mortality and morbidity. These clinical trials primarily include patients in New York Heart Association class II and III and often only include patients with a Left Ventricular Ejection Fraction (LVEF) $<40 \%$. However, in today's clinical practice, the cardiologist and other health care providers are increasingly confronted with patients in NYHA class IV. At the same time more patients are admitted with symptoms of heart failure and normal systolic function. Although the therapeutic and prognostic implications of systolic dysfunction and primary diastolic dysfunction are different, ${ }^{5-7}$ the symptoms and signs that patients exhibit seem often similar. ${ }^{5}$ Information on the quality of life of patients with severe heart failure and patients with normal systolic function is scarce. Therefore the following research questions were formulated:

I. What is the quality of life in an older population with heart failure?

2. Are there differences in quality of life between patients with systolic and diastolic dysfunction?

3. Which clinical, demographic and selt-care variables are related to quality of life of these patients?

\subsection{Method}

\section{Patients}

During the time period May I994 to March 1997.828 patients were admitted to the cardiology ward of the University Hospital in Maastricht with symptoms of heart failure. To evaluate the accuracy of the heart failure diagnosis, the Boston scoring system was used. ${ }^{8}$ In this scoring system the various signs and symptoms documented in the history, physical examination and chest radiography are given a score. The score could range from o to 12 , with a score of 8 or higher being designated as heart failure. After verifying the diagnosis, patients were included in the study if they met the following criteria: NYHA class III and IV, diagnosed with heart failure longer than 3 months, older than 50 years of age and literate in Dutch. Patients were excluded if they had a co-existing severe chronic debilitating disease, had a psychiatric diagnosis, had a previous CABG/PTCA or valve replacement in the last 6 months or were expected to have such a treatment within 3 months. Two hundred and twenty-five patients were eligible for inclusion in the study, I 86 agreed to participate based on informed consent. 
Table 9. I: Overview of instruments and their reliability's used in the study

\begin{tabular}{lll}
\hline Instrument & $\begin{array}{l}\text { theoretical } \\
\text { range }\end{array}$ & $\begin{array}{l}\text { Cronbach's } \\
\text { alpha }\end{array}$ \\
\hline
\end{tabular}

\section{Quality of life}

Functional status:

- heart failure functional status inventory

(MET-level)

-6-minute walk

13 items $\quad 0-7.83$

meters $\quad 0 .$.

Psychosocial adjustment to illness (PAIS)

- total

- health care orientation

- vocational environment

- domestic environment

46 items $\quad 0 . .138 \quad 0.70$

8 items $0 . .24 \quad 0.70$

6 items $\quad 0 . . .18 \quad 0.75$

- sexual relationships

- extended family relationships

8 items $\quad 0 . .24 \quad 0.66$

- social environment

6 items $\quad 0 . . \mathrm{I} 8 \quad 0.90$

5 items $\quad 0 . .15 \quad 0.70$

- psychological distress

6 items $\quad 0 . .18 \quad 0.84$

$\begin{array}{lll}7 \text { items } & 0 . .2 \text { I } & 0.78\end{array}$

symptoms

- number of symptoms

- symptom distress

- symptom severity

$\begin{array}{ll}7 \text { items } & \text { 0...6 } \\ \text { VAS }^{a} & \text { o...10 } \\ \text { VAS } & \text { o...10 }\end{array}$

overall well-being

- Cantril's ladder of life

Ladder $\quad$ o... IO

\section{Self-care}

- heart failure self-care behavior scale $\quad$ ig items $0 . . .19 \quad 0.6 \mathrm{I}$

- general self-care agency (ASA)

24 items $\quad$ o...I20 0.77

${ }^{a}$ VAS: Visual Analogue Scale

Data were collected on left ventricular ejection fraction (LVEF) obtained from twodimensional echocardiography. Based on LVFF, patients were divided into 2 groups: Group I representing patients with primarily systolic heart failure and Group II, representing patients with predominantly diastolic heart failure. Patients with a LVEF $\leq 40 \%$ ( $n=144$ ) were considered as having primary systolic heart failure." "Patients with a LVEF $>50 \% \quad(n=23)$ were considered having predominantly diastolic heart failure. ${ }^{6}$ Patients with a LVEF ranging from 4 I to $50(n=19)$ were re-evaluated by a cardiologist who determined the patient group based on clinical data and data from echocardiog- 
raphy. Six of these patients were designated as Group I and I 3 as group II. After this procedure, Group I consisted of 150 patients and Group Il of 36 patients.

\section{Instruments}

In this study three data collection measures were used, namely quality of life, selfcare and demographic \& clinical measures. Data were collected from the medical chart and via interview during admission of the patient, as soon as the patient could be interviewed. The 6-minute walk was assessed one or two days before discharge.

\section{Quality of life}

To evaluate quality of life a multi-dimensional approach was used. It is gencrally accepted that both objective and subjective dimensions must be included to adequately assess the impact of heart failure on the quality of life. ${ }^{12 \cdot 16}$ Previous investigators have recommended using the three dimensions of functional capabilities. symptoms, and psychosocial perceptions. ${ }^{14.17}$ In this study a mix of subjective and objective instruments measured these three dimensions (table 9. r).

functional capabilities To asisess functional capabilitics, the Heart Failure Functional Status Inventory was used. ${ }^{17}$ This is a self-report questionnaire used in previous studies in this population. ${ }^{1-1 \times}$ Thirteen physical activities are listed and patients are asked if they can perform that activity. If patients cannot perform the activity, they are instructed to indicate by which symptom the physical activity is limited. Each activity was assigned a metabolic equivalent (MET) based on previous research. ${ }^{17.19}$ For example, if patients can bathe themselves, that activity is assigned 2 METs. In a previous study content validity and interrater reliability was established. ${ }^{i 7}$ To measure functional status in a more objective way the 6-minute walking test was used. ${ }^{20.21}$ Patients were asked to walk as far as possible in 6 minutes in a hospital corridor. The distance covered was measured, as described by previous investigators. ${ }^{17.20-22}$ The 6 -minute walk test provides a useful alternative to treadmill exercise testing in the assessment of the severity and prognosis of heart failure..$^{2.22}$ Patients consider the test to be closely related to their daily physical activity." Standardized directions were given to the patient and the same hospital corridor was used each time. No encouragement was given during the test. ${ }^{23}$ Symptoms experienced by patients during the walk (e.s. angina, dyspnea) were recorded.

symptoms Symptoms were assessed by a questionnaire on symptom occurrence, symptom severity and symptom distress. Symptoms that were assessed were: ankle edema, sleep disturbance, loss of appetite, fatigue, dyspnea and cough. A total score of symptoms was calculated by adding the number of symptoms ( $\mathrm{min}$. o, max. 6). Patients were also asked to rate symptom severity and distress on a 10-point scale. A severity and distress score was calculated as the average score on all symptoms experienced. 
psychosocial adjustment to illness A translated version of the Psychosocial Adjustment to Illness Scale was used to measure the changes a person has experienced on seven psychological and social dimensions as a result of physical illness. ${ }^{24}$ Reliability coefficients for the Dutch version of the PAIS ranged from 0.66 to (1.90 on the different subscales.

overall well-being To get a measure of overall well-being, Cantrils Ladder ("ladder of life") was used. ${ }^{25}$ Patients were asked to rate their sense of well-being with Io reflecting best possible life and o reflecting worst possible life. This instrument has been used in previous studies and is considered a valid measurement of "global well-being". ${ }^{26}$

\section{Self-care}

The Appraisal of Self-care Agency (ASA) Scale was used to assess patients' ability to care for him/herself. ${ }^{27}$ The ASA is a 24-item self-appraisal instrument. Scores range from 24 to 124 , in which 24 represents minimal and 120 maximal abilities for selfcare. In this study Chronbach's alpha of the ASA scale was 0.80 . In addition, a specific behavior instrument was developed, the Heart Failure Self-care Behavior Scale. This is a 19-item questionnaire, with each item listing a specific activity related to heart failure. For example "I weigh myself twice a week" or "I restrict my sodium intake". For each item the patient is asked to respond with yes or no. A total score is calculated by all positive answers. Cronbach's alpha for this scale was 0.63 .

\section{Demographic and clinical data}

At the time of admission to the hospital, data were collected on NYHA classification, demographics, etiology and medication.

\section{Analysis}

Descriptive statistics were used to characterize the study population. To compare the clinical, demographic and self-care characteristics of the patients with systolic and diastolic dysfunction, t-tests (2-tailed) for continuous variables and the chi-square statistic for discrete variables were used. Correlations were obtained using Pearson productmoment correlation coefficients. Three scparate backward multiple regression analyses were used to identify variables that best predict the three components of quality of life.

\subsection{Results}

\section{Demographic, clinical and self-care characteristics}

Demographic, clinical and self-care characteristics of patients in the two groups are listed in table 9.2. In the total group the majority of the patients were male, married and retired or on a disability pension. The age ranged from 50 to 94 years (mean age of $73 \pm 9$ years). Most patients $(62 \%)$ were NYHA classification IV. The mean 
Table 9.2: Demographics, clinical characteristics and self-care in relation to type of heart failure ( $n=186$, values given as $n(\%)$ or mean \pm sd)

\begin{tabular}{|c|c|c|c|c|}
\hline & $\begin{array}{l}\text { total group } \\
(n=186)\end{array}$ & $\begin{array}{c}\text { group I } \\
\text { (systolic HF) } \\
(\mathrm{n}=150)\end{array}$ & $\begin{array}{c}\text { group II } \\
\text { (diastolic HF) } \\
(\mathrm{n}=36)\end{array}$ & p value \\
\hline \multicolumn{5}{|l|}{ Demographics } \\
\hline Age in years & $73 \pm 9$ & $73 \pm 9$ & $77 \pm 8$ & $<0.05$ \\
\hline \multicolumn{5}{|l|}{ Persons providing: } \\
\hline Emotional support & $1 . I \pm 2 . I$ & $\mathrm{I} . \mathrm{I} \pm 2 . \mathrm{I}$ & $0.9 \pm 2.0$ & ns \\
\hline Practical support & $3.5 \pm 2.6$ & $3.6 \pm 2.7$ & $3 \cdot 3 \pm 2.2$ & $\mathrm{~ns}$ \\
\hline Male gender & $107(58 \%)$ & $94(63 \%)$ & I $3(36 \%)$ & $<0.005$ \\
\hline Married & $99(53 \%)$ & $84(56 \%)$ & $15(42 \%)$ & ns \\
\hline \multicolumn{5}{|l|}{ Socio-economic status } \\
\hline Low & $126(68 \%)$ & $102(68 \%)$ & $24(67 \%)$ & \\
\hline medium/high & $60(32 \%)$ & $48(32 \%)$ & I $2(33 \%)$ & ns \\
\hline \multicolumn{5}{|l|}{ Clinical characteristics } \\
\hline Length of heart disease in years & $9 \pm 8$ & $9 \pm 8$ & $7 \pm 7$ & ns \\
\hline Quetelet index $\left(\mathrm{kg} / \mathrm{m}^{2}\right)$ & $24.7 \pm 4.8$ & $24.5 \pm 4.6$ & $25.2 \pm 5.6$ & ns \\
\hline $\operatorname{LVEF}(\%)$ & $34.5 \pm \mathrm{r} 3.4$ & $29.2 \pm 7.5$ & $56.4 \pm 9.9$ & - \\
\hline Number of previous admissions & $3 \pm 2$ & $3 \pm 2$ & $3 \pm 2$ & ns \\
\hline Prior MI & $108(58 \%)$ & $96(65 \%)$ & $12(33 \%)$ & $<0.00 \mathrm{I}$ \\
\hline Prior CABG & $48(26 \%)$ & $42(28 \%)$ & $6(17 \%)$ & ns \\
\hline \multicolumn{5}{|l|}{ Co-morbidity } \\
\hline Diabetes mellitus & $56(30 \%)$ & $45(30 \%)$ & I I $(3 \mathbf{I} \%)$ & ns \\
\hline Hypertension & $53(29 \%)$ & $38(25 \%)$ & I $5(42 \%)$ & 0.05 \\
\hline Lung disease & $43(23 \%)$ & $37(25 \%)$ & $6(17 \%)$ & ns \\
\hline Rheumatoid arthritis & $12(7 \%)$ & $8(5 \%)$ & $4(11 \%)$ & ns \\
\hline NYHA III & $3 I(17 \%)$ & $28(19 \%)$ & $3(8 \%)$ & \\
\hline NYHA III-IV & $40(22 \%)$ & $32(22 \%)$ & $8(22 \%)$ & \\
\hline NYHA IV & I I $4(62 \%)$ & $89(60 \%)$ & $25(70 \%)$ & $\mathrm{ns}$ \\
\hline \multicolumn{5}{|l|}{ Self-care } \\
\hline HF related behavior & $9.2 \pm 3$ & $9.2 \pm 3$ & $9.4 \pm 3$ & ns \\
\hline General self-care & $89.5 \pm 12$ & $89.6 \pm$ I I & $89.1 \pm 12$ & $\mathrm{~ns}$ \\
\hline
\end{tabular}

LVEF of the total sample was $34.5 \%$ ( \pm 13.4 ). The underlying reasons for heart failure, as mentioned in the medical chart were ischaemic heart disease ( 98 patients, $53 \%$ ), valvular disease ( 86 patients, $46 \%$ ), cardiomyopathy ( 42 patients, $23 \%$ ) and hypertension $(23 \%)$. Patients could be classified with more than one underlying reason for heart failure.

Fifty-eight percent of the patients had a history of MI and $26 \%$ had had a CABG in the past. On average, patients had been diagnosed with heart disease for 9 years and the majority of them had been hospitalized at least once with a cardiac event. Almost 
Table 9.3: Medication on admission and discharge of the total group $(n=186)$

\begin{tabular}{|c|c|c|c|c|}
\hline & \multicolumn{2}{|c|}{ admission } & \multicolumn{2}{|c|}{ discharge } \\
\hline & $\mathrm{n}$ & $\%$ & $\mathbf{n}$ & $\%$ \\
\hline Diuretics & 156 & 84 & 170 & 91 \\
\hline Vasodilator therapy $^{a}$ & 133 & 72 & 145 & 78 \\
\hline Nitrates & I 30 & 70 & 157 & 84 \\
\hline Anticoagulant therapy & 90 & 48 & I I 2 & 60 \\
\hline Digoxine & 79 & 43 & 88 & 47 \\
\hline Antiplatelet therapy & 52 & 28 & $4 I$ & 22 \\
\hline Anti arrhythmic drugs & $5^{r}$ & 27 & 60 & 32 \\
\hline Calcium antagonists & 35 & 19 & 30 & I6 \\
\hline Beta blockers & I 8 & 10 & I 6 & 9 \\
\hline Dopaminergic drugs & 18 & 10 & 22 & 12 \\
\hline
\end{tabular}

$a_{\text {including ACE-inhibitors }}$

one-third of the patients had atriul fibrillation at time of admission. At admission, most of the patients were using diuretics $(84 \%)$, vasodilators $(72 \%)$ and nitrates $(70 \%)$ (table 9.3). Serum sodium was $139( \pm 4) \mathrm{meq} / \mathrm{l}$ and creatinine was $147( \pm 79) \mu \mathrm{mol} / \mathrm{l}$.

Of the specific self-care behaviors related to heart failure, patients reported on average compliance with 9 of the 19 self-care behaviors. On the general self-care agency scale, patients scored an average of 89.5 ( \pm I 2$)$.

\section{Quality of life}

Quality of life as described by the three dimensions of functional capabilities, symptoms and psychosocial perceptions, are described in table 9.4. Of the total sample, 113 patients $(61 \%)$ completed the 6-minute walk. Twenty-three patients did not complete this test because they refused to so or because they were discharged without the possibility of completing the test. Fifty patients were not able to complete the test due to physical disabilities. Of the I I 3 patients, 25 (22\%) were unable to walk 25 meters: the maximum distance covered in 6 minutes was 543 meters. On average patients were able to walk 172 ( \pm 113$)$ meters. Patients in NYHA-class III walked longer distances than patients in class III-IV and IV (216 m, $160 \mathrm{~m}, 158 \mathrm{~m}$, respectively); however, these differences did not reach statistical significance ( $F=I .9, p=0.16$ ). Forty-three patients did not report any symptoms during the test; 7 complained of dyspnea, 23 had fatigue, 6 reported both dyspnea and fatigue, 4 reported dizziness and 5 suffered from leg pain.

Patients reported functioning in their daily lives at a mean level of $4.5 \mathrm{MET}$. Only 12 patients stated they were able to perform heavy work such as scrubbing floors or lifting heavy furniture. On average, patients reported having four different symptoms ( \pm I.5) of advanced heart failure. Most of them experienced dyspnea ( $90 \%$ ), fatigue $(73 \%)$, sleep disturbance $(70 \%)$ and ankle edema (70\%). Symptom severity and symp- 
Table 9.4: Dimensions of quality of life in relation to type of heart failure ( $n=186$, values given as $n(\%)$ or mean $\pm s d)$ )

\begin{tabular}{|c|c|c|c|c|}
\hline & $\begin{array}{l}\text { total group } \\
(n=186)\end{array}$ & $\begin{array}{c}\text { group I } \\
\text { (systolic HF) } \\
(\mathrm{n}=150)\end{array}$ & $\begin{array}{c}\text { group II } \\
\text { (diastolic HF) } \\
(n=36)\end{array}$ & $\mathrm{p}$ value \\
\hline \multicolumn{5}{|l|}{ Functional capabilities } \\
\hline 6 min walk in meters & $\begin{array}{c}172 \pm 133 \\
(n=113)\end{array}$ & $\begin{array}{r}177 \pm 138 \\
(n=88)\end{array}$ & $\begin{array}{l}\text { I } 55 \pm: 112 \\
(n=25)\end{array}$ & ns \\
\hline MET & $4.5 \pm I .6$ & $4.5 \pm 1.7$ & $4.4 \pm \mathrm{I} .4$ & ns \\
\hline \multicolumn{5}{|l|}{ Symptoms } \\
\hline Dyspnea & $168(90 \%)$ & $134(89 \%)$ & $34(94 \%)$ & ns \\
\hline Fatigue & I $36(73 \%)$ & $107(71 \%)$ & $29(81 \%)$ & ns \\
\hline Sleep disturbance & $130(70 \%)$ & $105(70 \%)$ & $25(69 \%)$ & ns \\
\hline Ankle edema & $122(66 \%)$ & $91(61 \%)$ & $3 I(86 \%)$ & $<0.005$ \\
\hline Cough & $93(50 \%)$ & $79(53 \%)$ & $14(39 \%)$ & ns \\
\hline Loss of appetite & $82(44 \%)$ & $66(44 \%)$ & I $6(44 \%)$ & ns \\
\hline number of symptoms & $3.9 \pm 1.5$ & $3.9 \pm i .5$ & $4.1 \pm 1.2$ & ns \\
\hline symptom severity & $7.0 \pm 2.3$ & $7 . I \pm 2.2$ & $6.7 \pm .2 .6$ & ns \\
\hline symptom distress & $7 . \mathrm{I} \pm \mathbf{2 . 6}$ & $7.2 \pm 2.5$ & $6.5 \pm 3.1$ & ns \\
\hline Total PAIS-score ${ }^{a}$ & $35 \cdot 5 \pm 19$ & $36.4 \pm 19.4$ & $32.1 \pm 17.1$ & ns \\
\hline Health care orientation & $7 . \mathrm{I}+4.4$ & $6.8 \pm 4.3$ & $8.4 \pm 4.6$ & $<0.05$ \\
\hline Vocational environment & $6.7 \pm 4.3$ & $6.8 \pm 4.4$ & $6.2 \pm 4.1$ & $\mathrm{~ns}$ \\
\hline Domestic environment & $4.8 \pm 3.5$ & $5.0 \pm 3.5$ & $3.9 \pm 3.1$ & ns \\
\hline Sexual relationships & $3.5 \pm 5.1$ & $3.7 \pm 5.2$ & $2.6 \pm 4.8$ & ns \\
\hline Extended family relationships & I. $5 \pm 2.4$ & $1.5 \pm 2.5$ & I. $3 \pm 2.2$ & ns \\
\hline Social environment & $6.7 \pm 5.7$ & $6.7 \pm 5.7$ & $4.8 \pm 5.4$ & ns \\
\hline Psychological distress & $5.6 \pm 4.6$ & $5.8 \pm 4.6$ & $4.8 \pm 4 \cdot 3$ & ns \\
\hline Overall well-being & $6.4 \pm 2.2$ & $6.4 \pm 2.2$ & $6.6 \pm 2.2$ & ns \\
\hline
\end{tabular}

${ }^{a}$ lower scores on the PAIS mean better psychosocial adjustment

tom distress was rated as average 7.2 on a Io-point scale.

On the Psychosocial Adjustment to Illness Scale patients reported most problems in social and vocational environment and least on extended family relationship.. On the ladder of life, patients placed themselves on average at $6.4( \pm 2.2)$ out of ro.

\section{Differences between patients with systolic and diastolic heart failure}

Group I patients (systolic heart failure) were more likely to be male, younger and had a higher prevalence of prior myocardial infarction. Systemic hypertension was diagnosed more often in group II (diastolic heart failure) (table 9.2). 
Table 9.5: Correlations between quality of life dimensions ( $p<0.001$ )

\begin{tabular}{|c|c|c|c|c|}
\hline & PAIS & MET & 6-min walk & \# symptoms \\
\hline MET & -0.32 & & & \\
\hline 6-min walk & ns & 0.41 & & \\
\hline \# symptoms & 0.32 & -0.38 & ns & \\
\hline well-being & -0.41 & ns & 0.36 & ns \\
\hline
\end{tabular}

On the quality of life dimensions (table 9.4). only the occurrence of ankle edema was different. More patients with diastolic heart failure reported having experienced ankle edema than patients with systolic heart failure $\left(\mathrm{x}^{2}=8.3, \mathrm{p}<0.005\right)$.

Group I patients (systolic dystunction) had an overall worse psychosocial adjustment to illness (higher scores on the PAIS). They had higher scores on all the subscales of the PAIS, except the domain "health care orientation". Patients with systolic dysfunction reported a statistically significant higher adaptation than patients with diastolic dysfunction. These differences were not significant except for the subscale health care orientation

\section{Relation between quality of life dimensions}

In table 9.5 the relations between the quality of life dimensions are presented. All dimensions were moderately interrelated, with exception of the 6-minute walk. The 6minute walk was not correlated with symptoms and psychosocial adjustment to illness.

Overall well-being score of patients was significantly correlated with two of the dimensions of quality of life, psychosocial adjustment $(r=-0.41)$ and functional capabilities (6-minute walk: $r=0.36$, MET level: $r=19, p<0.005$ ). That is, the higher the global feeling of well-being, the better the functional capacity and the better psychosocial adjustment to illness was reported. The number of symptoms was not related to overall well-being. To determine how much these three components of quality of life predicted the overall sense of well-being of patients, a separate hackward multiple regression analysis was used with overall well-being as the dependent variable and $\mathrm{MET}$ level, 6-minute walk, PAIS-score and number of symptoms as predictors. Psychosocial adjustment, MET-level and 6-minute walk explained $25 \%$ of the variance of global well-being.

\section{Relation between quality of life and clinical, demographic, and self-care variables}

Three separate backward multiple regression analyses were used to identify variables that best predict the three components of quality of life (table 9.6). Based on findings from literature the variables from table 9.I were entered into the model. Instead of LVEF. type of heart failure (systolic/diastolic) was entered into the model.

Demographic clinical characteristics and self-care behavior explained $26 \%$ of the variance in psychosocial adjustment to illness (as measured by the PAIS). NYHA class 
Table 9.6: Results (Standard $\beta$ ) of backward multiple linear regression analyses with the quality of life dimensions as the dependent variables

\begin{tabular}{|c|c|c|c|}
\hline & \multicolumn{3}{|c|}{ Quality of Life } \\
\hline & $\begin{array}{r}\text { Psychosocial } \\
\text { adjustment } \\
\text { PAIS }\end{array}$ & $\begin{array}{r}\text { Functional } \\
\text { capacity } \\
\text { MET }^{b}\end{array}$ & $\begin{array}{c}\text { Symptoms } \\
\text { number }\end{array}$ \\
\hline & Adj $R^{2}=0.26$ & $\operatorname{Adj~} R^{2}=0.3^{8}$ & $\operatorname{Adj} R^{2}=0.2 \mathrm{I}$ \\
\hline \multicolumn{4}{|l|}{ Demographics } \\
\hline Age & & & -0.20 \\
\hline Gender & & -0.42 & 0.27 \\
\hline \multicolumn{4}{|l|}{ Clinical characteristics } \\
\hline Weight loss during admission & & & 0.24 \\
\hline Diabetes & & O.I 3 & \\
\hline Lung disease & & -0.17 & \\
\hline NYHA class III-IV & 0.20 & & \\
\hline NYHA class III & 0.05 & & \\
\hline No. of previous admissions & $0.3 \mathrm{I}$ & & 0.20 \\
\hline Prior bypass & 0.16 & & \\
\hline \multicolumn{4}{|l|}{ Self-care } \\
\hline HF related behavior & & -0.14 & \\
\hline General self-care & -0.41 & 0.38 & $\multimap 0.22$ \\
\hline
\end{tabular}

aPAIS: Psychosocial Adjustment to Illness Scale: higher scores means worse adjustment

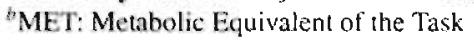

III-IV, low previous admission rate, having a history of bypass surgery, and a higher self-care agency were associated with a higher level of psychosocial adjustment to illness.

Demographic, clinical characteristics and self-care behavior explained $38 \%$ of the variance of functional capacity as measured by MET level. Being male, having diabetes, not having lung disease and better self-care were associated with higher MET levels (i.e. patients were able to perform more strenuous activities of daily life).

Demographic, clinical characteristics and self-care behavior explained $21 \%$ of the variance in number of symptoms. Being older, being male, having lost fewer kilos during admission, fewer previous admissions and a higher self-care agency were associated with fewer symptoms. 


\subsection{Discussion}

\section{Quality of life and related factors}

This study described objective and subjective dimensions of quality of life in a sample of older patients with systolic or diastolic heart failure in NYHA III and IV. Functional capabilities of this sample are relatively low, compared to findings from previous research. On average patients walked 172 meters in 6 minutes. There was a large difference within the group. Some patients only walked 20 meters and others walked up to 54.3 in 6 minutes. For comparison, in a study of patients in NYHA class III and IV by Dracup et al., ${ }^{17}$ the average distance walked was 255 meters and in a study by Stevenson et al. ${ }^{28}$ patients walked 445 meters. In another study, normal subjects walked 683 meters in 6 minutes. ${ }^{21}$

The results suggest that this sample may have had more severe disease, which explains a relatively low level of functioning. Part of the differences can be explained by the higher age of this sample, since walking distance correlates significantly with age. ${ }^{22}$

Another explanation is that these patients completed the test during admission to the hospital instead of during a visit to an outpatient clinic or during evaluation for transplantation. These differences suggest that patients in daily practice that are admitted to the hospital are often in a worse condition than patients in clinical trials or those who arc evaluated in a transplant clinic. The total population of hospital patients with heart failure probably even will be worse than reflected in this study, since 50 patients in the sample could not take the test because of their physical condition and 23 others would not take the test or refused (with one of the main reasons that they thought it might exhaust them too much). Some authors question whether the 6-minute walk does capture important elements of quality of life for some patients, for example patients who must live or prefer to live a sedentary life-style. ${ }^{16}$ In this study, however, performance on the 6-minute walk correlated significantly with overall well-being. Patients that could walk longer distances reported higher scores on overall quality of life.

Patients in this study also reported lower average functioning in their daily lives compared to other studies. Patients reported functioning at a mean level of 4.5 METs. For comparison, in other studies of patients with advanced heart failure, MET levels of 5.5 .9 and 5.3 were reported. ${ }^{17.28 .29}$ Post-transplantation samples reported levels of 7.9 and $7.3 \mathrm{METs}{ }^{28.29}$ As one might anticipate, comorbidity was related to levels of functioning. Patients with lung disease reported lower levels of functioning. Patients with multiple conditions have been described as showing greater decline in functioning and well-being than those with one condition. ${ }^{30}$ The additive effects of comorbid conditions on functional status and well-being underscore the importance of considering both the primary diagnosis and comorbidity. ${ }^{30}$ Having diabetes was also significantly related to higher level of functioning. It is likely that these patients have had a chronic condition for longer and have adjusted their activities slowly to their chronic disease.

In this study, patients reported higher psychosocial adaptation compared with other studies with similar patient populations and with patients recovering from a cardiac event. ${ }^{17.3 k}$ Dracup et all. ${ }^{17}$ converted their PAIS scores to standardized area l-scores with a score of 50 as the reference norm using a reference group of patients with ischaemic 
heart disease. After converting our PAIS scores to the same standardized area t-scores, patients reported a better psychosocial adjustment to illness than their heart failure sample ( 48 vs. 55 ). A possible explanation is that patients in this study were older and their expectations of life might have been less high than patients who are struck by a cardiac event while functioning in an active life or than younger patients with heart failure who expect to have a transplant.

Patients from the sample had an average length of heart disease of 9 years (ranging from 3 months to 40 years), meaning that patients were often already known with for example an MI or angina in the past. Previous studies have demonstrated that chronically ill patients have a remarkable capacity to adapt to their illness and generally will report better quality of life than individuals in the general population who are asked to imagine themselves having a chronic illness and to rate their quality of life. ${ }^{32}$

In contrast to other studies clinical factors were related to psychosocial adjustment. ${ }^{17}$ Patients with a history of bypass surgery, NYHA class III-IV and more hospital admissions in the past reported more problems in adaptation. Since the proportion of patients that return to the hospital increases with every new readmission, it could be important to evaluate patients' problems with adaptation to prevent possible readmission. ${ }^{33}$

Symptoms of heart failure were consistent with findings from others. ${ }^{17}$ Younger patients and women reported more symptoms than older and male patients did, which is consistent with other researchers, who reported higher frequencies of psychological and psychosomatic complaints in female cardiac patients. ${ }^{34}$ Patients with more admissions in the past reported more symptoms during this admission. These patients are probably in a worse condition than patients that are not readmitted that often. As expected, patients that lost more weight during admission reported more symptoms at admission.

All three dimensions of quality of life were related to self-care. Patients who reported higher abilities to care for themselves reported higher levels of functioning, better psychosocial adjustment and fewer symptoms. Based on these results, one has to be: careful with assigning cause and effect between self-care and quality of life variables. In the case of the relationship between psychosocial adjustment to illness, one might argue that patients with high self-care abilities would have fewer problems adapting to their illness. Enhancing patients' self-care abilities by education and support could help patients adapt to their heart failure. Looking at the relationship between self-care and functional status or symptoms, this seems to be less clear. However patients could have fewer symptoms because they have higher self-care abilities or their self-care abilities could be restricted because of their symptoms. More research is needed to gain insight into these relationships.

Patients' rating of their overall well-being in this study (6.4) was comparable to a sample of patients before their bypass surgery who rated their overall well-being as. 6 pre-operatively. ${ }^{26}$ On first instance. one might argue that patients' overall quality of life is not as bad as one might would expect. However, patients in cardiac rehabilitation and patients after cardiac surgery rated their overall quality of life much higher ( 8 and 7.5). ${ }^{26.35}$ This may be due to the fact that the life expectancy of these patients is better than that of patients with chronic heart failure. Overall well-being of patients was 
related to psychosocial adjustment and functional capabilities. However, only $25 \%$ of the variance was explained by these variables. Health related quality of life constitutes one dimension of quality of life; economic and social aspects play a major role. ${ }^{16,36}$

\section{Diastolic/systolic dysfunction}

The sample with diastolic dysfunction was significantly older, consisted of more female patients and more often had a history of MI and hypertension. This is comparable to other studies. ${ }^{5.6 .11}$ Although prognosis in patients with normal systolic function is better than patients with systolic dysfunction, their quality of life is as bad. ${ }^{37}$ No considerable differences in quality of life between patients with diastolic and systolic dysfunction were found. Patients reported the same symptoms and the same number of symptoms, with the exception of ankle edema, which was reported significantly more often by patients with diastolic dysfunction. Patients also did not differ significantly in different aspects of psychosocial adjustment, with the exception of health care orientation. meaning that patients with systolic heart failure reported less problems with the medical system and treatment than patients with diastolic heart failure. Functional capabilities did not differ either.

In clinical practice, patients with heart failure and a normal systolic function comprise a large number of all cases of heart failure. In a recent study it was found that $70 \%$ of subjects with clinical heart failure had normal left ventricular systolic function. ${ }^{33}$ Although the most appropriate approach for diagnosis and treatment of diastolic dysfunction has not been defined completely ${ }^{38}$ it seems important to consider quality of life issues in this population. because their quality of life is as compromised as in a systolic heart failure population.

\section{Study limitations}

In this study quality of life was assessed based on the three dimensions identified by Wenger et al. ${ }^{14}$ By using three dimensions of quality of life it is not possible 10 give a "single one" score for quality of life. However, by considering dimensions instead of a total score, it is possible to look at different aspects of quality of life. Knowledge of the different aspects can help shape the development of appropriate intervention strategies impacting on quality of life.

To assess functional capabilities patients" self-report was used and the 6-minute walking test. Patients only pertormed the 6 -minute walk once according to our protocol. It is possible that absolute distances walked might have increased with subsequent walks due to the "training effect" previously documented. ${ }^{22.39}$ However even though distance may increase during multiple testing. first and second walks have been shown to be highly correlated. ${ }^{22}$ It is thus unlikely that additional walks would have materially altered our results. Fifty patients could not take the 6-minute walking test because of their physical condition and 23 would not take the test or refused primarily because they thought it might exhaust them too much. These high numbers of patients that could not perform the test also confirm the statement that patient comorbidity (e.g. arthritis) and frailty limit the use of the 6-minute walk. ${ }^{16}$ The HFFSI can be used in a 
frail population, however it is based on self-report.

\subsection{Conclusion and clinical implications}

Patients with heart failure seen in clinical practice are often not comparable to patients described in major clinical trials or patients that are admitted for transplant evaluation. Their functional capabilities are more compromised, but they may have fewer problems with psychosocial adjustment. It is known that quality of life in heart failure is diminished in patients with systolic dysfunction. It is also important to notice that patients with normal systolic function also report low quality of life, compared to other samples. In treating these patients it is also important to consider quality of life issues. Interventions to enhance quality of life in heart failure patients have to be developed. All three dimensions of quality of life were related to patients' abilities to care for themselves. It could be important to enhance self-care abilities of patients to improve psychosocial adaptation to illness.

\subsection{References}

I. Ho KK, Pinsky JL, Kannel WB, Levy D. The epidemiology of heart failure: The Framingham study. J Am Coll Cardiol 1993; 22: 6A- I3A.

2. Cowie MR, Mosterd A. Wood DA. Deckers JW. Poole-Wilson PA. Sutton GC. Grobbee DE. The epidemiology of heart failure. Eur Heart J 1997; 18: 209-225.

3. Cohn JN. Current concepts in the treatment of congestive heart failure. Cardiology 1997; (suppl 2): 2-6.

4. Taylor SH. Congestive heart failure: Towards a comprehensive treatment. Eur Heart J 1996; I 7(suppl B): 43-56.

5. Senni M, Redfield MM. Congestive heart failure in elderly patients. Mayo Clin Proc 1997: 72: 453-460.

6. McAlister FA. Teo KK. The management of congestive heart failure. Postgrad Med J 1997: 73: 194-200.

7. Vasan RS. Benjamin EJ. Levy D. Congestive heart failure with normal left ventricular systolic function. Ach Intern Med I 996; I 56: I 46-I 57.

8. Carlson KJ, Lee DC. Goroll AH, Leahy M, Johnson RA. An analysis of physicians' reasons for prescribing long-term digitalis therapy in outpatients. J Chron Dis 1985: $38: 733-739$.

9. Konstam M, Dracup K, Baker D et al. Heart failure: evaluation and carc of patients with left ventricular systolic dysfunction. Clinical Practice Guideline No I 1. AHCPR Publication No. 94-06I2. Rockville, MD: Agency for Health care policy and research, public health service, US Department of Health and Human Services, June 1994.

I0. Anorow WS. Echocardiography should be performed in all elderly patients with congestive heart failure. J Am Geriatr Soc 1994; 42: 1300-1302.

I 1. Pernenkil R. Vinson J, Shah AS, Beckham V. Wittenberg C, Rich MW. Course and prognosis in patients. Am J Cardiol 1997: 79: 216-2 19. 
12. McCullough LB. Concept of quality of life: a philosophical analysis. In: Wenger NK, Mattson ME, Furberg CD, Elinson J. (eds.) Assessment of quality of life in clinical trials of cardiovascular therapies. New York: Le Jacq Publishing, 1984: 25-35.

13. Levine S, Croog SH. What constitutes quality of life? In: Wenger NK, Mattson ME. Furberg CD. Elinson J, editors. Assessment of quality of life in clinical trials of cardiovascular therapies. New York: Le Jacq Publishing, 1984: 46-56.

14. Wenger NK, Mattson ME, Furberg CD, Elinson J, editors. Assessment of quality of life in clinical trials of cardiovascular therapies. New York: Le Jacq Publishing, 1984 .

15. Aaronson NK. Quantitative issues in health related quality of life assessment. Health Policy 1988; I0: 217-230.

I6. Hadom D, Baker D, Dracup K, Pitt B. Making judgements about treatment effectiveness based on health outcomes: theoretical and practical issues. J Qual Impr 1994: 20: 547-554.

17. Dracup K. Walden JA, Stevenson LW, Brecht ML. Quality of life in patients with advanced heart failure. J Heart Lung Transplant 1992; I I: 273-279.

18. Hawthorne MH, Hixon ME. Functional status, mood disturbance and quality of life in patients with heart failure. Progress Cardiovasc Nurs 1994: 9: 22-32.

19. Fardy P, Yanowitz F, Wilson P. Cardiac rehabilitation of the coronary patient. Philadelphia: Lea \& Febiger, I 988.

20. Guyatt GH, Thompson PJ, Berman LB, Sullivan MJ, Townsend M, Jones NL, Pugsley SO. How should we measure function in patients with chronic heart and lung disease. J Chron Dis 1985; 38: 5r 7-524.

21. Lipkin DP, Scriven AJ, Crake T, Poole-Wilson PA. Six minute walking test for assessing exercise capacity in chronic heart failure. BMJ 1986; 292: 653-655.

22. Bittner V, Weiner DH, Yusuf S, Rogers WJ, McIntyre KM, Bangdiwala S, Kronernberg MW, Kostis JB. Kohn RM, Guilotte M. Greenberg B, Woods PA, Bourassa MG. Prediction of mortality and morbidity with a 6-minute walk test in patients with left ventricular dysfunction. JAMA 1993; 270: 1702-1707.

23. Guyatt GH, Pugsley SO, Sullivan MJ, Thompson PJ, Berman LB, Jones NL, Fallens EL, Taylor DW. Effect of encouragement on walking test performance. Thorax 1984; 39: 818-822.

24. Derogatis L. Scoring and procedures manual for PAIS. Baltimore: Clinical Psychometric Research, 1976.

25. Cantril H. The pattern of human concerns. New Brunswick: Rutgers University Press. 1965 .

26. Senten CMS. The well being of patients having CAB surgery: a test of Orem's self-care nursing theory [Doctoral thesis]. Maastricht: University of Maastricht, I 99 I.

27. Brouns G, Evers G, Isenberg M, Philipsen H, Senten CMS. Appraisal of Selfcare Agency scale [in Dutch|. Maiastricht, 1988.

28. Stevenson LW. Sietsema K, Tillisch JH et al. Exercise capacity for survivors of cardiac transplantation or sustained medical therapy for stable heart failure. Circulation I y9(): 81 : $78-85$. 
24. Walden JA. Stevenson LW, Dracup K. Wilmarth J, Kobashigawa J, Moriguchi J. Heart transplantation may not improve quality of life for patients with stable heart lailure. Heart Lung I 989; I 8: 497-506.

30. Stewart AL, Greentield S, Hays RD. et al. Functional status and well-being of patients with chronic conditions. JAMA 1989; 262: 907-9I 2.

31. Moser DK, Dracup K. Psychosocial recovery from a cardiac event: the influence of perceived control. Heart \& Lung 1995: 24: 273-280.

32. Adang EMM, Kootstra G, Baeten CGMI, Engel GL. Quality of life ratings in patients with chronic illnesses (letter to the editor). JAMA 1997; 277: 1038.

33. Mosterd A. Epidemiology of heart failure. [Doctoral thesis] Rotterdam: Erasmus University of Rotterdam, 1995.

34. Wicklund I, Herlitz J, Johansson S, Bengtson A, Karlson BW, Persson NG. Subjective symptoms and well-being difler in women and men after myocardial infarction. Eur Heart J I 993: 14: I 315-1319.

35. Packa DR, Branyon ME, Kinney MR. Khan SH, Kelley R, Miers LJ. Quality of life of elderly patients enrolled in cardiac rehabilitation. J Cardiovase Nurs I989; 3: $33-42$.

36. Muirhead J, Meyerowitz BE, Leedham B, Eastburn TE, Merrill WH, Frist WH. Quality of life and coping in patients awaiting heart transplantation. J Heart Lung Transplant 1992; 11: 265-272.

37. Tresh DD, McGough MF. Heart failure with normal systolic function: a common disorder in older people. J Am Geriatr Soc I 995; 43: I 035 -' 1042.

38. Lehinan DJ, Gerson MC, Hoit BD, Walsh RA. Mechanisms, diagnosis, and treatment of diastolic heart failure. Am Heart J I 995; 1 30: I53-I 66.

39. Knox AJ, Morrison JF, Muers MF. Reproducibility of walking test results in chronic obstructive airway discase. Thorax 1988; 43: 388-392. 


\title{
Chapter 10
}

\section{Effects of education and support on self-care and quality of life}

\begin{abstract}
To study the effects of education and support an experimental study was performed, enrolling I 79 patients (mean age $73,58 \%$ male NYHA III, IV) with heart failure. Three dimensions of quality of life (functional capabilities, symptoms and psychosocial adjustment to illness) were assessed during interviews at baseline and at 1,3 and 9 months after discharge. In addition, an overall well-being score was obtained. During these interviews data on self-care agency and self-care behavior were also collected.

Self-care abilities did not change as a result of the intervention but the self-care behavior in the intervention group was higher than the self-care behavior in the control group during follow up. The intervention proved to be effective for patients with both high and low levels of self-care behavior at baseline. The effect of the supportiveeducative intervention on quality of life was limited. Quality of life as measured by functional capabilities, number of symptoms and psychosocial adjustment improved after hospitalization in both groups, with no differences between intervention and control group throughout the study period. However, there was a trend indicating differences in symptom frequency and distress.

It is concluded that the intervention is effective in improving self-care behavior but a more intensive intervention is needed to show effectiveness in improving quality of life.
\end{abstract}

Adapted from:

- Jaarsma T, Halfens R, Huijer Abu-Saad H. Dracup K, Diederiks J, Tan F. Selfcare and quality of life in patients with advanced heart failure: the effect of a supportive educative intervention. Heart and Lung (accepted for publication) 


\subsection{Introduction}

Heart failure is a very common, disabling and deadly disorder, and has recently reached epidemic proportions. The prevalence and incidence of heart failure rise strongly with age; the prevalence increases from, approximately $\mathrm{I} \%$ in people in their fifties to over ro\% in people older than 80 years. ${ }^{1-4}$ The number of patients with heart failure is expected to grow further as the proportion of elderly within the population increases, as the prognosis of patients with heart failure improves by surgical and medical interventions and as survival from myocardial infarction improves. ${ }^{2,4}$

Symptoms and treatment of heart failure have a great impact on the lives of patients with heart failure and therefore improving quality of life is generally recognized as one of the major goals of treatment of patients with heart failure. ${ }^{5-7}$ Quality of life may be secn as a reflection of the way that patients experience changes in their health status and other aspects of their lives and is defined as a multi-dimensional and subjective concept. $^{\gamma-12}$ Dimensions of quality of life that are considered important for patients with heart failure are functional capabilities, symptoms and psychosocial perceptions. ${ }^{10}$ In addition, a subjective overall feeling of well-being of the patient is considered important, since this can reflect the values and preferences of individual patients. ${ }^{8}$

In previous studies it is found that patients with heart failure describe their quality of life as poor ${ }^{13-16}$ and that interventions to improve quality of life need to be targeted at reducing depression and hostility, increasing daily activity levels improving knowledge on heart failure and learning self-care skills. ${ }^{14.15}$ Educating and supporting patients about heart failure treatment and consequences may expected to increase self-care abilities and improve self-care behavior. ${ }^{17,18}$ Higher self-care abilities and improved self-care behavior can give patients more control of their daily lives. These are expected to help patients deal better with their social function (e.g. in household, family) and as a result may have an influence on their psychological state (e.g. anxiety, depression). If patients can take better care of themselves and adhere to heart failure treatment, it can be expected that they will experience fewer symptoms and better functional capabilities. ${ }^{4.19}$ In addition, education and support may help patients learn to live with the consequences of the disease and can affect the personal experiences of the severity of the symptoms and the level of distress." In previous rescarch in this population self-care abilities and self-care behavior were associated with improved quality of life and an overall feeling of well-being. ${ }^{22}$ In longitudinal study with bypass patients, self-care behavior related to smoking cessation and regular exercive was related to higher levels of well-being. ${ }^{21}$

In summary, it is hypothesized that education and support will incruast self-care agency and self-care behavior and have a positive effect on quality of life as reflected by three dimensions (functional capabilities, symptoms and psychosocial adjustment) and an overall well-being scure. 


\subsection{Method}

\section{Patients}

Patients who were admitted to the cardiology ward of the University Hospital of Miantricht (the Netherlands) with symptoms of congestive heart failure were potentially eligible. After verifying the diagnosis with the Boston score, ${ }^{-3}$ patients were included in the study if they met the following criteria: New York Heart Association functional class III and IV, diagnosed with heart failure longer than 3 months, older than 50 years of age and literate in Dutch. Patients were excluded from the study if they suffered from a co-existing severe chronic debilitating disease; if they were discharged to a nursing home; if they had a psychiatric diagnosis; and if they had a previous bypass surgery, angioplasty, valve replacement in the last 6 months or were expected to have such a treatment within 3 months. The institutional review boards approved the study.

\section{Study design}

An experimental design was used in this study. From May 1994 to March I 997 patients admitted to the cardiology ward were screened for their potential eligibility to the study. The attending physician determined the Boston score and checked the inclusion criteria. The researcher/research assistant obtained informed consent and collected base-line data from the medical chart and by interview. Patients were randomly assigned to receive either care as usual or a supportive-educative intervention. All patients were followed for nine months. Data were collected by interview at 1,3 and 9 months after discharge.

\section{Intervention and control group}

The intervention consisted of intensive education by a study nurse about the consequences of heart failure in daily life, using a standard nursing care plan developed by the researchers for older patients with heart failure. ${ }^{2-4}$ Important topics were discussed with every patient: for example. recognition of warning symptoms of worsening heart failure, sodium restriction, fluid balance, and compliance. In addition, individual problems were discussed: for example, problems in social interaction, sexual function and limited access to the general practitioner. Most patients received, on average about, 4 visits in the hospital, I telephone call and I home visit. During admission to the hospital, the study nurse assessed the patients' educational and counseling needs, provided education and support for the patient (and family). gave the patient a card with warning symptoms and discussed issues related to discharge. Within one week after discharge, the study nurse telephoned the patient at home to assess potential problems and to make an appointment for a home visit. During the home visit the study nurse reinforced and continued education as warranted by the patient situation. If needed, the home care nurse was informed in writing about specific patient needs. Between hospital discharge and the home visit, patients could call the study nurse in case of problems. After the home visit, the patient was advised to call their cardiologist, general practitioner or emergency heart center in case of problems. 
Patients assigned to the "care-as usual" (control group) received all standard care. This meant that a nurse or physician, depending on their individual insight or the patients' questions, provided these patients with education about medication and life style. Patients from the control group did not receive structured education, information about warning symptons, a follow-up telephone call or home visits by a nurse. Patients from the control and intervention groups were never assigned to the same room on the nursing unit. The two study nurses were involved in data collection as researcher and research assistant. However, the person who collected the data was never the same nurse who visited the patient for the intervention.

\section{Data collection}

\section{Demographic and clinical data.}

Clinical data were collected from the medical chart of the patient at the time of enrollment. These included: medical history, comorbidities, laboratory data, left ventricular ejection fraction (LVEF), New York Heart Association Classification (NYHA), weight, height, and medications. At the same time the patient was interviewed to collect demographic data (age, gender, marital status, socio-economic status, social support and living situation). Patients also completed the 6-minute walk, within 48 hours of discharge.

\section{SelF-care Agency and Self-care Behavior}

The Appraisal of Self-care Agency (ASA) Scale ${ }^{25}$ was used to assess patients' ability to care for him/herself. On this 24-item self-appraisal instrument, scores range from 24-120. This scale is used in other (Dutch) cardiac populations and is considered a reliable and valid instrument. ${ }^{21.26}$ The ASA-scale was administered at the time of enrollment, and at 3 and 9 months after discharge. Cronbach's alpha of the ASA scale in this study ranged from 0.80 to 0.87 .

Self-care behavior was assessed using the Heart Failure Self-care Behavior Scale. This is a 19 -item questionnaire, developed for this study, with each item listing a specilic activity related to heart failurc; for example "I weigh myself twice a week" or "I restricl my sodium intake". For each item the patient is asked to respond with yes or no. A total score is calculated hased on all positive answers. Data on self-care behavior were collected at the time of enrollment, and at 1.3 and 9 months after discharge. Validity was established by panel of experts. In this study Cronbach's alpha for this scale ranged from 0.62 to 0.68 .

\section{Quality of life}

Quality of life was evaluated using a multi-dimensional approach with both objective and subjective dimensions. ${ }^{27-29}$ Previous investigators have recommended using the three dimensions of functional capabilities, symptoms, and psychosocial perceptions. ${ }^{10.14}$

Functional capabilities: To assess functional capabilities, the Heart Failure Functional Status Inventory was used. ${ }^{14}$ This is a self-report questionnaire used in 
previous studies in this population. ${ }^{5.15}$ Thirteen physical activities are listed and patients are asked if they can perform that activity. If patients cannot perform the activity, they are instructed to indicate by which symptom the physical activity is limited (dyspnea or fatigue). Each activity was assigned a metabolic equivalent (Met) based on previous research. ${ }^{4.30}$ For example, if patients can bathe themselves, that activity is assigned 2 Mets. In a previous study content validity and interrater reliability was established. ${ }^{14}$ A mean score of the three highest scored items is calculated. Functional capabilities were assessed at the time of enrollment, and at 3 and 9 months after discharge.

Symptoms: Symptoms were assessed by a questionnaire on symptom occurrence, symptom severity and symptom distress. Patients were asked if they experienced the following symptoms during the last month: ankle edema, sleep disturbance, loss of appetite, fatigue, dyspnea and cough. A total score of symptoms was calculated by adding the number of symptoms ( $\min 0, \max 6$ ). Patients were also asked to rate symptom severity and distress on a I0-point scale. A severity and distress score was calculated as the average score on all symptoms experienced. Symptoms were assessed at the time of enrollment and at I (only number of symptoms), 3 and 9 months after discharge.

Psychosocial adjustment to illness: To measure psychosocial adjustment to illness. a translated version of the Psychosocial Adjustment to Illness Scale (PAIS) was used. ${ }^{31}$ The PAIS is a 46-item self-report questionnaire that measures the changes a person has experienced on seven psychological and social dimensions as a result of physical illness. These seven dimensions are health care orientation, vocational environment, domestic relationships, sexual relationships, extended family relationships. social and leisure activities and psychological distress. Cronbach's alpha in this study ranged from 0.66 to 0.90 on the different subscales. The PAIS was administered at time of enrollment, and 3 and 9 months after discharge

Overall well-being: To get a measure of overall well-being, Cantril's Ladder ("ladder of life") was used.32 Patients were asked to rate their sense of well-being with 10 reflecting best possible life and o reflecting worst possible life. This instrument has been used in previous studies and is considered a valid measurement of "global well-being"." Patients rated their overall well being at time of enrollment, I, 3 and 9 months after discharge.

\section{Statistical analysis}

Descriptive statistics are expressed as means \pm standard deviation (sd). The control and experimental group werc compared by Chi-square test for discrete variables and by Student's t-test for continuous variables. Corrections for multiple testing were made by modifications of Holm. ${ }^{33}$

Since attrition was rather high and attrition seemed to be different in the control and intervention group, bias may have existed in favor of the intervention group (i.e. patients with worse outcomes may have died). To correct for this, we also performed an 
Table I0. I: Exclusion and attrition during the study period

\begin{tabular}{|c|c|c|}
\hline Admitted to cardiology ward with HF & & 828 \\
\hline readmissions & $-\mathrm{I} 84$ & \\
\hline non-screened & -66 & \\
\hline died during screening & -14 & \\
\hline & -264 & \\
\hline number of patients eligible & & 564 \\
\hline excluded according criteria: & & \\
\hline history $<3$ months & $-17 \mathrm{I}$ & \\
\hline Psychiatric diagnosis, dementia, cancer & $-3 I$ & \\
\hline NYHA < III, or cardiac intervention & -22 & \\
\hline Boston score $<6$ & -12 & \\
\hline Age $<50$ & -12 & \\
\hline Discharged to nursing home & -9 & \\
\hline Language & -5 & \\
\hline More than one exclusion criterion & -76 & \\
\hline & -352 & \\
\hline Target population & & 226 \\
\hline No infurmed consent & -40 & \\
\hline Baseline sample (randomized) & & I 86 \\
\hline died befure dischirge & -7 & \\
\hline & -7 & \\
\hline Discharged alive & & 179 \\
\hline died within 1 month & $-\mathrm{II}$ & \\
\hline nonresponse within I month & o & \\
\hline & $-\mathrm{II}$ & \\
\hline I month & & 168 \\
\hline died between $\mathrm{I}-3$ months & -14 & \\
\hline nonresponse between $1-3$ months & -4 & \\
\hline & -18 & \\
\hline 3 month & & 150 \\
\hline died between $3 \rightarrow 9$ months & -13 & \\
\hline nonresponse between $3-9$ months & -5 & \\
\hline & -18 & \\
\hline 9 months & & 132 \\
\hline
\end{tabular}

alternative analysis in which we assume that patients who dropped out did not improve their self-care agency and self-care behavior (the null hypothesis).

The relationships between the dimensions of quality of life and the self-care vari- 
ables were assessed using Pearson's correlation coefficients, with correction for attenuation. Linear regression analysis was used to correct the well-being score for the baseline score. Overall significance level was set at $5 \%$.

\subsection{Results}

\section{Study patients}

During the time period May I994 to March I997, 828 admissions for heart failure to the cardiology ward of the University Hospital in Maastricht were registered. Of these, 186 were included in the study; however, before discharge 7 patients died, leaving 179 patients in the study at discharge. Reasons for exclusion are reported in table IO.I. During the 9-month period of follow-up, 16 patients (17\%) in the control group died compared to 22 patients $(26 \%$ ) in the intervention group (not stalistically significant). Attrition due to non-response from the study was the same $(5 \%)$ in both groups. Hundred and thirty-two patients remained in the study at 9 months. Comparing the baseline characteristics of the patients that dropped out $(n=47)$ to the responders $(n=132)$, we found patients who dropped out were significantly older, lived more often in an old people's home, diagnosed with hypertension and had more often cardiomyopathy as underlying reason for heart failure. Lab-results showed higher levels of serum sodium, BUN and creatinine at baseline. The baseline characteristics of the two groups stayed comparable. Although not significant, attrition was higher in the intervention group and there was a trend toward more patients with NYHA-class IV dropping out in the intervention group.

The baseline demographic and clinical characteristics of the patients are shown in table 10.2. The mean age of the patients was 72 years; $60 \%$ were male and most lived independently at time of enrollment. During the study period 20 patients changed their home situation to dependent living, 6 patients from the control group and 14 patients from the intervention group. At time of enrollment, most of the participating patients were NYHA class IV and the mean ejection fraction was $34 \%$. Average distance walked as measured by the 6 minute walking test was 173 meters ( \pm 133 ).

\section{Self-care}

No statistically significant differences were found (after correction for multiple testing) between the two groups in self-care abilities (table 10.3). The supportive educative intervention was effective, however, in enhancing self-care behavior post-discharge. On average, patients complied with 9 of the 19 items of self-care behavior. One month after discharge, patients from both the groups reported higher self-care behavior compared with their baseline. Intervention patients reported complying with i 4 of the 19 self-care behaviors compared to $\mathbf{I} 2$ in the control group $(\mathrm{t}=3.8, \mathrm{p}=0.00 \mathrm{I})$. Both control and intervention patients decreased their self-care behavior over time. However, intervention patients still reported complying with more behaviors than control paticnts at 3 months ( $\mathrm{I} 2.2$ vs. I $0.6, \mathrm{t}=2.9, \mathrm{p}=0.005$ ) and at 9 months ( $\mathrm{I}$ I.2 vs. $\mathrm{I} 0.3, \mathrm{t}=1.6, \mathrm{p}=0 . \mathrm{I}$ I). The results at 9 months are however not significant. 
Table 10.2: Demographic and elinical characteristics at baseline of the patients that participated during 9 months of the study $(n=132)$

\begin{tabular}{llccc}
\hline & $\begin{array}{c}\text { Total } \\
\mathrm{n}=\mathrm{I} 32\end{array}$ & $\begin{array}{c}\text { Control } \\
\mathrm{n}=74\end{array}$ & $\begin{array}{c}\text { Intervention } \\
\mathrm{n}=58\end{array}$ & p value \\
\hline $\begin{array}{l}\text { Demographics } \\
\text { Age in years }\end{array}$ & $72 \pm 9$ & $72 \pm \mathrm{IO}$ & $72 \pm 9$ & $\mathrm{~ns}$ \\
$\begin{array}{l}\text { Persons providing: } \\
\quad \text { Emotional support }\end{array}$ & $\mathrm{I} . \mathrm{I} \pm 2.0$ & $\mathrm{1} .2 \pm 2.3$ & $\mathrm{I} . \mathrm{I} \pm \mathrm{I} .7$ & $\mathrm{~ns}$ \\
$\quad \begin{array}{l}\text { Practical support } \\
\text { Male gender }\end{array}$ & $3.4 \pm 2.6$ & $3.3 \pm 2.6$ & $3.4 \pm 2.9$ & $\mathrm{~ns}$ \\
Married & $79(60 \%)$ & $47(64 \%)$ & $32(55 \%)$ & $\mathrm{ns}$ \\
Dependent living & $73(55 \%)$ & $4 \mathrm{I}(55 \%)$ & $32(55 \%)$ & $\mathrm{ns}$ \\
& $\mathrm{I0}(8 \%)$ & $8(\mathrm{II} \%)$ & $2(3 \%)$ & $\mathrm{ns}$
\end{tabular}

\section{Clinical characteristics}

Length of heart disease (years)

$\begin{array}{cccc}9 \pm 7 & 9 \pm 7 & 9 \pm 8 & \text { ns } \\ 4.1 \pm 5 & 3.6 \pm 4 & 4.7 \pm 6 & \text { ns } \\ 34 \pm 14 & 34 \pm 14 & 36 \pm 13 & \text { ns } \\ 3.2 \pm 2.6 & 3.2 \pm 2.6 & 3.1 \pm 2.6 & \text { ns } \\ 75(57 \%) & 47(64 \%) & 28(48 \%) & \text { p }<0.05 \\ 30(23 \%) & 16(22 \%) & 14(24 \%) & \text { ns }\end{array}$

Prior CABG

Co-morbidity

Diabetes mellitus

Hypertension

Lung disease

Rheumatoid arthritis

Sodium (meq/l)

BUN (mg/dl)

Creatinine $(\mu \mathrm{mol} / \mathrm{l})$

NYHA III

NYHA III-IV

NYHA IV

$\begin{array}{ccc}42(32 \%) & 22(30 \%) & 20(35 \%) \\ 33(25 \%) & 19(26 \%) & 14(24 \%) \\ 34(26 \%) & 21(28 \%) & 13(22 \%) \\ 7(5 \%) & 3(4 \%) & 4(7 \%) \\ 139 \pm 3 & 139 \pm 4 & 140 \pm 3 \\ 12 \pm 6 & 12 \pm 6 & 12 \pm 7 \\ 134 \pm 59 & 132 \pm 49 & 135 \pm 70 \\ 22(17 \%) & 15(20 \%) & 7(12 \%) \\ 29(22 \%) & 17(23 \%) & 12(21 \%) \\ 81(61 \%) & 42(52 \%) & 39(67 \%)\end{array}$

ns

ns

ns

ns

ns

ns

ns

ก)

Since it was argued that the difference in atrition between the two groups might have biased the outcomes in favor of the intervention group, an analysis was presented in which we assume that patients who dropped out did not improve their self-care agency and self-care behavior from baseline. As reponed in table 10.3, follow-up differences in self-care agency and self-care behavior were smaller between the two groups, but the differences in self-care behavior at $\mathrm{I}$ and 3 months between the two groups remained statistically significant.

To investigate the interaction between the pre-test score and the change in self- 
Table r0.3: Self-care abilities, self-care behavior, per protocol analysis and alternative analysis

\begin{tabular}{lccrr}
\hline \multicolumn{5}{c}{ Per protocol } \\
\hline & control & intervention & & \\
& $\mathrm{n}=74$ & $\mathrm{n}=58$ & $\mathrm{t}$ & $\mathrm{P}$ \\
\hline Self-care abilities & & & & \\
Baseline & $92 . \mathrm{I} \pm \mathrm{I} I .3$ & $88.6 \pm \mathrm{I}$ I.2 & $\mathrm{I} .6$ & $0.1 \mathrm{I}$ \\
3 months (n=I50) & $94.2 \pm \mathrm{I} 2.9$ & $92.5 \pm \mathrm{I}$ I.5 & 0.74 & 0.46 \\
9 months ( $\mathrm{n}=\mathrm{I} 32)$ & $96.4 \pm \mathrm{I} 3.7$ & $90.9 \pm \mathrm{I} 2.8$ & 2.2 & $0.034^{a}$
\end{tabular}

Self-care behavior

\begin{tabular}{|c|c|c|c|c|}
\hline Baseline & $9.4 \pm 3.1$ & $8.7 \pm 3.1$ & I. 2 & $0.2 \mathrm{I}$ \\
\hline I month & $12.2 \pm 2.9$ & $14.2 \pm 2.9$ & 3.8 & $<0.001$ \\
\hline 3 months & $10.6 \pm 3.2$ & $I 2.2 \pm 3 . I$ & 2.9 & 0.005 \\
\hline 9 months & $10.3 \pm 2.8$ & II $.2 \pm 3 . I$ & I. 6 & o. I I \\
\hline
\end{tabular}

Alternative analysis

\begin{tabular}{lccrr}
\hline & $\begin{array}{c}\text { control } \\
\mathrm{n}=95\end{array}$ & $\begin{array}{c}\text { intervention } \\
\mathrm{n}=84\end{array}$ & $\mathrm{1}$ & $\mathrm{P}$ \\
\hline $\begin{array}{l}\text { Self-care abilities } \\
\text { Baseline }\end{array}$ & $91.5 \pm \mathrm{I} 1.2$ & $87.8 \pm \mathrm{II} .5$ & $2 . \mathrm{r}$ & 0.036 \\
3 months & $92.5 \pm \mathrm{I} 2.8$ & $91.8 \pm \mathrm{I} 2.8$ & 0.35 & 0.72 \\
9 months & $94.4 \pm \mathrm{I} 3.3$ & $90.4 \pm 13.5$ & 1.9 & 0.056
\end{tabular}

Self-care behavior

\begin{tabular}{lrrrr} 
Baseline & $9.5 \pm 3.0$ & $8.9 \pm 3.0$ & 1.3 & 0.20 \\
I month & $12.2 \pm 2.9$ & $13.8 \pm 3.4$ & 3.3 & $<0.001$ \\
3 months & $10.2 \pm 3.3$ & $11.6 \pm 3.1$ & 2.9 & $<0.005$ \\
9 months & $10.1 \pm 2.9$ & $10.4 \pm 3.1$ & 0.7 & 0.47 \\
\hline
\end{tabular}

not statistically significant after correction for multiple testing according to Holm (25)

care behavior (the effect of the intervention) at the 3 follow-up measurements, the sample was divided into four groups: "high and deteriorating", "high and improving". "low and deteriorating" and "low and improving". For example, the group "high and deteriorating" comprised patients that scored above the median on self-care behavior at baseline (9) and who did not improve or whose score deteriorated at the follow-up measure (table 10.4). At 3 months a significant interaction was found between group, baseline score and change in time between baseline and 3 months (chi-square=18.0, $\mathrm{p}<0.00 \mathrm{I}$ ). This means that patients in the intervention group who reported a high selfcare behavior at baseline were more likely to improve and less likely to deteriorate than patients in the control group. 
Table 10.4: Interaction between self-care behavior at baseline and the effect of the intervention on self-care behavior

\begin{tabular}{|c|c|c|c|c|c|c|c|}
\hline $\begin{array}{c}\text { period } \\
\text { (months) }\end{array}$ & & $\begin{array}{c}\text { high and } \\
\text { deteriorating }\end{array}$ & $\begin{array}{l}\text { high and } \\
\text { improving }\end{array}$ & $\begin{array}{c}\text { low and } \\
\text { deteriorating }\end{array}$ & $\begin{array}{l}\text { low and } \\
\text { improving }\end{array}$ & $\chi^{2}$ & P \\
\hline \multirow{2}{*}{$0-1$} & $\mathrm{CG}$ & I $8(20 \%)$ & $26(29 \%)$ & $3(3 \%)$ & $44(48 \%)$ & \multirow{2}{*}{6.5} & \multirow{2}{*}{0.090} \\
\hline & IG & $5(7 \%)$ & $23(30 \%)$ & $2(3 \%)$ & $46(6 r \%)$ & & \\
\hline \multirow{2}{*}{$0-3$} & $\mathrm{CG}$ & $27(34 \%)$ & $11(14 \%)$ & $8(10 \%)$ & $34(43 \%)$ & \multirow{2}{*}{ I 8.0} & \multirow{2}{*}{0.000} \\
\hline & IG & $6(9 \%)$ & $18(27 \%)$ & $2(3 \%)$ & $40(61 \%)$ & & \\
\hline \multirow{2}{*}{$0-9$} & $\mathrm{CG}$ & $25(34 \%)$ & $10(14 \%)$ & $9(12 \%)$ & $30(4 \mathrm{I} \%)$ & \multirow{2}{*}{7.6} & \multirow{2}{*}{0.053} \\
\hline & IG & $8(14 \%)$ & $13(23 \%)$ & $6(11 \%)$ & $30(53 \%)$ & & \\
\hline
\end{tabular}

\section{Quality of life}

\section{Functional capabilities}

Table I 0.5 shows that functional capabilities slightly increased in both groups 3 months after discharge and slightly decreased at 9 months. The increase from baseline at 3 months in the intervention group was $0.6 \mathrm{MET}(\mathrm{p}=0.0 \mathrm{r}$ ). After correction for multiple testing this increase was not significant. No difterences were found between the two groups in functional capabilities at baseline and follow-up.

\section{Symptoms}

The average number of symptoms decreased significantly in both groups from 3.9 at baseline to an average of 1.9 and 2.2 symptoms at 3 months follow-up. No difference in number of symptoms was found between patients from the two groups at any of the 4 measurement times. At all 4 measurement times most patients suffered from dyspnea. Even 9 months after the initial hospitalization more than $50 \%$ of the patients reported being short of breath, mostly at exertion. A considerable number of patients $(>60 \%)$ reported fatigue and sleep disturbance as symptoms at admission to the hospital. Almost one-third of the patients still reported these symptoms during follow-up. Ankle edema, cough and loss of appetite were also symptoms that some patients still suffered during follow-up.

The average severity of symptoms decreased $(\mathrm{p}<0.00 \mathrm{I})$ after discharge in both groups. Compared to the control group, patients from the intervention group reported higher symptom severity at baseline and lower symptom severity during follow-up. Since this might indicate that the severity of symptoms decreased more in patients from the intervention group than patients in the control group, additional analy'ses were performed on the change scores from baseline between groups (table 10.6). Patients from the intervention group reported a significantly larger decrease in symptom severity between baseline and 9 months follow-up than patients from the control group $(-2.7$ vs. $-0.6, t=2.4, p=0.02$ ). It was noted that a large number of missing values among patients in the intervention group existed. To correct for possible bias, an alternative analysis was performed with the missing values were replaced by a change score of $o$, according to the null-hypotheses. The described trend indicating a larger decrease in 
Table I0.5: Quality of life scores at baseline and during follow-up ( $n=132)$

\begin{tabular}{|c|c|c|c|c|c|}
\hline & & Baseline & I month & 3 months & 9 months \\
\hline \multirow{2}{*}{$\mathrm{MET}^{a}$} & $\mathrm{CG}$ & $4.7 \pm 1.7$ & - & $5.0 \pm 1.9$ & $4.7 \pm 2.2$ \\
\hline & IG & $4.6 \pm I .7$ & - & $5.2 \pm \mathrm{r} .7$ & $4.8 \pm 1.5$ \\
\hline \multirow{2}{*}{ Number of symptoms ${ }^{b}$} & $\mathrm{CG}$ & $3.9 \pm 1.3$ & $I .9 \pm I .4$ & $1.9 \pm x .5$ & $2.0 \pm 1.6$ \\
\hline & $\mathrm{IG}$ & $3.9 \pm 1.7$ & $1.8 \pm 1.5$ & $2.2 \pm 1.6$ & $2.0 \pm 1.7$ \\
\hline \multirow{2}{*}{ Symptom severity ${ }^{e}$} & CG & $6.7 \pm 2.4$ & - & $5.8 \pm 2.8$ & $5.9 \pm 2.3$ \\
\hline & IG & $7.6 \pm 2.2$ & - & $5.4 \pm 2.8$ & $5.3 \pm 2.8$ \\
\hline \multirow{2}{*}{ Symptom distress $^{d}$} & $\mathrm{CG}$ & $6.7 \pm 2.8$ & - & $5 \cdot 5 \pm 3 \cdot x$ & $5.9 \pm 2.7$ \\
\hline & IG & $7 \cdot 5 \pm 2.6$ & - & $5.2 \pm 3.2$ & $5 \cdot 3 \pm 2.9$ \\
\hline \multirow{2}{*}{$\mathrm{PAIS}^{e}$} & $\mathrm{CG}$ & $35.3 \pm 19.4$ & - & $30.4 \pm 20.3$ & $29.2 \pm 2$ I. 3 \\
\hline & IG & $36.2 \pm 16.0$ & - & $31.9 \pm 20.7$ & $28.4 \pm 21.6$ \\
\hline \multirow{2}{*}{ Overall well-being $f$} & CG & $6.3 \pm 2.2$ & $6.4 \pm 2.1$ & $6.7 \pm 1.9$ & $6.2 \pm 2.1$ \\
\hline & IG & $6.8 \pm 2.2$ & $7.2 \pm 1.5$ & $6.6 \pm 2.0$ & $6.7 \pm 1.9$ \\
\hline
\end{tabular}

${ }^{a}$ MET: Functional capabilities: baseline -3 months in the intervention group: $t=2.6, p=0.0$; ; after correction for multiple testing, not statistically significant

${ }^{b}$ Number of symptoms: statistically significant decrease from baseline in both groups $(\mathrm{p}<0.000)$, no differences between groups

'Symptom severity: control group - intervention group at baseline $t=3.1 \quad p=0.04$; after correction for multiple testing, not statistically significant. Statistically significant decrease from baseline in both groups $(p<0.01)$

${ }^{d}$ Symptom distress: control group - intervention group at baseline $t=-1.8 . p=0.08$ : after correction for multiple testing, not statistically significant. Statistically significant decrease from baseline in both groups $(\mathrm{p}<0.01$ )

'PAIS: Psychosocial adjustment to illness: Baseline score -9 months score: control group $t=2.3$, $p=0.03$ i intervention group: $t=2.3, p=0.03$ after correction for multiple testing, not statistically significant, no ditferences between groups

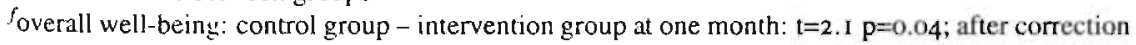
for bascline score: $t=0.1 \mathrm{I}, \mathrm{p}=0.9 \mathrm{I})$

symptom severity than control patients remained ( -1.2 vs. $-0.4, t=1.8, p=0.07$ ), but was not statistically significant

Similar to symptom severity, the average symptom distress decreased significantly ( $\mathrm{p}<0.00 \mathrm{I}$ ) after discharge in both groups. Patients from the intervention group reported higher symptom distress at baseline compared to patients from the control group. Patients from the intervention group reported a significantly larger decreases in symptom distress than patients from the control group ( -2.6 vs. $-0.8, t=2.1, p=0.04)$. After correction for multiple testing, this difference was not significant. It was also noted that a large number of missing values among patients in the intervention group existed. To 
Table I0.6: Change in symptom severity and symptom distress

\begin{tabular}{lrrrrr}
\hline & Group & n & Change & t & p \\
\hline Symptom severity & & & & & \\
\hline Change baseline-3 months & CG & 46 & $-0.7 \pm 3.5$ & I.8 & 0.07 \\
& IG & 33 & $-2.1 \pm 3.6$ & & \\
Change haseline-9 months & CG & 42 & $-0.6 \pm 3.8$ & & \\
& IG & 26 & $-2.6 \pm 3.3$ & 2.3 & 0.02 \\
Symptom distress & & & & & \\
\hline Change baseline-3 months & CG & 53 & $-1.3 \pm 3.7$ & I.5 & 0.14 \\
& IG & 38 & $-2.5 \pm 4.0$ & & \\
& & & & & \\
Change baseline-9 months & CG & 48 & $-0.8 \pm 3.7$ & 2.1 & 0.04 \\
& IG & 30 & $-2.6 \pm 3.3$ & & \\
\hline
\end{tabular}

correct for possible bias, an alternative analysis was performed with the missing values were replaced by a change score of $u$, according to the null-hypotheses. The described trend indicating a larger decrease in symptom distress than control patients remained $(-1.3$ vs. $-0.5, t=1.6, p=0.1 \mathrm{I})$, but was not statistically significant.

\section{Psychosocial adjustment to illness}

The total PAIS score decreased for both groups, compared to baseline, indicating better psychosocial adjustment to illness. In both groups, improvement from baseline to 9 months was statistically significant (control $t=2.3 p=0.03$, intervention: $t=2.3$, $\mathrm{p}=0.03$ ). No differences were demonstrated between the two groups at the three points in time in total score or in any of the 7 domains.

\section{Well-being}

Patients often stated that they had difficulty expressing their well-being on a ladder ranging from $0-10$, resulting in several missing values on this scale. Analysis of the well-being scores of the surviving 132 patients revealed that 1 month after discharge, intervention patients reported a statistically significant higher well-being score (7.2 $\pm \mathrm{I} .5)$ than the controls $(6.4 \pm \mathbf{I} .5) .(\mathrm{t}=2 . \mathrm{I}, \mathrm{p}=0.04)$. To identify any bias resulting from missing scores, an additional analysis was conducted on patients who completed all 4 measurements on well-being. Patients from the intervention group still reported higher well-being scores after $I$ months than patients from the control group ( $7 . \mathrm{I} \pm \mathrm{x} .5$ vs. $6.4 \pm 2.0, t=1.9, p=0.068$ ). However this difference was not statistically significant. In addition, it was observed that intervention patients started with a higher well-being score at baseline. After correction for baseline score, the change in well-being was not statistically different in the control and intervention group ( $t=0$. I I, $p=0.9$ I). 
Table 10.7: Correlation coefficients between quality of life and self-care variables at baseline, 3 months and 9 months follow-up

\begin{tabular}{|c|c|c|c|c|c|c|}
\hline & \multicolumn{2}{|c|}{$\begin{array}{l}\text { Baseline } \\
\text { self-care }\end{array}$} & \multicolumn{2}{|c|}{$\begin{array}{l}3 \text { months } \\
\text { self-care }\end{array}$} & \multicolumn{2}{|c|}{$\begin{array}{l}9 \text { months } \\
\text { self-care }\end{array}$} \\
\hline & agency & behavior & agency & behavior & agency & behavior \\
\hline \multicolumn{7}{|c|}{ correlation coefficients without correction } \\
\hline Self-care agency & & 0.14 & & $0.2 \mathrm{I}^{\dagger}$ & & $0.30^{\ddagger \ddagger}$ \\
\hline Functional capacity & $0.43^{\text {t+ }}$ & -0.10 & $0.36^{+1}$ & 0.10 & $0.49^{\ddagger \ddagger}$ & 0.12 \\
\hline No. of symptoms & $-0.30^{1+1}$ & 0.13 & $-0.39^{\text {f+ }}$ & -0.03 & $-0.30^{\ddagger \ddagger}$ & -0.04 \\
\hline Psych. adj. to illness & $-0.34^{\text {th }}$ & 0.13 & $-0.50^{\ddagger \ddagger}$ & $-0.20^{\dagger}$ & $-0.5 \mathrm{I}^{\ddagger \ddagger}$ & $-0.27^{\dagger}$ \\
\hline Well-being & O.II & -0.16 & 0.15 & 0.10 & $0.22^{\dagger}$ & $0.24^{\dagger}$ \\
\hline \multicolumn{7}{|c|}{ correlation coefficients corrected for attenuation } \\
\hline Self-care agency & & 0.20 & & 0.28 & & $0.4 \mathrm{I}$ \\
\hline Functional capacity & 0.48 & -0.13 & 0.39 & -0.12 & 0.53 & 0.15 \\
\hline No. of symptoms & -0.34 & 0.17 & -0.42 & -0.03 & -0.32 & -0.05 \\
\hline Psych. adj. to illness & -0.44 & 0.19 & $-0.6 \mathrm{I}$ & -0.27 & $-0.6 \mathrm{I}$ & -0.38 \\
\hline Well-being & 0.12 & 0.20 & o.I 6 & 0.12 & 0.24 & 0.30 \\
\hline
\end{tabular}

$\dagger: \mathrm{p}<0.05$

t+: $\mathrm{p}<0.001$

\section{Relationship quality of life and self-care}

There was a limited relationship between self-care abilities and heart failure self-care behavior at baseline and at 3 and 9 months after discharge (0.14, $0.2 \mathrm{I}$, and 0.30 ) (table 10.7).

Self-care ability was related to the 3 dimensions of quality of life at baseline and at 3 and 9 months after discharge as expressed by functional capabilities $(r=0.43,0.36$. $0.49, \mathrm{p}<0.00 \mathrm{I})$, psychosocial adjustment to illness $(\mathrm{r}=-0.34,-0.50,-0.51, \mathrm{p}<0.001)$ and symptoms $(r=-0.30, r=-0.39, r=-0.30, p<0.001)$. Self-care abilities correlated slightly with overall score of well-being, only at 9 months after discharge $(r=0.22$, $\mathrm{p}<0.05$ ).

Heart Failure Self-Care Behavior only showed a slight relationship with one of the quality of life dimensions, namely psychosocial adjustment at 3 and 9 months after discharge $(r=-0.20, r=-0.27$, p. 0.05). Heart Failure Self-Care Behavior correlated slightly with overall score of well-being only at 9 months after discharge $(r=0.24$, $\mathrm{p}<0.05$ ).

Correlations alter correction for attenuation are reported in table I0.7. 


\subsection{Discussion}

In this study it was expected that the supportive-educative intervention would increase the self-care abilities of patients, would improve the heart failure self-care behavior, and as a result would improve patients quality of life. Education and support was directed toward helping patients to get and remain motivated to comply with the regimen, to ask for help if symptoms worsened, and to adapt their activities. This pleads lor education and support for patients with low and with high self-care behavior, since reinforcement is an important strategy to keep patients motivated to conduct self-care behavior. ${ }^{3.4}$

Self-care abilities did not change as a result of the intervention but the self-care behavior in the intervention group was higher than the self-care behavior in the control group during follow up. With an alternative analysis, correcting for the effect of difference in attrition between the two groups, the difference in self-care behavior between the two groups during follow-up remained signiticant.

The intervention proved to be effective for patients with both high and low levels of self-care behavior at baseline. The effect of the supportive-educative intervention on quality of life was limited. Quality of life as measured by functional capabilities, number of symptoms and psychosocial adjustment improved after hospitalization in both groups, with no differences between intervention and control groups throughout the study period.

There was a trend indicating difference in change in symptom severity and distress between the two groups. Patients from the intervention group experienced their symptoms as being less frequent and less distressing 9 months after follow-up. This could be due to the intervention since patients talked a lot about their symptoms, their actions to influence symptoms and their expectations in the future. The trend in differences in experiencing symptoms indicates that although the number of symptoms can hardly be changed by education and support, the way patients experience them can be affected by a nurse. It is possible that patients in the intervention group, through the skills they learned, were better able to cope with their symptoms on the longer term ( 9 months). In a study on cardiac transplant candidates it was found that higher symptom distress correlated significantly with higher stress, less life satisfaction, and more functional disability. Interventions that teach a patient to cope with their chronic situation. like education, counseling, stress management, are advised in that patient population. ${ }^{20}$

It is noticeable that some dimensions of quality of life stayed low during the recovery period. Patients, on average, still suffered from 2 symptoms of heart failure during follow-up and that functional capabilities were low and changed slightly. Patients from this study reported lower MET levels (4.6-5.2) compared to patients with advanced heart failure from other studies reporting Met-levels of 5 to $5.9 .{ }^{4.35}$. 30 This might be due to differences in age and comorbidity in the samples. Compared with other studies, patients from this study reported high levels of psychosocial adaptation. A possible explanation is that patients in this study were older and they probably expect to have changes in their health status and don "t mind adjusting their activity levels, compared to younger patients. In addition, patients in this study had a long history of disease (mean 9 years. range 3 months to 37 years). Previous studies have demonstrated that chroni- 
cally ill patients have a remarkable capacity to adapt to their illness and generally will report better quality of life than individuals in the general population who are asked to imagine themselves having a chronic illness and to rate their quality of life ${ }^{37}$ The overall average well-being score of patients in this study remained rather constant over time. These scores are comparable to a sample of patients before their bypass surgery but lower than patients in cardiac rehabilitation and patients after cardiac surgery rated their overall quality of life much higher ( 8 and 7.5). ${ }^{21.38}$ This may be because the life expectancy of these patients is better than that of patients with chronic heart failure.

Limited association existed between the self-care abilities and the heart failure selfcare behavior. The absence of effects of education and support on the self-care abilities and the limited relationship between self-care abilities and heart failure self-care behavior can probably explained from the lack of sensitivity for change of the ASA scale. In previous research on CABS patients ASA scores also changed minimally as a result of surgery ( 89.7 to 92.1 ). ${ }^{21}$ The scale addresses general items that might be slightly affected by education and support. In addition, these general items might not be related to self-care behavior specific to heart failure. Maybe patients are perfectly able to take care of themselves, but do not integrate this in their daily behavior that is needed as a result of their heart failure.

However, the assessment of the general self-care abilities of heart failure patients was valuable in that they were moderately related to all three dimensions of quality of life, but not to the patients' rated overall well-being score. Self-care agency was related to psychosocial adjustment, functional capabilities and symptoms, patients with more self-care abilities reported better outcomes. The direction of causality is unknown. Do patients who feel better and have a better quality of life take better care of themselves, or do patients who can take better care of themselves report a higher quality of life? Additional studies are needed to explore this relationship.

We also expected that patients reporting better heart failure related self-care behavior (e.g. comply with diet, weighing) would report better quality of life. However, we only found a limited relationship between self-care behavior and psychosocial adjustment to illness and well-being. Symptoms and functional capabilities were not found to be related to self-care behavior. Better behavior does not always lead to better quality of life outcomes, reflecting the complexity of mechanisms underlying improving outcomes.

Despite the trend of differences in experiences of symptom frequency and distress. one can argue that the intervention failed to show effectiveness in improving quality of life. Few randomized studies are available that test nurse-led interventions and their effect on quality of life. In one study quality of life improved (baseline-9o days) as a result of comprehensive multidisciplinary intervention. ${ }^{19}$ In a recent study testing the effect of a management program including patient education, self-management, and follow-up no effects on quality of life were found. ${ }^{39}$ Those researchers argued that the intervention was successful in reducing readmissions and health care costs without impairing quality of life. In other words no harm was done to the patient, while the health care system benefited. It has to be questioned if health care interventions are strong enough to improve quality of life of these elderly advanced heart failure patients. It is difficult to get insight into what really constitutes a good quality of life in this 


\subsection{References}

I. Ho KK, Pinsky JL, Kannel WB, Levy D. The epidemiology of heart failure: The Framingham study. J Am Coll Card 1993; 22: 6A-13A.

2. Cowie MR, Mosterd A, Wood DA, Deckers JW, Poole-Wilson PA, Sutton GC, Grobbee DE. The epidemiology of heart failure. Eur Heart J 1997; 18 : 209-22.5.

3. Hoes AW, Mosterd A, Grobbee DE. An epidemic of heart failure? Eur Heart J I 998; 19(suppl. L): 2-Io.

4. McMurray JJV, Petrie MC, Murdoch DR, Davie AP. Clinical epidemiology of heart failure: public and private health burden. Eur Heart J I998; I9(suppl. P): 9-I6.

5. Wiklund I, Swedberg K. Some methodological problems in analyzing quality of life data in severe congestive heart failure. J Clin Res Pharma I 99 I ; : 265-273.

6. Taylor SH. Congestive heart failure: Towards a comprehensive treatment. Eur Heart J I996; I 7(suppl. B): 43-56.

7. Cohn JN. Current concepts in the treatment of congestive heart failure. Cardiol ogy I997: (suppl 2): 2-6.

8. Gill TM. Feinstein AR. A critical appraisal of the quality of life measurements. JAMA 1994; 272: 619-626.

9. McSweeny AJ, Creer TL. Health-related quality of life assessment in medical care. Disease-a-Month 1995; I: I-72.

10. Wenger NK, Mattson ME, Furberg CD, Elinson J. (eds.) Assessment of quality of life in clinical trials of cardiovascular therapies. New York: Le Jacq Publishing, 1984 .

II. Bulpitt CJ, Fletcher AE. Measurement of the quality of life in congestive heart failure-influence of drug therapy. Cardiovasc Drugs Ther I 988; 2: 419-424.

I 2. Hays RD, Anderson R, Revicki D. Psychometric considerations in evaluating health-related quality of life measures. Qual Life Res 1993; 2: 44 I-449.

13. Grady KL. Quality of life in patients with chronic heart failure. Crit Care Nurs Clin North Am 1993; 5: 66 I-670.

14. Dracup K. Walden JA. Stevenson LW, Brecht ML. Quality of life in patients with advanced heart failure. J Heart Lung Transpl 1992: I I: 27.3-279.

15. Hawthorne MH, Hixon ME. Functional status, mood disturbance and quality of life in patients with heart failure. Progr Cardiovasc Nurs 1904; 9: 22-32.

16. Westlake C. Dracup K. Predictors of quality of life for patients with advanced heart failure. Circulation r 998 (suppl I): 482.

17. Stockdale-Whoolley $\mathrm{T}$. The effects of education and support on self-care agency. Publ Health Nurs 1984: 97-I06.

18. Dodd MJ. Efficacy of proactive information on self-care in chemotherapy patients. Cancer Nurs I988; 2 1 5-225.

19. Rich MW. Beckham V, Wittenberg C. Leven CL, Freedland KE, Carney RM. A multidisciplinary intervention to prevent the readmission of elderly patients with congestive heart failure. N Engl J Med I995: 333: I Iyo-I 195.

20. Grady KL. Jalowiec A, Grusk BB, Williams CW. Robinson JA. Symptom distress in cardiac transplant candidates. Heart Lung 1992: 2 I: 434-439. 
2I. Senten CMS. The well being of patients having CAB surgery: a test of Orem's self-care nursing theory [Doctoral thesis]. Maastricht: University of Maastricht, 1991 .

22. Jaarsma T, Halfens R, Huijer Abu-Saad H, Dracup K, Stappers J, van Ree J. Quality of life in older patients with systolic and diastolic heart failure. Eur $\mathrm{J}$ Heart Failure 1999; I: 15 I-I60.

23. Carlson KJ, Lee DC, Goroll AH, Leahy M, Johnson RA. An analysis of physicians' reasons for prescribing long-term digitalis therapy in outpatients. J Chron Dis $1985 ; 38: 733-739$.

24. Jaarsma T, Halfens R. Cleuren C. Education and guidance of a patient with chronic heart failure. A case study [in Dutch]. Verpleegkunde I997: 12: 205 I6.

25. Brouns G, Evers G, Isenberg M. Philipsen H, Senten CMS. Appraisal of Selfcare Agency scale [in Dutch]. Maastricht, I 988.

26. Evers GCM. Appraisal of self-care Agency: the ASA-scale [Doctoral thesis]. Maastricht: University of Maastricht, I 989.

27. Levine $\mathrm{S}$, Croog SH. What constitutes quality of life? In: Wenger NK, Mattson ME, Furberg CD, Elinson J. (eds). Assessment of quality of life in clinical trials of cardiovascular therapies. New York: Le Jacq Publishing, 1984: 46-56.

28. Aaronson NK. Quantitative issues in health related quality of life assessment. Health Policy 1988; 10: 217-230.

29. Hadorn D, Baker D, Dracup K, Pitt B. Making judgements about treatment effectiveness based on health outcomes: theoretical and practical issues. J Qual Impr 1994: 20: 547-554.

30. Fardy P, Yanowitz F, Wilson P. Cardiac rehabilitation of the coronary patient. Philadelphia: Lea \& Febiger, 1988.

31. Derogatis L. Scoring and procedures manual for PAIS. Baltimore: Clinical Psychometric Research. I976.

32. Cantril H. The pattern of human concerns. New Brunswick: Rutgers University Press, 1965 .

33. Holm S. A simple sequentially rejective multiple test procedure. Scand J Stat I 979; 6: 65-70.

34. Burke LE, Dunbar-Jacobs J. Adherence to medication, diet, activity recommendations: from assessment to maintenance. J Cardiovasc Nurs 1995: 9: 62-79.

35. Stevenson LW, Sietsema K, Tillisch JH et al. Exercise capacity for survivors of cardiac transplantation or sustained medical therapy for stable heart failure. Circulation I 990; 8r: 78-85.

36. Walden JA. Stevenson LW, Dracup K, Wilmarth J, Kobashigawa J. Moriguchi J. Heart transplantation may not improve quality of life for patients with stable heart failure. Heart Lung I 989; 18: 497-506.

37. Adang EMM, Kootstra G, Baeten CGMI, Engel GL. Quality of life ratings in patients with chronic illnesses (letter to the editor). JAMA 1997; 277: 1038.

38. Packa DR, Branyon ME, Kinney MR, Khan SH, Kelley R. Miers LJ. Quality of life of elderly patients enrolled in cardiac rehabilitation. J Cardiovasc Nurs 1989 ; 3: $33-42$. 
39. Cline CMJ, Israelsson BYA, Willenheimer RB, Broms K, Erhardt LR. Cost effective management program for heart failure reduces hospitalization. Heart 1998; 80: 442-446.

40. Fonarov GC, Stevenson LW, Walden JA, Livingston NA, Steimle AE, Hamilton MA, Moriguchi J, Tillisch JH, Woo MA. Impact of a comprehensive heart failure management program on hospital readmission and functional status of patients with advanced heart failure. J Am Coll Card 1997; 30: 725-732.

4I. Stewart S, Pearson S, Horowitz JD. Effects of a home-based intervention among patients with congestive heart failure discharged from acute hospital care. Arch Int Med 1998; 158: 1067-1073.

42. Hanumanthu S, Butler J, Chomsky D, Davis S. Wilson JR. Effect of a heart failure program on hospitalization frequency and exercise tolerance. Circulation I 997; 96 (9): 2842-2848.

43. Brooten D, Naylor MD. Nurses effect on changing patient outcomes. Image 1995; 27: 95-99.

44. Shah NB, Der E, Ruggerio C, Heidenreich PA, Massie BM. Prevention of hospitalization for heart failure with an interactive home monitoring program. Am Heart J 1998; 135: 373-378.

45. Coats AJS, Adamopoulos S, Radaelli A, McCance A, Meyer TE, Bernardi L, Solda PL, Davey P, Ornerod O, Forfar C, Conway J, Sleight P. Controlled trial of physical training in chronic heart failure. Circulation 1992; 85: 21 I9-2I3I.

46. Wielinga RP, Huisveld IA, Bol E, Dunselman PHJM, Erdman RA, Baselier MRP, Mosterd WL. Effects of exercise training in chronic heart failure. Eur Heart J 1999; 20: 872-879.

47. Feenstra J, Grobbee DE, Jonkman FAM, Hoes AW, Stricker Ch. Prevention of relapse in patients with congestive heart failure: the role of precipitating factors. Eur Heart J 1998; 80: 432-436.

48. Strömberg A. Heart Failure clinics. Editorial. Heart I 998; 80: 426-427. 


\title{
Chapter 11
}

\section{Changes in quality of life in patients with heart failure}

\begin{abstract}
From both a clinical and theoretical perspective it is important to identify predictors of change of quality of life. In this study we analyzed which clinical, demographic, self-care and health care variables are related to a change in quality of life of patients with chronic heart failure.

Data were pooled from complete data sets of patients from an experimental study $(n=74)$ in which patients were followed for 9 months for data-collcction on quality of life, self-care and resource utilization. Multiple regression analyses were performed with the change score of each dimension of quality of life (functional capacity, symptoms and psychosocial adjustment) and well-being as the dependent variable. Clinical, demographic, self-care and health care variables were entered as the predictors.

The baseline score mainly predicted the changes in 3 dimensions of quality of life and in overall well-being. Of the demographic variables. age and gender were limited related to a change in quality of life over time. In addition, patients who were older and patients with a relative bad physical condition at baseline were less likely to improve their quality of life. In addition, self-care abilities were related to a change in quality of life but little relationship appears to exist between resource utilization and quality of life.
\end{abstract}

Adapted from:

- Jaarsma T, Halfens R, Huijer Abu-Saad H, Dracup K, Diederiks J, Tan F. Changes in quality of life in patients with heart failure: relationships with self-carc, clinical characteristics and demographics (submitted to Eur J Heart Failure). 


\subsection{Introduction}

Quality of life is recognized as a major treatment objective in chronic heart failure. ${ }^{1-9}$ It is a multidimensional and subjective concept that reflects patients' experiences with changes in their health status and other aspects of their lives. ${ }^{10}$ It encompasses the capabilities, symptoms and psychosocial characteristics that describe an individual's ability to function and to derive satisfaction from a variety of roles. ${ }^{\text {" }}$

The quality of life of patients with chronic heart failure is often poor. ${ }^{12-15} \mathrm{Re}-$ searchers have described a relationship between quality of life and various demographic and clinical variables in patients with heart failure. ${ }^{2.13 .16}$ Quality of life was found to be moderately related to patients' ability to care for themselves and their reported heart failure related self-care behavior (e.g. daily weighing, resting, and taking medication). ${ }^{17}$ Investigators have recommended interventions to improve quality of life of heart failure patients targeted at reducing depression and hostility, increasing daily activity levels and leaning self-care. ${ }^{8,12,13}$ Some authors report an improvement of quality of life as a consequence of patient education and support, ${ }^{18}$ while others describe no effect. ${ }^{19,20}$ Little information is known on the relationship between readmission and patients' quality of life. In addition, most studies on quality of life in heart failure patients are cross-sectional and little evidence is available on changes in quality of life over time. Longitudinal studies are important to identify predictors of change of quality of life. ${ }^{21,22}$ Identification of predictors of change in dimensions of quality of life and of overall well-being is important from both a clinical and theoretical perspective. Clinically we need to understand quality of life dimensions so we can design and test interventions. Theoretically we need to test our theories about quality of life and its components/dimensions and determine how quality of life can be changed.

We therefore formulated the following research question: Which clinical, demographic, self-care and health care variables are related to a change in quality of life of patients with chronic heart failure?

\subsection{Method}

Data were pooled from an experimental study on the effects of a supportive-educative nursing intervention on self-care, readmission and quality of life. ${ }^{20}$ Patients in the intervention group received extra education and support by a nurse, while the control patients received care as usual. Patients were followed for 9 months for data-collection on quality of life variables at baseline and 3 and 9 months after discharge. No differences were found between groups regarding quality of life and resource utilization. ${ }^{20}$ Data were used to conduct a prospective cohort analysis.

\section{Subjects}

Patients with heart failure who were admitted to the cardiology ward of the University Hospital of Masstricht (NL) and met the inclusion criteria were asked to participate in the study. The inclusion criteria were: Boston score $>6,{ }^{23}$ New York Heart Association (NYHA) functional class III or IV, diagnosed with heart failure longer than 
3 months, older than 50 years of age and literate in Dutch. Patients were excluded if they suffered from a co-existing severe debilitating disease; if they were discharged to a nursing home, if they had a psychiatric diagnosis or if they had previous bypass surgery, angioplasty, or valve replacement in the last 6 months or were expected to have such a treatment within 3 months.

\section{Data collection}

\section{Demographics and clinical data}

Demographics were collected during the baseline interview, which took place in the hospital prior to discharge. These included: age, gender, marital status, socio-economic status, social support and living situation. Clinical data were collected from the medical chart of the patient at the time of enrollment. This included medical history, comorbidities, laboratory data, left ventricular ejection fraction, NYHA, weight, height and medications.

\section{Resource utilization}

Data on readmission and visiting the emergency heart center were collected from the hospital database at 3 and 9 months after discharge. Patients self-report determined the number of contacts with the General Practitioner (GP) and home nursing care.

\section{Quality of life}

To evaluate quality of life a multi-dimensional approach was used, with the three dimensions of functional capabilities, symptoms, and psychosocial perceptions. ${ }^{3.24}$ In this study a mix of subjective and objective instruments measured these three dimensions.

Functional capabilities: To assess functional capabilities, activities of daily living were assessed with the Heart Failure Functional Status Inventory. This is a self-report questionnaire used in previous studies in this population. ${ }^{3.13}$ Thirteen physical activities are listed and patients are asked if they can perform that activity. If patients cannot perform the activity, they are instructed to indicate by which symptom the physical activity is limited. Each activity was assigned a metabolic equivalent (MET) based on previous research ${ }^{3.25}$ For example, if patients can bathe themselves, that activity is assigned 2 METs. In a previous study content validity and interrater reliability was established. ${ }^{3}$

Symptoms: Symptoms were assessed by a questionnaire on symptom occurrence Symptoms that were assessed were: ankle edema, sleep disturbance, loss of appetite, fatigue, dyspnea and cough. A total score of symptoms was calculated by adding the number of symptoms (range $0-6$ ).

Psychosocial adjustment to illness: A translated version of the Psychosocial Adjustment to Illness Scale (PAIS) was used to measure the changes a person has experienced on seven psychological and social dimensions as a result of physical 
illness. ${ }^{26}$ Reliability coefficients for the Dutch version of the PAIS ranged from 0.74 to 0.81 . Lower scores on the PAIS reflect better adjustment.

Overall well-being: To get a measure of overall well-being. Cantril's Ladder ("ladder of lite") was used." Patients werc asked to rate their sense of well-being with Io reflecting best possible life and o reflecting worst possible life. This instrument has been used in previous studies and is considered a valid measurement of "global well-being".

\section{Self-care}

The Appraisal of Self-care Agency (ASA) Scale was used to assess each patient's ability to care for him/herself. ${ }^{28}$ The ASA is a 24 -item self-appraisal instrument. Scores range from 24 to 124 , in which 24 represents minimal and I 20 maximal abilities for self-care. (reliability coefficients $0.80-0.87$ ). In addition, a specific behavior instrument was developed, the Heart Failure Self-care Behavior Scale. This is a 19-item questionnaire, with each item listing a specific activity related to heart failure. For example "I weigh myself twice a week" or "I restrict my sodium intake". For each item the patient is asked to respond with yes or no. A total score is calculated by all positive answers (reliability coefficients $0.62-0.68$ ).

\section{Statistical Analysis}

\section{Quality of life dimensions}

Dependent variables: Change scores for the quality of life dimensions and selfcare variables were calculated by subtracting the baseline-score from the score at 3 months $(0-3)$ and subtracting the baseline score from the score at 9 months (0$9)$. For each time period $(0-3$ and $0-9)$ three linear multiple regression analyses were performed with the change score of each dimension (functional capacity, symptoms and psychosocial adjustment) as the dependent variable.

\section{Predictors:}

- Patients reporting high quality of life can be expected to have different change scores than patients who report low quality of life. Therefore. the baseline of the three dimensions of quality of life were entered as predictors: functional capabilities, number of symptoms and psychosocial adjustment at baseline

- High self-care can be expected to be predictive of better physical and psychosocial adaptation and better compliance with heart failure treatment. Therefore self-care agency and self-care behavior at baseline, change in self-care agency and self-care behavior were entered as predictors

- Demographic and clinical variables were entered in the model if they had shown a significant relationship with the dimensions of quality of life at baseline (Jaarsma, rg99a). These were: age, gender, NYHA class, weight loss during admission, having lung disease, having diabetes, history of bypass surgery and the number of cardiac admissions prior to enrollment. 
Table Ir.I: Demographic and clinical characteristics $(n=74)$

\begin{tabular}{|c|c|c|}
\hline & $\mathrm{n}(\%)$ & mean \pm sd \\
\hline \multicolumn{3}{|l|}{ Demographics } \\
\hline Age (years) & & $71 \pm 9$ \\
\hline Male gender & $43(58 \%)$ & \\
\hline Married & $44(60 \%)$ & \\
\hline Dependent living & $4(5 \%)$ & \\
\hline \multicolumn{3}{|l|}{ Clinical characteristics } \\
\hline \multicolumn{3}{|l|}{ Baseline } \\
\hline Left Ventricular Ejection Fraction (\%) & & $35 \pm 14$ \\
\hline Weight change during admission $(\mathrm{kg})$ & & $-5 \pm 5$ \\
\hline History $\mathrm{MI}^{a}$ & $4 \times(55 \%)$ & \\
\hline History $\mathrm{CABG}^{b}$ & I $6(22 \%)$ & \\
\hline Diabetes & $20(27 \%)$ & \\
\hline $\mathrm{COPD}^{c}$ & $2 \mathrm{I}(28 \%)$ & \\
\hline NYHA III & I $2(16 \%)$ & \\
\hline NYHA III-IV & $19(26 \%)$ & \\
\hline NYHA IV & $43(58 \%)$ & \\
\hline No. of previous cardiac admissions & & $3.1 \pm 2.6$ \\
\hline \multicolumn{3}{|l|}{ Follow-up } \\
\hline \multicolumn{3}{|l|}{ No. of Readmissions } \\
\hline baseline -3 months & & $0.28 \pm 0.65$ \\
\hline baseline -9 months & & $0.74 \pm 1.2$ \\
\hline \multicolumn{3}{|l|}{ No. of readmission days } \\
\hline baseline -3 months & & $2.76 \pm 7.2$ \\
\hline baseline $\rightarrow$ months & & $6 \pm 12$ \\
\hline \multicolumn{3}{|l|}{ No. of contacts with General Practitioner } \\
\hline baseline- 3 months & & $3.6 \pm 3.5$ \\
\hline baseline-9 months & & $7 \cdot 9 \pm 7$ \\
\hline \multicolumn{3}{|l|}{ Visits to Emergency Heart Center } \\
\hline baseline -3 months & & $0.26 \pm 0.62$ \\
\hline baseline-9 months & & $0.49 \pm 1$ \\
\hline \multicolumn{3}{|c|}{ No. of contacts a month with home nursing care } \\
\hline baseline- 3 months & & $0.47 \pm 2$ \\
\hline baseline -9 months & & $1.5 \pm 7$ \\
\hline
\end{tabular}


- Since we were also interested in the relationship of resource utilization and quality of life, the following variables were also entered: number of readmissions, number of visits to the emergency heart center, number of readmission days, number of visits to GP, and the number of home nursing care visits.

- Patients from the intervention group $(n=37)$ received extra education and support and patients from the control group received care as usual $(n=37)$. To control for the effect of the intervention, the group assignment was also entered.

\section{Overall well being}

Two regression analyses with the overall well-being score at 3 and 9 months as the dependent variable were conducted. The baseline score, the change in the three dimensions (functional capabilities, symptoms and psychosocial adjustment) and selfcare, demographic and clinical variables were entered as the predictor variables. The variable group (intervention vs. control) was also entered.

\subsection{Results}

\section{Study patients}

Between May 1994 and March 1997. 179 patients were recruited for the study. During the 9 month period of follow-up, 132 patients remained in the study: attrition to mortality was $38(29 \%)$ and $9(7 \%)$ to non response. Complete data on all demographic, clinical, self-care and quality of life variables were obtained from 74 patients. Patients often had difficulty with scoring general well-being on a ro-point scale. They did not think of it on a "ratio" scale, but just thought of it as bad, not so bad, bothersome, annoying etc. Asking them to score it was often a problem, causing several missing values.

The baseline demographic and clinical characteristics of the patients are shown in table I1.1. The mean age was 71 years of age (range 50-87). Most patients were male $(58 \%)$ and $60 \%$ were married. Most patients were retired or living on a disability pension. At time of enrollment, most of the participating patients were NYHA IV $(58 \%)$ and the mean ejection fraction was $35 \%$.

\section{Change in self-care and quality of life}

As shown in table 11.2 , the mean change of self-care agency and self-care behavior was relatively small. This is also the case in the quality of life variables. However, looking at individual changes of patients. $60 \%$ of patients increased their self-care abilities within 3 months of discharge and $72 \%$ increased their self-care behavior at 9 months, with large variety between individuals (table I I.3).

Between baseline and 3 months most patients $(55 \%)$ experienced an increase in functional capacity. $80 \%$ reported fewer symptoms and $62 \%$ improved in their psychosocial adjustment to illness (lower scores reflect better adjustment). The same trend was noted at 9 months after discharge. Looking at the mean change in the overall wellbeing score of patients, the average change was close to zero (at 3 months: 0.38 , at 
Table I I.2: Baseline score and change in self-care and quality of life at 3 and 9 months after discharge $(n=74)$

\begin{tabular}{lrr}
\hline & mean \pm sd & \multicolumn{1}{c}{ range } \\
\hline Self care agency & & \\
baseline & $9 \mathrm{I} \pm \mathrm{II}$ & $68 \ldots \mathrm{I} \mathrm{I} 6$ \\
change baseline-3 months & $3 \pm \mathrm{II}$ & $-23 \ldots+23$ \\
change baseline-9 months & $3 \pm \mathrm{I} 4$ & $-38 \ldots+34$
\end{tabular}

\section{Self-care behavior}

baseline

change baseline- 3 months

change baseline- 9 months

$$
\begin{array}{lr}
9 \pm 3 & 1 \ldots 17 \\
3 \pm 5 & -11 \ldots+14 \\
2 \pm 4 & -6 \ldots+10
\end{array}
$$

\section{Functional capacity}

baseline

$$
5 \pm 2 \quad 2 \ldots 8
$$

change baseline -3 months

$$
0.7 \pm 2 \quad-3 \ldots+5
$$

change baseline $\rightarrow$ months

$$
0.3 \pm 2 \quad-3 \ldots+4
$$

\section{Number of symptoms}

baseline

$$
\begin{array}{cc}
4 \pm 1.4 & 0 \ldots 6 \\
-2 \pm 1.8 & -5 \ldots+3 \\
-2 \pm 1.7 & -5 \ldots+2
\end{array}
$$

\section{Psychosocial adjustment to illness}

baseline

change baseline -3 months

change baseline- 9 months

$$
\begin{array}{cc}
35 \pm 16 & 9 \ldots 76 \\
-4 \pm 18 & -55 \ldots+43 \\
-7 \pm 21 & -55 \ldots+61
\end{array}
$$

\section{Overall well-being}

baseline

change baseline-3 months

change baseline -9 months

$\begin{array}{rr}6.5 \pm 2.2 & 0 . .10 \\ 0.37 \pm 2.5 & -8 \ldots+9 \\ 0.03 \pm 2.7 & -8 \ldots-8\end{array}$


Table I1.3: Individual change in self-care and quality of life at 3 and 9 months after discharge $(n=74)$

\begin{tabular}{llcc}
\hline & & \multicolumn{2}{c}{ percent change } \\
& & $0-3$ months & $0-9$ months \\
\hline Self-care agency & Increase & 60 & 65 \\
& Decrease & 37 & 34 \\
Self-care behavior & Same & 3 & I \\
& Increase & 72 & 66 \\
& Decrease & 23 & 26 \\
Functional capacity & Same & 5 & 8 \\
& Increase & 55 & 60 \\
Number of symptoms & Decrease & 23 & 27 \\
& Same & 22 & 13 \\
Psychosocial adjustment to illness & Increase & 35 & 4 \\
& Increase & 6 & 80 \\
& Decrease & 80 & 16 \\
& Same & 14 & 68 \\
& Decrease & 62 & I \\
Well-being & Same & 3 & 38 \\
& Increase & 38 & 39 \\
& Decrease & 28 & 23 \\
& Same & 34 & \\
\hline
\end{tabular}

"Lower scores mean better adjustment; a decrease means improvement in adjustment 
9 months 0.027 ). However, looking at individual changes we notice that between baseline and both 3 and 9 months after discharge, the overall well-being score increased in $38 \%$ of patients. The range of increase was from $\mathrm{r}$ to 9 points on a ro point scale. In a considerable minority of patients the overall feeling of well being did not change from baseline ( 3 months, $34 \%, 9$ months $23 \%$ ).

\section{Relationships with changes in quality of life}

Table II.4 displays the results of the linear regression analyses performed with the change scores of each of the three dimensions of quality of life as the dependent variable. Changes in all three dimensions of quality of life (functional capabilities, symptoms and psychosocial adjustment to illness) were related to their baseline score. Other variables were related in a limited way to the change in the dimensions of quality of life.

Change in functional capabilities was negatively related to the baseline score ( $-0.7 \mathrm{I}$ at 3 months and -0.63 at 9 months, $p<0.00$ r), meaning that lower functional capabilities at baseline were associated with improvement and better functional capabilities at baseline were associated with a decrease in functional capabilities over time. Self-care agency at baseline and improvement of self-care agency was related to improvement of functional capacity at 3 months $(0.44, p<0.005$ and $0.36, p<0.05)$. There was a negative relationship between the change in functional capabilities at 3 months and self-care behavior at baseline $(-0.42, \mathrm{p}<0.05)$; low self-care behavior at baseline was related to improvement of functional capacity. Age, comorbid lung disease and diabetes were negatively related to changes in functional capabilities between baseline and 3 months $(\mathrm{p}<0.05)$.

The change in the number of symptoms was strongly related to the number of symptoms at baseline ( $0.6 \mathrm{I}$ at 3 months and 0.65 at 9 months, $\mathrm{p}<0.00 \mathrm{I}$ ). More syıup toms at baseline were related to a greater decrease of symptoms. In addition, higher functional capabilities at baseline were related to a greater decrease in symptoms at 3 months $(-0.42, p<0.005)$. No self-care variables were related to a change in number of symptoms. Change in symptoms at 9 months was related to the number of contacts with the GP $(0.37, p<0.05)$. Increase in symptoms was related to more contacts with the GP $(0.37, \mathrm{p}<0.05)$, female gender $(-0.0 .25, \mathrm{p}<0.05)$ and being in the control group $(0.25, \mathrm{p}<0.05)$. Weight loss during admission was related to an increase in symptoms at 3 months $(0.21, \mathrm{p}<0.05))$.

Change in psychosocial adjustment to illness was negatively related to the bancline measurement: good adjustment at baseline (low PAIS-score) was related to poor psychosocial adjustment on follow-up $(-0.57$ at 3 months and -0.54 at 9 months. p . 0.00r).

Functional capacity at baseline was negatively related to change in PAIS at 9 months. meaning that patients with higher functional capacity at baseline had improvement of psychosucial adjustment within 9 months follow-up. Changes in self-care abilities over the 3 months time period were positively related to an increased psychosocial adjustment.

In addition, worsening of psychosocial adjustment was related to an incrcised num- 
Table Ir.4: Results of regression analyses $(\beta)$ with the change in quality of life dimensions as the dependent variables $(n=74)$

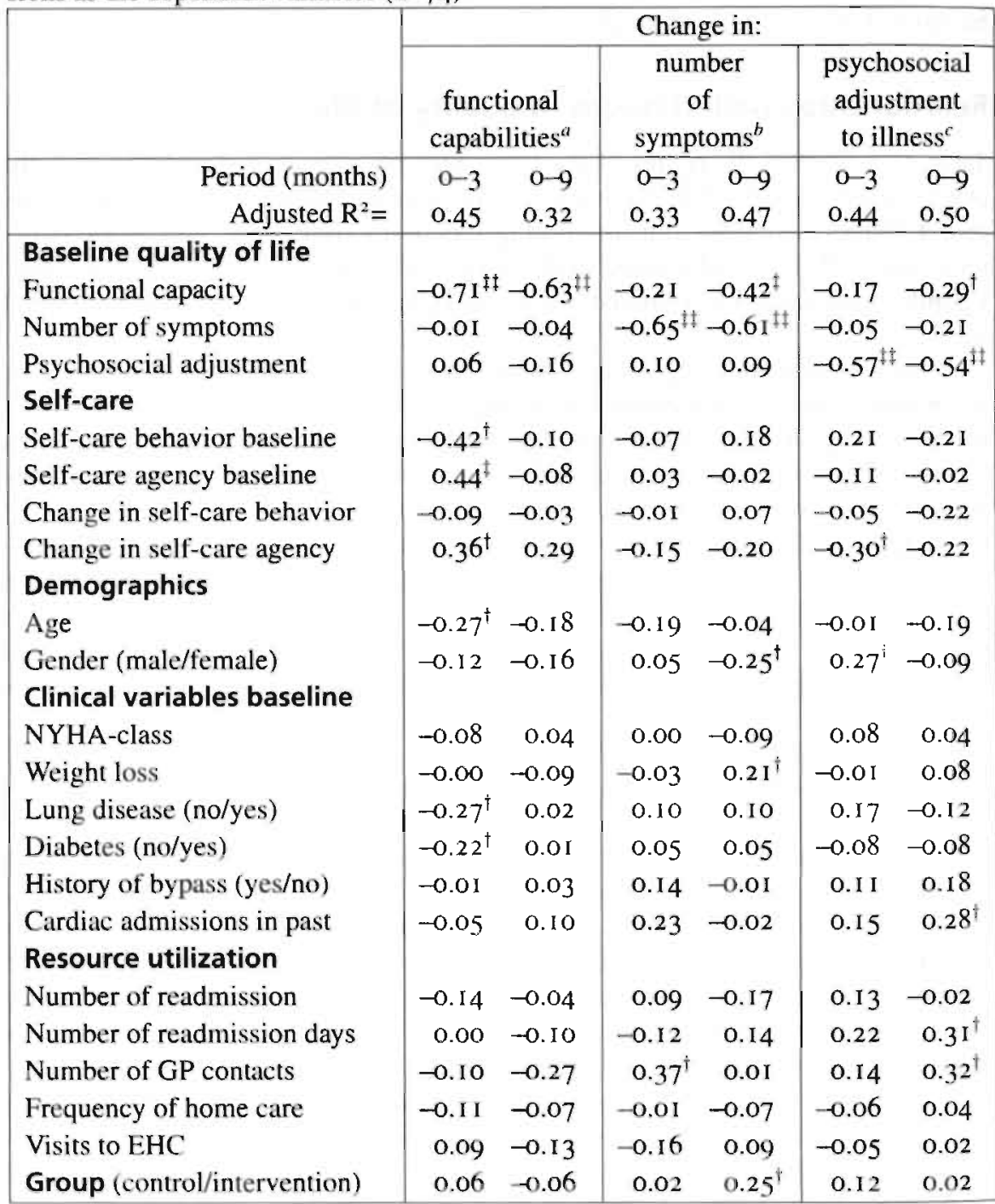

$\mathrm{i}: \mathrm{p}<0.05$

$\$: p<0.005$

t+: $\mathrm{p}<0.001$

"higher scores mean increase in functional capacity over time

${ }^{b}$ higher scores mean increase in symptoms over time

chigher scores mean increase in PAIS = worse adjustment 
ber of readmission days at 9 months $(0.3 \mathrm{r}, \mathrm{p}<0.05)$ and the number of contacts with the GP at 9 months $(0.32, p<0.05)$. Number of admissions for cardiac reasons prior to enrollment in the study was also related to a worsening of psychosocial adjustment within 9 months. Males reported improvement in psychosocial adjustment at 3 months (0.27, $\mathrm{p}<0.05)$.

\section{Change in overall well-being}

The results of the two regression analyses on the change in overall well-being are shown in table I1.5. Overall well-being at baseline was strongly related to the change score at follow-up ( -0.75 at 3 months and -0.83 at 9 months). At 3 and 9 months the change in PAIS was related to the change in overall well-being $(-0.29,3$ months, -0.25 .9 months, $p<0.05$ ), meaning that patients who improved their psychosocial adjustment, also reported improvement in well-being. At three months, no other variables were significantly related to the change in overall-well-being. At 9 months, change in overall-well-being was negatively related to the frequency of home nursing care, previous readmissions and NYHA-functional class; patients with more home nursing care, more admissions in the past and low functioning (higher NYHA class) were more likely to report a worsening of their overall well being.

\subsection{Discussion}

The emphasis of treatment of patients with heart failure should be on improving quality of life. ${ }^{7.9}$ However, the most appropriate way to measure quality of life is difficult to determine.

In our study we used three dimensions and a subjective overall score to describe patients quality of life, knowing that these dimensions might have a certain amount of overlap and therefore not being able to "just" add the three dimensions to one total score. In addition to the dimensions we also asked the patients to evaluate their overall well-being with a single score. Data were too limited (reliability of the scales, several missing values) to conduct a LISREL analysis. Another limitation of the study is the small sample size and the relative large number of variables tested. needing caution in interpreting results. A third limitation was that patients often had difficulty scoring their "quality of life" on a scale. Visual analogue scales may be difficult to use in elderly, very ill patient populations. ${ }^{29}$ Another measurement issue to consider is the self-report of the contacts with the general practitioner and home nursing care. Other data on resource utilization were collected from a hospital database.

In this study the overall well-being stayed the same between baseline and 3 months after hospital discharge in $34 \%$ of the patients, but functional capabilities and psychosocial adjustment to illness increased in most patients and the number of symptoms decreased. The baseline score mainly predicted the changes in 3 dimensions of quality of life (i.e. functional capabilities, symptoms and psychosocial adjustment to illness). Patients with good quality of life were more likely to deteriorate and patients with worse quality of life were more likely to improve on the three dimerisions of quality of life and well-being. This finding may be explained by statistical regression, meaning that patients with high baseline scores will score relatively lower at the post-test and low pretest scorers will score relatively higher ${ }^{30}$ However, independent of the baseline 
Table I I.5: Results of regression analyses $(\beta)$ with the change in overall well-being between 3 months and baseline and 9 months and baseline as dependent variables $(n=74)$

\begin{tabular}{|c|c|c|}
\hline \multirow{3}{*}{$\begin{array}{r}\text { Period (months) } \\
\text { Adjusted } \mathrm{R}^{2}=\end{array}$} & \multicolumn{2}{|c|}{$\begin{array}{l}\text { Change in Over- } \\
\text { all well-being }\end{array}$} \\
\hline & $0-3$ & $0-9$ \\
\hline & 0.49 & 0.71 \\
\hline \multicolumn{3}{|l|}{ Quality of life } \\
\hline Baseline well being & $-0.75^{1 \hat{4}}$ & $-0.83^{1 t}$ \\
\hline Change in functional capacity & -0.12 & 0.10 \\
\hline Change in number of symptoms & 0.06 & -0.02 \\
\hline Change in psychosocial adjustment & $-0.29^{\dagger}$ & $-0.25^{\dagger}$ \\
\hline \multicolumn{3}{|l|}{ Self-care } \\
\hline Change in self-care behavior & 0.05 & o.or \\
\hline Change in self-care agency & O. I I & 0.00 \\
\hline \multicolumn{3}{|l|}{ Demographics } \\
\hline Age & -0.12 & $0.0 \mathrm{I}$ \\
\hline Gender & -0.08 & -0.13 \\
\hline \multicolumn{3}{|l|}{ Clinical variables baseline } \\
\hline NYHA-class & -0.05 & $-0.18^{\dagger}$ \\
\hline Weight loss & -0.07 & -0.06 \\
\hline Lung disease (no/yes) & 0.00 & -0.06 \\
\hline Diabetes (no/yes) & 0.03 & 0.03 \\
\hline History of bypass (yes/no) & -0.07 & -0.09 \\
\hline Cardiac admissions in the past & -0.11 & $-0.20 t$ \\
\hline \multicolumn{3}{|l|}{ Resource utilization } \\
\hline Number af readmission & -0.01 & 0.03 \\
\hline Number of readmission days & 0.06 & -0.09 \\
\hline Number of GP contacts & -0.01 & -0.10 \\
\hline Frequency of home care & $-\mathrm{O} . \mathrm{I} 3$ & $-0.19^{1}$ \\
\hline Visits to emergency heart center & -0.13 & -0.09 \\
\hline Group (control/intervention) & 0.04 & 0.13 \\
\hline
\end{tabular}

t: $\mathrm{p}<0.05$

tt: $p<0.001$

ahigher scores mean improvement of quality of life 
score several predictors were related to the change in quality of life. Although there was not one single predictor that was related to all three dimensions, the separate predictors can be used to tailor interventions to those patients who are expected to require special intervention to alter their quality of life.

In general, patients who were older and patients with a relative bad physical condition at baseline (more prior admissions, NYHA IV, low functional capabilities, diabetes, lung disease, and high weight loss during admission) were less likely to improve their quality of life. Patients with multiple conditions and with more severe disease have been described as showing greater decline in functioning and well-being than those with one condition. ${ }^{2.31}$ This might suggest that elderly and physically vulnerable patients need tailored multidisciplinary interventions that focus on their specific situation. ${ }^{18}$ In a recent study from the Netherlands researchers found that an increase in exercise performance was related to an increase in general well-being and a reduction in feelings of disability. However, in patients with an exercise duration of less that 7 minutes at entry exercise test, training was not effective. ${ }^{32}$ This suggests a regular rehabilitation and or education programs should be adapted to this population. It also necessitates broad multidisciplinary co-operation between specialists (e.g. internist, cardiologist and geriatric specialist) and between professions (e.g. nurse, physician, and physical therapist) and sites of care (e.g. in the hospital, at the outpatient clinic and the primilry care) 3.1 .4

Paticnts who were able to take good care for themselves (i.e. had high self-care agency) or paticnts who improved their self-care abilities reported more improvement of functionil capacity and psychosocial adjustment than patients with low self-care agency at bascline. This suggests that in addition to the predictors age and physical condition. self-care agency can be used to tailor interventions. Patients with low selfcare agency may need help to use or enhance social support or to get home nursing care. Maybe they cannot take care of themselves, but nurses can help them arrange for care.

Patients with improved psychosocial adjustment to illness reported improvement in overall well-being during the study period. It is important to address the possibilities to improve psychosocial adjustment to illness in patients during recovery. Interventions aimed at adaptation could include patient and family counseling, involvement of community services or providing help in vocational problems.

Little is known about the relationship between changes in quality of life and resource utilization. In general little relationship appears to exist between resource utilization and quality of life. In those few cases where relationships were statistically significant. increased resource use over the 9 months was related to poorer quality of life or overall well-being, possibly a reflection of the sickest patients having the poorest quality of life and seeking the most care. Awareness of symptoms could explain the reported increase in symptoms of the patients in the intervention group.

A puzzling issue is the difference between male and female patients in regard to their change in number of symptoms and psychosocial adjustment to illness. Male patients reported less change in the number symptoms and improved in psychosocial adjustment. Differences between male and female patients were also found in a study of Chin \& Goldman ( 1998 ). They found that women with heart failure had signif- 
icantly lower scores for physical function and vitality. These outcomes could result in poorer psychosocial adjustment, an outcome not measured by these researchers. ${ }^{35}$ More research is needed to establish differences between men and women in quality of life and in interventions (e.g. exercise programs) possible differences between man and women should be considered.

In summary, baseline quality of life and well-being are the most important predictors of those states at 3 and 9 months; however several demographic, physical, psychosocial, self-care and health care variables are related to a change in quality of life. These predictors can be used to target future interventions to specific patient populations. Improving quality of life needs a very individual approach and interventions need to be tailored to the specific situation of the patients including, elderly and physically vulnerable patients. Programs with various components like for example, a home visit, a multidisciplinary team, discharge planning and a heart failure clinic and have resulted in improved outcomes. ${ }^{18,19,36-39}$ Broadening the multidisciplinary approach to the whole continuum of care, including specialized nursing care in hospital and including home care, exercise programs and social support can possibly improve outcomes.

\subsection{References}

1. Wiklund I. Lindvall K. Swedberg K. Zupkis RV. Self-assessment of quality of life in severe heart failure. An instrument for clinical use. Scand J Psychol 1987; 28: $220-225$.

2. Eriksson H, Svardsudd K. Larsson B, et al. Quality of life in early heart failure. The study of men born in I9 13. Scand J Prim Health Care 1988; 6: 16 I-167.

3. Dracup K. Walden JA, Stevenson LW, Brecht ML. Quality of life in patients with advanced heart failure. J Heart Lung Transplant 1992; I I: 273-279.

4. Rector TS, Cohn JN. Assessment of patient outcome with the Minnesota Living with Heart Failure questionnaire: reliability and validity during a randomized. double-blind, placebo-controlled trial of pimobendan. Pimobendan Multicenter Research Group. Am Heart J 1992; 124: 1017-1025.

5. Guyatt GH. Measurement of health-related quality of life in heart failure. Special Issue: Heart disease: The psychological challenge. Irisch J Psych 1994: I5: $148-163$.

6. Rogers WJ, Johnstone DE, Yusuf S, et al. Quality of life among 5,025 patients with left ventricular dysfunction randomized between placebo and enalapril: the Studies of Left Ventricular Dysfunction. The SOLVD Investigators. J Am Coll Cardiol I994; $23: 393-400$.

7. The Task Force of the Working Group on Heart Failure of the European Society of Cardiology. The treatment of heart failure. Eur Heart J I 997: 18: 736-753.

8. Tyni-Lenne, R. Gordon A, Jansson E, Bermann G, Sylven C. Skeletal Muscle endurance training improves peripheral oxidative capacity, exercise tolerance, and health-related quality of life in women with chronic congestive heart failure secondary to either ischemic cardiomyopathy or idiopathic dilated cardiomyopathy. Am J Cardiol 1997; 80: 1025-1029. 
9. Cohn JN. Current concepts in the treatment of congestive heart failure. Cardiology 1997: (suppl 2): 2-6.

10. Gill TM, Feinstein AR. A critical appraisal of the quality of life measurements. JAMA I 994; 272: 6I9-626.

11. Wenger NK. Assessment of quality of life: a medical imperative. Cardiovasc Drugs Ther 1988: 1: 553-558.

12. Dracup K, Baker DW, Dunbar SB, et al. Management of heart failure. II. Counseling, education, and lifestyle modifications. JAMA 1994; 272(18): 1442-6.

13. Hawthorne MH, Hixon ME. Functional status, mood disturbance and quality of life in patients with heart failure. Progr Cardiov Nurs 1 994; 9: 22-32.

14. Westlake C, Dracup K. Predictors of quality of life for patients with advanced heart failure. Circulation 1998 (suppl I): 482 .

15. Grady KL. Quality of life in patients with chronic heart failure. Crit Care Nur Clin North Am 1993; 5: 661-670.

16. Rosen RC, Contrada RJ, Gorkin L. Kostis JB. Determinants of perceived health in patients with left ventricular dysfunction: a structural modeling analysis. Psychosom Med 1997; 59: 193-200.

17. Jaarsma T, Halfens R, Huijer Abu-Saad H, Dracup K, Stappers J, van Ree J. Quality of life in older patients with systolic and diastolic heart failure. Eur J Heart Failure I 999; I: 15 I-I 60.

I 8. Rich MW. Beckham V, Wittenberg C, Leven CL, Freedland KE, Carney RM. A multidisciplinary intervention to prevent the readmission of elderly palients with congestive heart failure. New Engl J Med I995; 333: I I 90-I I 95.

19. Cline CMJ, Israelsson BYA, Willenheimer RB, Broms K, Erhardt LR. Cosi effective management programme for heart failure reduces hospitalisation. Heart I 998: 80: 442-446.

20. Jaarsma T, Halfens R, Huijer Abu-Saad H, Dracup K, Gorgcls A. van Ree J, Stappers J. Effects of education and support on self-care and resource utilisation in patients with heart failure. Eur Heart J r 999; 20: 673-682.

21. Oldenburg B, Macdonald GJ, Perkins R. Predictiors of quality of life in a cohort of end-stage renal disease patients. J Clin Epidemiol 1988; 44: 555-564.

22. Patrick DL, Bergner M. Measurement of health status in the 1990 . Ann Rev Public Health I 990 ; I I : $165-183$.

23. Carlson KJ, Lee DC, Goroll AH, Leahy M, Johnson RA. An analysis of physicians' reasons for prescribing long-term digitalis therapy in outpatients. J Chron Dis $1985 ; 38: 733-739$.

24. Wenger NK, Mattson ME, Furberg CD, Elinson J. (eds.) Assessment of quality of life in clinical trials of cardiovascular therapies. New York: Le Jacq Publishing, 1984 .

25. Fardy P, Yanowitz F, Wilson P. Cardiac rehabilitation of the coronary patient. Philadelphia: Lea \& Febiger, 1988.

26. Derogatis L. Scoring and procedures manual for PAIS. Baltimore: Clinical Psychometric Research, 1976.

27. Cantril H. The pattern of human concerns. New Brunswick: Rutgers University Press, 1965. 
28. Brouns G, Evers (i. Isenberg M. Philipsen H, Senten CMS. Appraisal of Selfcilre Agency scale [in Dutchl. Maastricht, 1988.

20. Wiklund I. Swedberg K. Some methodological problems in analyzing quality of lite data in severe congestive heart failure patients. J Clin Res Pharmacoepidemiology I 99 I; 5: 265-273.

30. Cook TD. Campbell DT. Quasi-experimentation. Design \& analysis issues for filed settings. Boston: Houghton Mifflin Company, 1979.

3I. Stewart AL. Greenfield S, Hays RD, et al. Functional status and well-being of patients with chronic conditions. Results from the Medical Outcomes Study. JAMA 1989; 262: 907-13.

32. Wielinga RP, Huisveld IA, Bol E, Dunsleman PHJM, Erdman RA, Baselier MRP, Mosterd WL. Effects of exercise training in chronic heart failure. Eur Heart J 1999; 20: 872-879.

33. Gibbs LME, Hall JA, Gibbs JS. Dying from heart failure: lessons from palliative care. BMJ I998; 317: 96I-962.

34. Kingma $\mathrm{H}$. Disease management of cardiac disease: a golden opportunity [in Dutch]. TSG I 999: 77: 49-50.

35. Chin MH, Goldman L. Gender differences in I-year survival and quality of life among patients admitted with congestive heart failure. Med Care $1998 ; 36$ : 1033-1046.

36. Fonarov GC, Stevenson LW, Walden JA, Livingston NA, Steimle AE, Hamilton MA. Moriguchi J. Tillisch JH, Woo MA. Impact of a comprehensive heart failure management program on hospital readmission and functional status of patients with advanced heart failure. J Am Coll Card I 997; 30: 725-732.

37. Hanumanthu S, Butler J, Chomsky D, Davis S. Wilson JR. Elfect of a heart failure program on hospitalisation frequency and exercise tolerance. Circulation 1997; 96: $2842-2848$.

38. Stewart S, Pearson S, Horowitz JD. Eflects of a home-based intervention among patients with congestive heart failure discharged from acute hospital care. Arch Int Med 1998; 158: 1067-1073.

39. Naylor MD, Brooten D, Campbell R, Jacobson BS, Mezey MD, Pauly MV. Schwartz JS. Comprehensive discharge planning and home follow-up of hospitalized elders. JAMA 1999; 281: 613-620. 


\section{Chapter 12}

\section{General discussion}

Although Mrs. Z is 54 years of age, she lives a very active life. With her two giant dobermann pinchers, her son and her husband, she lives in a beautiful house in a small village near Maastricht. During the daytime she does housework for several young families and during the evenings she is active in the carnival committee and a music club. However, for the past few months, she has not felt so well. She feels short of breath during work, only sleeps a few hours in a chair and has a persistent cough. Her legs are swollen at the end of the day and she feels very tired. First she decides to take it easy on the social activities (probably this fu you know...). Of course, she will not let her family down, and she goes to bed early and rests after she finishes working. A visit to the family doctor ends up in a hospitalization at the cardiology department. After close examination, the diagnosis hear failure was established. During her hospital stay, medications are prescribed and she is advised to "take it easy" and "restrict your salt". There she is: always helping people out and now...? How about the dogs, could she still walk them? Does she have to give up all housework with the young families? How should she tell them? And how about carnival, is she still allowed to work on the preparations? How about alcoholic beverages? Is she still allowed to drink some beer during festivities? And all these medications: captopril, lasix, ... how should she divide them throughout the day?

After his wife died, $M r . B$ (age 8I) moved to the nursing home "The 12 gardens" and feels content. After several hospital admissions in the last 2 years, he hopes he will never see the hospital again. His two sons are dead, but his grandchildren (with their children) come to visit each month and he enjoys it. He takes his meals in his room prepared by the care facility, and nursing aides help him with his daily activities. The nursing staff gives him medication. On Sunday he skips all his medications, since one of the pills is a "water-pill" and he does not want to be in the bathroom during the church service or during the visits of his grandchildren. He visits the cardiologist every 3 months for check ups, but really does not like this. Most of the time he is hospitalized before the three months are over. He does not want to be in the hospital anymore, not even at the outpatient department. Why can't the nursing staff or the family doctor take care of him so he can stay home in peace?

These two examples illustrate the complexity and diversity of the consequences of 
heart failure in the day-to-day lives of patients. In this dissertation, different aspects of the impact of heart failure have been discussed, for example the impact on self-care, readmissions and quality of life. In this final chapter of the dissertation the research findings are discussed in two sections: I) Reflections on theory and methods 2) Implications for practice and research.

\subsection{Reflections on theory and methods}

\section{Why was this study important?}

Heart failure hals hecome a significant health problem, with increasing numbers of patients entering the hospital. Symptoms and treatment have a large impact on the lives of paticnts with heart failure. In addition, increased resource utilization of patients with heart failure have a great economic impact.' To improve outcomes of patients with heart lailure. for example to improve quality of life and decrease readmissions, various new care mudels have been developed and used. However, few models have actually been tested on their effectiveness. In this study the effect of a supportive-educative nursing intervention on self-care, resource utilization and quality of life were tested.

\section{What were the major findings of the study?}

In this study we found that extra education and support increased self-care behavior of patients with heart failure. The intervention proved to be successful for patients with low self-care behavior at baseline as well as for patients with high self-care behavior. Although a difference existed in self-care behavior during follow-up of patients in the control and intervention groups, the barriers to self-care behavior were not considerably different between the two groups. Limitations in knowledge, decision-making and skills were identified as barriers for behavior in both groups. Suggestions for improving care of patients were formulated based on these results.

A trend towards fewer intervention patients being readmitted and visiting the emergency heart center was found. The use of other resources, however. like home care or contacts with a general practitioner did not differ between patients from the intervention and the control groups. Suggestions on increasing intensity of the intervention were formulated based on these results. No differences in quality of life were found between patients with systolic or diastolic heart failure and between patients in the intervention or the control groups. Results suggested an effect of education and support on the subjective feeling of severity of symptoms and level of distress. Only a limited association between quality of life and clinical and demographic variables at baseline existed. A change in quality of life was associated with the baseline score and several demographical (age, gender), physical (comorbidity, functional capacity, history), psychosocial (adjustment), self-care (agency and behavior) and health care (readmission, contacts with general practitioner, home nursing care) variables. Based on these results, additional improvement of the intervention was suggested and directions for future research formulated. 


\section{Was the theoretical framework useful in this study?}

The function of theory is to describe. explain or predict limited properties of reality. In this dissertation concepts from Orem's general theory of nursing were used to develop the intervention, to construct the research model and to structure data collection on self-care limications. " It was difficult to use Orem's theory to prescribe concrete nursing care or use concepts directly from the theory in practice or research. However. the theory was used successfully to structure nursing care and dati collection in a consistent and systematic way. ${ }^{4}$ By using Orem's theory of nursing as a frame of reference, we aimed to structure the complex care process for heart failure patients (and their families). Consequences of heart failure are often viewed from a biomedical perspective and interventions are often aimed at controlling symptoms and adhering to the medical regimen. By using the multi-dimensional approach of the self-care requisites from Orem's theory both physical and psychosocial consequences of heart failure were addressed in the intervention. By considering all three types of limitations for self-care (knowledge, judgment/decision-making and courses of action) and reviewing the nursing helping techniques that are appropriate in a supportive-educative system, the intervention was not restricted to aspects in knowledge but also included additional aspects like priority setting and support. In addition, concepts on actual and potential needs were used to address the current problems of patients and to prevent future problems. ${ }^{3}$ As can be expected from a general theory of nursing, disease-specific information could not be derived from Orem's theory. Information from practice and research was used to further develop the intervention. It was also experienced that by applying the theory in detail, extensive, impractical lists with capabilities of a heart failure patient arose, resulting in the need for the capabilities to be summarized into a workable list. On the other hand, it was sometimes difficult to separate concepts that were described in theory but not recognized in practice. Similarly, concepts needed reformulating or redefining before they could be used in the current study.

To develop a research model a core idea from Orem's self-care deficit theory was used. ${ }^{3}$ To adequately care for themselves in a changing health situation, patients need to take certain care measures and therefore they need particular knowledge and skills (self-care abilities). Self-care is described as "the practice of activities that individuals initiate and perform on their own behalf in maintaining life, healthy functioning. personal development and well being."3 In this study it was hypothesized that increasing self-care ability and improving self-care (behavior) by education and support will have effects on resource utilization and quality of life. This is reflected in the research model (figure I 2.1).

\section{Did we use the appropriate intervention?}

The intervention tested was developed for this study, using knowledge from theory. literature and nursing practice. Interventions from the literature, from standard nursing care plans in the Netherlands, and from interviews with nurses in hospital and home care were used to formulate concrete actions. Although the content of this nursing intervention seems very thorough and complete, several comments in regard to the intervention can be made. 


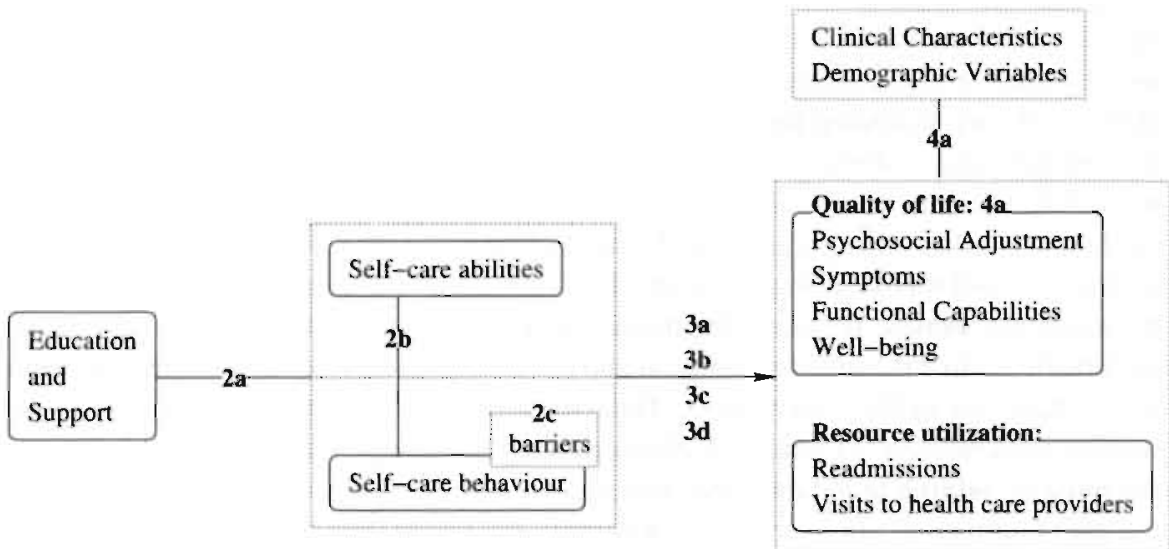

Research Questions

1 What constitutes the optimal education and support in patients with heart failure? (not depicted)

2a What is the effect of education and support on self-care abilities and self-care behavior of patients with heart failure?

2b Do self-care abilities relate to self-care behavior

2c What are barriers for self-care behavior?

3a Do self-care abilities and self-care behavior relate to resource utilization?

3b What is the effect of education and support on resouce utilization?

3b Do self-care abilities and selt-care behavior relate to quality of life?

3d What is the effect of education and support on quality of life?

4a What are determinants of quality of life

4b Does a change in quality of life relate to resource utilization, clinical characteristics and demographic variables? (longitudinal approach, not depicted in the model)

Figure I2.1: Research model 
First, we restricted the intervention to a "nursing" intervention. The rationale for this was that we wanted a simple and inexpensive intervention that would be easy to implement in every hospital (in the Netherlands). Since not all hospitals have the resources to construct a heart failure clinic, i.e., a heart failure specialist or multidisciplinary heart failure teams, it was attractive to develop such a nursing intervention. During the study, however, experiences revealed the importance of close contacts with other disciplines, especially the cardiologist and the general practitioner. Several times, patients called the study nurse with questions that demanded consultation of a physician (e.g. problems with medications or increased symptoms). In other patients, closer communication with home care would have increased the effect of the intervention, for example, in assisting patients with keeping records of their daily weights, taking the right medications or assisting patients with problems related to family functioning. These experiences are supported by literature, in which the effect of a multidisciplinary intervention is described to improve outcomes..$^{5.6}$ On the other hand, a recent study demonstrated the effects on readmission and mortality of a nursing home-based intervention. ${ }^{7}$ Cline (1998) found a significant effect on number of rehospitalization days as a result of a nurse-led management program (with the ability to contact a cardiologist when needed). ${ }^{8}$ Our findings are important to demonstrate that nursing care had effect on self-care behavior and has the potential to improve outcomes.

A second limitation of our intervention was the time of follow-up. The intervention started in the hospital, with the nurse assessing the patients' needs and starting education and support. During the hospital stay of the patient. education and support was continued, guided by the standard nursing care plan, using different patient education materials. Within three days of discharge, the nurse contacted the patient to check his condition and make an appointment for a home visit. Within seven days a home visit was made. During the home visit, education and support was continued, as warranted by the patient situation. Between discharge and the home visit, patients could call the study nurse in case of problems. After the home visit, the patient was advised to riturn to usual care (general practitioner, emergency heart center, cardiologist etc.) So, follow-up ended after Io days. One of the major topics during the intervention was that patients could recognize their symptoms and contact the appropriate health care provider. For some patients this was their general practitioner, for others the cardiologist or intemist. In case of emergency or problems with access to health care, patients were told to go to the emergency heart center. In our study, a trend towards fewer patients from the intervention group visiting the emergency heart center was found. This can mean that intervention patients experienced fewer symptoms that needed acute care or that they had fewer problems accessing usual health care providers. However, experiences during the study revealed that although some patients knew when and who to contact in case of increasing symptoms, they could not get the attention of a health care provider in time due to weekend shifts or busy schedules of specialists. So even with an increased self-care behavior, they were not able to stay out of the hospital. Patients sometimes needed reinforcement of education, for example to stimulate them to restrict their fluids or to adjust their diuretic dose in-between visits to the cardiologist. A longer follow-up by the study nurse could have solved these problems. This is also supported by literature in which intensive and extended telephone follow-up is 
described to be important ${ }^{5,6,9-13}$ The exact follow-up time needed is not described and is different in every study: 30 days, ${ }^{11} 90$-days, ${ }^{5} 6$ months, ${ }^{6,10,13} 8$ months, ${ }^{8}$ and I year. ${ }^{9}$

A third limitation was that only two study nurses implemented the intervention. Both nurses had several years of experience on a cardiology ward, but no advanced cardiac nursing training program like a clinical cardiac nurse specialist program. One of the nurses had finished CCU training in the past and the other nurse had participated in two cardiac masters courses in the USA. To enhance the similarity of the intervention, the intervention was described in detail in a manual and regular consultation took place about the patient education and support. The advantage of using a restricted number of study nurses is the assurance that the intervention is delivered as planned and that the intervention does not differ considerably from one person to another (which otherwise inflates error variance and decreases the chance of obtaining true differences). ${ }^{14}$ On the other hand, although we have no indication, individual characteristics of these two motivated and experienced nurses might have influenced the outcomes.

A final comment has to be made about the "care-as-usual" which was provided to the control group. Based on personal experience and the literature a considerable amount of variation in providers' practice exists. ${ }^{15-17}$ The diversity is reflected in different prescription practices by physicians ${ }^{15.17}$ and different decisions by nurses in the same cases. ${ }^{16}$ In caring for patients with heart failure, little standardization in care exists in day-to-day care. Although more (medical) guidelines for heart failure patients are produced, their implementation is still in a immature state. As a result. it is difficult to describe the care-as-usual that was provided to our control group. Comparing our rehospitalization rates of the control group with the control groups of other studies we notice some differences. In the control group of the study by Rich et al. ( 1995 ), a 90-day readmission rate for cardiac causes of $39 \%$ was noticed in the control group, compared to $24 \%$ in our study. ${ }^{5}$ This suggests that our care-as-usual may not be comparable to care-as usual in other studies. It also suggests that in some cases the intervention might not have had as strong an effect as expected.

\section{Did we use the proper design for the study?}

An experimental design with one pre-test and three post-tests was used. An experimental design is considered to offer the most convincing evidence concerning the effects one variable can have on another. ${ }^{18}$ Using a "short-term" post-test (I-month) and a "long-term" post-test (9-month) was considered appropriate. During the first post-test. which took place I month after discharge, not all variables were measured. The rationale for this was that we did not want to burden the patients with a lengthy interview so close after discharge, or so close after the home-visit of the study nurse. The first post-test data on the dimensions of quality of life and self-care abilities were collected at 3 months. However, since the effect of the intervention on self-care behavior was largest on short term, effects on quality of life might have been missed.

By drawing from an envelope. patients were randomly assigned to receive either care-as-usual or the supportive-educative intervention. Patients from the control and intervention group were never assigned to the same room on the nursing unit. Therefore contamination of the two groups was minimized. Theoretically it was possible 
that patients in the Experimental group transmitted information to control patients by showing them the symptom list or other written material. In addition another form of diffusion of intervention might have occurred. ${ }^{14}$ Although the study period lasted a few years, the awareness of nurses and physicians on the ward could have been raised as a result of the presence of two research nurses on the unit, informing about heart failure patients every day. This might have resulted in some decrease in difference between the intervention and control situation. However, no major changes in care plans or structured education policy were noted during the time of the intervention.

\section{Did we use the proper instruments?}

Established and internationally used instruments were selected, when possible. The instrument to describe self-care behavior was developed for this study. Several comments in regard to the instruments have to be made.

Self-care: The Appraisal of Self-care Agency scale (ASA) was used to measure self-care abilities of patients. Although this instrument had proven to be reliable and valid for use in a cardiac population, ${ }^{19.20}$ the question is whether this instrument was sensitive enough to reflect changes in self-care abilities related to education and support. At the same time the questionnaire contains several items that would be unlikely to change with a supportive-educative intervention as tested in this study, such as "I take measures to maintain sanitary conditions in my personal environment" or " over the years I have developed a circle of friends that can be called upon when help is needed". The items are formulated for a general population.

To get more insight into the mechanisms of the intervention, information on the behavior of patients was considered vital. To measure self-care behavior, we constructed a scale that consists of 19 behaviors patients should perform to maintain health and well-being. These items were derived from literature, and discussed with experts in the field of heart failure. Conceptually, three dimensions were distinguished, but these were not confirmed by factor analysis. As a result it was decided not to use the subscales for analysis. Although the alpha of this scale was low $(0.62-0.68)$, based on the importance of the content of the items for heart failure patients it was decided to use the 19-item scale as unidimensional scale. Currently, additional work is being done in co-operation with international colleagues to improve the scale. Wording of the scale will be changed and items regarding alcohol and tobacco use and regarding a fiu shot are being added.

To measure the barriers for self-care behavior, answers of patients were written down and categorized by wo research nurses into the categories: knowledge, decision and skills. Although this way of data collection gives results close to patients experiences, this procedure was time consuming. Results can be used to develop a semi-structured questionnaire to assess barriers of patients for self-care behavior.

Resource utilization:

To gain insight into the resources patients used, different data were collected from patients' self report. At first it was planned to only use the self-report of patients. However, patients often could not remember their rehospitalization. or they confused it with their initial hospitalization. Reasons for readmission also were difficult to obtain from 
self-report. This is consistent with the finding of Friedman et al., (1998) who reported that patients often do not recognize their symptoms as being due to heart failure. ${ }^{21}$ It was therefore decided to use the hospital database and patient medical record to document readmissions and visits to the outpatient department. Data on contacts with the general practitioner, home nursing care and other care providers were only registered by using patient self-report. Some patients recorded this in their diary, while others reported verbally. Patients often did not exactly know what the reason for their visit to the general practitioner was or they combined a check-up with another reason, e.g. their flu shot. Another difficulty was that it was often not possible to distinguish between home nursing care and home help from self-report. Patients often stated that "someone from the green cross [local home nursing organization]" came to help them. Additional work is needed to get more detailed insight into the contacts with the general practitioners, home nursing care and other care providers. Using a patient diary or analyzing medical and nursing records to get insight into the number and reasons of contacts with these health care providers is suggested.

Quality of life: In this study both objective and subjective dimensions of quality of life were described. The problem with quality of life studies, however, always relates to the validity of the measures. In this study we used instruments that had also been described in other studies in comparable populations. ${ }^{22,23}$ Three dimensions of quality of life were measured: functional capacity, symptoms and psychosocial adjustment to illness.

Functional capacity was measured by the Heart Failure Functional Status Inventory (HFFSI). ${ }^{22}$ This questionnaire was useful for patients since it used descriptions of daily activities patients performed. However, the questionnaire only addressed the kinds of activity patients could perform and not the length of time patients could perform this activity. A minor improvement would be the length of the activity. In addition to this questionnaire we collected data on the 6-minute walking test. At baseline 113 $(6 \mathrm{I} \%)$ patients completed this test and 50 patients could not because of their physical condition. Twenty-three refused, primarily because they thought it might exhaust them too much. The high number of patients that could not perform the test shows that patients' comorbidities (e.g. arthritis, vascular disease and frailty) limit the use of the 6minute walk. The HFFSI can be used in frail populations, since the activities evaluated are activities of daily life. This questionnaire can also easily be administered by phone or in an interview, while use of the 6-minute walk requires a clinic visit.

Symptoms were measured with a checklist on number, severity and level of distress. Although it is important to ask patients about their symptom distress, ${ }^{24}$ the visual analog scale may not have been the most appropriate instrument. A lot of patients had difficulty scoring the severity and distress on a 10-point scale. They did not think of it as a scale. but just thought of it as bad, not so bad, bothersome, annoying, etc. Asking them to score it was often a problem. leading to several missing values. Visual analog scales maybe difficult for this elderly, very ill patient population to grasp. ${ }^{25}$

The psychosocial adjustment to illness scale was translated for this study to Dutch and tested as a reliable and valid instrument. ${ }^{26}$ The PAIS is a lengthy instrument with a lot of reading for the patient. Several patients stated that they found it a difficult instrument and stated some dimensions as irrelevant to their situation (especially in 
regard to vocational environment and sexual relationships).

In addition to the questionnaires on psychosocial adjustment, functional capacity, and symptoms, the "ladder of life" was used to get an overall subjective score of quality of life. The same problem was experienced as described with symptom severity and distress; patients felt it was difficult to score their happiness on a ro-point scale (ladder). ${ }^{25}$

It is, however. questionable if our instruments were sensitive enough to measure change over time. Maybe a more disease-specific instrument is needed with more concise and targeted areas, such as dysfunction as result of symptoms and treatment, functional impairment in daily activities, including length of activities and anxiety or depression. ${ }^{25.27}$ Nevertheless, an instrument that is too sensitive and disease-specific can be questioned on grounds of clinical significance. The Dutch version of the Minnesota Living with Heart Failure Questionnaire which has recently been tested as a reliable and valid method to measure quality of life can be considered as a valuable instrument. ${ }^{28}$ Yet, scoring format $(0-5)$ still can be difficult. ${ }^{25}$

\section{What other variables should have been measured?}

It would have been valuable if we had collected data on self-care behavior with a more reliable instrument. It is important to gain insight into the underlying mechanisms affecting outcomes. Therefore information on the behavior of patients. as result of the intervention is needed. Knowledge of the patient also could have been a valuable variable that might have given insight into the effect of the intervention. Although increasing knowledge may not automatically lead to increased self-care behavior, it would have been interesting to know what the effect of the intervention was on the knowledge level of the patient. ${ }^{29}$ If knowledge did not improve as result of this kind of intervention, other strategies might be needed in future interventions. In addition, more in depth data on the underlying mechanisms and effects of adherence to treatment can be useful to evaluate and optimize interventions. ${ }^{30}$ We assessed patients' self-reported use of medications by one of the questions on the heart failure related self-care behav. ior, and found a very high compliance rate $(88 \%)$. This is not comparable with other studies in which compliance rates of only $10-50 \%$ were reported ${ }^{31-33}$ From literature it is known that self-report is not a reliable instrument and that more sophisticated methods to collect data on adherence are available. ${ }^{30.34}$ The use of continuous electronic monitoring in this patient population should be explored. ${ }^{35}$ Since we did find an effect of the intervention on severity of symptoms and the level of symptom distress during the recovery period, data on coping mechanisms might have been valuable to explain this effect. Knowledge about how people actually adjust to their heart failure and mechanisms they use to cope with the disease in daily life is needed.

\section{Were the most relevant patients included?}

Inclusion/exclusion: To enhance the homogeneity of the sample we formulated several inclusion and exclusion criteria. As a consequence, of the 828 patients admitted to the cardiology ward of the University Hospital in Maastricht with symptoms of heart 
failure, only 225 were eligible. Of the 828 admissions, 184 ( $22 \%$ ) were readmissions. Since patients could only enter the study once, 644 patients were screened. Among the remaining 644 patients, $458(71 \%)$ were excluded for various reasons. Forty patients did not want to participate because they felt too ill to do so. Age and gender of these 40 patients did not differ from the patients that participated in the study. By excluding such a large group, results limit the external validity of the findings.

\section{Attrition}

As can be expected in a group of advanced heart failure patients, a high attrition rate due to mortality was found. ${ }^{25}$ In the 9 -month follow-up period, 16 patients ( $\left.17 \%\right)$ in the control group died compared to 22 patients $(26 \%)$ in the intervention group. Attrition due to nonresponse was the same $(5 \%)$ in both groups. A comparison of the baseline characteristics of the control and intervention patients that dropped out of the study revealed no selective attrition, so the baseline characteristics of the control and interventions patient remained comparable. However, patients that dropped out of the study were significantly older, living more often in a home for the elderly, and diagnosed with hypertension. Cardiomyopathy was more often the underlying reason of heart failure. Laboratory results showed higher levels of serum sodium, BUN and creatinine at baseline in patients that dropped out of the study compared to patients that completed all three follow-up measurements. Since attrition was rather high and since it seemed to be different in the control and intervention group, we have also presented an analysis (chapter 10 ) in which we assumed that patients who dropped out did not improve their self-care agency, self-care behavior or quality of life since baseline (the null hypothesis).

We chose not to structurally use "substitute scores" for quality of life of patients that dropped out due to mortality, and therefore analyses were restricted to subjects that completed all follow-up measurements. Assigning a substitute score to dead patients was not considered as meaningful. ${ }^{25}$ Due to attrition, different sample sizes were reported in the different chapters. The high drop out restricts the generalizablity of the results to subjects that are in relatively good condition.

Systolic-diastolic:

In this study we first decided to include only patients with a LVEF $<40 \%$. However, during the first months of the study we decided to include patients with a diastolic dysfunction in the study too. Although the most appropriate guidelines for diagnosis and treatment of systolic and diastolic dysfunction differ, ${ }^{36}$ the supportive-educative intervention was expected to be beneficial for all patients with heart failure. The standard nursing care plan could be used for both groups, since global topics are applicable for all patients (e.g. warning signs, medication) but the content of the information was tailored to the individual patient.

High and low risk

In contrast with other recent studies, patients in this study were not screened for their risk for readmission. ${ }^{5.7}$ Rich et al. (1995) found effects on readmission in patients that were considered as high risk for early readmission (prior history of heart failure. four or more hospitalizations in the preceding 5 years, heart failure precipitated by acute myocardial infarction or uncontrolled hypertension). ${ }^{5}$ Steward et al. (1998) also selected high-risk patients for their analysis of effects of a home based intervention. ${ }^{7}$ 


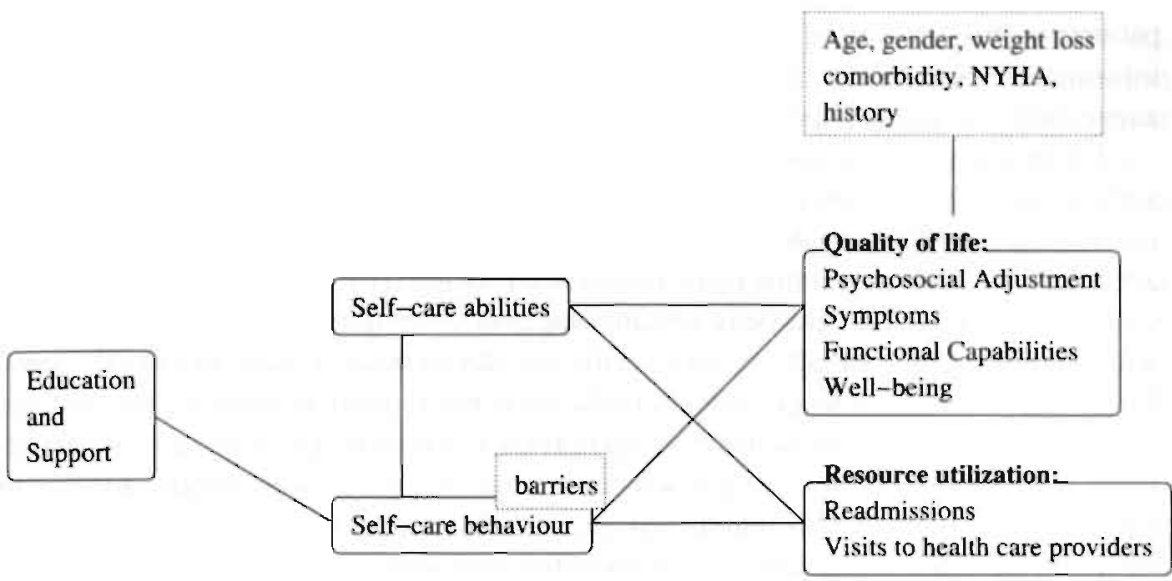

Figure I 2.2: Final model

Although patients in the present study were elderly and admitted with heart failure, they were not screened for high risk for readmission.

In chapter I I of this dissertation additional factors that might identify a high risk population were described. Patients with a relative bad physical condition at baseline (more prior admissions, NYHA IV, low functional capabilities, diabetes. Iung discise, and high weight loss during admission) were less likely to improve their quality of life. Patients who were not able to take good care for themselves (i.e. had low selfcare agency) or patients who did not improve their self-care abilities reported less improvement of functional capacity and psychosocial adjustment than patients with high self-care agency at baseline. In future studies it should be considered to target interventions to a high risk sample.

\section{Why were differences only assessed by univariate analyses?}

To compare the control and intervention groups univariate statistics were used. with correction for multiple testing. ${ }^{3-}$ In this way results could clearly be interpreted with a conventional correction. Looking at the trend in time of the (wo) groups and at the clinical significance of the results, no additional multivariate analysis seemed appropriate.

\section{What are consequences of the results for the research model, research questions and theoretical framework?}

In figure 12.2 the statistically significant results of the baseline and follow-up measures are summarized in one model. Some relationships were found only once, others during all 4 measurement times (baseline, I,3,9 months after discharge). Although testing Orem's general theory of nursing was not the purpose of the study, some general statements on this theory can be made.

The first research question (What constitutes the optimal education and support in 
patients with heart failure?) was partly answered be presenting an intervention with information from theory, research and practice. In the second part of this chapter suggestions to optimize the intervention are provided.

There was no significant effect of this supportive-educative program on self-care agency but there was an effect on self-care behavior (research question 2). In theory self-care abilities are described as a modifiable concept (developed, operable and adequate). It is also stated that self-care agency is defined by qualities ascribed to individuals and that patients can be in specific stages of development. What persons can do with respect to practical affairs varies with age, developmental state and health state. ${ }^{3}$ In our study we did not find an effect of education and support on the self-care abilities. The mean change in both groups was 3 points on a scale ranging from $24-120$. In previous research on a bypass sample, a mean change of 4 points was found compared to a preoperative score. ${ }^{19}$ This minor change can indicate that self-care abilities, as measured by the ASA scale, reflects a personality characteristic instead of a modifiable concept. Maybe patients, at this stage of their life, are not able to make large changes their self-care abilities. This hypothesis, however, needs to be validated., since on an individual level we did find changes in self-care agency.

The relationship between self-care abilities and self-care behavior was moderate and was only found at 3 and 9 months after discharge (research question 2 b). Selfcare agency was measured with a general questionnaire and self-care behavior with a disease-specific questionnaire. The general items might not be related to heart failure specific self-care behavior. Or maybe patients are perfectly able to take care of themselves or think they can, as is reflected in the ASA scale, but do not integrate this in the daily behavior needed as a result of their heart failure. Other patients with a good heart failure related self-care behavior (e.g. daily weighing, exercising) may not report taking care of themselves in more general aspects of life (sanitary conditions, safety). The barriers described were associated with limitations in knowledge, attitude and skills (research question $2 \mathrm{c}$ ). However, they did not change much as the result of the intervention. The description of the limitations in theory was too abstract to use in research, but could be reformulated.

Self-care abilities and self-care behavior were related to resource utilization and quality of life at different moments in time (research questions 3 and 4). In addition, patients with good self-care agency or patients that improved self-care agency reported more improvement in quality of life dimensions than patients with low or stable selfcare agency. This supports the statement that self-care is directed toward healthy functioning, personal development and well-being. However, the direction of causality needs to be studied. Can patients who feel better take better care of themselves, or do patients who take better care of themselves have a better quality of life?

One should question the possible overlap in the concepts psychosocial adjustment to illness and self-care agency. One might argue that patients with high self-care abilities would have fewer problems adapting to their illness (or visa versa), or one could argue that an important part of self-care is the incorporation of health and diseaserelated measures in daily life. This is also partly reflected by the concept psychosocial adjustment to illness. Further study of the concept of self-care agency is needed. Although the supportive-educative intervention improved self-care behavior, it was not 
strong enough to effect resource utilization and quality of life. As already discussed, interventions need to focus not only on the content of care but also on the organization of care. Nursing theories can be very helpful in describing and organizing the content of nursing care, but broadening of the scope beyond our discipline is needed. In addition to the need to give concrete form to concepts from Orem's theory, more work is needed on defining appropriate nursing roles. Orem described in her theory different methods nurses can use in caring for patients: acting or doing for another, guiding and directing, providing support, providing a developmental environment and teaching. A new relevant helping method might be "managing the care process". Although this also can be considered as an integrative part of nursing, the importance of this aspect in caring for chronically ill patients during hospital stay but especially after discharge should be emphasized.

In this study we found that education and support did not have considerable effects on resource utilization and quality of life. What really constitutes quality of life of patients and what actually can improve the quality of life is often very different between individuals and involves a lot of factors. Even if we find out what determines quality of life for older patients with heart failure, it should be questioned if we can design an intervention that improves these aspects of quality of life, and further if we can measure this. It is known that patients adapt their sense of well-being and their internal standard against which the impact of the disease is evaluated. As a result it complicated to evaluate effects on quality of life ${ }^{38}$ Therefor it seems not logical to conclude that our intervention was not useful for the quality of life. Indeed, although the intervention has no considerable measurable effect, we still are convinced that such an intervention benefits our patients and that in some way a contribution to improvement of aspects of their lives was made. A more systematic intervention by a nurse specialist regarding education and support should be preferred to a non-systematic intervention, in which aspects may be forgotten. However, maybe it is not realistic to think that such a hard to influence characteristic like quality of life could be changed by a rather simple intervention in the planning of care. To change quality of life, more rigorous interventions probably are needed.

\subsection{Implications for practice and research}

\section{How could the intervention be improved?}

The intervention had several limitations. Improvements in the intervention suggented here are guided by recent publications and experiences during the project.

Update the content of the intervention: In improving care, it is important to use both research and theory. The intervention, presented in this study, used information from theory, research and practice. A constant update of such an intervention is necessiry. Education and counseling based on pertinent literature and individually adjusted to the patient abilities can improve outcomes. ${ }^{39}$ Combining evidence-based knowledge from randomi/ed trials with individual clinical expertise will result in optimal clinical decisions. ${ }^{\circ}$ 
Maintain format: in-hospital and at home: Starting education in an early phase of recovery is considered important. ${ }^{41}$ In addition, continuity of care should be guaranteed. A home-visit made by the nurse known to the patient was experienced as positive by patients. The importance of a home visit is also supported by Steward et al, who described the positive effects of a home based intervention. In an earlier study, Ashby ( 1988 ) reported the positive effects of a home-based intervention by a nurse in patients with heart failure. ${ }^{42}$ Nurses in our study revealed that specitic problems appeared during the home visits; for example, patients showed additive salt products and asked if they were allowed in their diet; they showed their medication boxes inappropriately filled. or nurses discovered medication in the ashtray. Home visits seemed to be valuable to reinforce patient education and enable nurses to intervene in new problems arising from transition. It also can be very useful for the frail elderly who have difficulties to come to an outpatient department. In a recent Swedish study it was concluded that among the elderly who are hospitalized for moderate-to severe heart failure, only a minority can be candidates for a hospital-based, outpatient, nurse monitored program aimed at symptom management after discharge from the hospital. ${ }^{43}$

Some researchers argued that more home visits and less in-hospital education is preferred, since patients often do not remember the in-hospital education. ${ }^{+4}$ It also should be considered that by enhanced monitoring the possibility of increased resource utilization, at least in the short term. could be expected. Weinberger et al. reported an increase in rehospitalization in a veteran population as a result of an intensive primary care intervention. ${ }^{10}$ However, by improving care, long-term problems should be prevented.

Maintain and expand documentation: In the intervention used in this study, documentation was obtained by checking important items of education and support. and checking if the interventions were completed in the standard nursing care plan. In addition, notes were kept on each patient contact to guarantee continuity. The importance of continuity is often stressed in regard to inpatient care. However, it is also important to keep up documentation in the outpatient situation, as a way to guarantee continuity of care and to evaluate actions taken or decisions made.

In our study, having the same nurse conduct the in-hospital education and the home visits also enhanced continuity. In expanding the number of patients, the length of follow-up and the hours of access to a health care provider, the need for proper documentation is even greater.

Extend follow-up: As discussed in the previous section, follow-up should be extended beyond 10 days. In the literature, various time periods of follow-up are described. West et al. described a physician-supervised, nurse-mediated home based system for heart failure management with nurse-initiated telephone contacts weekly for 6 weeks after the initial visit to the intemist or cardiologist. Episodes of heart failure needing intervention prompted weekly telephone contact for the next 6 weeks. ${ }^{13}$ For patients who remained clinically stable, routine 
nurse-initiated telephone contacts occurred at 8,10,12,16,20 and 24 weeks. A comprehensive heart failure, management program reported by Fonarov et al. described telephone calls 2 to 3 days after any major medication change and routine intervals between 2 and 8 weeks, as warranted by clinical stability, patient sophistication and need for reassurance. ${ }^{6}$ In a study by Kornowski et al., follow-up consisted of a weekly home visit by a physician. ${ }^{9}$ There probably is not one "best" schedule for follow-up. However, there seems some agreement among experts in the importance of a short time (I week) between discharge and the first clinic visit, and the need for weekly follow-up for an extended period of time. ${ }^{45}$

Include disciplines beyond nursing: A multidisciplinary approach is preferred, with regular contacts with a cardiologist. general practitioner, home health care nurse, dietitian, physical therapist and social worker. However, it should be noted that probably not every hospital can provide intensive programs as described in the literature, ${ }^{5.6}$ because a lot of physicians and many clinics may not have a sufficient number of patients to justify these interventions. ${ }^{{ }^{6}}$ Depending on the resources of the organization, the size and intensity of the team may vary.

It should be stressed, however, that the role of the nurse should go beyond "helping decreasing the doctors workload". Nurses should have an important role in providing education, support and counseling to improve self-management skills of patients. Our study showed that nursing education and support can increase self-cure of patients and can probably play a role in decreasing resource utilization. It would be a pity not to use this information to develop a care model in which the nurse has a pivotal role. It is important that nurses are equal partners in these multidisciplinary programs ${ }^{47}$ and they therefore should be appropriately trained. In the Netherlands no organized training program for advanced nursing practice exists. Efforts to enhance the knowledge and skills of nurses who play an important role in the extended care of heart failure patients should be encouraged.

Extend methods (tailored): The heart failure population is very diverse regarding symptoms, functional capacity, adjustment and behavior. As discussed in chapter 7 , patients ${ }^{\prime}$ reasons for not complying with the regimen were also very diverse. This diversity calls for a very tailored approach to the patient and family. In addition to the standard topics that have to be discussed with every patient, the content and details of the information, the approach used and the methods have to be individualized. Positive experiences have been reported with computertailored interventions. In such a method, information provided to the patient is tailored to his/her specific situation. For example, patients are instructed about which warning signs are important and which health care providers they should contact. A combination of oral and written information should be used and maybe group interventions should be considered. A diary to register improvement or to improve symptoms and actions can be very useful.

Follow-up also should be tailored to specific patients' needs. Some patients only need one home visit and an easy accessible person in case of problems; other 
patients may be in need of weekly telephone calls and a monthly home visit by the cardiologist.

Knowledge from health education theories, for example self-efficacy, can be used to improve interventions. Self-efficacy beliefs are defined as the perception that one can master a certain task or perform adequately in a given situation. ${ }^{48}$ Peoples thoughts about the ability to perform certain behaviors can influence their activities. Previous experiences, observations from others, social influence and the physiological state of a person affects self-efficacy beliefs. Helping a patient to get a positive experience with certain behaviors, role modeling and social support can be important interventions to enhance the patient's belief that he or she can perform this behavior and will benefit from it.

Methods like telephonic monitoring to measure weight and assess symptoms, using a diary for monitoring progress or electronic event monitoring to monitor and improve patient compliance can be considered. ${ }^{3.35 .44}$ These methods are relatively new and first studies in this patient population have been reported. ${ }^{35.49}$

Adapt to possibilities of the organization: As described earlier, there are different models for patient care of chronic heart failure patients. Studies on, for instance. heart failure clinics, a heart failure specialist. a heart failure advanced home practitioner and home care programs show positive effects. However, not all interventions are suited to all centers..$^{5-13.50 .51}$ For example, Steward et al. (1998) found their home-based intervention was effective in a high-risk socially disadvantaged patient population in Australia. ${ }^{7}$ Implementing this intervention in another situation may not guarantee the same effects. Patients who are admitted to the hospital are often in a worse condition than patients in clinical trials or those who are evaluated in a transplant clinic. This has to be considered before implementing an intervention tested in such a situation, e.g. the study of Fonarov et al.(1997). ${ }^{6}$ The major point to be made is that although basic agreement can be achieved on the content of care needed by patients with heart failure, the organization of the care should be closely adapted to the needs of the patient group and the resources of the organization. Different models (e.g. heart failure outpatient clinic, heart failure nurse specialist, community nurse specialist) may be appropriate depending on the stage of the disease, patient population and regional resources. ${ }^{43}$ At the same time it is interesting to discuss the possibility of specialized "heart failure centers" in which the expertise in managing all aspects of heart failure (e.g. optimized medical treatment, education and support, optimal care in hospital and at home) is available for both professional that are involved in the various stages of treating and caring for heart failure patients, and for patients and families.

Extend accessibility: In our intervention the study nurse was available only the first 10 days after discharge during office hours. Many patients need a health care provider during the weekend or the night. Sometimes advice on extra diuretics is needed: patients needs their electrolytes checked, or patients need to ventilate their anxiety. Experiences from heart failure nurses or heart failure clinics in the 
United States are instructive: a 24-hour coverage can be achieved by involving an attending physician or a nurse from the evening or night shift. ${ }^{22}$ After assessing the problem, the patient can be asked to call back during office hours or in case of emergency can be asked to come to the emergency (heart) center.

Extend family and patient involvement: The intervention used in this study mainly focused on the patient. Family members were involved as much as possible, depending on the situation. As described in chapter 4, to make this supportiveeducative program more family-focused, additional work is recommended. Increased social support by family members can enhance compliance of the patient to the complex medical regimen. ${ }^{30,53} \mathrm{High}$ levels of stress were described among family members of congestive heart failure patients. ${ }^{54}$ Interventions to maintain and increase social support might be effective in improving outcomes. Maybe a group intervention, in which the patients can support each other and their family members can join them. should be considered.

In addition, involvement of the patient in his/her care should be encouraged. Previous research found that patients' own assessment of readiness for discharge seems to be predictive of the need for subsequent readmission. Patients who felt they were discharged too soon were more likely to be readmitted than patients who felt they were ready to be discharged..$^{55.56}$

Include the whole spectrum of disease: Although much attention is given to the usefulness and effectiveness of "carchy" interventions like a heart failure clinic or a nurse specialist, where concrete results on decreasing readmission and costs can be expected, it is advised to cover the "whole spectrum of disease; from prevention to terminal care" in future guidelines for heart failure patients.

More attention is needed for the specific care needed for the end stage of life. ${ }^{57}$ A lot of heart failure patients have symptoms as severe as those in patients with cancer managed by palliative care team. ${ }^{58}$ Palliative care, places emphasis on the care of patients with active. progressive far advanced disease. for whom the prognosis is limited, who may benefit from a multidisciplinary approach, and the focus of care is quality of life. ${ }^{58.59}$ Palliative care is often associated with cancer or AIDS, but the services for patients in the terminal stages of heart failure could be improved. There is an urgent need for more investigation into symptom relief for the advanced stages of heart failure and the possibilities of joint treatment by general practitioners and specialists. ${ }^{57.58 .60)}$ Palliative care inight be successful in using the same approach that helps, for example, cancer or Aids patients, but one should be careful to not overwhelm conventional hospice and specialist care. ${ }^{6 t}$ With proper educated palliative care teams on heart failure that consider the risk of sudden death, the long disease process, symptom relieving interventions and the high number of comorbidities in this patient population, terminal care for heart failure patients could be better organized..$^{62-63}$

Some of these recommended changes (longer follow-up, involvement cardiologist, access to of heart failure nurse) are implemented in the outpatient department care-model in the University Hospital of Matastricht which was started after finishing this study. ${ }^{64}$ 


\section{What research would be useful in future?}

In the previous discussion several suggestions to improve care and critical reflections on instruments and populations have been made. From this information the following directions for future research can be formulated:

I. Mechanisms underlying resource utilization and quality of life

(a) Dala are needed on reasons for readmission in patients with heart failure. There are a few studies that describe reasons for readmission ${ }^{31.65 .60}$ however. information from the Netherlands is not available for this specific patient population. This information is needed to further improve care for patients with advanced heart failure.

(b) Although there is some evidence of improved compliance following a comprehensive discharge program, more research is needed on the mechanisms of multi-factorial interventions. In future research effects of interventions on self-care, compliance, and psychosocial variables (e.g. depression. and anxiety) should be measured, in addition to outcome measures like mortality, readmission and costs. Concepts like self-care and self-care agency or self-efficacy can be useful in these studies.

(c) It is difficult to measure and change quality of life in patients with advanced heart failure. Research should be conducted to gain insight into what constitutes and influences quality of life in these severely ill patients and how we can measure this.

2. The intervention

(a) More research is needed on the effectiveness of interventions like a heart failure clinic, a home care program or a nurse practitioner. A lot of money and human energy is spent on the development and implementation of these projects. Appropriate prospective clinical trials are needed to evaluate various strategies.

(b) What is the appropriate "dose" of the intervention (addressing the whole continuum of care, from proper education and treatment after a large myocardial infarction to palliative care in terminal heart failure patients)?

(c) Not all heart failure patients need specialist care in heart failure clinics. The role and intensity of specialization versus generalization in medical and nursing care should be explored. Additional work is needed to gain more and detailed insight into the role of general practitioners and home nursing care in the care of patients with heart failure. Aspects of continuity and coordination of care should be addressed. 


\subsection{References}

I. McMurray JJV, Petrie MC, Murdoch DR, Davie AP. Clinical epidemiology of heart failure: public and private health burden. Eur Heart J 1998; 19(suppl. P): 9-16.

2. Fawcett J, Downs F. The relationship of theory and research ( $2^{\text {nd }}$ ed.). Philadelphia: FA Davis Company, 1992.

3. Orem DE Nursing: Concepts of practice ( $5^{\text {th }}$ ed.) St. Louis: Mosby 1995.

4. Huch MH. Theory-based practice: Structuring nursing care. Nurs Scie Quarti I 995; 8: 6-7.

5. Rich MW. Beckham V. Wittenberg C, Leven CL, Freedland KE, Carney RM. A multidisciplinary intervention to prevent the readmission of elderly patients with congestive heart failure. N Engl J Med I 995; 333: I I90-I I95.

6. Fonarov GC, Stevenson LW, Walden JA, Livingston NA, Steimle AE, Hamilton MA, Moriguchi J, Tillisch JH, Woo MA. Impact of a comprehensive heart failure management program on hospital readmission and functional status of patients with advanced heart failure. J Am Coll Cardiol 1997; 30: 725-732.

7. Stewart S, Pearson S, Horowitz JD. Effects of a home-based intervention among patients with congestive heart failure discharged from acute hospital care. Arch Intern Med 1998: 1 58: 1067-1073.

8. Cline CMJ, Israelsson BYA, Willenheimer RB, Broms K, Erhardt LR. Cost effective management programme for heart failure reduces hospitalization. Heart 1998; 80: 442-446.

9. Kornowski R, Zeeli D. Averbuch M. Finkelstein A. Schwartz D, Moshkovitz M. Weinreb B, Hershkovitz R. Eyal D. Miller M. Levo Y. Pines A. Intensive homecare surveillance prevents hospitalization and improves morbidity rates among elderly patients with severe congestive heart failure. Am Heart J 1995; 129: $762-766$.

I0. Weinberger M, Oddone EZ, Henderson WG. Does increased access to primary care reduce hospital readmissions? N Engl J Med 1996; 334: I 44 I-1 147.

I I. Hanumanthu S, Butler J. Chornsky D, Davis S. Wilson JR. Effect of a heart failure program on hospitalization frequency and exercise tolerance. Circulation 1997; $96: 2842-2848$.

12. Smith LE. Fabbri SA. Pai R. Ferry D, Heyman JT. Symptomatic improvement and reduced hospitalization for paticnts attending a cardiomyopathy clinic. Clin Cardiol I 997: 20: 949-954.

13. West JA, Miller NH, Parker KM, Senneca D, Ghandour G, Clark M, Greenwald G, Heller GS. Fowler MB. DeBusk RF. A comprehensive management system for heart failure improves clinical outcomes and reduces medical resource utilization. Am J Cardiol 1997; 79: 58-63.

14. Cook TD, Campbell DT. Quasi-experimentation. Design \& analysis issues for field settings. Boston: Houghton Mifflin Company, I 979.

I 5. Clark KW, Gray D. Hampton JR. Evidence of inadequate investigation and treatment of patients with heart failure. Br Heart J 1994; 7 I: 584-587.

I6. Hamers JPH. Postoperative pain in children. Assessment and intervention [Doc-toral thesis]. Maastricht: University of Maastricht, I995. 
17. McMurray JJV. Failure to practice evidence-based medicine: why do physicians not treat patients with heart failure with ACE-inhibitors? Eur Heart J 1998; I9(suppl. L): I5-22.

18. Polit DF, Hungler BP. Nursing Research. Principles and methods ( $4^{\text {th }}$ ed.) Philadelphia: JB Lippincott Company, I 99 I.

19. Senten CMS. The well being of patients having CAB surgery: a test of Orem's self-care nursing theory [Doctoral thesis]. Maastricht: University of Maastricht, I $99 \mathrm{I}$.

20. Evers GCM. Appraisal of self-care agency: the ASA-scale [Doctoral thesis]. Maastricht: University of Maastricht, 1989.

2 I. Friedman MM, Fields PAF, Griffin JA. The relationship between heart failure patients' symptom interpretation and time until admission. Circulation I998 (suppl I): 482 .

22. Dracup K, Walden JA, Stevenson LW, Brecht ML. Quality of life in patients with advanced heart failure. J Heart Lung Transplant I992; 1 I: 273-279.

23. Hawthorne MH, Hixon ME. Functional status, mood disturbance and quality of life in patients with heart failure. Progr Cardiovasc Nurs 1994; 9: 22-32.

24. Grady KL, Jalowicc A, Grusk BB, Williams CW, Robinson JA. Symptom distress in cardiac transplant candidates. Heart Lung 1992; 2 r: 434-439.

25. Wiklund I. Swedberg K. Some methodological problems in analyzing quality of life data in severe congestive heart failure patients. J Clin Res Pharmacoepidemiology 1991; 5: 265-273.

26. Krook J. Reliability and validity of the Dutch version of the PAIS [in Dutch] [Masters thesis]. Maastricht: University of Maastricht. Health Sciences, 1996.

27. Rector TS, Cohn JN. Assessment of patient outcome with the Minnesota Living with Heart Failure questionnaire: reliability and validity during a randomized, double-blind, placebo-controlled trial of pimobendan. Pimobendan Multicenter Research Group. Am Heart J I 992: [ 24: $1017-1025$.

28. Wijbenga JAM, Duivenvoorden HJ. Balk AHMM. Simoons ML, Erdman RAM. Quality of life in chronic heart failure. Validation of the Dutch version of the Minnesota Living with Heart Failure Questionnaire [in Dutch]. Cardiologie 1998: 5: 627-63 r.

29. Miller NH. Compliance with treatment regimens in chronic asymptomatic diseases. Am J Med I 997; I02: 43-49.

30. Burke L.E, Dunbar-Jacobs J. Adherence to medication, diet, activity recommendations: from assessment to maintenance. J Cardiovasc Nurs 1995; 9: 62-79.

31. Ghali JK. Kadakia S, Cooper R. Ferlinz J. Precipitating factors leading to decompensation of heart failure. Arch Intern Med 1988: 148: 2013-2017.

32. Monane M, Bohn RL. Gurwitz JH. Glynn RJ, Avorn J. Noncompliance with congestive heart failure therapy in the elderly. Arch Intern Med 1994: 1 54: 433437 .

33. Vinson JM. Rich MW. Sperry JC. Early readmission of elderly patients with congestive heart failure. J Am Geriatr Soc 1990; 38: 1290-1 295.

34. De Geest $S$. Subclinical noncompliance with immunosuppressive therapy in heart transplant recipients [Doctora] thesis]. Leuven: Katholieke Universiteit Leuven. 1996. 
35. Kruse W, Gwinner PK, Nikolaus T, Oster P, Schlierf G. Measurement of drug compliance by continuous electronic monitoring: a pilot study in elderly patients discharged from hospital. J Am Geriatr Soc 1992; 40: I 15 I-I 155.

36. Tresh DD, McGough MF. Heart failure with normal systolic function: a common disorder in older people. J Am Geriatr Soc 1995; 43: 1035-1042.

37. Holm S. A simple sequentially rejective multiple test procedure. Scand J Statis 1979; 6: 65-70.

38. Adang EMM, Kootstra G. Baeten CGMI, Engel GL. Quality of life ratings in patients with chronic illnesses (letter to the editor) JAMA 1997: 277: 1038.

39. Dracup K, Baker DW, Dunbar SB, Dacey RA, Brooks NH, Johnson JC. Oken C, Massie BM. Management of Heart Failure, counseling, education, and lifestyle modifications. JAMA 1994; 272: 1442-1446.

40. Sackett DL, Rosenberg WMC, Gray JAM, Haynes RB, Richardson WS. Evidence based medicine: what it is and what it isn't. BMJ 1996; 312: 71-72.

4I. Damoiseaux V, Visser Aph (eds.). Patient education, an interdisciplinary approach [in Dutch]. Assen: Van Gorcum, 1988.

42. Ashby BSH. Home teaching: Effect on compliance, hospital readmissions and days of rehospitalization for patients with chronic congestive heart failure. Unpublished doctoral dissertation, Virginia Commonwealth University, Richmond, 1988.

43. Ekman I, Andersson B, Ehnfors M, Matejka G, Persson B, Fagerberg B. Feasibility of a nurse-monitored, outpatient-care programme for elderly patients with moderate-to-severe, chronic heart failure. Eur HeartJ 1998; 19: 1254-1260.

44. K. Dracup personal communication, November 1998, and S. Stewart, personal communication, August 1998 .

45. Beyond four walls: cost-effective management of chronic congestive heart failure. Washington DC: Advisory Board Company, 1994.

46. Shah NB, Der E. Ruggerio C, Heidenreich PA, Massie BM. Prevention of hospitalization for heart failure with an interactive home monitoring program. Am Heari J 1998; 135: 373-378.

47. Cline CMJ. Hear failure clinics (editorial). Heart I998: $80: 426-427$.

48. Bandura A. Self-efficacy mechanism in human agency. American Psychologist 1982; 37: 122-147.

49. Mancini D, Cordisco MA. Beniaminovits A, Prince M. Use of telemedical monitoring to decrease rate of hospitalization in patients with severe heart failure. Circulation I998 (suppl I): 483.

5o. Cintron G, Bigas C, Linares E, Aranda JM, Hernandez E. Nurse practitioner role in a chronic heart failure clinic: in hospital time, costs, and patient satisfaction. Hearl Lung 1983; 12: 237 240.

51. Noyes DA, Calder CM, Polynzyk CA, Caroll DL, DiSalvo TG. Outcomes of an advanced practice nurse home care program for hear failure patients. Circulation 1998 (suppl 1): 483 .

52. Rich M, Paul S. How to organize a heart fajlure clinic. How-to-session Scientific. Sessions American Heart Association 1998.

53. Hubbard P, Muhlenkamp AF, Brown N. The relationship between social support and self-care practices. Nurs Res 1984:33: 266-270. 
54. Doering LV, Dracup K, Walden J, Westlake C, Livinston N, Hamilton MA. What predicts the emotional health of spouses of advanced heart failure patients? Circulation 1998 (suppl I): 64 .

55. Andrews K. Relevance of readmission of elderly patients discharged from a geriatric unit. J Am Geriatr Soc I986; 34: I 5-2 r.

56. Williams EL, Fitton F. Factors affecting early unplanned readmission of elderly patients to hospital. BMJ 1988; 297: 784-787.

57. Linden B. Severe heart failure: a focus on the quality of care. Nurs Times 1995; 9r(Aug I6): 38-39.

58. Gibbs LME, Hall JA, Gibbs JS. Dying from heart failure: lessons from palliative care. BMJ 1998; 317 : 96r-u62.

59. Doyle D. Palliative medicine -... - a time for decision. Palliative Med 1994; 74 : 253-2.55.

6o. Lynn J. An 88-year-old woman facing the end of life. JAMA 1997; 277: 16331640.

6I. Jones S. Palliative care in terminal cardiac failure (letter to the editor). BMJ 1995; 310 : 805 .

62. Gannon C. Palliative care in terminal cardiac failure. Hospices cannot fulfill such a vast and diverse role. (letter to the editor). BMJ 1995; 310: I410-14 I I.

63. Beattie JM, Murray RG, Brittle J, Catanheira T. Small numbers of patients with terminal cardiac failure may make considerable demands on services (letter to the editor). BMJ 1995:310: 1411 .

64. Lucas CMHB, Jaarsma T, Cleuren G, Wellens HJJ. Intensivering van begeleiding en follow-up van patiënten met chronisch hartfalen volgens het Maastrichts poliklinisch model. [in Dutch] Cardiologie 1999; 6: 123-127.

65. Michalsen A. Konig G, Thimme W. Preventable causative factors leading to hospital admission with decompensated heart failure. Heart r998; 80: 437-44I.

66. Opasich C. Febo O, Riccardi PG et al. Concommitant factors of decompensation in chronic heart failure. Am J Cardiol 1996; 78: 354-357. 


\section{Summary}

Heart failure patients are a group of chronic patients whose number is growing. The aging of the population, the increasing chances of surviving acute cardiac problems and the improved recognition of heart failure have resulted in increased numbers of chronic heart failure patients.

Heart failure is described as a complex clinical syndrome rather than an objective definable disease, and it is frequently characterized as the complex of symptoms that are related to the inadequate perfusion of tissue during exertion and often to retention of fluid. Heart failure patients often suffer from symptoms like breathlessness or fatigue, either at rest or during exertion, or/and ankle swelling. These symptoms have a major impact on the daily life of patients and their families. In addition, treatment, life-style changes, and insecure prognosis have a large influence on their lives.

The growth in the number of patients with heart failure necessitates a shift in the emphasis of the health care system. In addition to the increased need for diagnosis and medical treatment, there is a growing emphasis on care and adequate follow-up of the chronic patient population. Different strategies are used to advance quality of care, improve patient outcomes and decrease use of resources. Nurses are increasingly involved in these new care initiatives that often are aimed at improving continuity of care between hospital and home. Although several models of care are described and are expected to improve care, no randomized Dutch studies have been reported that evaluate the effect of nursing care in a heart failure population.

In this thesis the importance of education and support is described and the development of a standard nursing care plan for patients with chronic heart failure is prenented. Finally the results of a study evaluating the effects of education and support in a heart failure population are presented. The first part of the thesis describes the background of the study.

Chapter $\mathbf{2}$ of this thesis provides an overview of the literature on factors associated with hospital readmission of older patients in general and heart failure patients in particular. Important factors reported to be related to rehospitalization are sociodemographic and medical factors, premature discharge, failing support system, medicationrelated problems and noncompliance. In addition, the role of nurses in preventing unplanned readmissions is described. In the literature interventions in the area of discharge planning, patient education and follow-up are recommended. Recently, a growing number of publications have appeared on improving the quality of care for patients with heart failure. Research into the effects, however, is limited. At the time of the start of the study. only I randomized clinical trial evaluating the effects of a multidisciplinary intervention had been published. In the growing number of studies 
that have since been published, however, different interventions, different populations and different heart care systems were evaluated, which makes the results not always comparable.

Chapter 3 presents an overview of nursing care for patients with heart failure as described in practice, in literature and in standard nursing care plans. Based on interviews with 45 nurses, a review of all pertinent literature published between I 983-1993 and a review of standard nursing care plans used in the Netherlands to care for patients with heart failure, four composite themes emerged: namely basic nursing care, assessment and observation, symptom-relieving interventions, and patient education. Caring for patients with heart failure is very complex and is often aimed at keeping a very delicate balance, for example, between rest and activity, fluid intake and elimination, and therapeutic cost and benefit. Treatment strategies for optimizing care for these patients are described and experimental evaluations of programs is recommended focusing on cost-effectiveness and quality of life.

Part II of this thesis describes the development and the content of the supportiveeducative intervention for patients with advanced heart failure.

Chapter 4 presents the development of a supportive-educative program that is designed to develop self-care abilities of patients with heart failure. To structure nursing care for these patients and their families in a consistent systematized way, Orem's General Theory of Nursing is used as a frame of reference.

As the disease progresses, patients have to make adjustments in their lives. To successfully make these adjustments, patients need certain knowledge and skills. Nurses can help patients by support, guidance, provision of a developmental environment and teaching ("supportive-educative" system). To use such a supportive-educative system successfully, nurses need to focus on specific needs for patients with heart failure. There is no known well-defined or structured program available that can be uscd to enhance heart failure patients' abilities to engage in self-care. Thus, to develop such a supportive-educative program for patients with heart failure, the needs and abilities of a "prototypicial" he:art failure patient were described. This information was used to develop an assessment tool that enables the "actual" needs and abilities of a specific heart failure patient to be described. Finally, a supportive-educative nursing program was designed for patients with heart failure.

By using a theory as frame of reference, various aspects of care could be structured in a consistent systematized way, recognizing the impact of heart failure on various aspects of life. Using the multi-dimensional approach of the theory consequences of heart failure, social and personal aspects were addressed.

In chapter 5 a case study is used explain and illustrate the intervention and to review the importance of the standard nursing care plan. In this case study a nurse educates and supports a patient with heart failure during hospital admission, telephone follow-up within 3 days and home visit within so days after readmission. Several standards topics (e.g. medication, fluids, daily weighing, and anxiety) are discussed, and with the specific patient attention is paid to sleeping problems, social isolation and problems with transportation.

The case demonstrated that using an assessment form and a standard nursing care plan enhanced the quality of care provided, by guarantecing continuity of care. The 
case study also showed the advantage of patients having easy access to specialist nurses in a well-documented and specialized environment. Restrictions in the care plan that were found include the length of the follow-up (only 7-I0 days) and the limited specific interventions for psychosocial problems.

Part III of the thesis reports the results of the study into the effects of the supportiveeducative intervention as described in the previous chapters.

Chapter 6 describes the method. A randomized controlled study was conducted to study the effects of a supportive-educative nursing intervention on self-care (agency and behavior), resource utilization and quality of life. Heart failure patients admitted to the cardiology ward (May 1994-March 1997) of the University Hospital in Maastricht (the Netherlands) were screened for potential eligibility to the study. Patients were randomly assigned to a control or intervention group. Patients in the intervention group $(n=84)$ received extra education and support from a nurse guided by a standard nursing care plan. The control group $(n=95)$ received care-as-usual. To evaluate the effect of the supportive-educative nursing intervention, data were collected at baseline (hospital admission), and after I, 3 and 9 months after discharge. Data were collected on selfcare agency, self-care behavior and use of resources (readmissions, contacts with health care providers). Patients were also asked to report on barriers for self-care behavior. Three dimensions of quality of life were evaluated: functional capacity, symptoms and psychosocial adjustment to illness, and a global score of overall well-being was given by the patient.

In total 564 patients were screened for eligibility for the study. Of these patients 22,6 met the inclusion criteria and 186 gave their informed consent. During the 9 months follow-up, 45 patients died $(24 \%)$ and 9 patients did not want to continue participation. In total 132 patients participated in the 4 interviews. The mean age of these patients was 72 years $( \pm 9), 60 \%$ were male and $45 \%$ were living alone.

Chapter 7 presents the effects of the supportive-educative intervention on self-care agency and self-care behavior. Data were collected by means of two questionnaires (Appraisal of Self-care Agency Scale, ASA) and the Heart Failure Self-care Behavior Scale). Additional data were collected on barriers for self-care behavior. Answers were categorized into limitations in knowledge. limitation in judgment/decision-making and limitation in skills. No significant differences were found in self-care agency between the two groups. Self-care behavior. however, did show significant differences.

Patients from both the intervention and the control group increased their self-care behavior within I month of discharge, probably as a result of hospitalization. The selfcare behavior of patients in the intervention group, however, was significantly greater at I and 3 months after discharge, compared to patients from the control group. Although both groups decreased self-care behavior during the following 8 months, the increase from baseline remained statistically significant in the intervention group, while this was not the case in the control group. Although a difference existed in self-care behavior of patients in the control and intervention group, the main reason for limited self-care behavior was not considerably different between the two groups. A trend towards fewer limitations in knowledge in the intervention group wasdiscerned. Despite intensive education and support, several patients in the intervention group reported limitations in self-care behavior. Some patients in the intervention group stated that a limitation 
of knowledge was their reason for not conducting self-care behavior, but the majority of the patients reported limitations in judgment and decision-making, implying that patients know how to behave, but choose to act differently.

Chapter 8 describes the effects of the supportive educative intervention on resource utilization. From the hospital computer database and a questionnaire, data were collected on readmission and contacts with health care providers. One month after discharge from the hospital and $14 \%$ of the patients had been readmitted to the hospital, with no differences between the control and intervention group. Three months after discharge this had accumulated to $3 \mathrm{I} \%$ in control patients and $26 \%$ in intervention patients (not significant). Nine months after discharge 47 patients $(50 \%)$ from the control group had been readmitted, compared to $3 \mathrm{I}(37 \%)$ of patients of the intervention group. $\left(\chi^{2}=2.8, \mathrm{p}=0.006\right)$. The same trend was found in visits to the Emergency Heart Center (EHC) of the hospital. During the 9 months of follow-up, relatively fewer intervention patients $(24 \%)$ visited the EHC: compared to patients from the control group $(38 \%)\left(\chi^{2}=2.7, \mathrm{p}=0.004\right)$. Reviewing the resource utilization in this study, we found that within I month of hospital discharge, 75 of the patients $(57 \%)$ had a followup appointment with their cardiologist. Only Io patients did not have any scheduled appointment with a cardiologist, internist or general practitioner within a month of discharge. We also found that patients with heart failure use a lot of health care resources within 9 months of discharge. On the other hand, patients showed limited use of home nursing care. home health and other health care services.

Only a limited relationship between resource utilization and self-care was found. Higher self-care abilities of the intervention patients were associated with fewer contacts with their General Practitioner. In the control group it was found that patients with higher scores on self-care behavior showed fewer readmission days for cardiac causes.

The reason for not finding a significant effect on resource utilization, while other comparable studies did find effects may lie in the differences in health care systems. Another explanation may be found in the "dose" of the intervention. Suggestions to improve the intervention include longer follow-up (by a nurse or a physician) and the increased accessibility of such a person.

In the subsequent chapters of the thesis the quality of life of patients with advanced heart failure is discussed.

Chapter 9 describes the quality of life of heart failure patients with decreased or normal systolic function. In addition, differences between patients with systolic and diastolic dysfunction were analyzed and factors relating to quality of life were assessed using regression analysis.

Three dimensions of quality of life (functional capabilities, symptoms and psychosocial adjustment to illness) and overall well-being score were assessed during interviews of 186 patients with chronic heart failure.

On average patients walked 172 meters in 6 minutes and reported functioning in daily life at a mean level of 4.5 MET. Patients experienced four different symptoms of heart failure. Most of them described dyspnea, fatigue. sleep disturbance and ankle edema. Problems with psychosocial adaptation occurred mostly in social and vocational environment. Overall well-being of patients was rated as a 6.4 on a 10-point 
scale. In regard to quality of life, the only differences between patients with systolic and diastolic heart failure was the occurrence of ankle edema and health care orientation. The variance in components of quality of life was partly explained by demographics and clinical characteristics. All three dimensions of quality of life were related to self-care.

Patients with heart failure seen in clinical practice are often not comparable to patients described in major clinical trials or patients that are admitted for transplant evaluation. Their functional capabilities are more compromised, but they may have fewer problems with psychosocial adjustment. Patients with normal systolic dysfunction also report low quality of life. It could be important to enhance self-care abilities of patients to improve psychosocial adaptation to illness.

The change in quality of life during the study is described in chapter Io and I I. As described previously, the intervention was effective on self-care behavior.

The intervention proved to be effective for patients with both high and low levels of self-care behavior at baseline. The effect of the supportive-educative intervention on quality of life was limited. Quality of life as measured by functional capabilities, number of symptoms and psychosocial adjustment improved after hospitalization in both groups, with no differences between intervention and control groups throughout the study period.

There was a trend indicating difference in change in symptom severity and distress between the two groups. Patients from the intervention group experienced their symptoms as being less frequent and less distressing 9 months after follow-up. We also expected that patients reporting better heart failure related self-care behavior (e.g. comply with diet, weighing) would report better quality of life. However, we only found a limited relationship between self-care behavior and psychosocial adjustment to illness and well-being. Symptoms and functional capabilities were not found to be related to self-care behavior. Better behavior does not always lead to better quality of life outcomes, reflecting the complexity of mechanisms underlying improving outcomes.

Despite the trend of differences in experiences of symptom frequency and distress, one can argue that the intervention failed to show effectiveness in improving quality of life. It is questionable whether health care interventions are strong enough to improve quality of life of these elderly advanced heart failure patients. It is difficult to get insight into what really constitutes a good quality of life in this patient population. Since optimizing quality of life is one of the major goals in heart failure treatment. health care providers and researchers should be focused on getting more information on quality of life and improving quality of life. From both a clinical and theoretical perspective it is important to identify predictors of change of quality of life.

Chapter 11 reports analyses on which clinical, demographic, self-care and health care variables are associated with a change in quality of life of patients with chronic heart failure. The data of patients with complete data-sets $(n=74)$ were used. Multiple regression analyses were performed with the change score of each dimension of quality of life (functional capacity, symptoms and psychosocial adjustment) and well-being as the dependent variable. Clinical, demographic, self-care and health care variables were entered as the predictors.

The baseline score mainly predicted the changes in 3 dimensions of quality of life 
and in overall well-being. Of the demographic variables, age and gender were slightly related to a change in quality of life over time. In addition, patients who were older and patients with a relatively bad physical condition at baseline (more prior admissions, NYHA IV, low functional capabilities, diabetes, lung disease, and high weight loss during admission) were less likely to improve their quality of life. This might suggest that elderly and physically vulnerable patients need tailored multidisciplinary interventions that focus on their specific situation (e.g. heart failure clinics, home visits, multidisciplinary approach, discharge planning and disease management). Patients who were able to take good care for themselves (i.e. had high self-care agency) or patients who improved their self-care abilities reported more improvement of functional capacity and psychosocial adjustment than patients with low self-care agency at baseline. This suggests that in addition to the predictors age and physical condition, self-care agency can be used to tailor interventions. Patients with low self-care agency may need help to use or enhance social support or to get home nursing care. Maybe they cannot take care of themselves, but nurses can help them arrange for care.

Patients with improved psychosocial adjustment to illness reported improvement in overall well-being during the study period. It is important to address the possibilities to improve psychosocial adjustment to illness in patients during recovery. Interventions aimed at adaptation could include patient and family counseling, involvement of community services or providing help in vocational problems. Further attention should be paid to differences between male and female patients.

Little relationship appears to exist between resource utilization and quality of life. In those few cases where relationships were statistically significant, increased resource use over the 9 months was related to poorer quality of life or overall well-being.

In the chapter 12 critical reflection on the study and suggestions theory, practice and research are presented.

The most important limitations of the study are the intensity ("dose") of the intervention, the insensitivity of the instruments, generalizability and the limited data collection on short term (I month).

In regard to using Orem's General Theory of Nursing, it is concluded that the theory was helpful in systematizing the intervention. However, the theory is often too abstract for practical use. It was suggested that several aspects need clarification (e.g. the relationship between self-care and quality of life) and several aspects can be added (e.g. the role of the nurse in managing the care process).

To improve the intervention Io recommendations are made. These are based on results of the study, recent literature and experiences during the study and the implementation in practice. The recommendations concern

- Content (constantly update, expand documentation, involve patient and family)

- Format/form (combine hospital and home visit. use additional interventions)

- Intensity (extend follow-up, improve accessibility)

- Inclusion of disciplines beyond nursing in hospital and in the community

- Adaptation to possibilities of the organization

Recommendations concerning research include research into mechanisms underlying resource utilization and quality of life and factors related to (a change in) quality 
of life of patients with heart failure. In addition, it is stressed that more randomized studies are needed to evaluate new care models for patients with heart failure, such as home-care programs, heart failure clinic or nurse practitioner. In these studies the intensity (dose) of the intervention should be considered. It is also recommended to stimulate research on the role of the general practitioners and home nursing care in the care of patients with heart failure. Aspects of continuity and co-ordination of care should be addressed in the whole disease process of the patient, meaning from optimal education and treatment after a myocardial infarction to palliative care in the terminal phase of heart failure. 


\section{Samenvatting}

Met de verschuiving van acute naar chronische ziekten in de Westerse wereld neemt het aantal patiënten met hartfalen fors toe. Mensen met coronairlijden leven langer dan voorheen, de sterfte bij hartinfarcten neemt af en de mogelijkheden voor opsporing en behandeling van hartfalen zijn toegenomen. Een eenduidige definitie van hartfalen ontbreekt weliswaar, maar algemeen gebruikelijk is de benadering dat hartfalen een complex klinisch syndroom is en geen objectief te definiëren ziekte. Hartfalen ontwikkelt zich als gevolg van een hartaandoening en wordt gekenmerkt door verschillende symptomen die samenhangen met een slechte doorbloeding van weefsel gedurende inspanning en het vasthouden van vocht.

Patiënten met chronisch hartfalen zijn vaak kortademig bij lichte inspanning of zelfs in rust, zijn snel moe, en houden vocht vast (bijvoorbeeld in de benen of in de buik). Deze symptomen hebben een grote invloed op het leven van de patiënten en hun familie.Maar ook de behandeling. verschillende leefregels en een onzekere toekomstverwachting hebben een grote impact op het dagelijks leven.

Bekend is dat steeds meer mensen met hartfalen worden opgenomen en dat het heropnamecijfer hoog is (14-50\% binnen 6 maanden, afhankelijk van het land en patiëntengroep). Uit de literatuur blijkt dat veel heropnames bij een betere zorg en follow-up waarschijnlijk voorkomen hadden kunnen worden.

De groei van het aantal patiënten met hartfalen heeft consequenties voor de gezondheidszorg. Met diverse nieuwe zorginitiatieven probeert men zowel in Nederland als in het buitenland in te spelen op de groeiende groep patiënten met hartfalen, maar er is op dit gebied in Nederland nog weinig onderzock gedaan.

Dit proefschrift bespreekt de noodzaak voor voorlichting en begeleiding voor patiënten met chronisch hartfalen, de ontwikkeling van een standaardverpleeglan voor voorlichting en begeleiding en de resultaten van een onder/oek naar de effecten hiervan.

$\mathrm{Na}$ de algemene introductie in hoofdstuk 1 wordt in deel I van het proefschrift de achtergrond van het onderzoek besproken.

Hoofdstuk 2 behandelt de redenen waarom oudere patiënten in het algemeen en specifiek oudere patiënten met hartfalen een tweede keer in het ziekenhuis belanden. Een aantal socio-demografische en medische factoren die met heropnames van oudere patiënten met hartfalen samenhangen zijn moeilijk of niet te beïnvloeden, maar er zijn ook factoren waar wel wat aan gedaan kan worden. Deze zijn met name: een te vroeg ontslag uit het ziekenhuis na de opname, onvoldoende sociale steun, problemen met betrekking tot medicatie (onderdosering, interactie) en therapie-ontrouw rond het dieet of de medicatie. 
Vervolgens wordt beschreven welke rol een verpleegkundige zou kunnen hebben in het voorkomen van onnodige heropnames. In de literatuur wordt een betere ontslagplanning en daarmee een betere voorbereiding op het leven na ontslag uit het ziekenhuis, geadviseerd. Een andere belangrijke interventie is voorlichting en begeleiding rond diverse onderwerpen zoals de symptomen, de medicatie, het dieet, beweging, de prognose, therapietrouw en de vraag wat te doen bij verslechtering. Een andere mogelijkheid om de zorg aan patiënten met hartfalen te verbeteren is gelegen in follow-up en nazorg. Dit kan in de vorm van telefonisch contact na ontslag, een huisbezoek van de verpleegkundige of een bezoek van de patiënt aan de polikliniek binnen korte tijd na ontslag uit het ziekenhuis.

In de afgelopen jaren is er al wat meer gepubliceerd over nieuwe vormen van verpleegkundige zorg aan patiënten met hartfalen. Onderzoek naar de optimale verpleegkundige zorg en de effecten hiervan zijn nog steeds schaars. Toen we ons onderzoek begonnen was er slechts één gerandomiseerd onderzoek naar de effecten van een multidisciplinaire interventie beschreven, daarna werden nog vier gerandomiseerde onderzoeken gedaan in verschillende landen, met verschillende interventies en verschillende populaties.

Over de inhoud van verpleegkundige zorg aan patiënten met chronisch hartfalen gat hoofdstuk 3. Hierin wordt verslag gedaan van de huidige zorg zoals in mijn inventariserend onderzoek uit $199+$ is beschreven. De informatic komt uit literatuurondersoek, uit de analysce van standaardverpleegplannen voor patiënten met hartfalen uit Nederland en uit semi-gestructureerde interviews met 45 verpleegkundigen uit het liekenhuis en van de thuiszorg. Vier belangrijke onderwerpen komen daaruit naar voren: basis-verpleegkundige zorg, observatie, symptoomverlichtende interventies en patiëntenvoorlichting.

Verpleegkundige zorg aan patiënten met hartfalen is ingewikkeld en is veelal gericht op het vinden van een -per definitie zeer wankel- evenwicht tussen bijvoorbeeld rust en activiteit, vochtinname en uitscheiding, voor- en nadelen van therapie. In dit hoofdstuk is een aantal aspecten van voorlichting beschreven: algemene voorlichting. prognose, activiteiten, dieet, medicatie en therapietrouw. Tot slot wordt gepleit voor het experimenteel testen van interventies waarbij zowel aandacht besteed wordt aan kosten-effectiviteit als aan de kwaliteit van leven van patiënten met hartfalen.

Deel II van dit proefschrift beschrijft de ontwikkeling en de inhoud van de interventie die in Maastricht werd ontwikkeld voor voorlichting en begeleiding van patiënten met chronisch hartfalen.

In hoofdstuk 4 wordt de verpleegkundige zelfzorgtheorie van Orem gebruikt om informatie uit literatuur en praktijk onder te brengen in een standaardverpleegplan dat bruikbaar zou moeten zijn in de voorlichting en de begeleiding van een patiënt met chronisch hartfalen. Bij het voortschrijdend hartfalen moet een patiënt zich in de loop van zijn leven met hartfalen herhaaldelijk aan veranderde omstandigheden symptomen, behandeling. leefregels- aanpassen. Hiervoor hebben patiënten kennis en vaardigheden nodig. Verpleegkundigen kunnen patiënten van informatie voorzien, adviezen geven. de patiënten helpen zich te ontwikkelen en kennis en vaardigheden aanleren. Hierbij dienen zij zich te richten op de specifieke behoeften van de patiënt met hartfalen en diens familie. Tot nu toe ontbrak een gestructureerd en welomschre- 
ven voorlichtings- en begeleidingsprogramma om patiënten te ondersteunen zodat zij optimaal voor zichzelf kunnen zorgen.

Om een dergelijke interventie te kunnen ontwikkelen was eerst een beschrijving nodig van alles wat een patiënt met hartfalen zou moeten kunnen doen om goed voor zichzelf te zorgen. Aan de hand hiervan kan men voor een individuele patiënt bekijken of deze activiteiten uit kan voeren en op welke punten hij/zij kennis, motivatie, training of andere ondersteuning nodig heeft. In het standaardverpleegplan is een anamnese opgesteld en staan bij verschillende onderwerpen mogelijke interventies van verpleegkundigen genoemd.

De theorie maakte het mogelijk om de informatie goed te ordenen en bood ruimte om aandacht te besteden aan de uitwerking van harfalen op verschillende aspecten van het leven.

In hoofdstuk 5 wordt deze nieuw-ontwikkelde interventie aan de hand van een casus besproken. De verpleegkundige bespreekt met een patiënt met hartfalen aan de hand van het standaardverpleegplan een aantal onderwerpen die van belang zijn om goed voor zichzelf te kunnen zorgen. De verpleegkundige bezoekt de patiënt een aantal maal in het ziekenhuis, neemt binnen 3 dagen na ontslag telefonisch contact met hem op en gaat binnen ro dagen op huisbezoek. Een aantal standaard onderwerpen komt in de gesprekken met de patiënt in het ziekenhuis aan de orde, bijvoorbeeld medicatie, vochtbeperking, regelmatig wegen, angst. Daamaast is er bij deze specifieke patiënt extra aandacht voor slaapproblemen, vereenzaming en vervoersproblemen. Het standaardverpleegplan dwingt de verpleegkundige steeds om volledig te zijn. Ze kan steeds nagaan of belangrijke punten aan de orde zijn geweest. Daamaast beschrijft het plan acties die de verpleegkundige direct uit kan voeren. Omdat het verpleegplan transmuraal is, wordt de continuiteit van de zorg voor de patiënt gewaarborgd en kan de verpleegkundige een aantal onderwerpen dat in het ziekenhuis al is aangekaart, thuis afronden. In de opzet van de interventie is de verpleegkundige een laagdrempelig aanspreekpunt en heeft alle nodige contacten in het ziekenhuis om snel in te kunnen grijpen. Het standaardverpleegplan bleek in de uitvoering een aantal beperkingen te hebben. Zo wordt de follow-up tijd van 7-Io dagen vrij kort gevonden en zijn de interventics voor psychosociale problemen summier uitgewerkt.

In deel III wordt verslag gedaan van het onderzoek naar de effecten van de eerder beschreven interventie. De centrale vraag in het onderzoek was: wat is het effect van extra voorlichting en begeleiding aan patiënten met hartfalen door een verpleegkundige in het ziekenhuis en thuis op hun zelfzorggedrag, hun gebruik van gezondheidszorgvoorzieningen en op hun kwaliteit van leven?

Hoofdstuk 6 behandelt de methode van het onderzoek. Om de onderzoeksvraag te beantwoorden is een experimenteel onderzoek gedaan. Patiënten die met de diagnose hartfalen waren opgenomen op de afdeling cardiologie van het AZM en die aan een aantal criteria voldeden, werden toegewezen aan een controlesituatie (verpleegkundige zorg zoals gebruikelijk) of aan de interventiesituatie (extra voorlichting en begeleiding aan de hand van het eerder beschreven standaardverpleegplan door een voor het project aangestelde verpleegkundige).

Patiënten die meededen in het onderzoek werden vier maal geïnterviewd: eerst in het ziekenhuis tijdens hun opname (baseline), vervolgens via de telefoon I maand 
na hun ontslag uit het ziekenhuis, en daarna nog eens drie en negen maanden na ontslag bij henzelf thuis. Er werden gegevens verzameld over hun zelfzorg (vermogen en gedrag), hun medische consumptie (o.a. heropnames, bezoek aan huisarts, wijkverpleging etc.,) en over de kwaliteit van hun leven (symptomen, psychosociale aanpassing en functionele capaciteit en hun algemene gevoel van welbevinden). Ook werd mensen gevraagd waarom ze bepaalde gezonde gedragingen (bijvoorbeeld regelmatig wegen) achterwege lieten.

In totaal werden tussen mei 1994 en maart 1997.564 patiënten gescreend om mee te duen aan het onderzoek. Van hen voldeden 226 aan de criteria en gaven 186 toestemming om mee te doen aan het onderzoek. Gedurende de follow-up periode van negen maanden overleden er 45 patiënten ( $24 \%$ ) en wilden negen mensen niet meer mee doen. Uiteindelijk hebben 132 patiënten aan alle 4 interviews deelgenomen. De gemiddelde leeftijd van deze patiënten was 72 jaar, $60 \%$ was man en $45 \%$ was alleenstaand.

In hoofdstuk 7 worden de effecten van de voorlichting en begeleiding van de verpleegkundige op het zelfzorgvermogen en het zelfzorggedrag besproken. Patiënten scoorden het vermogen om voor zichzelf te zorgen aan de hand van de vragenlijst "Appraisal of Self-care Agency Scale" (ASA). Daamaast werd in een interview gevraagd naar hun gedrag rond hun behandeling en symptomen, bijvoorbeeld regelmatig wegen, de arts waarschuwen bij symptomen (Heart Failure Self-care Behavior Scale). Ook werd gevraagd naar de eventuele barriëres die zij ondervonden in dat gedrag De uitspraken werden gerangschikt onder kennis, attitude/keuze of vaardigheid/mogelijkheden. Er werd geen significant verschil gevonden tussen de twee groepen als men kijkt naar het vermogen om voor zichzelf te zorgen. Wat betreft gedrag bleek dat mensen uit beide groepen hun gedrag significant verbeterden vergeleken met de baseline score. Echter patiënten uit de interventiegroep rapporteerden wel een beter zelfzorggedrag dan patiënten in de controlegroep. De effecten van de interventie waren een maand na ontslag het grootst en waren drie maanden na ontslag nog aanwezig, maar na negen maanden was het verschil tussen de twee groepen niet meer statistisch significant.

De barriëres voor gezond gedrag waren in beide groepen niet verschillend, behalve dat er een trend was dat patiënten uit de interventiegroep minder vaak een tekort aan kennis als barriëre aangaven dan patiënten uit de controle groep. Opvallend was dat zelfs na intensieve voorlichting en begeleiding, voor enkele items van gezond gedrag een gebrek aan kennis een belangrijke barriëre is. Verder geven veel mensen aan wel te weten dat ze bepaalde dingen eigenlijk zouden moeten doen (bijv. een arts waarschuwen bij symptomen) maar dat ze dat bewust niet doen.

In hoofdstuk 8 worden de effecten van de voorlichting en begeleiding (zoals beschreven in deel II) op het gebruik van gezondheidszorgvoorzieningen gepresenteerd. Uit de computerbestanden van het AZM en op basis van een vragenlijst werden gegevens verzameld over heropnames. contacten met artsen, verpleegkundigen en andere hulpverleners in de eerste en de tweede lijn. Een maand na opname in het ziekenhuis was $14 \%$ van de patiènten minstens eénmaal opnieuw in het ziekenhuis opgenomen geweest: dit cijfer lag voor beide groepen patiënten gelijk. Na drie maanden liep dit heropnamecijfer op tot $31 \%$ voor patiënten uit de controlegroep en $26 \%$ voor patiënten 
uit de interventie groep (dit verschil was statistisch niet significant). Na negen maanden waren 47 patiënten $(50 \%)$ uit de controle groep minstens éénmaal heropgenomen geweest, tegen $31(37 \%)$ van de interventiepatiënten. $\left(\chi^{2}=2.8, p=0.006\right)$. Een zelfde trend werd gevonden in het gebruik van de Eerste Harthulp $(\mathrm{EHH})$ van het ziekenhuis. Binnen de negen maanden van de follow-up periode deden relatief minder patiënten uit de interventiegroep $(24 \%)$ een beroep op de EHH dan patiënten uit de controlegroep (38\%) $\left(\alpha^{2}=2.7, p=0.005\right)$. Uit de gegevens over het bezoek aan andere hulpverleners bleek dat de meeste mensen binnen één maand contact hadden gehad met een arts (huisarts, cardioloog of internist). Veel patiënten zijn onder controle van meerdere specialisten maar slechts een beperkt aantal mensen heeft contact met de thuiszorg (wijkverpleging of gezinsverzorging) of met een fysiotherapeut, diëtiste etc.

Er werd tevens een -beperkte- relatie tussen gebruik van gezondheidszorgvoorzieningen en zelfzorg gevonden. Bij patiënten uit de interventiegroep was een hoger zelfzorgvermogen gerelateerd aan minder contacten met een huisarts. In de controlegroep bleek dat laag zelfzorggedrag gerelateerd was aan meer cardiologische heropnames. Dat we geen significant effect konden vinden op heropnames, terwijl andere soortgelijke studies in bijvoorbeeld de Verenigde Staten een dergelijk effect wel aantonen, kan liggen aan het feit dat in Nederland het aantal heropnames bij voorbaat al lager is. Een andere reden is dat de "dosis" van de interventie nog niet hoog genoeg was, oftewel dat de interventie versterkt zou moeten worden door langere follow-up (door een arts of een verpleegkundige) en dat er een laagdrempelig aanspreekpunt zou moeten zijn waar de patiënt met vragen en problemen terecht kan.

De volgende hoofdstukken van het proefschrift gaan over de kwaliteit van leven van patiënten met hartfalen.

In hoofdstuk 9 wordt de kwaliteit van leven van patiënten met systolische dysfunctie en patiënten met diastolische dysfunctie beschreven. Zijn er verschillen in de kwaliteit van leven van deze twee groepen patiënten en welke demografische, klinische en zelfzorgvariabelen vertonen een relatie met de drie gemeten dimensies van kwaliteit van leven (functionele capaciteit, symptomen en psychosociale aanpassing aan de ziekte)? Ook werd gekeken in hoeverre het algemeen welbevinden van patiënten door deze drie dimensies werd verklaard.

De I 86 patiënten (gemiddelde leeftijd 73 jaar, $58 \%$ mannen) die aan de eerste meting van het onderzoek meededen (tijdens opname in het ziekenhuis) werden op grond van hun linker ventrikel ejectiefractie (evt. aangevuld met klinisch oordeel van de cardioloog) ingedeeld in twee groepen: voornamelijk systolische dysfunctie $(n=150)$ of diastolische dysfunctie $(n=36)$. Aan de patiënten werden vragen gesteld over symptomen (welke, hoe vaak en hoe vervelend), psychosociale aanpassing aan de ziekte (PAIS), en hun functionele capaciteit (MET). Ook deden zij de 6-minuten-looptest. Op een Io puntsschaal scoorden mensen hun algemeen gevoel van welbevinden, dat gemiddeld op een $6.4 \mathrm{lag}$. Mensen liepen gemiddeld 172 meter in 6 minuten en hun gemiddelde functionele capaciteit was 4.5 MET. Tijdens de opname rapporteerden mensen gemiddeld vier symptomen: meestal kortademigheid, vermoeidheid, slaapproblemen en dikke benen. Problemen in psychosociale aanpassing deden zich meestal voor op het gebied van sociale en huishoudelijke activiteiten. In de kwaliteit van leven was het enige verschil tussen de twee groepen dat de patiënten met diastolische dysfunc- 
tie relatief vaker enkeloedeem hadden dan patiënten met systolische dysfunctie en dat patiënten met systolische dysfunctie minder problemen hadden met de medische behandeling en het gezondheidszorgsysteem. Slechts een beperkt aantal demografische en klinische factoren hing samen met de kwaliteit van leven. Het zelfzorgvermogen hing samen met alle drie dimensies van de kwaliteit van leven; het zelfzorggedrag vertoonde alleen een zwak verband met de functionele capaciteit. Ook werd het algemeen welbevinden maar in beperkte mate verklaard door de drie dimensies van kwaliteit van leven.

Vergeleken met patiënten uit andere onderzoeken hadden de patiënten in dit onderzoek een slechtere functionele capaciteit maar ze vertoonden een betere psychosociale aanpassing aan de ziekte. Dit kan verklaard worden door een verschil in populatie (leeftijd) of in de situatie (opgenomen, transplantatiekliniek etc.).

De algemene conclusie luidt dat zowel patiënten met systolische als patiënten met diastolische dysfunctie een verminderde kwaliteit van leven hebben en dat interventies om de kwaliteit van leven van patiënten te verbeteren gericht moeten zijn op beide groepen. Aandacht voor de zelfzorg van de patiënt kan in dergelijke interventies van belang zijn.

Hoe in de loop van het onderzoek de kwaliteit van leven is veranderd staat beschreven in hoofdstuk Io en I 1 .

Hoofdstuk 10 behandelt het effect op kwaliteit van leven van de voorlichting en begeleiding door een verpleegkundige. Hierboven werd al duidelijk dat deze interventie effect had op het zelfzorggedrag van patiënten. Dit effect bleek aanwezig te zijn zowel bij mensen met een hoog als laag zelfzorggedrag tijdens opname.

Gedurende de negen maanden van follow-up nam het aantal symptomen af, verbeterde de psychosociale aanpassing van patiënten en was er een verbetering in hun functionele capaciteit. Hun algemene gevoel van welbevinden bleef redelijk constant tijdens de nametingen. Er waren slechts kleine verschillen in aspecten van kwaliteit van leven tussen de patiënten in de controlegroep en patiënten in de interventiegroep. Alhoewel verpleegkundige begeleiding het aantal symptomen niet verminderde, leek het er wel op dat er bij patiënten uit de interventiegroep een grotere afname in de mate van symptomen was en in de last die zij hiervan ondervonden.

Er werd slechts een beperkt verband gevonden tussen zelfzorggedrag en de kwaliteit van leven. Zelfzorggedrag hield alleen verband met de psychosociale aanpassing aan de ziekte en met het algemene welbevinden van de patiënt. Hoe moeilijk het ook is om de kwaliteit van leven van oudere patiënten met hartfalen te verbeteren, het is toch nodig om hier aandacht aan te besteden. Meer aandacht voor het verbeteren van functionele capaciteit, het goed instellen op medicatie en het toesnijden van behandeling en zorg op de individuele patiënt zijn noodzakelijke maatregelen. Verder wordt gepleit voor onderzoek naar wat de kwaliteit van leven van deze patiënten bepaalt en hoe die verbeterd kan worden. Vanuit praktisch en theoretisch perspectief is het belangrijk te weten welke factoren verband houden met een verandering in kwaliteit van leven.

Hoofdstuk 11 bevat analyses over de veranderingen in kwaliteit van leven en factoren die daarmee in verband gebracht worden. Aan de hand van de gegevens van de patiënten die alle vragenlijsten hadden ingevuld $(n=74)$ werden onderzocht welke klinische, demografische en zelfzorgvariabelen een relatie hadden met een verandering in 
functionele capaciteit, symptomen en psychosociale aanpassing. Daarnaast werd gekeken in hoeverre een verandering in functionele capaciteit, psychosociale aanpassing en symptomen samenhingen met een verandering in het algehele welbevinden, naast demografische, klinische en zelfzorgvariabelen.

Met name de toestand van de patiënt bij opname (hun baseline score) bleek bepalend te zijn voor de situatie na drie en na negen maanden na ontslag. Verder werd gevonden dat oudere patiënten en patiënten met een relatief slechte fysieke conditie bij opname (veel heropnames in het verleden, NYHA IV, lage functionele capaciteit, co-morbiditeit en veel vochtverlies tijdens opname) minder verbetering in kwaliteit van leven hadden dan patiënten met een relatief betere conditie of jongere patiënten. In interventies (naast voorlichting denke men hier ook bijvoorbeeld aan revalidatie) moet men rekening houden met de oudere patiënten en fysiek kwetsbare patiënten. In feite dient men verschillende vormen van interventies te overwegen, bijvoorbeeld een thuisbezoek, een multidisciplinair team, transmurale zorg, ontslagplanning en/of een hartfalencentrum.

Verder blijkt dat patiënten met een hoog of verbeterd zelfzorgvermogen ook een grotere verbetering ondervonden in hun functionele capaciteit en psychosociale aanpassing dan mensen die een laag of niet verbeterd zelfzorgvermogen hadden. Ook dit gegeven is van belang als men een interventie op een patiënt af wil stemmen.

Een verbetering in psychosociale aanpassing hing samen met een verbetering van het algemene gevoel van welbevinden. Het verbeteren van psychosociale aanpassing betekent bijvoorbeeld dat men psychosociale begeleiding biedt aan de patiënt en diens familie, dat er hulp in de huishouding komt of dat men een of ander vorm van maatschappelijke dienstverlening inschakelt. Ook dient hierbij aandacht te zijn voor mogelijke verschillen tussen mannen en vrouwen.

Er werd nauwelijks verband gevonden tussen het gebruik van gezondheidszorgvoorzieningen en de kwaliteit van leven, behalve dat de mensen met meerdere heropnamedagen en meer contacten met de huisarts ook een lagere kwaliteit van leven rapporteerden.

In hoofdstuk 12 worden de resultaten van het onderzoek kritisch bekeken en aanbevelingen gedaan voor theorie, praktijk en verder onderzoek. Niet alle verbanden die wij hadden voorondersteld zijn ook gevonden: daarom is het model dat in de introductie werd gepresenteerd, aangepast.

De belangrijkste beperkingen van dit onderzoek betroffen de kracht (de dosis) van de interventie, de algemeenheid van de meetinstrumenten, de generaliseerbaarheid, en de beperkte gegevensverzameling op de korte termijn ( 1 maand).

De verpleegkundige theorie van Orem blijkt een nuttig instrument te zijn geweest om gegevens te ordenen en systematiek aan te brengen in de voorlichting en begeleiding van de patiënten. Toch merk ik op dat Orem's theorie zich door haar abstractheid moeilijk leent voor praktisch gebruik en dat een aantal aspecten verduidelijking behoeven (zoals de relatie tussen zelfzorg en de kwaliteit van leven) of misschien toegevoegd (bijvoorbeeld de rol van de verpleegkundige in het management van het zorgproces).

Voor de verbetering van de interventie zijn ro aanbevelingen opgesteld. Deze aanbevelingen zijn niet alleen gebaseerd op de uitkomsten van het onderzoek, maar ook op recente literatuur, ervaringen opgedaan gedurende het onderzoek en de implementatie 
in de praktijk. De aanbevelingen betreffen

- de inhoud (het constant actualiseren van het verpleegplan, het verbeteren van de verslaglegging, de participatie van patiënt en familie);

- de vorm (de combinatie ziekenhuis en thuisbezoek, het gebruik van extra interventies);

- de intensiteit (het verlengen van de periode van follow-up, het verbeteren van laagdrempelige toegang);

- de multidisciplinariteit zowel in de eerste als in de tweede lijn;

- het inpassen van een interventie in de eigen organisatie en regio.

Enkele van deze veranderingen (langere follow-up, samenwerking met de cardioloog, laagdrempelige toegang tot de verpleegkundige) zijn overgenomen in het huidige polikliniekmodel in Maastricht dat na het onderzoek van start is gegaan.

In het slot van dit hoofdstuk worden aanbevelingen gedaan voor verder onderzoek. Onderzoek naar mechanismen die verantwoordelijk zijn voor medische consumptie en factoren die gerelateerd zijn aan (de verandering) in kwaliteit van leven kan inzicht opleveren waarmee de zorg aan patiënten met chronisch hartfalen verder verbeterd kan worden.

Daarnaast wordt benadrukt dat meer gerandomiseerd onderzoek nodig is om nieuwe interventies voor patiënten met hartfalen zoals thuiszorgprogramma's, een polikliniek of een nurse practitioner te evalueren. Cruciaal is ook dat we erachter moeten komen wat de juiste intensiteit (dosis) van de interventie is. Ook wordt gepleit voor racer onderzoek naar de rol van de eerste lijn in de zorg voor patiënten met hartfalen. Hierbij moet men het hele ziekteproces van de patiënt in ogenschouw nemen, dus van goede voorlichting en behandeling na een hartinfarct tot palliatieve zorg bij terminale patiënten met hartfalen. 


\title{
Dankwoord / Acknowledgement
}

\author{
Danken kun je alleen als je beseft dat je iets gekregen hebt \\ Conny Palmen in de Erfenis, 1999
}

De meeste dankwoorden eindigen met het bedanken van de partner voor de steun en het relativeren van het werk. In dit dankwoord wil ik beginnen met het bedanken van Pierre voor zijn onvoorwaardelijke steun maar vooral voor het niet relativeren van het werk ("Hoezo een . vrije middag... Is hoofstuk 5 dan al af?") Pierre, je geloof in mijn mogelijkheden en je geduld ("het was toch al af?") zijn de grootste steun die een onderzoeker en partner zich kan wensen.

Verder hebben aan het onderzoek en de totstandkoming van dit proefschrift veel mensen een bijdrage geleverd. Ik wil mijn bijzondere dank uitspreken voor de patiënten met hartfalen die meegedaan hebben aan het onderzoek door het beantwoorden van veel vragen. De gastvrije ontvangst in zeer diverse huizen in "Maastricht en omstreken" en de openheid tijdens de interviews heb ik erg gewaardeerd. Ik hoop dat ik uw antwoorden zo heb kunnen gebruiken dat ze bij zullen dragen aan de verbetering van de patiëntenzorg.

Ger Cleuren, jij bent een onmisbare collega geweest in dit onderzoek door je rol in de dataverzameling en de interventie. Jouw niet-aan-te-tasten positieve instelling en werklust heeft ertoe geleid dat we toch ruim 700 interviews hebben afrond, exclusief de bezoeken aan patiënten voor de interventie. Je hulp met het Maastrichts was onmisbaar voor zo'n Friese onderzoeker en helaas is de cursus Maastrichts er wat bij gebleven. Ger. mijn dank is groot hopelijk zien we elkaar nog vaak ("es God bleef").

Ook heb ik veel te danken aan de verpleegkundigen en afdelingsecretaresses van de afdeling $B_{3}$ van het Academisch Ziekenhuis Maastricht. Door hun medewerking tijdens het onderzoek en collegiale belangstelling naar de voortgang voelde ik me thuis op de afdeling en verliep de dataverzameling en interventie vlekkeloos. Dit werd mede ondersteund door de medewerking van de arts-assistenten en cardiologen werkzaam op de afdeling B3.

Mijn promotoren Prof. dr. H. Huijer Abu-Saad en dr. K. Dracup wil ik mijn oprechte dank uitspreken. Huda, ik heb veel van je geleerd, je had altijd goede adviezen over artikelen en ideeën over de directe zorg.

Kathy, few people have the privilege to work with someone they admire as a role model and I know that many colleagues envy me. Thank you for your support, you have learned me so much about research, writing and other aspects of life.

Mijn co-promotor dr. R. Halfens wil ik ook bijzonder bedanken. Ruud, jij was projectleider van het onderzoek en ik heb je begeleiding zeer gewaardeerd. Verschillende 
benaderingswijzen heb je op me los moeten laten om me zo ver te krijgen, variërend van het stellen van deadlines, beloningen (tuinstoelen, dropjes) en de paradoxale benadering (nee natuurlijk kun jij dat niet). Vooral veel meedenken in verschillende stappen van het onderzoek en mijn proefschrift hebben me vooruit geholpen.

De leden van de beoordelingscommissie wil ik bedanken voor het beoordelen van het proefschrift. Met name Prof.dr. H. Philipsen (voorzitter van de commissie). Hans, vanaf mijn sollicitatie als "dr. Dekkerkandidaat", en later als doctoraalstudent heb je mij gestimuleerd in mijn onderzoekscarriëre. Mede dank zij jou innoverende ideeën is dit project geworden wat het is. Veel dank daarvoor.

De leden van de "projectgroep" die meegedacht hebben in de opzet en voortgang van het onderzoek ben ik ook veel dank verschuldigd. Jan Stappers, Ton Gorgels, Jan van Ree en Jos Diederiks dank ik voor de adviezen in verschillende fasen in het onderzoek en bij het voorbereiden van publicaties.

$\mathrm{Bij}$ de vakgroep verplegingswetenschap heb ik een geweldig leerzame, collegiale en vooral ook leuke tijd (gehad). Vele collega's hebben me geholpen gedurende verschillende fasen van het onderzoek en van mijn proefschrift: Met name met Afke heb ik heel wat uren analyse op verschillende aspecten van onderzoek en leven mogen delen. Andere keywords op de vakgroep waren (en zijn) shockeren (Annemie), gniffelen (Louk), keuken (Jan), hulp (Marianne), wachtwoorden (Arnold). yoga (Scarlett), roze vragen (Judy), delen (Inez), kolven (Inge), zin en onzin (Ger B), theorieën (Harry). gezelschap (Katinka), transmuraal (Jos en Gert) adviezen (Nicolle), power (Nynke). Speciale dank ook voor Roos die voor mij tijdens mijn verlof een aintal interviews heeft afgenomen en gegevens heeft verwerkt. Het secretariaat (Heidi, Martha en Julie) is al helemaal onmisbaar geweest vanwege hun hulp en koninklijke humor.

Enkele collega's van de "oude" tijd Neeltje, Jacqueline, Thijs, Margreet, Karen en Theo wil ik bedanken voor hun hulp bij mijn eerste stappen binnen de universiteitswereld. Corry, jij hebt me niet alleen leren salsadansen maar samen met Arjen heb je me ook zicht gegeven op belangrijke aspecten in het leven.

Docenten en collega's van de sectie verplegingswetenschap van de Universiteit Groningen en het Academisch Ziekenhuis Groningen hebben een belangrijk aandeel gehad in de aanloop tot dit onderzoek en uiteindelijk in het proefschrift.

Ook Ben van Steenkiste bedankt voor je hulp bij je inbreng op het gebied van "quality of life".

Frans Tan heeft me geholpen met de statistische keuzen en me veelvuldig geduldig uitgelegd waarom ik toch echt de goede keuzes heb gemaakt.

Ook op mijn relatief nieuwe werkplek bij de Nederlandse Hartstichting heb ik veel steun gehad van alle collega's van verschillende afdelingen, veel dank voor jullie geduld met mijn altijd-maar-hartfalen-verhaal, het gestress rond het boekje en mijn ontduiken van de vakantie.

Mijn huidige "baas", Marina Senten ben ik grote dank verschuldigd. Marina, wie had, toen ik met je startte aan het replica-onderzoek, kunnen denken dat jij. I I jaar later, in "mijn" corona zou zitten? Bedankt voor je "model staan", je input in het begin van het onderzoek, je steun en je heldere kijk op wetenschap en het leven.

De Nederlandse Hartstichting wil ik in het bijzonder bedanken voor het vertrouwen om dit onderzoek te starten en voor de financiële steun. Tijdens de start van het 
onderzoek was onderzoek naar "hartfalen en verpleegkunde" nog vrij nieuw in Nederland en ik heb het dan ook zeer op prijs gesteld dat ons project als stuurproject van start kon gaan. In het bijzonder wil ik George Jambroes danken voor de rol in de start en voortgang van het onderzoek. Anneke Craanen heeft vanaf het begin vertrouwen gehad in het belang van het onderzoek en heeft door haar heldere kijk op mogelijkheden en knelpunten in de zorg veel input geleverd aan de "general discussion" van dit proefschrift.

Bob Wilkinson heeft de Engelse tekst gecorrigeerd, waarvoor mijn dank en Felix de Laar heeft de Nederlandse samenvatting (en veel van mijn ander geschrijf) leesbaar gemaakt.

Collega's in de redactie van Cordiaal en collega's van de werkgroep Wetenschappelijk Onderzoek van de Nederlandse Vereniging voor Hart- en Vaatverpleegkundigen wil ik bedanken voor hun inspiratie.

Over de paranimfen kan ik een additioneel boek schrijven. Martje, onze discussies over hoe het toch anders had gekund met meneer Poort van de afdeling C2va (Thg I) in het AZG en jouw doctoraalscriptie "therapietrouw bij patiënten met decompensatio cordis" zijn voor mij het begin geweest van dit proefschrift. In de voortgang heb jij een hele belangrijke rol gespeeld. Ook jij hield erg van de paradoxale benadering (natuurlijk wordt het nooit wat). En van jou kan ik altijd weer leren dat het allemaal draait om die individuele patiënt met hartfalen, die het weer kunnen breien misschien als grootste levensgeluk ervaart en dat je daar als verpleegkundige vaak veel aan bij kunt dragen. Onze wandelingen, brieven, hotel Bali-ervaringen en persoonlijke formuleringen zijn voor mij onmisbaar geweest (en dan niet alleen voor het proefschrift). Hopelijk worden we het nog eens over het open raam.

Mijn andere paranimf, Fetzen, heeft echt helemaal aan de geboorte van mijn onderzoeksenthousiasme gestaan. Op je studentenkamer aan de Meeuwerderweg hebben we voor een HBO-V opdracht een onderzoek uitgedacht over het gebruik van huismiddeltjes door studenten en waren we tot diep in de nacht bezig met ingewikkelde redeneringen en andere dingen. Fetzen, jouw onvoorwaardelijke steun in mijn leventje en interesse voor vele aspecten van het leven is voor mij onvergetelijk. Ook Joep en Rien bedankt voor het uitlenen van deze kanjers en jullie belangstelling voor mijn werk.

Verder wil ik andere vrienden bedanken voor hun steun en belangstelling en mijn excuses aanbieden voor vergeten en niet bijgewoonde verjaardagen, bevallingen of andere feesten. Gelukkig was ik toch welkom in Groningen, Maastricht, Sittard, Haarlem, Limbricht. Arnhem, Berg en Terblijt, Winsum, Harderwijk en Utrecht. Ook de grote en kleine vrienden in Sauwerd en Onnen: bedankt. Marianne. Lucas, Peter, Els, Sanne, Niels, Pjotr, Tim en Mila, bedankt voor de zinnige en onzinnige activiteiten van de afgelopen jaren.

De leden van Judoclub TSUKURI en met name Wil Lüschen en Conny Libotte hebben me in Maastricht veel geleerd. Helaas heb ik niet genoeg techniek meegenomen om de zwarte band te halen, maar ik heb me altijd erg thuis gevoeld op de club.

The research group of UCLA has been very supportive in my work. Lynn, Debra, Mary, Donna and Liz were always willing to help me with my scientific endeavors (abstracts, papers) or practical matters (how to get a safe room in Dallas). From you 
I have learned a lot about the importance and the rules of publishing and the importance of having nice colleagues in the same field of interest. Also other international colleagues in the field of Nursing and Heart Failure have taught me a lot: Sabina, Jan, Anna, Simon and other colleagues, thank you for all our discussions.

Tot slot wil ik al mijn familie bedanken en dan met name mijn ouders en broers.

Heit en Mem: Ek al bin ik net altyd de plattrape paadsjes gien, jim hawwe der my altyd op oanstien dat ik "trochleare" soe, en jim wiene der altyd foar ús. Tige tank dêrfoar. Ek myn twa broers wol ik betankje; om't se broers binne, en dat is in suske wol nedich om sa fier te kommen.

De allerlaatste regel is voor Wietse, die ik wil ik bedanken voor het genoegen nemen met afgekolfde melk en met het pre- en postnataal meereizen naar nationale en internationale congressen. 


\section{Curriculum Vitae}

Tiny (Trijntje) Jaarsma werd op 19 mei 1964 te Drachten geboren. Na het afronden van het VWO in 1982 , verhuisde zij naar Groningen en volgde de HBO-verpleegkunde (1982-1986). Hierna werkte zij op verschillende afdelingen in het Academisch Ziekenhuis Groningen, onder andere op de afdelingen interne geneeskunde en cardiologie. In 1988 werd zij "verpleegkundig onderzoeker in opleiding" binnen het Dr. Dekkerprogramma van de Nederlandse Hartstichting. Dit vulde zij in door van 1988 tot 1991 Gezondheidswetenschappen te studeren (in MUG verband, in Groningen) en het uitvoeren van een replica-onderzoek bij CABG patiënten in samenwerking met onderzoekers van de Universiteit Maastricht. Daarnaast bleef ze parttime werken als verpleegkundige op de afdeling cardiologie van het AZG. Na haar afstuderen werkte ze I jaar als toegevoegd docent bij de vakgroep verplegingswetenschap aan de Universiteit Maastricht. In 1993 bracht ze 6 maanden door in de Verenigde staten aan de University of California at Los Angeles voor onderzoek en verdere studie. Daarna starte ze bij de vakgroep Verplegingswetenschap van de UM met een inventariserend onderzoek van 6 maanden en vervolgde dit met een onderzoeksproject van 5 jaar naar verpleegkundige zorg en hartfalen. Hier werkt ze momenteel (0.3 FTE) als onderzoeker. Daarnaast werkt ze (0.7 FTE) als projectmedewerker bij de Nederlandse Hartstichting. In deze functie coördineert zij de "commissie hartfalen 2000 ".

Tiny Jaarsma is daarnaast voorzitter van de werkgroep "Wetenschappelijk Onderzoek" van de Nederlandse Vereniging voor Hart- en Vaatverpleegkundigen (NVHVV) en was de afgelopen 6 jaren redacteur van Cordiaal. Namens de NVHVV is zij voorzitter van de Working Group of Cardiovascular Nursing van the European Society of Cardiology (ESC). Recentelijk werd zij Nurse Fellow of the European Society of Cardiology (NFESC). 


\section{Curriculum Vitae}

Tiny (Trijntje) Jaarsma was bom on May I9, 1964 at Drachten, the Netherlands. After completing high school in I982, she moved to Groningen to the Academy for Health Care and in 1986 she received her bachelors degree in Nursing. In the following years she worked as a nurse on several wards in the University Hospital Groningen, mostly in internal medicine and cardiology. From I 988 to I 99 I she became "nurse researcher in training" within the "Dr. Dekker Program", of the Netherlands Heart Foundation. During this time she studied Health Sciences at Maastricht University and participated in a study of a research group at the same university. Concurrently. she utso worked part-time as a nurse on the cardiology ward of the University Hospital Groningen. After receiving her masters degree in 1991 , she worked for 1 year as an assistant professor at the department of nursing science of Maastricht University. In 1993 she visited the University of California at Los Angeles for 6 months for further study and research. Subsequently, she worked as a researcher at the department of nursing science of Maastricht University on two projects on nursing care and heart failure. Currently she still works there as a researcher (0.3 FTE) and she also works as coordinator of the National Guidelines on Heart Failure at the Netherlands Heart Foundation.

Tiny Jaarsma is chair of the research working group of the Netherlands Association of Cardiovascular Nursing (NVHVV) and has been a member of the editorial team of "Cordiaal" (the Dutch journal for cardiovascular nurses). As representative of the NVHVV, she is chairing the Working Group of Cardiovascular Nursing of the European Society of Cardiology (ESC). Recently she became Nurse Fellow of the European Society of Cardiology (NFESC). 


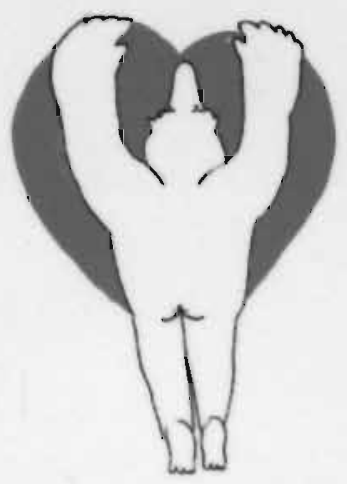

